\title{
CONFUCIAN VALUES AND SCHOOL LEADERSHIP IN VIETNAM
}

By

Truong Dinh Thang

\begin{abstract}
A thesis
submitted to the Victoria University of Wellington in fulfilment of the requirements for the degree of Doctor of Philosophy in Education
\end{abstract}

Victoria University of Wellington 





\section{ACKNOWLEDGEMENTS}

I am indebted to a number of people that have helped in the course of my study.

My sincere appreciation goes to my supervisors, Dr Kabini Sanga and Dr Cherie $\mathrm{Chu}$, for their support. The writing of this thesis was a long and at times painful journey of discovery; eased considerably by their patience, scholarship and encouragement.

I am also grateful for the scholarships from the Vietnamese Ministry of Education and Training and the Victoria University of Wellington.

I also acknowledge Quang Tri Teacher Training College for supporting my studies at Victoria University of Wellington, New Zealand.

I am indebted to school leaders and teachers who participated in this study. Their enthusiastic sharing and cooperation is appreciated.

I offer my sincere thanks to all my friends who have cheered me up throughout this journey. Their endless encouragements had inspired me towards the completion of this thesis.

Special thanks to all my family members who have provided me with love and encouragement through the years I have lived far from home.

Finally, I would like to dedicate this $\mathrm{PhD}$ thesis to my father and my mother who have scarified their whole life to their children. They have encouraged me to pursue an academic journey to obtain an excellent education for my family. My wholehearted appreciation goes to my beloved wife, Mrs Nguyen Thi Hong and my son, Truong Dinh Duy (Bean) for their love and unconditional support throughout the years. They have been my anchors in the past few years and always will be. 


\section{"Kỷ sở bất dục, vật thi ư nhân"}

Điều gì mình không muốn thì đùng làm cho người

What you do not wish for yourself, do not do to others

\section{(Confucius)}




\begin{abstract}
This research focuses on school leadership in the Vietnamese context, particularly the Confucian-influenced context within Vietnamese cultural boundaries. Confucian values are believed to be the significant and dominant value structure within Vietnam, therefore this research seeks to understand how Vietnamese school leaders exercised leadership within the construct of a Confucian discourse. It examines how the exercise/practice of four leadership functions (exercising power, building relationship, making decisions, and conflict solving) are influenced by Vietnamese cultural values.
\end{abstract}

A qualitative research approach was applied for this phenomenological interpretive study. Four methods of data collection were adopted, consisting of interviews (individual and focus-group interviews), observations, document analysis and questionnaires. School leaders and teachers, drawn from three case study schools were invited as participants.

The findings suggest that, although Confucian thought has waned in the contemporary Vietnam, Confucian values are still reflected in participants' perceptions about school leadership and in the manner of everyday leadership and management practices, particularly in the four pre-defined leadership functions. Confucian authority chains, seen as the paternalistic culture of obedience and respecting authority, have transferred into contemporary Vietnamese school leadership and management. These are preserved and reinforced by the political and administrative structures and contemporary leadership practices. A reconceptualised model of có uy leadership is offered, together with suggestions for leadership effectiveness based on Confucian values within a Vietnamese context. 


\section{TABLE OF CONTENTS}

ACKNOWLEDGEMENTS. .. $\mathrm{i}$

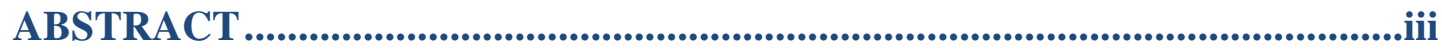

TABLE OF CONTENTS .................................................................................iv

LIST OF TABLES ..........................................................................................ix

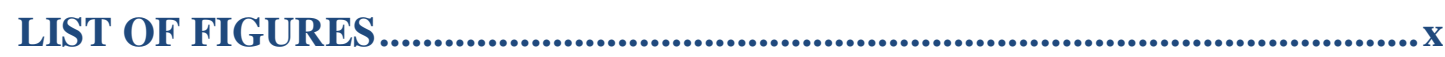

CHAPTER ONE: PREAMBLE TO THE STUDY ..............................................1 1

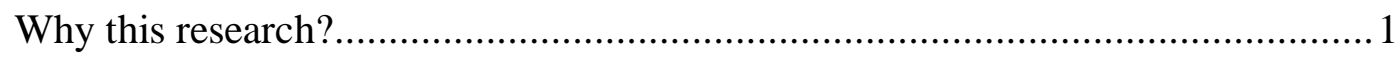

Personal experiences and observations ................................................ 1

An initial review of literature on school leadership and societal cultures ...........4

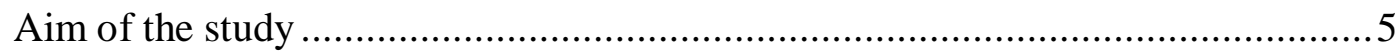

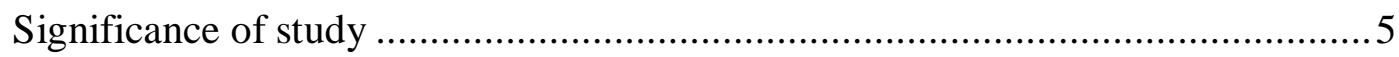

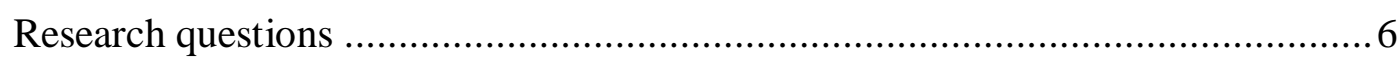

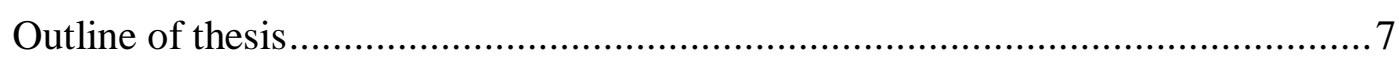

CHAPTER TWO: CONFUCIANISM IN VIETNAM - HISTORICAL PERSPECTIVES AND PREVAILING DISCOURSES ......................................8

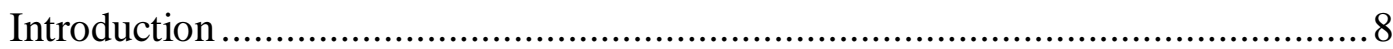

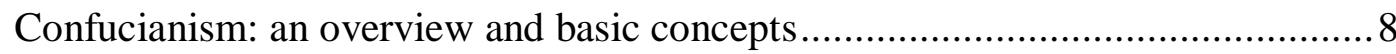

Confucianism introduction to Vietnam.......................................................... 12

The survival, adjustment and influence of Confucianism in Vietnamese Society. 15

Reflections of Confucian values in Vietnamese society................................. 19

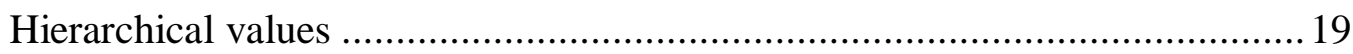

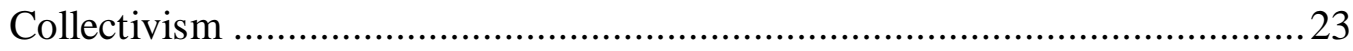

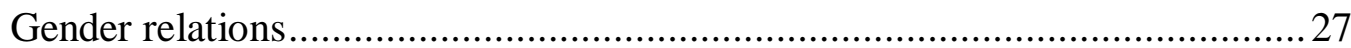

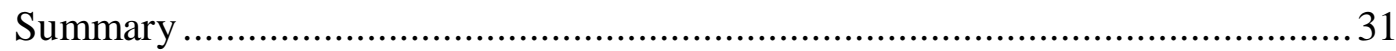

CHAPTER THREE: CONCEPTUALISING CULTURE AND SCHOOL

LEADERSHIP .................................................................................................................... 32

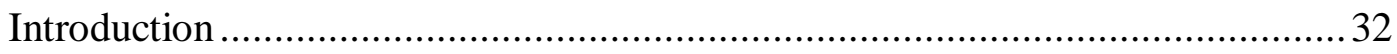

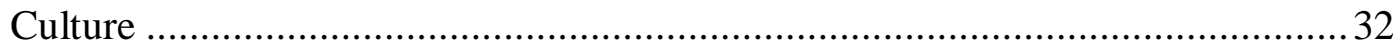

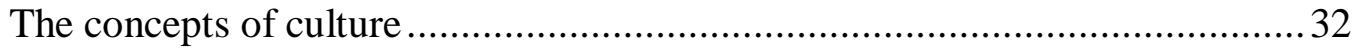

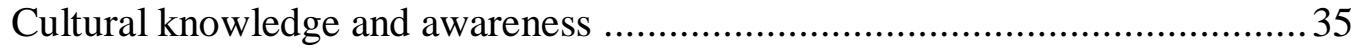

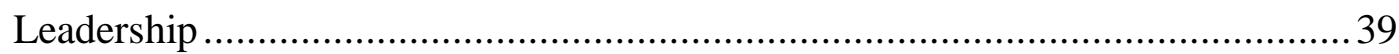

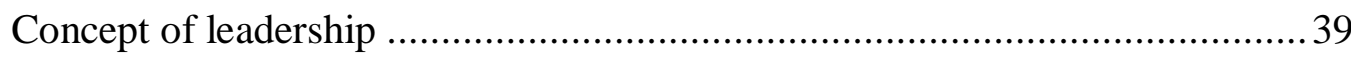




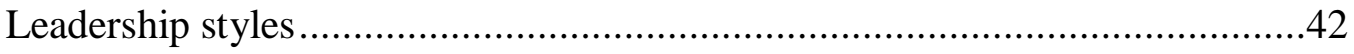

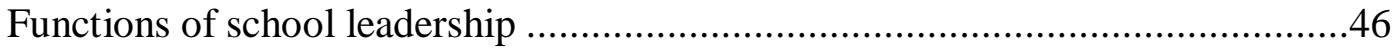

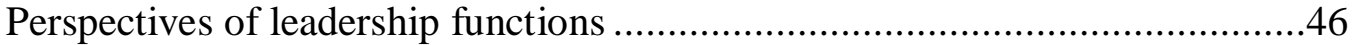

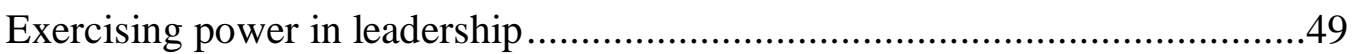

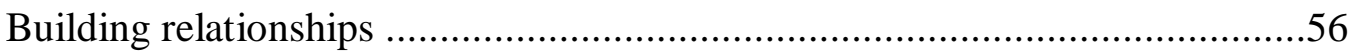

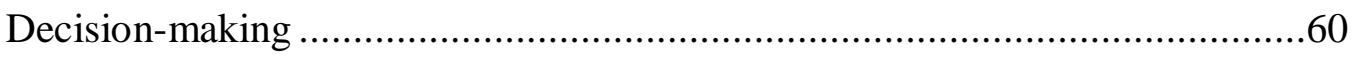

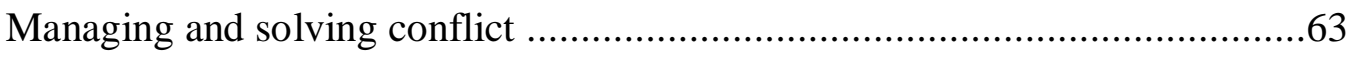

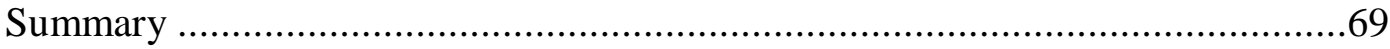

CHAPTER FOUR: METHODOLOGY ...............................................................70

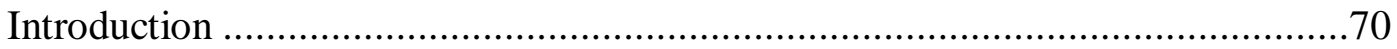

Interpretivism: A choice of research paradigm .............................................. 70

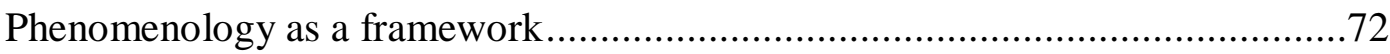

Phenomenology: a choice of methodology ............................................. 72

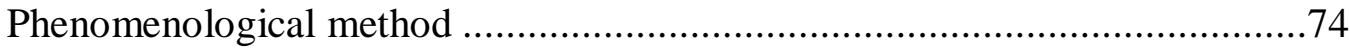

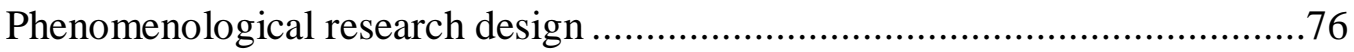

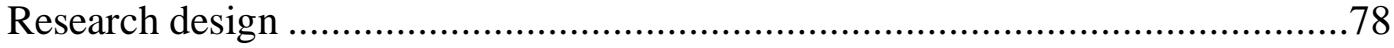

Qualitative research - The choice of research method .................................78

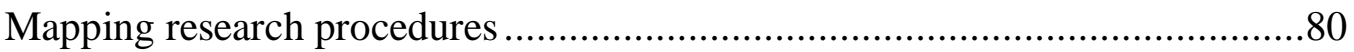

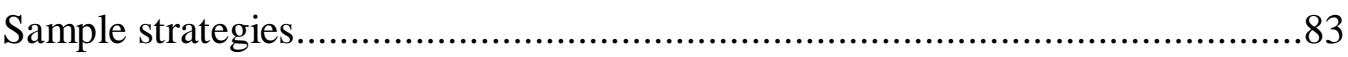

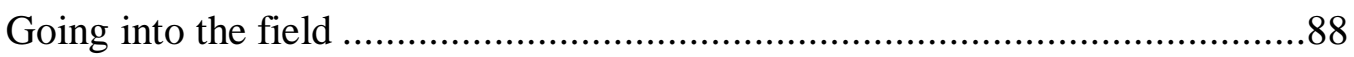

Piloting interview questions and questionnaires.........................................98

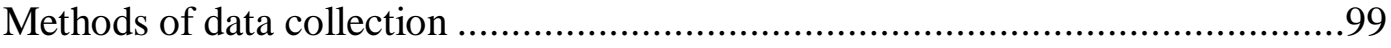

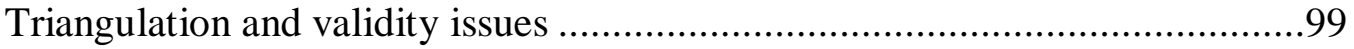

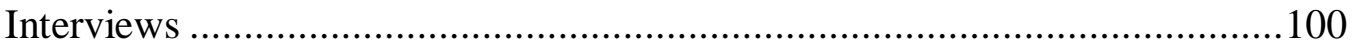

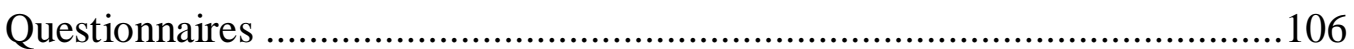

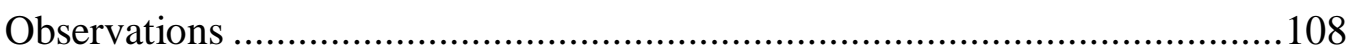

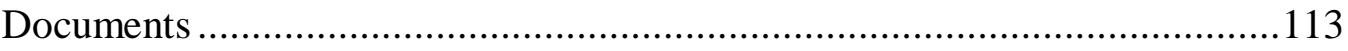

Qualitative data management and analysis .................................................113

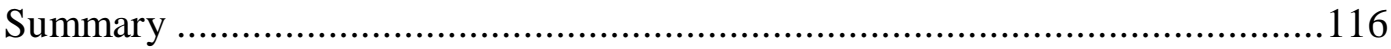

CHAPTER FIVE: CASE DESCRIPTION .......................................................118

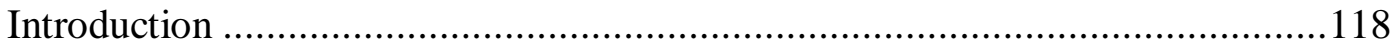

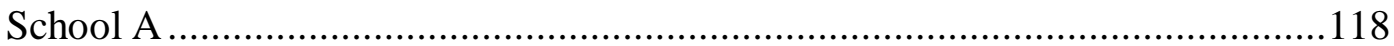

Background of school: A reflection on power and administration structure....118

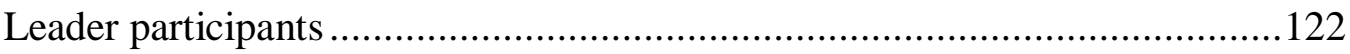




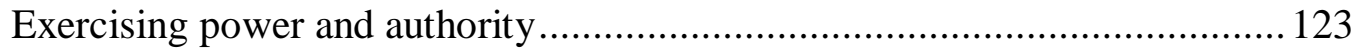

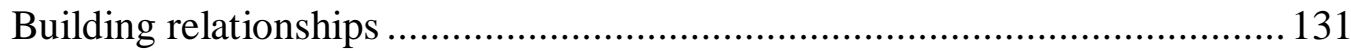

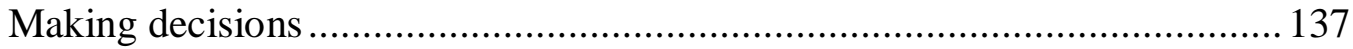

Managing and solving conflict ............................................................... 143

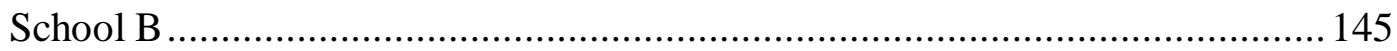

Background of school: A reflection on power and the administrative structure 145

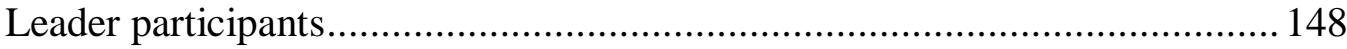

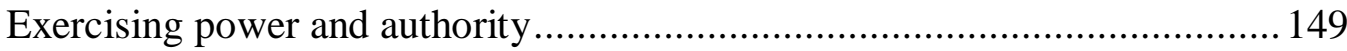

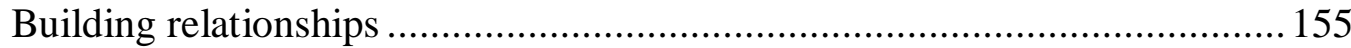

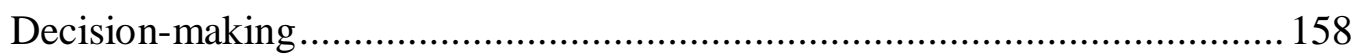

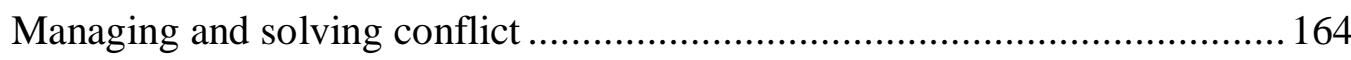

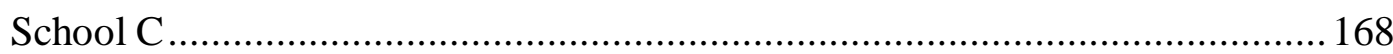

Background of school: A reflection on power and administration structure ... 168

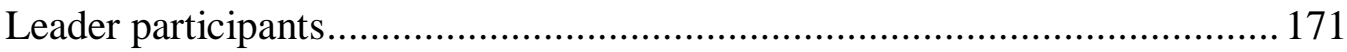

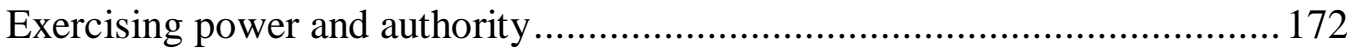

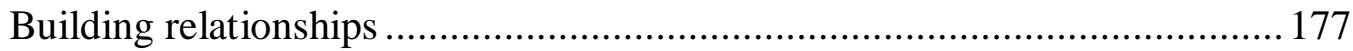

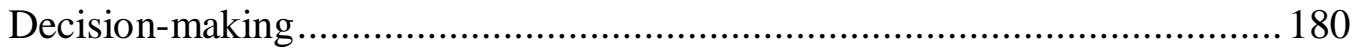

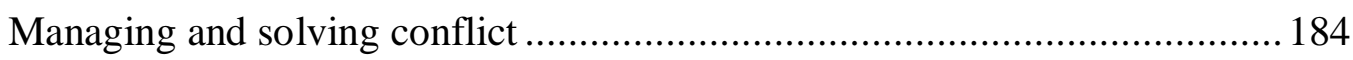

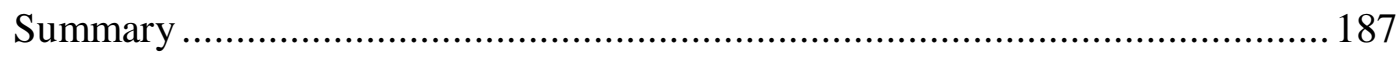

CHAPTER SIX: CROSS-CASE ANALYSES...................................................189

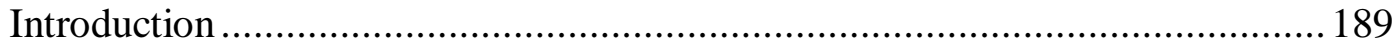

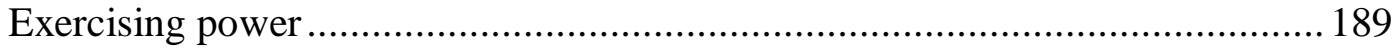

The hierarchical administrative system ................................................... 189

Participation of women in school leadership ............................................ 191

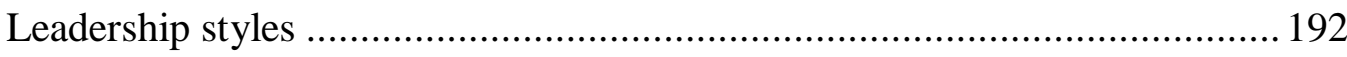

Concentration on discipline and enforcement of rules to establish managerial

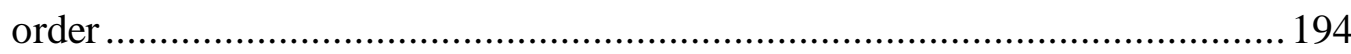

The importance of leader's prestige and charisma in the process of exercising

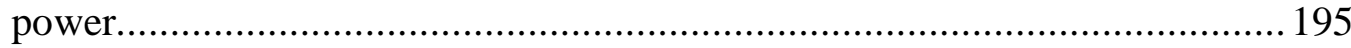

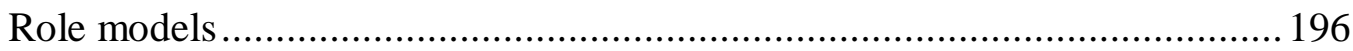

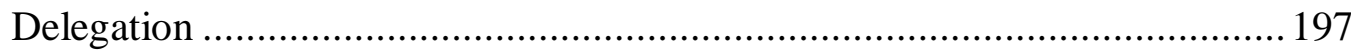

The dilemma of respecting hierarchy and promoting democracy ................. 198

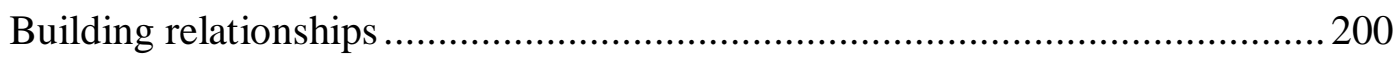


Preservation of harmony within a hierarchical sphere 200

Relation-centered leadership: preservation of harmonious relationships as investments 201

Power, position, status and age …............................................................203

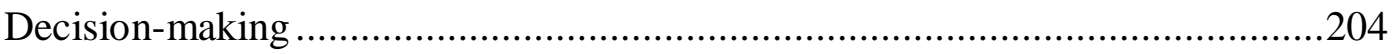

Hierarchical decision-making process: Habit of obedience .........................204

Teacher involvement in decision-making process: Obstacles of cultural values .206

Democracy for the decision-making process...........................................207

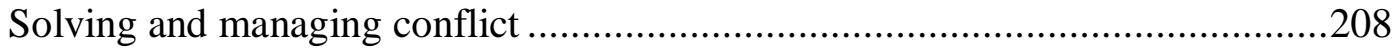

Avoiding conflict and confrontation: The importance of harmony ................208

The illusion of superficial harmony ........................................................209

Lý and Tình approaches: A dilemma in solving conflict ...........................210

Leaders and older people as intermediaries for conflict .............................211

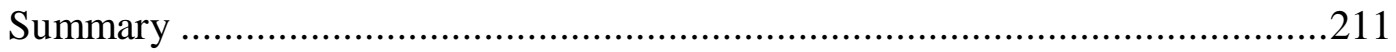

CHAPTER SEVEN: THE NATURE OF VIETNAMESE SCHOOL

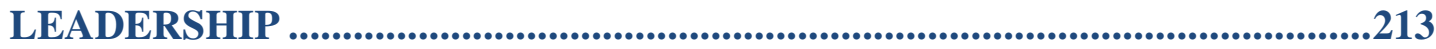

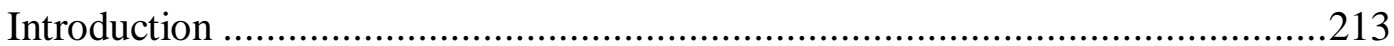

The nature and extent of Confucian influence on Vietnamese school leadership 213

The reflection of hierarchy-penetrated mind in exercising power..................214

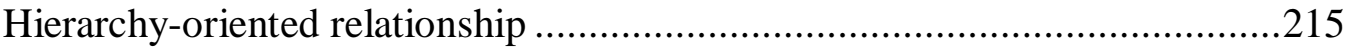

The influence of cultural values on decision-making .................................218

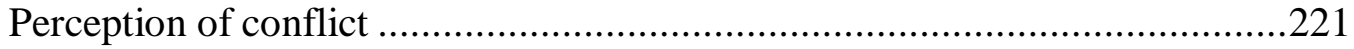

Cultural expectations about gender in school leadership .............................223

The particular nature of Vietnamese school leadership .................................226

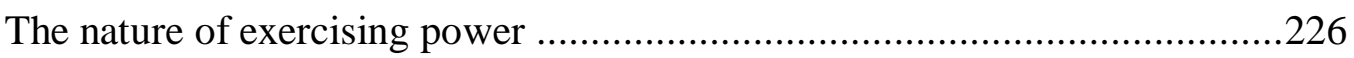

The nature of building relationships ...................................................23

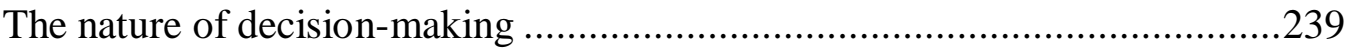

The nature of conflict management and solution.......................................242

Reconceptualisation of Vietnamese có uy leadership ...................................249

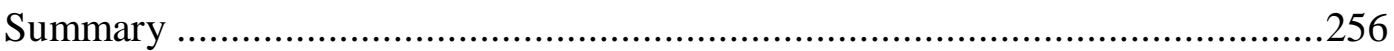

CHAPTER EIGHT: RESEARCH IMPLICATIONS AND CONCLUSION ...258

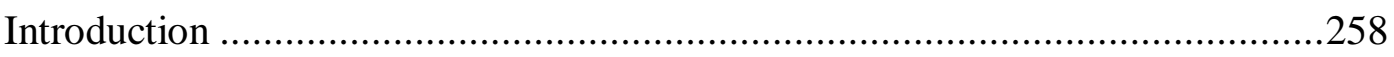

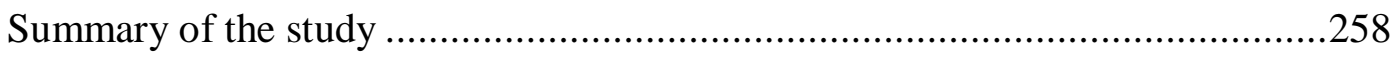




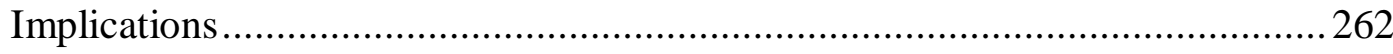

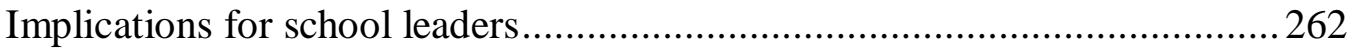

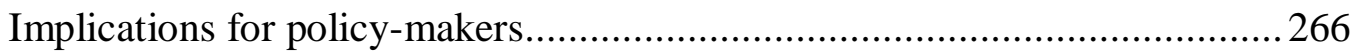

Possible improvements for any further study.............................................. 270

Recommendations for future research ..................................................... 270

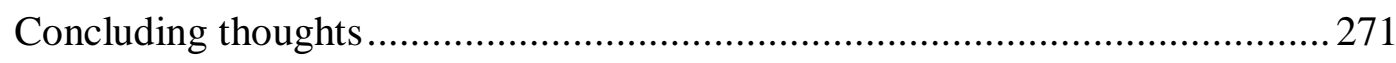

REFERENCES ...................................................................................273

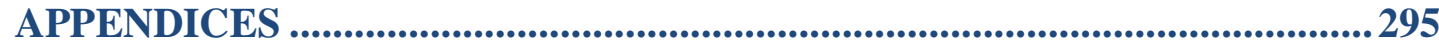

Appendix 1: The National Education System of Vietnam...............................2.295

Appendix 2: Letter to Director of Quang Tri Education and Training Service ... 296 Appendix 3: Letter to the Head of District Education-Training Service .............2297 Appendix 4: Letter to the Principal ...............................................................2 298

Appendix 5: Research Information Sheet ................................................. 299

Appendix 6: Participant Consent Form ......................................................... 300

Appendix 7: Interview questions with principal (English and Vietnamese versions)

Appendix 8: Interview questions with vice-principal (English and Vietnamese versions) 305

Appendix 9: Focus group interview questions with teacher participants (English and Vietnamese versions)

Appendix 10: Questionnaire for teacher participants (English and Vietnamese versions) 311

Appendix 11: Observation Guidelines. 


\section{LIST OF TABLES}

Table 1: Characteristics of individualism and collectivism ................................24

Table 2: Dimensions of societal and organisational cultures ..................................37

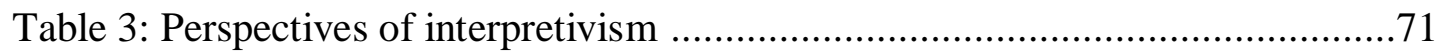

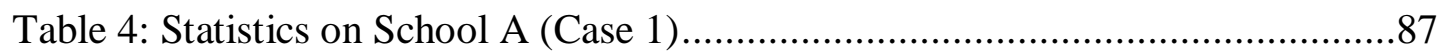

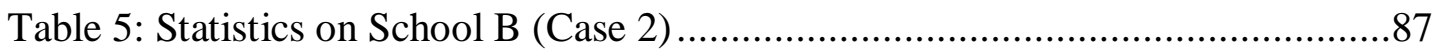

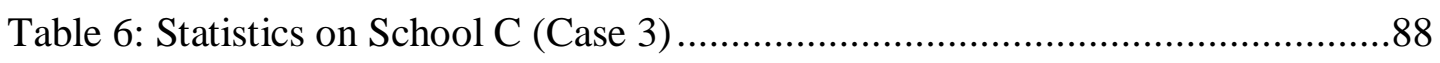

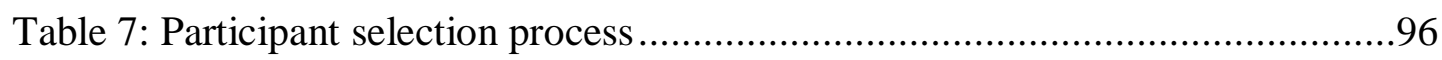

Table 8: Statistics of the Principal Board of the School A from its establishment up to

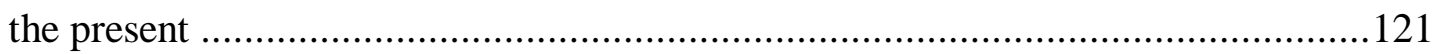

Table 9: The gender statistics of the current management staff of School A .........122

Table 10: Opinion contribution in School A meetings ...........................................142

Table 11: Statistics of the Principal Board of School B from its establishment until

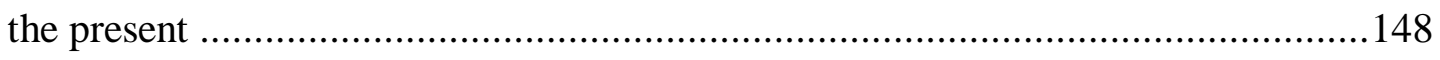

Table 12: The gender statistics of the current management staff of School B ........148

Table 13: Opinion contribution in School B meetings .........................................161

Table 14: Statistics of the Principal Board of School C from its establishment until

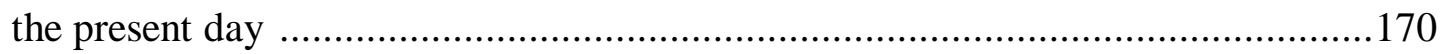

Table 15: The gender statistics of the current management staff of School C ........170

Table 16: The attributes of low and high standard of morality in leadership ..........196

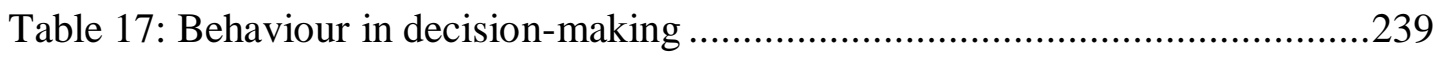

Table 18: The attributes of authoritarian and moral leadership styles ...................251 


\section{LIST OF FIGURES}

Figure 1: Matrix of Confucian values and leadership functions ...........................48

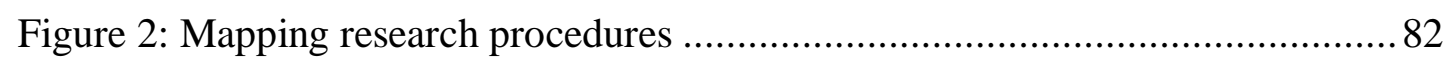

Figure 3: Process of data management ........................................................... 115

Figure 4: The Power and Management Structure of School A ............................ 120

Figure 5: The Power and Management Structure of School B ............................ 147

Figure 6: The Power and Management Structure of School C ............................. 169

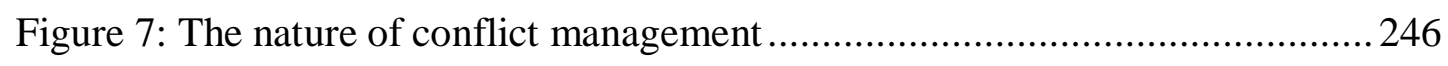

Figure 8: Model to conceptualise có uy leadership ...........................................254 


\section{CHAPTER ONE: PREAMBLE TO THE STUDY}

This research project investigated and sought understanding of how Vietnamese school leaders exercised leadership as influenced by Confucian discourse, a predominant feature of Vietnamese culture. School leadership is a socially bound process which is inextricably linked to the cultural values and customs of a society. Consequently, the inclusion of a cultural element is not only necessary, but essential in the study of education leadership.

In this introductory chapter, the following sections are presented: (1) Why this research? (2) Aims of the study; (3) The significance of the study; (4) Research questions; and (5) Outline of the thesis.

\section{Why this research?}

The rationale behind undertaking this research can be expressed under two broad categories: (1) personal experiences and observations and (2) an initial review of the literature on school leadership and societal cultures.

\section{Personal experiences and observations}

My interest in the connections between Vietnamese societal culture in general and Confucian values in particular and school leadership began during my Masters degree studies in New Zealand a few years ago. As an awardee of a New Zealand Official Development Assistance (NZODA) scholarship in 2003, I was sent a handbook, which stated:

\footnotetext{
When you come to study in New Zealand it will take you time to adjust to the lifestyle and culture here. You will be surrounded by new and different languages, cultures and foods... New Zealanders may look and act differently to what you are used to. What you considered normal in your own home country might be looked at differently in New Zealand. Our social customs, etiquette or mannerisms might not be what you consider appropriate or normal. These differences and variations can all have an effect on you and may affect your academic progress and general. (New Zealand Ministry of Foreign Affairs and Trade, 2003, p. 36)
}

On arrival in New Zealand, I soon found that culture mattered. I realised that what I did and thought differently from New Zealanders was derived from my culture. As I experienced student life in New Zealand and accessed Western literature on 
leadership, I became more interested in the impacts of societal culture on school leadership. I challenged myself with the question: How and to what extent is Vietnamese school leadership influenced by Vietnamese traditional cultural values?

After completing an MA degree in New Zealand, I returned to my home country and worked as a lecturer of educational leadership. This teaching role gave me opportunities to work with school leaders in the training programmes for educational leaders of nursery, primary and secondary schools in Vietnam. I knew from experience that the courses provided to school leader learners were based on educational theories, models and knowledge of leadership which were often derived from Western perspectives, or Western-affected perspectives, often without consideration of how these operated in a Vietnamese cultural context. They often lacked inclusion of cultural features and values in the thinking and reflection of school leader learners when they analysed or discussed the situation-based topic of leadership. There was a missing cultural variable in Vietnamese training course books for school leaders and in the leadership reflection practices of school leader learners.

As I observed the teaching and work styles of my Vietnamese colleagues, I noted that teachers still applied teacher-centered approaches to their teaching; leaders continued to show their long-lasting preferences of hierarchical and "top-down" leadership styles. With my own experience of over 10 years of working within the school environment, I realised that it was not easy for teachers to give up teachercentered approaches as these were embedded understandings of teachers' traditional roles. It seemed that teachers were treating students as empty vessels to be filled with knowledge. Vietnamese students too, appeared to accept teachers' traditional roles. Students seemed to readily accept teachers as the carriers and the embodiment of knowledge and wisdom. Commonly, students would display a habit of passive learning. The relationship between teachers and students was clearly hierarchical in the Vietnamese context while leaner-centered learning required students to be active and responsible participants in their own learning (Weimer, 2002).

I further observed similar practices in Vietnamese school leadership. While the practices of grassroots democracy were encouraged in schools and other organisations in Vietnam, the relationships between leaders and staff appeared to 
remain hierarchical. I noted that the practice of leadership at the school where I worked was deeply embedded in the discourse of "respect" and "obedience". I observed that the functional relationship between school leaders and staff was vertically constructed. This was evident in the way staff members addressed leaders during their communication, how school leaders made decisions and built relationships with staff, and how teachers participated in decision-making processes. Sometimes I was privy to complaints or criticisms from my colleagues about administrative work or their leaders' decisions. Such complaints or criticisms were often expressed in a confidential manner rather than being raised in school meetings or directly reported to school leaders. I realised that challenging the school leaders' power was not a wise option for teachers and staff in the process of exercising power and decision-making. Rather than expressing and defending their own opinions when they were not satisfied with leaders' decisions, teachers and staff would habitually choose to keep silent and obey. I found myself asking, even when Vietnamese teachers and staff had rights, why did they find it so difficult to confront their school leaders' power? From my experience, I found that although teachers and staff in my school had divergent ideas, they appeared very reluctant to be involved in any discussion process. They seemed to avoid conflict as a way to maintain harmony. I would ask: were harmonious values of Confucianism prevailing in the Vietnamese context brought into school leadership practice? Was this an instance of cultural norms (the software of the mind, according to Hofstede, 1994) being manifested in practice? More and more such "cultural questions" came to mind. In my work context, I constantly observed cultural phenomena such as "harmony", “obedience", "face-saving", and "respect for the elders" as everyday occurrences in school leadership. These leadership practices seemed to be the bases of how school leaders built and maintained their relationships, how they managed conflict, how they made decisions and exercised power. But how and in what ways did such cultural values impact the leadership within Vietnamese school contexts? This question begged exploration. This was the question which inspired me to conduct this research project. Premised on the practices of school leadership in Vietnam, this question suggested that leadership in Vietnamese schools could be understood as a particular phenomenon. What could this be like? How would I describe it accurately at this point in time in Vietnamese modernisation experience? 


\section{An initial review of literature on school leadership and societal cultures}

Armed with my experiences and observations of school leadership in the Vietnamese context, I decided to do an initial literature review of the field. I noted that, generally, the relationships between societal culture and educational leadership in research have inadequately been examined or investigated over the last several decades (Hallinger \& Leithwood, 1998; Walker \& Dimmock, 2002). This is unlike international business management or cross-cultural psychology which have acknowledged the importance of societal culture. In my initial literature search, I have also noted that where societal culture and educational leadership are explored, the applications are assumed acultural. For instance, Greenfield (1984) suggests that the nineteenth and twentieth centuries have been dominated by Western paradigms of leadership and the intellectual traditions and practices of other cultures are often judged without questioning the implicit assumptions embedded in Western cultures. According to Hallinger and Leithwood (1998), "this tendency has resulted in the transfer of a Western knowledge base to non-Western societies, often without sufficient concern for its cultural salience and validity" (p. 133).

In searching for literature on the impacts of societal culture on school leadership in Vietnam, I found that this was a neglected area. This is unfortunate, given that societal culture in Vietnam can usefully be understood as an evolving mix of traditional, socialist and modernising influences. Socialism began its course since the Socialist Republic of Vietnam was established in 1945. A modernising (or new culture) can be seen as the new social norms and values imported into Vietnamese society since Vietnam began its Đổi mới (Renovation) and Mở cưa (Open door) policies in 1986. When Vietnam turned to the West for modernisation in the last few decades, the country gradually adopted Western models of social organisation. As a result, newer social values from the West have been adopted and practised in the society. Of these three influential social sources, traditional is believed to be the significant and dominant one. Traditional has existed for thousands of years since Vietnam came into being in about the seventh century B.C. It is believed that traditional is associated with a system of virtues and values rooted in Confucianism, which was imported into Vietnamese society during a thousand years of Chinese invasion. It seems that new social values have emerged in modern Vietnamese 
society. Confucian values still have a strong influence and concurrently exist with the new social values.

Given that the modernisation influences of Vietnam are strongly Western, the lack of scholarship on societal culture and school leadership is of concern. As stated previously, leaders and teachers in Vietnam do not typically admit or acknowledge the influences of culture on school leadership. As generally said of some Asian countries, Confucian values exist but people's "acculturated lens" blinds them to the effects of culture (Hallinger \& Leithwood, 1998). I have also found support in the literature for including culture (context) in the study of school leadership. Walker and Dimmoc (2002), for instance, argue that incorporating societal culture into educational research will enrich, contextualize and refine the field.

In summing up this section, it is restated that my experiences and observations of the practice of school leadership in Vietnam, together with my initial literature search into the subject matter had interested me to pursue this topic of study. As a Vietnamese leader educator, I wanted to explore the nature of school leadership as a phenomenon in the Vietnamese context. Particularly, I wanted to understand the relationships between cultural influences and leadership practice. I wanted to deepen my understanding of school leadership in my national context, one which is outside, yet is influenced by an Anglo-American culture. As Hallinger and Leithwood (1996) have put it, that I might "find out what we don't know we don't know" (p. 98).

\section{Aim of the study}

My research is aimed at seeking a deeper understanding of how and why school leaders do what they do in the Vietnamese cultural context. In this study Confucian discourse will be treated as a dominant cultural feature and its influence on school leadership will be investigated.

\section{Significance of study}

There are several aspects of this study which make it significant. Firstly, research on the impact of societal culture on educational leadership in Vietnam is almost nonexistent. Consequently, this study will fill the gap in the leadership literature related 
to Vietnamese school leadership. It is also expected to set up a foundation-stone of literature on the influence of Confucian values on Vietnamese school leadership.

Secondly, a number of scholars have pointed out that there has been very little research on the impact of societal culture on school leadership (e.g., Dimmock \& Walker, 2005; Hallinger \& Leithwood, 1998, 1996; Walker \& Dimmock, 2002; Wong, 1998). This study is expected to provide empirical data that contributes and enriches literature on societal culture in the study of educational leadership.

Thirdly, as Dimmock and Walker (2005) have pointed out, we cannot understand specific practices, behaviours and beliefs unless we take into account the culture of which they are a part. This study will expose the grounds and nature of Vietnamese school leadership through a cultural lens. Doing so will be useful in educational leadership courses as this provides leader learners with deeper understanding of the nature of Vietnamese school leadership through a cultural perspective. This helps to diversify the ideas and practices of school leadership, which up till now have largely been hidden in the shadows of dominant Western paradigms.

Fourthly, by examining the influence of Confucian values on school leadership, it will add to the literature on school leadership that is unique to countries of Confucianism-affiliated societies. In other words, this study is significant in its implication for school leadership in Confucian-influenced contexts.

\section{Research questions}

My primary research question is:

\section{How is Vietnamese school leadership influenced by Confucian values?}

From this question, three sub-questions are asked as follows:

1. What are the nature and impacts of Confucianism on the:
a) exercise of power?
b) building of relationships?
c) undertaking of decision-making? 
d) nature of problem-solving?

2. How effective is school leadership as perceived from Confucian values?

3. What are the implications for school leadership in Confucian-influenced contexts?

\section{Outline of thesis}

This Chapter One has served as an introduction. Consequently, it has outlined the rationale, aim, and significance of the study. Furthermore, this chapter has presented the research questions and an outline of the thesis.

Chapter Two provides a review of the history of Confucian values in Vietnam. This review helps readers understand the cultural context of past and contemporary Vietnam. This chapter also discusses the dominant discourses of Confucian values.

Chapter Three is an exploration of the literature on societal culture and leadership. The chapter conceptualises culture and leadership, discusses the leadership theories and examines the connections between culture and leadership practice. The chapter also discusses the four pre-defined leadership functions in detail and examines how societal cultures influence these functions in practice.

Chapter Four addresses the philosophical, theoretical and methodological aspects of this research. It explains the adoption of interpretivism as a research paradigm, phenomenology as a research framework and describes the research methods.

Chapter Five presents the data description of the three case study schools. Each case is described following four pre-defined research themes, namely exercising power, building relationships, decision-making, and managing and solving conflict.

Chapter Six is the cross-case analysis of the three case study schools. The approach used mirrors that which is used in Chapter Six, wherein four pre-defined themes are compared and contrasted.

Chapter Seven discusses the findings. School leadership beliefs and practice are discussed and examined in order to conceptualise and expose the grounds and nature of school leadership in Vietnamese contexts.

Chapter Eight presents the implications and conclusions of the study. 


\section{CHAPTER TWO: CONFUCIANISM IN VIETNAM - HISTORICAL PERSPECTIVES AND PREVAILING DISCOURSES}

\section{Introduction}

This chapter examines Confucian values in Vietnamese society. It provides a historical overview of Confucianism in Vietnamese society and discusses prevailing Confucian discourses. In a nutshell, this chapter describes the basic concepts of Confucianism, the cultural context of Vietnam and Vietnamese thought and action. The topics covered in this chapter are as follows:

(1) Confucianism: an overview and basic concepts

(2) Confucianism introduction to Vietnam: examines how Confucianism was historically introduced and rooted;

(3) The survival, adjustment and influence of Confucianism in Vietnamese society: presents the historical aspects of the survival, adjustment and influence of Confucianism;

(4) Reflections on Confucian values in Vietnamese society: focuses on the dominant discourses of hierarchy in relationships, collectivism, and gender relations.

As a delimitation, Confucian values in Vietnam are the main social and historical concern of this chapter. Other important historical concerns are not part of the focus of this study.

\section{Confucianism: an overview and basic concepts}

Confucianism can be defined as a worldview, an ethical system, a political ideology, and a scholarly tradition developed from the teachings of the Chinese philosopher Confucius (551-479 BC) (Goldin, 2011; Tu, 1998a; Yao, 2000). It is believed that Confucius was not a "creator" but a "transmitter" of Confucianism who played a key role in the development of the tradition which had originated long before his time (Yao, 2000). As Tu (1998a) pointed out, he tried to "retrieve the meaning of the past 
by breathing vitality into the seemingly outmoded rituals" (p. 5). His teachings flowed from the belief that chaos and disorder developed from the misuse and abuse of ritual/propriety and the collapse of music. Consequently, he spent all his life striving to "restore the value of rituals and propagate the rules of propriety" (Yao, 2000 , p. 22). He had a strong belief that chaos and disorder of the society originated from the management of a bad government, in which rulers were not enacted in accordance with the true values of their roles. To establish a righteous government, the power of moral virtues rather than the power of cruel and punitive laws should be cultivated because "moral virtues could produce trust and faith in people, while punitive measures might stop wrongdoing only for a moment" (Yao, 2000, p. 22).

At the heart of Confucianism is humanism; the basic principles of humanity (Goldin, 2011; Liu, 1998; Rosemont Jr, 2006; Tu, 1998a; Yao, 2000), in which moral cultivation and living in a moral way is the life-long endeavour of human beings. These principles are built on the belief that human beings are teachable, improvable and perfectible through personal and communal endeavour especially self-cultivation and self-creation. The principles are believed to be "the root of social relationships, the foundation of the stability, peace and prosperity of the state, the family and individuals" (Yao, 2000, p. 26). Some basic concepts of Confucian can be summarised as follows:

The five virtues: Fundamental to Confucianism is virtue. Virtuous behaviour leads to good outcomes. Confucians believe that there are five basic virtues (ngũ thuòng) that a person needs to cultivate to become a virtuous man. These are:

(1) Humanness/benevolence (nhân): This is a fundamental assumption of Confucianism - that all people are inherently good and, thus, capable of operating in a way that is empathetic, humane and full of care for others. When people are not educated or developed properly, this intrinsic quality breaks down - people become hateful, rash, uncaring, undisciplined - and chaos comes into life at every level. One of the famous Confucian teachings about humanness is "what you do not wish for yourself, do not do to others."

(2) Righteousness (nghia): This is upholding what is morally right above everything else and sacrificing oneself for it, if needs be. It is a moral disposition to do good things. "Righteousness" is opposite to "one's own 
profit". A Confucian belief is that a noble man (người quân tư) comprehends righteousness, a small man (kẻ tiểu nhân) comprehends his own profit.

(3) Propriety/rites (lễ): People should behave and act in accordance with their role, status, rank, and position within a structured society. It is believed that without rites it is impossible to give everyone his position in society, the social order is then disturbed.

(4) Knowledge (trî): In Confucian view, people have to learn constantly and people can only achieve their understanding of life by learning. Learning and reflection about what is learnt can lead to righteousness.

(5) Integrity (tín): This is the principle of honesty in life. Being honest with oneself and being honest with the people around you to build trust and confidence.

Roles, responsibilities and relationships: Confucianism presents the individual not as a detached entity but always as part of human relationships. In relationships, both parties have obligations. Consequently, knowing and fulfilling one's roles in these relationships is believed to build up a society of harmony. According to Confucianism, there are five basic interpersonal relationships (bonds) in a society as follows: King (ruler) to subject; father to son; husband to wife; elder brother to younger brother; and friend to friend. Within these relationships, each individual has certain responsibilities; each relationship involves special virtues; and each relationship implies a hierarchy between the two parties. Specific duties are prescribed to each of the participants, including: Affection between parents and children; righteousness between sovereign and subordinate; separate functions between husband and wife; proper order between the older and the younger; trustworthiness among friends (Mencius, IIIA, 4, cited in Tamney \& Chiang, 2002, p. 51).

Self-cultivation and role model: Confucians value self-cultivation. Self-cultivation is considered as long-life learning that one person must pursue for his whole life. Great significance is placed on the ability of each individual to learn, to become educated, and to eventually become a moral and upstanding person. Self-cultivation involves not only educating oneself, but also picking up on the good traits in others, imitating 
them and modeling them to other people. According to Confucius, if you want to be the king of the world you have to be a king of yourself: you have to go through selfcultivation, to be a role model of integrity, of ethics, of honor, and propriety. You cannot just transform the world without first transforming yourself (Chen \& Lee, 2008). Each person must continually improve himself by learning to become a "gentleman" or a noble man. The importance of being a "gentleman" is described in the words of Confucius: "The character of the noble man is like wind; the character of the petty man is like grass. When the wind blows over the grass, it must bend" (Analects 12.19, cited in Goldin, 2011, p. 24).

Concept of Harmony: Harmony is the central theme of the Confucian doctrines. In Confucian thought, seeking harmony is the principal target in interpersonal relationships between human beings. The whole tradition of Confucianism developed out of the deliberations about how to establish or re-establish harmony in conflicts and disorder. According to Confucian teachings, conflict arises from the relation between oneself and others, and harmony is the result of an appropriate accommodation of one's own needs to the requirements of others (Yao, 2000). Hence, to quest equilibrium and harmony in life, a person needs to balance his needs with the needs of others. In a practical sense, Confucius encouraged people to acknowledge the ultimate importance of societal order in which each individual should fulfill his responsibility in accordance with his designated role in order to build a harmonious family, community and society as a whole. This belief is emphasised in the Confucian teaching: "Let the ruler be ruler, the subject be subject; the father be father, and the son be son" (cited in Bucar \& Barnett, 2005, p. 109). Confucius believed that when people and things are in their proper places, relations are smooth, operations are effortless, the good is sought, and harmony is achieved. In a stereotypical interpretation, Confucian is presented as favouring harmony above all else. However, Confucian ethics recognise disagreement and debate as a common phenomenon in human life. What is important is an individual's approach to conflict and disagreement. Harmony, while a fundamental objective in human relations, must not be achieved by sacrificing benevolence and righteousness, the cardinal Confucian virtues (Romar, 2009). 
These basic descriptions of Confucian virtues, beliefs and thought are deemed essential for my exploration of the phenomenon of leadership in a Vietnamese school context.

\section{Confucianism introduction to Vietnam}

Since the Chinese invasion and control of Vietnam between 111 B.C and 939 A.D, Vietnam has had a history of Confucianism for almost 1000 years (Jamieson, 1993; Bich, 1999; Taylor, 1998). In about the seventh century B.C, Vietnam came into being with its original name Văn Lang or the kingdom of Văn Lang, which was founded and ruled by Vua Hùng (Hung kings) in "Châu thổ Sông Hồng" (the Red River delta, an area that descends from the mountains and enters the plain - the northern part of Vietnam). This kingdom was the first governmental structure of the ancient Vietnamese people and it was created approximately 2,500 years ago. The kingdom was then conquered by a neighbouring chieftain from the northern part of present-day Vietnam and the southern part of Chinese Guangxi Province. Âu Lac was then formed in the last decade of the third century B.C. Âu Lac was then conquered and annexed to Nam Việt (Nan Yueh), a kingdom founded by a Qin named Triệu Đà (Zhao Tuo), in 179 B.C. It became a colonial southern province of China named Giao Chỉ (Jiao Zhi) after the Han dynasty defeated Triệu Đà in 111 B.C. The Chinese Emperor Han Wu-Ti placed Vietnam under a military governor in 111 B.C. and for the next 900 years Vietnam was part of Chinese history. Confucianism was introduced into Vietnam during this millenary Chinese domination. The year of 111 B.C was known as a significant milestone of Chinese culture, Confucian promulgation and influences in Vietnam. During the first centuries of Chinese domination, Vietnamese people had still kept their own culture until a large number of Chinese, officials and their descendants came to settle and tried to spread their way of life and Confucianism among the Vietnamese.

In 40 A.D, the uprising led by Hai Bà Trung (Two Trung sisters) forced the Chinese out of Vietnam for several years. In 43 A.D Han dynasty's expeditionary force recaptured Vietnam. Since this period, the Chinese domination had been maintained for centuries although "revolts broke out periodically, producing new culture heroes, more shrines, and more legends" (Jamieson, 1993, p. 8). 
Vietnam re-acquired its independence in 939 A.D after the Tang dynasty had collapsed. To describe this historical period of change, Jamieson (1995) wrote:

During the early years of independence, no monarch could integrate the land firmly. Leadership in Vietnam rested ambiguously on two separate concepts of political legitimacy: indigenous tradition and a heavily Sinicized system of politics and administration that had been assimilated during thousand years of Chinese rule. (p. 9)

Ralston, Tong, Maignan, Napier and Nguyen (2006) offered a similar view when they discussed this historical period:

During those thousand years, the Chinese provided Vietnam with technology and knowledge, as well as Chinese institutions and systems, including an appreciation for education. However, perhaps more importantly, the Chinese code of conduct, Confucianism, was also exported to Vietnam. Chinese influence on Vietnam was not only passed through its ruling system and officials but also by the migration of Chinese people, even to the present day. (p. 90)

Confucianism and the Chinese ways of life spread into society as well as Buddhism and Taoism. Buddhism, introduced by Indian monks was more influential than Confucianism and Taoism since it met the religious needs of the Vietnamese people. Confucianism gained more influence when Hán học (Chinese language study) was encouraged and became an official language. Schools of Chinese language were opened and the number of people who used the Chinese language gradually increased. The language served as a bridge to connect Chinese culture with Vietnamese culture. It served as a tool to propagate Confucianism through Vietnamese society (Huy, 1998).

According to Đại Việt sủ ký toàn thu (1993) (Complete Historical Annals of Dai Viet), the ups and downs of Confucianism depended on how Confucianism was perceived to serve that dynasty or emperor. Under the Ly dynasty (1009-1225), Confucianism was not highly recognised because Vietnamese rulers were devoted to Buddhism. They tried to extend the influence of Confucianism, which they considered necessary for their rule. In the year 1070, Văn Miếu - Quốc Tử Giám (Temple of Literature - Imperial Academy) ${ }^{1}$ was built. Dedicated to Confucius, this served as a school for crown princes. The year 1075 marked the revival and development of Confucianism when King Ly Nhan Tong organised the first national Confucianist examinations to recruit talented people to govern the nation. The

\footnotetext{
${ }^{1}$ It was considered as the first university in Vietnam
} 
Confucianist examinations continued to be held during the Tran dynasty (12251400). Confucianism and the Chinese laguange were encouraged not only for high officials but also for national education. In 1253, another Quốc học Viện (national university) was established with the purpose of teaching Tú Thu (Four Classics of Confucianism: The Analects, The Mencius, The Great Learning, and The Doctrine of the Mean) and Ngũ Kinh (Five Books: The Book of Rites, The Book of History, The Spring and Autumn Annals, The Book of Poetry, and The Book of Change).

The Tran dynasty was overthrown by peasant revolts and the Ho dynasty (14001407) was formed. After the seven-year-government of Ho Quy Ly emperor, Vietnam was re-captured by China during the Ming dynasty. According to Đại Việt sủ ký toàn thu (1993), the Ming tried to civilize Vietnamese people by propagating the Chinese way of life, beliefs and literature. They forced the Vietnamese to adopt Chinese clothing, and they changed cult practices by setting up their own local altars. Confucian temples were built in every district. At the same time, the Chinese moved to spread their culture in Vietnam, especially Neo-Confucianism as officially defined by the Ming court They established 69 medical, 54 astrological, and 126 Confucian schools (Whitemore, 1977).

Vietnam regained its independence and the Le dynasty was established in 1428 after 21 years of Chinese domination. The period of the Le dynasty accepted NeoConfucianism. Some sovereigns in the Le court were also Confucianist, such as Nguyen Trai (1380-1442). Emperor Le Thanh Tong was believed to be a "fervent disciple" of Confucianism. Under the regime of Le kings (1428-1788), NeoConfucianism had an impact in terms of its influence on government. Quốc Tử Giám was re-opened to educate the children not only of high officials but also of common people also (Cuong \& Ha, 2007). In 1496 Le Thanh Tong imposed Neo-Confucianist practices on Vietnamese people by encouraging people to get married according to Confucianist rites. He published a moral code of Confucianism including 24 articles and ordered people to learn them thoroughly (Huy, 1998). Under the 37-year government (1460-1479) of the king Le Thanh Tong, Neo-Confucianism had a profound impact on ideology and consequently became a dominant element of discourse (Jamieson, 1995). 
The Le dynasty was temporarily usurpered by the Mac dynasty (1527-1592) in 1527. Vietnam was ruled by Mac Dinh Chi, a great Confucianist scholar of the fourteenth century who gained his prestigious title of Trạng Nguyên ${ }^{2}$. The Mac supported NeoConfucianism and maintained what the King Le Thanh Tong had done to spread and impose Neo-Confucianism in Vietnamese society (Whitmore, 1997). Moral Confucian disciplines in Vietnamese society continued to be applied when the Le dynasty was restored in 1593 and existed until 1788. The Vietnamese people during this time were strictly required to follow the requirements of Confucian moral disciplines concerning the relationship of people (Đại Việt sủ ký toàn thu, 1993).

Confucianism is said to have reached its highest influence in Vietnam and received a new impetus since the Nguyen dynasty (1802-1945) began to hold power in 1802 (Huy, 1998). The rulers of the Nguyen dynasty perceived recent Vietnamese society as being disorganised, chaotic and decadent. As a result, they tried to seek "new" groundwork for society by making Confucianism the foundation of the national culture. Qing Code was almost copied under the government of Emperor Gia Long (1802-1819) to make the legal code Hoang Viet luat le (Laws and Regulations of Imperial Viet). Emperor Minh Mang (r. 1820-1840) modeled his government after that of the Chinese court. He also promulgated 10 articles of good conduct to be studied by the whole nation, in order to reinforce Confucianist morality (Huy, 1998). Under the Nguyen dynasty, Confucianism assumed to shape the traditional Vietnamese culture that has been kept on into the whole of the twentieth century and the early years of the twenty-first century to interact with Western influences and the globalisation process. The historical aspect of the survival, adjustment and influence of Confucian values in Vietnam are examined in the next section.

The survival, adjustment and influence of Confucianism in Vietnamese Society

The history of Confucianism in Vietnamese society suggests that Confucian development and its survival were directly related to the replacement of one dynasty with another. However, Confucianism was not always a shadow of political change and was not always dependent on how a government perceived and imposed it on a

\footnotetext{
${ }^{2}$ A title awarded to a man who passed the national examinations with the highest recognition in every subjects. It was considered as "PhD degree" in feudal systems in Vietnam.
} 
society (Yao, 2000). Confucianism existed and survived as it met the needs of the society and created its own disciplines that were accepted as ways of life. Confucianism changed and adapted to fit new political and social demands. In this sense, de Bary points out: "... Confucianism was less dependent on the state for survival than the state on it. Even though affected by the rise and fall of dynasties, Confucianism found ways to survive" (1988, p. 110).

The imprint of Chinese civilization and Confucian thought have waned in the contemporary period. However, the core values of Confucianism remain deeply rooted in Vietnamese society; impacting on philosophy, culture, society, economy, and politics (Ashwill \& Diep, 2005; Bich, 1999; Jamieson, 1993). It is estimated that 60 to $70 \%$ of all Vietnamese words are Sino-Viet which shows the influence of Chinese culture and Confucianism.

To describe the Confucian influence on Vietnamese society, Dao Duy Anh in Khổng giáo phê bình tiểu luận (Short critique of Confucianism) stated that:

For more than two thousand years, Confucianism has existed in China and in our society [Vietnamese society] without changing, and thus from the past to now, all through society, not only the ranks of Confucian scholars, but the common people as well became imbued with the Confucian spirit. We can say that throughout one's life, whether in Chinese society or in Vietnamese society, one breathed a Confucian atmosphere, fed on the milk of Confucianism, ate Confucianism, and even died with Confucian rites. From thought, language, and the actions of individuals to learning and the social system, nothing escaped the control of Confucian philosophy and ritual teaching. (cited in McHale, 2002, p. 422)

Although this statement might not be completely true in the present day, it proves that the long-term influence of Confucian beliefs on Vietnamese society cannot be fully erased and replaced by new beliefs. In the book Nho Giáo xusa và nay (Confucianism Past and Present), Dam (1999) discussed the negative and positive features of Confucianism in Vietnamese society. Although his arguments and ideas are likely to be debatable for their "inconsistent", "sharply Marxist-Leninist", "seemingly contradictory propositions" (Taylor, 2002), his voice is consistent with the influence of Confucianism on Vietnamese society. Dam concluded:

Regardless of the inexistence or collapses of the temples of literature or the shrines of Confucius; regardless of the disappearance of "Confucian association", Confucianists or "teachers of Confucianism", the [Vietnamese] society will retain its Confucian relevance, morality, doctrine, and approach. (p. 470) 
Vietnam gained its independence from French colonialism in 1945 and the last feudal regime was eliminated. Consequently, people have accepted a new way of life without some concepts of Confucianism, which used to be assumed as "fundamental values" in the old society. Such principles as "Tam Tòng" (Three Submissions) which taught women that "when she is young, she must submit to her parents. After her marriage, she must submit to her husband. When she is widowed, she must submit to her son", have gradually disappeared. In the past, Vietnamese women who remained widows after their husbands had passed away were highly praised. This is not the case in present time. Vietnamese women now enjoy equality of sexes and opportunities. Nevertheless, Vietnam is still very much a patriarchal society (Ashwill \& Diep, 2005) due to long-standing impacts of Confucianism. It is no doubt that the "inequality of sexes" is not completely eliminated. In Confucianism, the patriarchal family is the main unit of society, in which duties and obligations are defined as those of a family to a father, a child to a parent, a wife to a husband, and a young brother to an older brother (Ashwill \& Diep, 2005; Jamieson, 1993; Yao, 2000). Vietnamese women generally accept their role as "good housewives" and their husbands as "the backbone of the family". A list of feminine "do's and don't's", often gathered together under the rubric of "Tú Đíc" (Four Virtues) reflected in Confucianism, including "công" (work), "dung" (physical appearance), "ngôn" (appropriate speech), "hạh" (comportment) is still used as official criteria to evaluate how good a woman or girl is.

With the process of modernisation and globalisation, Vietnamese have become more open to the world. The cultural interaction with the world has brought new social values, norms, beliefs and ways of life. Traditional values have remained in Vietnamese society as the underpinnings of the culture. Jamieson (1993) used two words to describe Vietnamese culture in the modern time: "change" and "continuity". "Change" is the process of accepting and developing the new cultural values imported into Vietnamese society. "Continuity" is the process of preserving and maintaining traditional values affected by Confucianism. For example, four or fivegeneration families which were common in the past are not so any more. However, the role of the family and the relationships among family members have not changed. The family is still the most basic unit, the strongest, and the most important. Vietnamese families continue to produce young men and women whose hopes, fears, 
guilt, and goals are family-centred. Families still follow a male-oriented kinship hierarchy in Vietnam (Jamieson, 1993).

In contemporary Vietnam, Four Classics of Confucianism (Tú Thu) and The Five Books (Ngũ Kinh) are no longer being used as sources of learning; Confucianists or teachers of Confucianism can no longer be found; Confucian organisations and institutions or examinations are no longer being built; Confucianism seems to have disappeared or "become extinct" (Dam, 1999). Nevertheless, elements of Confucian heritage have been transmitted to the present, as in hidden values in Nationalist and Communist doctrines, principles, ethics, and public opinions (Jamieson, 1993). Every primary or secondary school (schools for children aged from 6 to 14) has a large red banner at the main entrance with the motto "Tiên học lễ, hậu học văn" (first thing to learn is rite, the second thing to learn is knowledge), which means that proper manners in human relations are the very first thing to be learnt and knowledge is considered secondary. This motto reflects the moral values of Confucianism which affect the Vietnamese educational philosophy and practice.

Evaluating moral education in the Vietnamese system, Doan (2005) divided the present system of morality into two: "traditional morality" and "socialist morality". He believed that "traditional morality" was embedded in Confucian values and beliefs that have had a long-lasting influence on Vietnamese culture and have been transmitted through informal channels of education. "Socialist morality" was enforced through formal channels of national curricula and in various social activities and movements. Few people would deny that there exists a link between the system of Confucian moral values and Vietnamese educational philosophy. Confucian moral values are not only reflected in social life but also in legal documents. The Education Law of the Socialist Republic of Vietnam posits that moral education in the primary school aims "to teach students to respect, love and show good behaviour towards grandparents, parents, teachers, older people; to love brothers, sisters, and friends; to be sincere, confident, eager to learn, and appreciative of nature's beauty" (Ministry of Education and Training, 2004, Chapter One, Article 20).

Many social factors originating from Confucian values and beliefs are still at work and are reflected in how people construct their logical thinking, behaviour and relationships. Confucian values and beliefs are still alive and transmitted by 
generations despite the passage of time, the process of modernisation and globalisation. It has been an indispensable part of Vietnamese history, traditions, and culture. The next section discusses three dominant prevailing Confucian discourses in Vietnamese society.

\section{Reflections of Confucian values in Vietnamese society}

\section{Hierarchical values}

\section{Hierarchical values in Vietnamese people's perspectives}

The nature of hierarchy is inherent in Confucian tradition (Slote \& Devos, 1998). Characteristics of hierarchy are still strongly reflected in population's ways of life. These are revealed in how people build relationships, how they use language in communication and how people perceive harmony in family or society. Bich (1999) states that the strength and vitality of hierarchical values in Confucianism influences the philosophy of a society to ensure stability, manage order, instability and chaos, and guarantees that state of affairs. The existence of hierarchical values is guaranteed and bounded by Confucian beliefs of social orders in which such factors as patriarchy, gender, age, roles, positions or social status are strongly emphasised. In this respect, Jamieson (1993) argues that the Vietnamese perception of the world stemming from Confucian values and beliefs rationalises and legitimises the hierarchical order of society, making hierarchy itself part of the intrinsic structure, a state of affairs that is both natural and unalterable.

Vietnamese people have inherited the Confucian teachings of the structure of society and education which place a heavy emphasis on absolute obedience to parent, elder, teacher, and superior. The authority of a superior, elder, parent, and teacher is unquestioned, and obedience to all is absolute (Slote, 1998a, 1998b). As in all Confucian societies, such a pattern of hierarchical structure has become deeply imprinted in the structure of family, organisation, and society. People have accepted it their own culture. Knowing one's place and role in family, school, work, and society is vitally important, and takes precedence over the individual. As a proverb puts it, you have to know exactly who is above you and who is below in the family or society order so that "kính trên, nhuờng duới" (you can yield to those below and respect those above). Another Vietnamese sayings is also instructive: "trên phải ra 
trên, duới phải ra duóit" (Above has to be above, and beneath has to be beneath). These beliefs are presented as a Confucian ideology concerned with maintaining social groups in good order, especially the family. Confucianism considers a nationstate as a large family. Orders in family are widely understood as orders of society in which one should know his/her position and role so as to fulfill his/her responsibilities with the purpose of benefiting his/her own family or community. This is strongly emphasised in Confucian perspectives: "let the lord be a lord; a subject be a subject; a father be a father; a son be a son" (Analects, cited in Tamney \& Chiang, 2002, p. 89).

Social status is important in Vietnamese society (Bich, 1999; Jamieson, 1993). Status is based on age, gender, educational achievement/studying degree, and social/political position. These are the roots of hierarchy and factors impacting on the people's language construction and behaviors. Vietnamese people often expect younger ones and those of lower social status to respect them, and, simultaneously, they respect their seniors. Within the discourse of hierarchy, a senior or an elder's criticism in a junior is taken for granted, but the other way round does not seem to be morally convincing, though the latter is still considered a legal act. Older people rarely accept young people's initiatives, opinions or critiques and they expect to be respected because of their experience, knowledge, and wisdom (Aswill \& Diep, 2005; Lan, 2002). This is reflected in the following Vietnamese saying: "trúng mà đòi khôn hơn vịt" (the egg cannot be as clever as the duck). This also reaffirms Te's (nd) conclusion that age is an asset, not a liability. In other words, age represents power and respect.

Jamieson (1993) states that, "traditional Vietnamese accept[ed] the principle of social hierarchy and care[d] passionately about face and relative status" (p. 31). This phenomenon has also been emphasised in a number of works exploring Vietnamese culture by Borton (2000), McLean (1995), Bich (1999), and Ashwill \& Diep (2005). The concept of equality does not imply the breaking down of the established hierarchy, especially the established hierarchy of parents and children. Traditional norms and values have influenced generations so profoundly that people feel it is hard to alter their ways of living. Breaking the established hierarchy is the most serious and unforgivable offence, no matter what reason and how right that person may be (Bich, 1999). 


\section{Hierarchical values in harmony and relationships}

Within the discourse of Confucianism lies the notion of the 'right' relationships. A person is always entwined in a web of relationships and defined by roles such as ruler, minister, father, husband, wife, son, or brother. In the matrix of these relationships, one has his/her own position which defines his/her responsibilities and obligations from which he/she must produce the "right" speech, "right" behaviours, or "right" actions to build a harmonious family, organisation, or society. Everyone is required to adhere to the responsibilities inherent in the five basic relationships: between ruler/superior and subject/ruled, between father and son, between husband and wife, between elder brother and younger, and between friend and friend ( $\mathrm{Tu}$, 1998; Young, 1998). These relationships are built in the hierarchal mechanism with one person "in charge" of the other. All, except the last (friend to friend), involve the authority of one person over another. Power and the right to rule belong to superiors over subordinates. In Mencius, five basic relationships are defined with distinctive words: love between father and son, duty between ruler and subject, distinction between husband and wife, precedence of the old over the young, and faith between friends (Mencius, IIIA.4, cited in Tu, 1998, p. 125). These relationships are built under the guidance of an ethical system, including the various codes of moral life, rules of propriety, patterns of behaviors and guidelines (Yao, 2000). Among these, family relationships are the most important from a Confucian perspective. Confucian ethics are not confined to the family. Confucianism believes: "If only everyone loved his parents and treated his elders with deference, the Empire would be at peace" (Mengzi; cited in Yao, 2000, p. 33). Confucianism takes family virtues as the cornerstone of social order and world peace. Its logic is that the family is the basic unit of the human community and that harmonious family relationships can lead to a harmonious society (Yao, 2000).

These Confucian principles of human relations are evident in contemporary Vietnamese society. When examining the concept of hierarchy in Vietnamese society, Bich (1999) places emphasis on family relationships. Everyone must know who their parents, grandparents, brothers/sisters and forebears are; their places in the order of precedence; where his or her own place is, and how to behave appropriately to each family member. In this respect, his/her allegiance to his/her family is essential must because the family is the centre of the common man's preoccupation 
and the backbone of Vietnamese society. Of these relationships, importance is on the relationships of parents and children and family harmony is laid on the children (Yao, 2000).

Social order is maintained by strict principles of human relations, both in the family and society. People build relationships within their positions and roles. These relationships are bound by the discourse of "respect" and "obedience". In effect, Confucian principles enforce absolute respect and obedience of children to parents, wife to husband, subordinate to superior, subject to master, and students to teachers. Respect and obedience are predominant in the relations between people (Te, nd). This is evident in attitudes toward older people. Respect and consideration for old age are derived from the obligation of filial piety that requires young people to respect and love their parents and parent-like members of the family. A long life is a sign of kindness and regard on the part of the deity for virtuous people. Elders are the carriers of tradition and the embodiment of knowledge and wisdom. Old people enjoy high respect, irrespective of wealth, education, or social position. This is expressed in both attitude and behaviour, particularly in the use of special terms of address. Unlike Western societies that put a premium on youth, Vietnamese society is proud of its old members. Age is an asset, not a liability (Te, nd)

Gender has an important meaning in Vietnamese hierarchy (this factor will be further discussed in the next section). Despite gender equality as encouraged by the government and in official legal documents (e.g, Law of Marriage and Family promulgated in 2000) and even with newly-imported norms and values from Western society, Vietnamese women continue to have a "secondary role" in a largely patriarchal society. There is a persistent tendency, in hierarchy, to denigrate the status of females and subjugate them to male dominance (Jemieson, 1993). It is a fact that men hold most of the positions of power in Vietnamese society (Ashwill \& Diep, 2005).

\section{Hierarchical values in terms of change}

Change means risk and thus, it is not always readily accepted, although it is acknowledged that change is necessary for development (Ashwill \& Diep, 2005). Seemingly, 'reform' or 'change' in a Confucian society is more problematic than in other societies. Vietnamese society is such a case. It is because "the reform of 
[Confucian] society begins at the top, among the rulers, and then reaches down to the lower orders of society" (Noss, 1974, p. 280). Change or reform comes from seniors and if the seniors do not initiate change, people accept the 'status quo' without any problems (Lan, 2002). "Change" in terms of learning and teaching attitude is also an issue. Confucian teachings place a heavy emphasis on absolute obedience to teachers. As Ferguson (2001) compares, "if Confucianism is a religion, then the teacher is the minister or priest" (p. 20). Vietnamese students consider their teacher as a "live resource of knowledge" and a person who "knows-all". They expect the teacher to know everything about a subject and believe in what they are taught without critically questioning. This phenomenon is so prevalent that many educators or policy makers often state that Vietnamese students are intelligent but lack selfreliance and creativity (Ngoc, 2008; Tuan, 2008).

\section{Collectivism}

\section{Collectivism versus individualism}

As a general understanding, collectivism is in opposition to individualism (Hofstede, 1980; Mead, 1967). Collectivism emphasises group-based values and the importance of integrity of the in-group and group goals. Individualism places emphasis on personal goals, less concern and emotional attachment to the in-groups (Park, Regh, \& Lee, 2005; Triandis, Bontempo, \& Villareal, 1988). In terms of organization culture, collectivism emphasises such values as loyalty, harmony, cooperation, unity, and conformity. The unquestioning acceptance of norms, attitudes, and values in an organization are its most important values (Park et al., 2005). In this respect, Park et al. (2005) point out some of the important features of collectivism, including the benefits and goals of an organisation are more important than an individual's; personal needs and desires should accord with organisational goals; the prosperity or prestige of the organisation should be above that of the individual; organizational goals should have priority over personal goals.

Ferraro (2002) offers a general comparison of individual-oriented society (individualism) and collective-oriented society (collectivism) in Table 1. These two terms are used to explain the development and expression of personal behavior and motives in a culture (Hofstede, 1980, 1997). They are used to differentiate Western culture from Asian culture (e.g., Hofstede, 1980, 1997; House et al., 2004). 
According to Englehart (2000), Asian society is labeled collectivist because its cultures are characterised by a set of values such as obedience to authority, intense allegiance to groups, and a submergence of individual identity in collective identity. In the GLOBE research by House et al. (2004), the findings showed that Confucian Asian countries such as China, Japan, South Korea, and Singapore exhibited high scores in institutional collectivism, and in-group collectivism. These countries were result-driven, and they encouraged the group to work together over individual interests.

Table 1: Characteristics of individualism and collectivism (Source: The cultural dimension of international business, Gary P Ferraro, 2002, p. 101)

\begin{tabular}{|l|l|}
\multicolumn{1}{|c|}{$\begin{array}{c}\text { Individual-oriented society } \\
\text { (Individualism) }\end{array}$} & \multicolumn{1}{c|}{$\begin{array}{c}\text { Collective-oriented society } \\
\text { (Collectivism) }\end{array}$} \\
\hline $\begin{array}{l}\text { Individuals are major units of social } \\
\text { perception. }\end{array}$ & $\begin{array}{l}\text { Groups are major units of social } \\
\text { perception. }\end{array}$ \\
\hline Explain others' behavior by personal traits & Explain others' behavior by group norms \\
\hline Success attributed to own ability & Success attributed to help of group \\
\hline Self defined as individual entity & Self defined in terms of group \\
\hline Know more about self than others & Know more about others than self \\
\hline Achievement for one's own sake & Achievement for benefit of group \\
\hline Personal goals over group goals & In-group goals over personal goals \\
\hline Values self-assuredness & Values modesty \\
\hline Values autonomy and independence & Values interdependence \\
\hline Fears dependence on others & Fears ostracism \\
\hline Casual connections to many groups & Strong connection to a few groups \\
\hline Few obligations to others & Many obligations to others \\
\hline Confrontation is acceptable & Rarmony is expected \\
\hline Task completion is important & \multicolumn{1}{|c|}{ Relations are important } \\
\hline
\end{tabular}

\section{Values of collectivism in Vietnam}

A number of authors have emphasised that a dominant discourse in Vietnam is collectivism (e.g., Ashwill \& Diep, 2005; Bich, 1999; Borton, 2000; Jamieson, 
1993). This cultural characteristic can be explained in terms of the influence of Confucian values. Hence, what key element makes Confucianism relevant to collectivism rather than individualism? According to Yao (2000), it is because Confucianism places much emphasis on human responsibility. Yao (2000) argues that one of the key issues in all traditions in the world is how to attain a kind of balance between action and responsibility. In this sense, one lives in a matrix of relationships and the self is at the centre. An individual's freedom or free choices without responsibility for others, the community or society at large would result in conflict (Yao, 2000). Harmony is foremost and penetrates all levels and dimensions of Confucian discourses. Confucianism explains that conflict first arises from the relation between oneself to others, and harmony is the result of an appropriate accommodation of one's own needs to the requirements of others (Yao, 2000).

The collectivity is evident in Vietnamese culture. A number of authors emphasised that Vietnamese people have a strong sense of community spirit (Bich, 1999; Borton, 2000; Ellis, 1995). As Borton (2000) points out, "Western culture places high value on the individual, whereas Vietnamese culture emphasizes the community" (p. 21). It is not by chance that those who study Vietnamese culture also characterise Vietnamese society as a "collective community". The prevailing discourse of Vietnamese culture as a collective community is apparent in everyday life. In family relationships, Confucian norms and values place a strong emphasis on collective community in which an individual is not an independent entity but is bound up with the family to which a person owes complete allegiance. According to Bich (1999),

Collective community [is] highlighted by the absolutely dominant influence of the family as a whole vis-à-vis everyone of its component members. ...While the raison d'être of the Western family may be to produce and support the individual, whose maturity will signal the attainment of its objective, in the Vietnamese family the raison d'être of each individual member [is] to continue, maintain, and serve the family. (p. 18)

Each member of the family is expected to live in harmony with others, sharing his or her ideas, responsibility, burdens and interests with other members. Members of a family are expected to subordinate their personal interests to those of the family. Their personal interests cannot run counter to the family interests but should comply with the latter (Bich, 1999). Vietnamese subdue their personal desires and aspirations if those go counter to the communal standards. In a bad situation, one can call on family members for support or help because they believe "mọt giọt máu đào hơn ao 
nước lã" (a drop of blood is better than a pond of water / blood is thicker than water). This saying means family ties are stronger than any other ties. In a bad situation, it is no one else but people of the same flesh and blood that have to be responsible first for supporting and helping each other. It is often said that "sẩy cha còn chú, sẩy mẹ bú di" (if your father passes away, there is still your paternal uncle for you to rely on; when your mother passes away, there is still your maternal aunt who will nurse you).

Dalton, Hac, Nghi and Ong (2001) conducted research on Vietnamese social relations and they suggested that although the social modernisation process affects the pattern of social relations among the public, the traditional orientations toward family and community remains. Ninety-nine percent of the respondents said that parents were to be respected regardless of their quality and faults; 97\% stated that "one of my main goals in life has been to make my parents proud". Vietnamese people believe in filial piety (hiếu) as the children's duty toward their parents.

Collectivism is also reflected in moral philosophy. People believe that merit acquired through virtuous deeds is then passed on to succeeding generations and even to future generations. What an individual does not only impacts on their own life but also has a strong influence on others in their family and people in different generations. Consequently, one is always encouraged to lead a virtuous life in the hope that their merit will benefit their family members. In contrast, if a person has committed wicked deeds in their life, their children or the family members of succeeding generations will pay the price (trả giá). People are admonished that "If the father's generation eats salt, the child's generation thirsts for water" (Đờ cha ăn mạnn, đời con khát nước) (Vietnamese saying). This saying means "children have to suffer for their parents' sins". Embedded in this saying is not only the presence of moral values that one has to pursue in life, but also the presence of "collectivism", which emphasises the responsibilities and obligations to fulfill for their family, succeeding generations and community. Vietnamese people view "guilt/sin" in the communitarian context, differing from what Western people do. Slote (1998b) points out:

In the West, guilt, which is related to shame, is essentially a personal matter; in Vietnam, one's transgressions have both a horizontal and a vertical dimension: they affect both the nuclear and extended family in the current generation and the well-being of the family for generations to come. Not only is this a powerful 
deterrent to improper behavior, more important, it is a glue, a bonding agent

(although not the only one) that holds the society together. (p. 325)

The relationships in a family are not only between living members, but also between the dead, living, and unborn members and in different generations. In Vietnamese people's perspective a family is understood as a "zoomed-out" human community stemming from ancestors to present and future generations. Each member is not an independent entity but a link in the generational chain (Bich, 1999).

The concept of "losing face" also reflects the feature of collective community. Borton (2000) stresses that "loss of face is painful in any society, but unbearable in Vietnam" (p. 24). Everyone from childhood is trained in communality with communal assessment as the highest standard. People modify their behaviours and attitudes accordingly. Otherwise a person would be subject to "social disgrace" and "losing face". Misconduct or failure of an individual is blamed not only on himself, but also on his parents, siblings, ancestors, friends and colleagues. Any success or fame achieved by an individual brings honor and pride to people or the community (Bich, 1999).

\section{Gender relations}

\section{Conception of Yin and Yang in gender relations}

Historically, early Vietnamese society was matrilineal and matrilocal. However, this changed with Chinese domination and colonisation since 111 B.C. Historians believed that Chinese culture with Confucian teachings were imported into society and then gender roles were changed. Society was totally transformed into patriarchy in about the sixth century (Frenier \& Mancini, 1996; Huy, 1998). Traditionally, Confucian teachings restricted Vietnamese women's roles within the discourse of the patriarchal family. Vietnamese folklore and literature stereotype women's roles and place in society as: chastity is prized; marriages are arranged; a married woman has to serve her husband and his family by maintaining housework; and women ought to bear children because such is their duties (Frenier \& Mancini, 1996). As earlier stated, women were taught "three Submissions" as guidelines for their whole life. She was glorified if she remained a widow for the rest of her life (Ashwill \& Diep, 2005; Bich, 1999; Frenier \& Mancini, 1996). In this sense, she was honored and praised for her faithfulness to her husband. One of the most famous legends praising 
Vietnamese women's "constant faithfulness" is "Waiting for husband" (Hòn Vọng Phu):

A woman who lived centuries ago, To Thi, unwittingly married her long-lost brother. When her husband learned the truth, he volunteered to go to war and never came back. The innocent To Thi carried her baby to the peak of a mountain and waited for her husband. She waited so long that she and her baby eventually turned to stone. And there she still stands, baby on her back, looking out toward the sky in longing. The mountain was later named Vong Phu. (Vietnamawesometravel, nd, p. 1)

Such legends and traditional gender norms are rooted in ways of thinking and have continuously influenced Vietnamese society. It is acknowledged that women are bound by the duties of conjugal fidelity and obedience to their father and husbands. Men are considered superior and women are inferior (Yeager, 1987). These traditional views are believed to be the product of Confucianism (Dam, 1999; Quy, 1992). According to $\mathrm{Li}$ (2000), in Confucianism, the two principles that govern the universe, the yang and yin, yang is superior and yin is inferior. The husband is yang even if he is from a humble family, and the wife is yin even if she is from a noble family. Therefore, the husband is superior and the wife is inferior. To describe gender roles, Jamieson (1993) also used the notions of yang and yin to refer to men and women. He believed that "there was a persistent tendency, rooted in the pervasive yin-yang notion of hierarchy, to denigrate the status of (Vietnamese) females and subjugate them to at least nominal male dominance" (p. 18).

\section{The transformation in gender relations}

Gender relations have been undergoing vast changes since the collapse of the last Vietnamese feudal system and communist ideology began in 1945. The first constitution of Vietnam, passed in 1946, stipulated that "all the rights that Vietnam has as a nation belong to its people regardless of racial, gender, wealth, class, and religious discrimination" (Vietnam's National Assembly, Chapter I, article 1) and "women and men have equal rights in all areas" (Vietnam's National Assembly, Chapter II, article 9). These changes were influenced by socialist ideology, pragmatic thinking, and the modernisation process. While Confucian precepts recognised and reaffirmed gender differences and patriarchy, socialist ideology has set out to reduce gender inequalities labeled as "backward" and "feudal" and emphasised the equality of men and women. Modern ideas and gender norms about women were gradually accepted by political leaders, who turned these ideas into public policies. For 
example, the Marriage and Family Law (2000) has attempted to promote gender equality in Vietnamese society. Some basic equal rights under this law are stated as follows:

1. Husband and wife are faithful to, love, respect, care for and help each other, and together build a prosperous, equal, progressive, happy and lasting family.

2. Husband and wife are equal to each other, having equal obligations and rights in all aspects of their family.

3. Husband and wife respect each other and preserve each other's honour, dignity and prestige.

4. Husband and wife are strictly forbidden to commit acts of ill-treatment, persecution or hurting the honor, dignity or prestige of each other. (excerpted from the Marriage and Family Law, National Assembly of Vietnam, 2000)

This law addresses the emerging phenomenon of cohabitation. Cohabitation between unmarried couples is no longer considered a criminal act. Before that, living arrangements were illegal. This law revised the marriage and family code of 1986 and it also recognises that a woman can have a child without a husband. Prior to 2000 , this issue was either nonexistent or vague in law. A girl's pregnancy without a husband was believed to be unacceptable

Mở cứa (Open Door) and Đổi Mới (Renovation) Policy ${ }^{3}$ have also opened up opportunities for women in terms of the work force, gender equality and leadership. According to the 1999 Census, the gap between the male and female portions of the work force is narrowing. This trend is the proof of closing gap in gender in education (Central Census Steering Committee 2000). The findings of a 1997-1998 survey indicate that the ratio of female to male students in college was $44 \%$ for public and $48 \%$ for private universities (Nam, 2001).

Changes in gender equality do not mean that the traditional conception of gender has disappeared. Recent sociological and psychological studies show that despite the obvious changes, women have been affected and held back by traditional ideas. In their research, Dalton et al. (2001) examined gender attitudes in several areas in Vietnam and they found some interesting outcomes: $48 \%$ believed that men had more right to a job when employment is scarce; $86 \%$ claimed that women needed to

${ }^{3}$ Đổi mói means "renovation". This name was given to the economic reforms initiated in 1986. Since then, market economy has been permitted and encouraged to replace the centralised - planned economy. 
have children in order to fulfill their roles; only $16 \%$ approved of a woman being a single parent; and 56\% said that men were better politicians than women. Scholars also believed that more women entering the workforce did not mean that their home duties were alleviated. In fact, women carried dual responsibilities because they earned a living from work and fulfilled their traditional roles as a mother and a wife at home (Dalton et al., 2001). One career-minded young Vietnamese woman described her "dual responsibilities" in her story as follows:

\begin{abstract}
You and I - we work, we have money and we are equal to men. Society respects us, praises us. The Vietnamese Women's Union even has awards with seemingly attractive and honorable names like "Good official, better housewife". The more it praises, the more we manage. We try hard to make everything run smoothly: housework (cooking, cleaning, washing), company work (meetings, advertising, managing). Being busy with loads of work, have we ever stopped to ask ourselves: "why do we have to work so hard like this?" (Ashwill \& Diep, 2005, p. 74)
\end{abstract}

The vast majority of women are in full-time positions outside of the family unit. Women are often doing the same work for the same pay as men and are making many decisions. Dalton et al. (2001) came to the conclusion that "despite the economic and social advances that women have made in the past generation, support for full gender equality is still lacking" (p. 11). This seems to support Quy's (1992) comments that thinking highly of men and less of women is a product of Confucianism. This has been deeply implicated in creating a tradition that has given greater dignity and power to men and has restricted women to the home and bearing the children. Bich (1999) has the same conclusion as Quy (1992). He concluded that the conception of gender equality is difficult to develop in Vietnamese society.

Men hold most of the positions of power and influence in the government, the business world, and academia. Although the National Strategy for the Advancement of Vietnamese Women approved in 2001 also calls for women to hold $50 \%$ of all positions in state agencies at all levels by 2010 , there is a sizable gap between verbal commitments to gender equality and actual practices (Hang, 2008). Between 19922007 , only $18.5-27.3 \%$ of Congress representatives were women; female local officials constituted $23 \%$ at the provincial level, $23 \%$ at the district level, and only $19.5 \%$ at the ward/commune level (Hang, 2008). Ashwill and Diep (2005) used the phrase "male-dominated world" to describe this social phenomenon in Vietnam. In 
this male-dominated world, most women will be low-level assistants and secretaries, not colleagues with major decision-making responsibility (Ashwill \& Diep, 2005).

Although there have been great efforts from the government to reduce gender inequality and the availability of socialist ideology and gender norms in modern time, Vietnamese women are still viewed through the lens of traditional standpoints of gender roles derived from Confucianism. Hang (2008) argues that Vietnamese women are continuously bounded by the prevailing norms of femininity couched in the language of the "heavenly mandate". Women continue to face long-entrenched stereotypes, in which they are expected to fulfill their "heavenly mandate roles" such as giving birth, breastfeeding, teaching children, caring for husbands and elderly relatives, doing chores at home. Fulfilling these "heavenly mandate roles", or "selfless endeavors" in traditional views, is still praised in verbal daily communication, mass media, books, schools and elsewhere, establishing the model ideal of womanhood.

\section{Summary}

This chapter has discussed the historical perspectives on Confucian values and examined the three dominant prevailing discourses in contemporary Vietnam. Although the imprint of Chinese civilization and Confucian values are believed to have waned in the contemporary period, the predominant elements of Confucian values have remained in place and continue to influence Vietnamese society. The communist revolution, the "open door policy" in the globalisation process, and the advent of socialist-oriented market economy have changed the nature of society and added new dimensions to Vietnamese culture, but Confucian-affiliated values continue to maintain a strong impact on the society. Such values and beliefs may not always be conscious as they are so deeply embedded that people do not even know what they are (Nias, Southworth, \& Yeomans, 1989). Yet, they are still at work and are reflected in the ways that Vietnamese people construct their logical thinking, behaviors, and in the ways they "do things around here". The next chapter conceptualises the notions of culture and leadership and examines how they are related to each other. 


\section{CHAPTER THREE: CONCEPTUALISING CULTURE AND SCHOOL LEADERSHIP}

\section{Introduction}

This chapter identifies the conceptual perspectives for this study. More specifically, the chapter clarifies the concepts of culture and leadership; discusses leadership theories and the four pre-defined leadership functions namely, exercising power, building relationships, decision-making, and managing and solving conflict. It also examines the relationships between societal culture and these leadership functions.

\section{Culture}

\section{The concepts of culture}

In a study investigating culture and leadership, it is first necessary to define the core concept of culture itself. As Bodley (2011) points out, the specific cultural concept that researchers work with is an important matter because it may influence the research problems they investigate, their methods and interpretations, and the positions they take on public policy issues. Consequently, it is appropriate to explore different scholars' perspectives about culture in order to have an overall understanding of the context.

There are many definitions of culture, but no single definition sufficiently covers all of its meanings. It is a fact that no single definition is heartily accepted by all social scientists as culture is clearly a difficult and abstruse concept to define (Banks, 1994; Dimmock \& Walker, 2005). The "old-fashioned" definition of culture formulated by Sir E.B. Taylor (1871) is that culture "includes knowledge, beliefs, art, morals, law, custom, and any other capabilities and habits acquired by man as a member of society" (cited in Banks, 1994, p. 82). However, according to Banks (1994), this definition is not popular among social scientists today as it is not a very helpful guide for research. It is so broad that we can neither observe nor explain everything (Banks, 1994). Hence, there is a need to have a definition of culture that is more specific, more precise and functional for modernised societies. 
The most widely accepted definition of culture suggests that culture consists of the beliefs, values, patterned and interrelated ideas (norms), symbols, or assumptions that are shared by people of a given group that distinguishes it from other groups (e.g., Bodley, 2011; Deal \& Kennedy, 1982; Deal \& Peterson, 1990, 1999; DimenSchein, 1977; Schein, 1992). These values and beliefs are shared, learned, transmitted cross-generationally, adaptive, and integrated (Bodley, 2011). Cultural values are generally understood as beliefs about what is good, right, and fair that are acknowledged and accepted by members within a group or people within a society, while cultural norms are definite principles or rules that serve as a cognitive guide or blueprint for human behaviours or actions (Black \& Mendenhall, 1990; Dimmock \& Walker, 2005). Culture provides people with knowledge or beliefs which they rely on to define what they should do and what they should not do. Culture makes us resist acting in a way that we think is wrong. One of the most important cultural characteristics that scholars have emphasised is that culture guides and shapes people's behaviours. This significant cultural feature has promoted a substantial number of scholars to investigate how a societal culture influences a leader's behaviours (e.g., Hofstede, 1997, 2001; House et al., 2004).

Some social scientists include material objects in their definitions of culture. Bodley (2011) suggests a definition of culture in which he stresses that there are at least three components of culture: what people think, what they do, and the material products they produce. Giddens (1989) suggests that the material goods people create reflect their cultural values and aspects. Similarly, Dimmock and Walker (2005) argue that culture is expressed through physical objects, such as art works, books, monuments and museums. However, some other social scientists go so far as to exclude material objects from their definition of culture. They often emphasise the intangible, symbolic, and ideational aspects of group life as the most important aspects of culture. As Banks (1994) points out:

Even social scientists who view tangible or material objects as part of culture believe that the interpretation of these objects and the rules governing their use constitute the essence of culture and not the artefacts themselves. (p. 83)

It would be agreed that a tattoo is not culture but it reflects a cultural feature of Maori people. Or Dong Son bronze drums are not Vietnamese culture but they convey one of the culture's finest examples of metalworking of the ancient Vietnamese people. 
The meaning of culture manifests itself in what and how people interact with each other, in marriage customs, patterns of relationships and even in the meaning embodied in the clothes people wear, what and how they eat, and the way they do their hair. Culture could be said to be something special possessed by people and only people. It is considered a significant factor in human evolution. We humans would be no different from animals if we did not have the need for knowledge. If we see culture in the light of a mental viewpoint, culture is perceived as a complex of ideas, or learned habits, that inhibit impulses and distinguish people from animals (Bodley, 2011).

Noticeably, common cultural values exist and overlap across cultures. However, basic values constitute the essence of culture and inform its own unique patterns within a particular society (Dimmock \& Walker, 2005). These basic values could be seen as a source of power that informs our modes of life and thoughts. They are basic rules within a society that drive people to choose to act in one way rather than another and bring the potential for social practices. For example, it would be surprising for Vietnamese people to witness a couple kissing in a public place in Vietnam. This reflects the cultural features of each region or each nation. As Geertz (1973) argues that "when we say we do not understand the actions of people from a culture other than our own, we are acknowledging our lack of familiarity with the imaginative universe within which their acts are signs" (pp. 12-13).

Banks (1994) suggests some remarkable characteristics of cultures. One of which is that cultures are dynamic, complex and changing. He argues "cultures are also systems; they must be viewed as wholes, not as discrete and isolated parts. Any change in one aspect of a culture affects all of its components" (Banks, 1994, p. 84). However, "changing" does not mean a new cultural value replaces the old one as if on a clean sheet; they both still stand and create a cultural diversity. In American society, for example, its culture is not homogeneous but heterogeneous as its society contains many sub-cultural groups living side by side.

What has been discussed offers an overall meaning of culture. It seems to be everything around us, embedded in our lives, in social structures and social practices. We can even see "a yoghurt" as a part of some cultures. It was not a feature of culture in our ancestors' time, but it is a feature of culinary culture in the modern 
world. The relationship between culture and people is mutual: people are a cultural subject and people are a product of culture, both influencing reciprocally.

People all belong to certain cultures. Culture influences us tremendously because it exists in all aspects of our lives and carries its own nuances for its own context. As Peterson and Deal (1998) point out, "culture is extremely powerful" (p. 28). Singing lullabies, for example, is not a cultural nuance of all countries, but it embodies one of the Vietnamese cultural aspects. The distinctive nuance of different cultures is reflected in two similar proverbs, considered as a lesson for people dealing with living in a new culture. One is from a Vietnamese perspective and another from the Western tradition:

"Nhập gia tuỳ tục" (when entering a family, follow its practices) (Vietnamese saying)

"When in Rome, do as the Romans do" (Western saying)

\section{Cultural knowledge and awareness}

This section presents knowledge and awareness about culture that is reflected in the different cultural dimensions. Culture is recognisable and observable but it seems to be difficult to measure and gauge (Walker \& Dimmock, 2002). Consequently, cultural dimensions are used as common benchmarks that help to understand cultural characteristics of a particular society, facilitate the description and measurement of a culture as well as serve as criteria for cultural studies and cross-cultural comparison (Dimmock \& Walker, 2005; Northouse, 2006). It is important to understand the dimensions of culture in cultural studies of educational leadership. As Gerstner and O’Day (1994) explained:

Leadership is a cultural phenomenon, inextricably linked to the values and customs of a group of people, we do not expect differences in leadership prototypes to be completely random. Rather they should be linked to dimensions of national culture. (p. 123)

In the past several decades, substantial numbers of studies have focused on identifying and classifying the dimensions of culture (e.g., Dimmock \& Walker, 2005; Hall, 1976; Hofstede, 1980, 1997, 2001; Trompenaars \& Hampden-Turner, 1997). One of the early studies that addressed cultural dimensions was conducted by Hall (1976). In the study, he reported that a primary characteristic of cultures is the 
degree to which they are individual-oriented or group-oriented. Since then, other scholars have developed and identified more dimensions of culture which have been used as benchmarks for research on culture or cross-culture and leadership, such as egalitarian versus hierarchical and person versus task orientation (Trompenaars \& Hampden-Turner, 1997).

In the area of culture and leadership, the studies by House and his colleagues (2004) offer the strongest body of findings to date (Northouse, 2006). Based on their own work and the work of others (e.g., Hofstede, 1980, 2001; Triandis, 1995), GLOBE researchers developed their own dimensions of culture. They identified nine cultural dimensions: uncertainty avoidance, power distance, institutional collectivism, ingroup collectivism, gender egalitarianism, assertiveness, future orientation, performance orientation, and human orientation. The GLOBE researchers used these nine cultural dimensions to analyse the cultural attributes of 62 different countries in order to examine how the differences in cultural attributes of the countries affected their approach to leadership.

In an effort to develop a framework for cross-cultural research into educational leadership, Dimmock and Walker (2005) and Walker and Dimmock (2002) have offered six cultural dimensions to study school leadership in cultural contexts. These cultural dimensions may apply at societal and school cultural levels. The sixdimensional model is described in Table 2. 
Table 2: Dimensions of societal and organisational cultures (Adapted from

Dimmock \& Walker, 2005 and Walker \& Dimmock, 2002)

\begin{tabular}{|c|c|}
\hline Societal cultures & Organisational cultures \\
\hline $\begin{array}{l}\text { - Power-distributed/power- } \\
\text { concentrated: degree to which } \\
\text { power is distributed among people } \\
\text { in the culture }\end{array}$ & $\begin{array}{l}\text { - Process/Outcome-oriented: } \\
\text { emphasis on process (bureaucratic } \\
\text { routines such as decision-making, } \\
\text { teaching) or emphasis on } \\
\text { outcomes (such as learning } \\
\text { achievement) }\end{array}$ \\
\hline $\begin{array}{l}\text { - Group-oriented/self-oriented: tight } \\
\text { or loose relationships among people }\end{array}$ & $\begin{array}{l}\text { - Person/task-oriented: emphasis on } \\
\text { care, consideration and welfare or } \\
\text { emphasis on job performance only }\end{array}$ \\
\hline $\begin{array}{l}\text { - Consideration/aggression: emphasis } \\
\text { on relationships, solidarity, } \\
\text { compromise, and negotiation v/s } \\
\text { emphasis on achievement, } \\
\text { competition, power, and } \\
\text { assertiveness }\end{array}$ & $\begin{array}{l}\text { Professional/parochial: committed } \\
\text { to teaching profession as a whole } \\
\text { or the particular school }\end{array}$ \\
\hline $\begin{array}{l}\text { - Proactivism/fatalism: attitude to } \\
\text { uncertainty and change: control or } \\
\text { accept things }\end{array}$ & $\begin{array}{l}\text { - Open/closed: the ease with which } \\
\text { resources (money, ideas, people) } \\
\text { are exchanged within organisation }\end{array}$ \\
\hline $\begin{array}{l}\text { - Generative/replicative: valuing the } \\
\text { generation of new knowledge and } \\
\text { ideas or adopting knowledge and } \\
\text { ideas from elsewhere }\end{array}$ & $\begin{array}{l}\text { - Control/Linkage; formal/informal; } \\
\text { tight/loose; direct/indirect: the } \\
\text { way in which authority and } \\
\text { control are exerted and } \\
\text { communicated between members }\end{array}$ \\
\hline $\begin{array}{l}\text { - Limited } \\
\text { relationship: interactions /holistic } \\
\text { relationships are determined by } \\
\text { formal rules and regulations or by } \\
\text { relationship obligations and } \\
\text { personal considerations }\end{array}$ & $\begin{array}{l}\text { - Pragmatic/normative: the way an } \\
\text { organisation serves its clients, } \\
\text { flexible and pragmatic or } \\
\text { standardised }\end{array}$ \\
\hline
\end{tabular}

Of all the research dimensions of culture, Hofstede's is perhaps the most cited and the most influential in studies on leadership and societal cultures (Bass \& Bass, 2008; Dimmock \& Walker, 2002; Northouse, 2006). In his ground-breaking work, Hofstede identified four major dimensions of culture and then developed them into five dimensions to explain cultural differences in behaviours. This framework has been widely used in business sector research and in cultural and cross-cultural studies of educational leadership (Dimmock \& Walker, 2005; Hallinger \& 
Leithwood, 1998; Walker \& Dimmock, 2002). His five cultural dimensions include: power distance, uncertainty avoidance, individualism/collectivism, masculinity/femininity, and long-term/short-term orientation. These dimensions are briefly explained as follows:

- Power distance: This refers to the degree of inequality that exists and is accepted among people of a particular group. People of high power distance groups accept an unequal distribution of power. Power is concentrated rather than being distributed. Whereas, people of low power distance view themselves as equals and power is shared and well distributed.

- Individualism/Collectivism: This dimension indicates the strength of people's relationships within the community. In individual cultures, people tend to focus on self and self-interest. There is little sharing of responsibility. In collective cultures, people's relationships are tight; loyalty and respect for members of the group are emphasised; people tend to take more responsible for each other's well being.

- Masculinity/femininity: Masculinity refers to assertiveness, whereas femininity accounts for "being caring". In masculinity-oriented cultures, men's and women's roles are clearly distinguished. Men are expected to be tough, assertive and strong. In femininity-oriented cultures, these roles are blurred. Men and women work together equally.

- Uncertainty avoidance: This dimension relates to the degree to which people of a given society react to and manage uncertainty and change in social situations. In high uncertainty avoidance societies, people tend to avoid ambiguous situations whenever possible; they are governed by rules and order and they seek a "collective truth"; they show their willingness to accept things as they are. In low uncertainty avoidance cultures, people accept new things and acknowledge value differences among people.

- Long-term/short-term orientation: This dimension reflects the degree to which people of a given society value long-term or short-term traditions and values. In long-term orientation societies, social obligations and long-term traditions are considered very important. Authority and status are 
emphasised; people do not display extravagance or act frivolously; loyalty and commitment are emphasised. In short-term cultures, equality and individualism are emphasised; people do not hesitate to introduce necessary changes.

According to Hofstede (1997), societies possess these five cultural features to different degrees. With regard to leadership, these cultural features impact leadership approaches and behaviours. For example, it is found that in societies with high power distance, power is concentrated on the few and leaders in such societies tend to be autocratic and authoritarian. In cultures with relatively low power distance, employees prefer a consultative management style, and there is more harmony between the more and the less powerful. Managers from countries with a culture characterised by low uncertainty avoidance exhibit stronger preferences for open discussion of conflicts than managers from countries with a high uncertainty avoidance culture. Leadership characteristics in collectivist societies emphasise relationships over tasks (Hofstede, 1980, 1997; Oudenhoven, Mechelse \& Dreu, 1998).

Although cultural dimensions have been mainly developed for cross-cultural research of leadership, it is necessary to include them as a conceptual framework for cultural research into educational leadership as they are research tools for analysis (Dimmock \& Walker, 2005; Hofstede, 1997, 2001; Walker \& Dimmock, 2002). Cultural dimensions can also be used as a lens that helps to understand the cultural characteristics of Vietnamese society.

\section{Leadership}

\section{Concept of leadership}

People know how important leadership is, but they do not seem to agree when they begin to discuss what it is. Hundreds of definitions of leadership have been offered. However, there is no all-around definition for leadership because "behind each definition, in turn, is a different theory about the source, process, and outcome of leadership" (Murphy, 2006, p. 3). Sixty-five different classification systems developed to define the dimensions of leadership have been found (Northouse, 2004). 
According to Northouse (2004), despite the multitude of ways that leadership has been conceptualised, there are four main components of leadership:

- Leadership is a process: process implies that a leader affects and is affected by followers.

- Leadership involves influence: influence is concerned with how the leader affects followers.

- Leadership occurs within a group context: leadership takes place within a group of individuals because where there is a leader, there are followers.

- Leadership involves goal attainment: directing a group of individuals toward a goal is an important feature of leadership. (p. 3)

Based on these components, a definition of leadership can be offered as follows: Leadership is seen as an influential process with the purpose of achieving the common goals of a group, an organisation or a country.

Different scholars have different views about the nature of leadership based on the function of leadership that they focus on. For example, Thomson (cited in Murphy, 2006, p. 4) states: "Leadership is best defined as getting the job done through people". There are two intertwined components emphasised in this definition: accomplishment (getting the job done) and influencing others (through people). Sanga and Walker (2005) use two words 'influence' and 'change' to describe the nature of leadership. They explain that "influence refers to the ability one has to persuade another person's thinking, speech, or action. Change refers to a shift, transition, or move to a new and more desirable situation" (p. 27). Through this view, change is the focus of leadership. Gardner (2007) has placed emphasis on the relation between the influence process and goal attainment. He defines leadership as "the process of persuasion or example by which an individual (or leadership team) induces a group to pursue objectives held by the leader or shared by the leader and his or her followers" (p. 17).

Ogawa and Bossert (1995) suggest that there are four basic assumptions that underlie most treatments of leadership: functions, role, the individual, and culture. The first is that leadership functions to influence organisational performance. The second assumes that leadership is related to organisational roles. The third sees leaders as individuals who possess certain attributes and act in certain ways. The fourth presumes that leaders operate within organisational culture. Although these scholars 
recognised the importance of cultural factors in leadership practice, they only emphasised the organisational cultures and seemed not to take notice of the importance of societal cultures. Recent literature has offered a broader meaning for this assumption. A substantial number of studies have found that leadership is exercised within societal cultures (e.g., Cheng, 1995; Dimmock \& Walker, 2005; Hallinger \& Leithwood, 1996, 1998; House et al., 2004; Walker \& Dimmock, 2002; Wong, 1998). Leaders work in the organisational culture which does not form and develop independently of societal culture, in which the organisations operate (Hallinger \& Leithwood, 1998; Heck, 2002; Walker \& Dimmock, 2002).

The review of literature suggests that school and leadership in other fields are common in nature but differ in defined outcomes. This is due to the different objectives that leaders and followers share and pursue. One example is while school leadership focuses on academic attainment, company leadership concentrates on developing a specific product. The utmost objective of school leadership is to mobilise and empower all members of the school community to work together toward the goal of an excellent education for all students (Murphy, 2006). Teaching and learning outcomes are considered the index for measuring effective school leadership.

The terms leadership and management are sometimes used interchangeably. Coleman (2005) notes that "the blurring together of these two concepts is not entirely surprising as in practice it is often the same people who are both leading and managing" (p. 7). Gardner (2007) argued that he cannot find a man who is an utterly first-class manager without a trace of the leader in him. He believed that this type of man does not exist because when a man is an utterly first-class manager he turns out to have quite a lot of the leader in him. In general:

Leadership is frequently seen as an aspect of management, with 'real leaders' often characterized as charismatic individuals with visionary flair and the ability to motivate and enthuse others - even if they lack the managerial or administrative skills to plan, organize effectively or control resources. On this basis it is often argued that managers simply need to be good at everything that leaders are not. (Law \& Glover, 2000, p. 13)

Other scholars tend to distinguish the terms leadership and management. In his assessment of the prospects for educational change, Fullan (1991) argues that leadership relates to mission, direction and inspiration whilst management involves 
designing and carrying out plans, getting things done, and working effectively with people. Bennis and Nanus (1985) offer a simple explanation: leadership is doing the right things, while management is doing things right. This definition is similar to Hodgson (1987), who defined leadership as path-finding and management as pathfollowing. Although scholars have put much effort into distinguishing the meanings of leadership and management, they all seem to agree that a school leader is both a leader and a manager because schools need to be both managed and led (Murphy, 2006). School leaders fulfil their jobs by performing leadership functions and managerial functions for the common goal of their school communities.

\section{Leadership styles}

Leadership theory suggests that leadership styles or behaviours have profound effects on subordinates, including how they relate both to the leader as well as to each other (Bass, 1990). The review of literature shows that researchers have described leadership styles in a variety of ways. Various types of leadership models or theories have been proposed and developed over the years in order to conceptualise leadership behaviours or styles, not all of them compatible. One of the most important reasons that many researchers have made efforts to build a typical leadership model or theory is to provide a "conceptual map" that leads to better understanding (Northouse, 2006).

Autocratic leadership: Autocratic leadership is a leadership style characterised by being arbitrary, controlling, power-oriented, coercive, punitive and closed-minded (Bass \& Bass, 2008). This style is also known as "authoritarian", "hierarchical", "top-down", “directive" (Bass, 1990; Dunlap \& Goldman, 1991; Lashway, 2006; McMurry, 1958; Northouse, 2006). The prevailing discourse emphasises that autocratic leaders tend to determine what is to be done, make and enforce the rules, set clear standards of performance, utilise rewards and power to obtain compliance, and threaten punishment for disobedience (Bass \& Bass, 2008; Lashway, 2006; Northouse, 2006). Five decades ago, McMurry (1958) portrayed an autocratic leader as follows:

The benevolent autocrat structures his subordinates' activities for them; he makes the policy decisions which affect them; he keeps them in line and enforces discipline. He is like a good quarterback, who does not ask the line to 
decide what plays to attempt or what information to use, but tells them - and woe betide the hapless player who refused to follow his orders. (p. 89)

Howard and Wellins (1994) listed five typical types of autocratic leader behaviours in work settings: 1) The controller enforces a prescribed way of working; 2) The commander tells what to do and expects obedience; 3 ) The ruler considers decisionmaking a privilege of management; 4) The judge evaluates subordinate performance and metes out rewards and punishment; and 5) The guard protects turf and hoards resources (cited in Bass \& Bass, 2006, p. 441).

This autocratic leadership style is believed to be "nondemocratic" (Bass \& Bass, 2008; Lashway, 2006; McMurry, 1958) because its "dark side" is recognised as "abusiveness, creating fear and distrust, using arbitrary and unconditional punishment, ignoring subordinates' information and inputs to decisions, and relying exclusively on one's own judgment" (Smither, 1991, cited in Bass \& Bass, 2008, p. 440).

Transactional leadership: In life, people build relationships based on the level of exchange they have. In organisational context, leaders or managers promise and guarantee benefits (such as rewards and high salaries) to subordinates in turn to the productivity. Such an exchange process reflects the characteristic of transactional leadership. Bass (1990) claims that transactional leaders use rewards (which need not be money or material; it can be anything) as their primary source of power. Subordinates comply with the leader when the exchange meets their needs. Hence, the relationship between the leader and the subordinates is seen as a series of rational exchanges that enable each to reach their goals (Bass, 1990). Transactional leadership emphasises the link between the effort and reward. Leaders motivate followers by setting goals and promising rewards for desired performance (Bass, 1985).

Transformational leadership: This leadership style is also called charismatic leadership (e.g., Lowe \& Gardener, 2001; Northouse, 2006) and known as "new leadership". As its name implies, transformational leadership is a process involved in changing and transforming individuals. Transformational leaders inspire and motivate followers, change attitudes, beliefs, and goals of individuals, try to help followers reach their fullest potential, satisfy their needs, treat them as full human beings (Bass, 1997; Lashway, 2006; Northouse, 2006). Bass and Avolio (1994) characterise transformational leaders by the four "I's": 1) Idealised influence allows the leader to 
serve as a role model that followers want to emulate; 2) Inspirational motivation builds enthusiasm, optimism, and team spirit; 3) Intellectual stimulation encourages innovation and creativity by questioning assumptions and supporting problem solving; and 4) Individualised consideration gives personalised attention to each individual. Scholars claim that in essence, transformational leadership produces greater effects than transactional leadership. While transactional leadership motivates followers to perform as expected and results in expected outcomes, transformational leadership results in performance, inspires followers to accomplish more than originally expected (Bass, 1997; Northouse, 2006).

Participative leadership: Other terms used to refer to the same or similar ideas are "facilitative leadership", "shared leadership", "democratic leadership", or "distributed leadership". Participative leadership refers to the process in which leaders encourage subordinates to participate actively in discussions, problem solving, and decision-making (Bass \& Bass, 2008; Lashway, 2006; Northouse, 2006). The basic philosophy of participative leadership is that organisations will work best when employees at all levels are actively engaged in solving problems and decision-making. The leader's role is to get that involvement (Lashway, 2006). Hence, participative leadership emphasises autonomy for subordinates, power sharing (empowerment), information sharing, consultation from subordinates, and delegation (Bass \& Bass, 2008; Lawler, 1986; Northouse, 2006). According to Bass and Bass (2008), participative leaders motivate subordinates inclusion, ownership, involvement, consensus, mutual help, cooperative orientation, and free and informed choice. Scholars claim that participative leadership offers a significant number of benefits, such as increasing the quality of decisions, contributing to the quality of employees' work lives, and increasing employees' motivation and satisfaction (Armenakis, Harris \& Mossholder, 1993; Locke \& Latham, 1990; Scully, Kirkpatrick, \& Locke, 1995; Smylie, Lazarus, \& Brownlee-Conyers, 1996; Somech, 2002).

Ethical/moral leadership: The importance of ethical or moral leadership for effective leadership has been recognised and discussed for centuries (Resick, Hanges, Dickson, \& Mitchelson, 2006; Resick et al., 2011) as leadership practice has an impact on the lives of those being led, it hence carries with it an enormous ethical burden and responsibility (Northouse, 2006). Leaders' leadership practices are 
bounded with ethical issues because leaders are founders of organisational culture who play a key role in establishing and reinforcing organisational values. As Northouse (2006) points out, "ethics is central to leadership because of the nature of the process of influence, the need to engage followers to accomplish mutual goals, and the impact leaders have on establishing the organisation's values" (p. 307).

Brown, Trevino and Harrison (2005) defined ethical leadership as "the demonstration of normatively appropriate conduct through personal actions and interpersonal relationships, and the promotion of such conduct to followers through two-way communication, reinforcement, and decision-making" (p. 120). As they explained, there are four components of this definition: the first is "the demonstration of normatively appropriate" which suggests that those who are perceived to be ethical leaders model conduct (e.g., honesty, trustworthiness, fairness, and care) that followers consider to be "normatively appropriate". The second is "promotion of such conduct to followers through two-way communication" which suggests that ethical leaders not only transfer ethical values to followers by modelling conduct, but they also provide followers with voice. The third is the "reinforcement" that implies that ethical leaders set ethical standards, reward ethical conduct and discipline those who don't follow the standards. The final element is that "decision-making" reflects that ethical leaders consider the ethical consequences of their decisions.

Resick et al. (2006) conducted a comprehensive review of literature and identified six key attributes that characterise ethical leadership, including character and integrity, ethical awareness, community/people-orientation, motivating, encouraging and empowering, and managing ethical accountability. In essence, as Resick et al. (2011) concluded, "ethical leadership addresses how leaders use their social power by being both moral individuals and moral managers" (p. 436).

Although the above-mentioned theories have made a significant contribution to the understanding of leadership, they are likely limited to adequately explain the diversity of school leadership practices in a global setting (Heck, 2002). There are two main reasons. Firstly, these theories have been developed in Western contexts, which may not entirely transfer to non-Western settings. Secondly, empirical studies reveal that the theory may work well in a specific context but may not work appropriately in other settings (Dimmock \& Walker, 2005; Heck, 2002; Northouse, 
2006). As Heck (2002) points out that the transformational leadership approach may describe Western efforts to restructure schools more accurately than it captures traditional school leadership in Asia or the Pacific Islands. Or Hallinger, Taraseina and Miller (1994) found out that their American instrumentation on instructional leadership failed to capture facets of school leadership as constructed by Thai secondary school principals. It can be argued that empirical studies on leadership practices or theories should include cultural factors in order to identify how they function in different cultural settings and how cultural variables influence leadership practices and schooling.

\section{Functions of school leadership}

\section{Perspectives of leadership functions}

The functions of leadership are varied and "can be carried out in many different ways, depending on the individual leader, the context, and the nature of goals being pursued" (Leithwood \& Riehl, cited in Murphy, 2006, p. 5). Although scholars have attempted to distinguish the functions of leadership from those of management, and there are clear differences between the two (Northouse, 2006), there seems to be a considerable amount of overlap. This is because leadership is, in many ways, similar to management. As Northouse (2006) points out:

When managers are involved in influencing a group to meet its goals, they are involved in leadership. When leaders are involved in planning, organising, staffing, and controlling, they are involved in management. Both processes involve influencing a group of individuals toward goal attainment. (p. 10)

He concludes:

In general, many of the functions of management are activities that are consistent with the definition of leadership. (p. 8)

Nearly a century ago, Fayol (1916) suggested eight managerial functions that a leader exercises: determining and deciding objectives, forecasting, planning, organizing, directing, coordinating, controlling, and communicating. Gulick and Urwick (1937) also offered five functions, which subsume the eight functions suggested by Fayol (1916). These functions include planning, organising, commanding, coordinating, and controlling. Based on the distinctive features of leadership and management, Adair (1983) identified five functions, known as five 
distinguishing leadership characteristics: giving directions, offering inspiration, building teamwork, setting an example, and gaining acceptance (cited in Law \& Glover, 2000).

In the effort to propose a framework for cross-cultural study in education leadership, Dimmock and Walker (2005) have merged the functions of leadership and management together. These functions, labelled as "leadership, management and decision processes", are believed to be one of the four elements of schooling and the core of school leadership. From these processes, it is suggested that eight managerial functions of school leadership (identified as eight elements) should be taken into account when examining the influence of societal culture on school leadership. These include collaboration, motivation, planning, decision-making, communication, conflict resolution, appraisal, and staff development. Dimmock and Walker (2005) argue that leadership practices, as exercised through these eight functions, reflect the societal cultures within which school leaders live and work. These functions can be explained as follows:

- Collaboration relates to the extent to which leaders and teachers are involved collaboratively in school management. It reflects the degree of participation that school members are involved in through the process of exercising power.

- Motivation reflects the extent to which teachers are motivated and whether and how school leaders enhance teacher motivation.

- School planning indicates how school leaders approach planning, who they involve in the process, and what they intend to achieve by it.

- Decision-making process reflects how school leaders approach the process and what methods by which decisions are made. It also reflects the degree of participation in which school members are involved.

- Communication indicates the modes of communication that are applied to management processes.

- Conflict resolution reveals how conflicts within the school community are approached and resolved. 
- Appraisal is the process that reflects how school members are evaluated or appraised.

- Staff development reflects how school leaders view the importance and conduct of staff development.

However, the authors claim that the eight elements cannot present a complete picture; nor do they address all of the complexities in real-life leadership situations. The literature indicates that a number of other functions are also exercised within the leadership domain, including "establishing direction” (Kotter, 1990), "visioning”, "modelling", "coaching", "mediating", and "managing" (Tschannen-Moran, 2007). Consequently, choosing what functions of school leadership are to be examined for this study depended on the research focus and context of school leadership. For this reason, the study focused on four distinctive leadership functions and how they are exercised under the influence of the three predominant features of Confucian values (discussed in Chapter II). The four leadership functions include exercising power, building relationships, decision-making, and managing and solving conflict. The research focus is described in Figure 1:

\begin{tabular}{|l|c|c|c|c|}
\hline $\begin{array}{c}\text { Leadership } \\
\text { functions } \\
\text { Cultural } \\
\text { values }\end{array}$ & Exercising power & $\begin{array}{c}\text { Building } \\
\text { relationships }\end{array}$ & Decision-making & $\begin{array}{c}\text { Managing/solving } \\
\text { conflict }\end{array}$ \\
\hline Hierarchy & $?$ & $?$ & $?$ & $?$ \\
\hline Collectivism & $?$ & $?$ & $?$ & $?$ \\
\hline Gender relations & $?$ & $?$ & $?$ & $?$ \\
\hline
\end{tabular}

Figure 1: Matrix of Confucian values and leadership functions (adapted from the Matrix of cultural dimensions and leadership elements by Dimmock \& Walker, 2005)

The following sections will conceptualise these four leadership functions and examine how they relate to the cultural values. 


\section{Exercising power in leadership}

\section{Concept of power}

There is no single definition or comprehensive and generally accepted conceptualisation of power even though there have been diverse and conflicting conceptualisations of power by the theorists (Hales, 1997). However, scholars agree that the concept of power is related to leadership because it is part of the influence process. Lukes (1974) sees power as the means by which people assert their preferred values and choices over those of other people and prevent other people making choices or challenge choices that have already been implemented. This view sees power as a force that behavioural theorists have emphasised when conceptualising the concept of power (e.g., Dahl, 1957; French, 1956; Pfeffer, 1981; Russel, 1938). For example, Dahl (1957) and Pfeffer (1981) perceive power as A's ability to change the course of action of B from what B would not otherwise do. Similarly, Northouse (2004) sees power as "the capacity or potential to influence". He argues that people have power when they have the ability to influence other people. According to Northouse (2004):

Ministers, doctors, coaches, and teachers are all examples of individuals who have the potential to influence us. When they do, they are using their power, the resource they draw on to effect change in us. (p. 6)

Accordingly, leaders are described as implementers of power (Nothouse, 2004). In this sense, power is conceptualised as a tool that leaders use to achieve their own ends. As Lashway (2006) argues, "power is the currency of leadership, an essential commodity for accomplishing anything" (p. 274). Contrary to this view of power, Burns (1978) saw power from a relationship standpoint. It is a process of reciprocal influence that occurs in relationships between leaders and followers. For Burns (1978), power is not an entity that leaders use over others to achieve their own ends, but instead it occurs in relationships and should be used by leaders and followers to benefit their collective goals (cited in Northouse, 2004, p. 7). It seems difficult to reach a consensus on the concept of power. However, here I aim to discuss and explore the literature of power by grouping the ideas under two headings: 1) The discourse of power over and 2) The discourse of power with, which are found in social science literature and have been widely discussed in the educational literature. 


\section{Exercising power in leadership: The process of "power over" and "power with"}

a) The discourse of 'power over'

Traditionally, power refers to controlling, dominating, coercing, and hierarchy. These words are used to describe how a person in a more powerful position influences a person in a less powerful position. One has power if he/she has the ability to change or control the behaviours, attitudes, opinions, objectives, needs, and values of another or to bring about certain intended consequences in the behaviour of others and to avoid outcomes which are not desired (Fennel, 1999; Rahim, 1989). Sergiovanni (1992) defines power as power over, a definition which "emphasizes controlling what people do, when they do it, and how they do it" (p. 133). Implied in these discourses of power over is that power consists of individuals struggling with one another for strength, control, superiority, and their separate interests. According to Fennell (1999), if we see power in this way, power reflects a linear causality wherein actions done by one individual cause repercussions for others. It is apparent, when power is considered as domination, controlling or hierarchy, some individuals will be winners while others become losers.

In terms of educational leadership and management, Sergiovanni (2001) views power over as an ineffective approach to leading schools. He states:

Power over is concerned with dominance, control, and hierarchy. One needs to be in a position of dominance, control, and hierarchy to exercise power over. One needs to have access to rewards and punishment, 'carrots' and 'bully' sticks. In reality, however, most principals don't have many carrots or bully sticks. Furthermore, people don't like carrots or bully sticks and resist power over leadership both formally and informally. Thus, this approach is rarely effective. (Sergiovanni, 2001, p. 152)

Within the discourse of power over, there are some kinds of power that are considered as resources which leaders use to control or modify people's behaviours. French and Raven (1959) are the first two authors who generalize the power sources into five categories as follows:

a) Legitimate power, the legitimate right of the leader, usually by virtue of the position that the leader holds to prescribe or control behaviour;

b) Coercive power, the leader's control over punishment;

c) Reward power, the leader's control over reward; 
d) Expert power, special knowledge or expertness;

e) Referent power, the subordinate's desire to identify with the leader.

Similarly, Handy (1993) and Hales (1997) offer definitions of power resources. However, they use different terms: physical power resources; economic power resources or resource power; knowledge power resources or expert power; and normative power resources. Hales (1997) and Handy (1993) further define two more power resources considered as position power (known as legitimate power) and personal power (known as referent power). For these authors, position power is based on the perception that leaders have the right to exercise influence because of their position/role; personal power is based on a sense of identification with leaders who display personal 'charisma' and the leadership qualities which others wish to copy.

Educational literature suggests that the school leader typically may use one or more of these power bases to accomplish any or all of the goals and objectives adopted for school (Hales, 1997; Johnson \& Short, 1998). Research on this issue suggests that the power resources chosen by school leaders potentially affect psycho-social dimensions for teachers as conflict, compliance, and empowerment, either positively or negatively" (Johnson \& Short, 1998).

The research conducted by Rahim (1989) exploring the relationships of leader power to compliance and satisfaction indicated that legitimate, expert, and referent power resources were positively associated with subordinate compliance. In contrast, reward power resource was not. Reward and coercive power resources were found to be associated with resistance or conflict. Only referent and expert power bases are positively associated with subordinate satisfaction and performance (Hinkin \& Schriesheim, 1989; Rahim, 1989; Yukl \& Falbe, 1991). Johnson and Short (1998) found that expert power has the strongest effect on teacher empowerment and the amount of conflict in their US based research. Legitimate power base related only to teacher compliance and teacher empowerment. Reward power was associated only with teacher compliance. The more referent power the teachers perceived the principal to hold, the less they perceived themselves to be in conflict with their principal, and the coercive power was negatively associated with teacher empowerment. These findings are consistent with Busch's study in the business 
context. According to Busch (1980), expert and referent power bases were positively related to employees' satisfaction with supervision and that legitimate and reward power bases showed no significant relationship to satisfaction with supervision.

In a study by Fennell (1999) four female principals were interviewed to explore 'power in the principalship'. She found that the principals used one or more power bases in some situations. The study revealed that there were times when legitimate power was required in order to create the most positive and productive environment. Some principals in the research were required to use positional power and legitimate influence to establish and maintain a fair and positive environment. So teachers and students could work productively.

\section{b) The discourse of 'power with'}

Power with and power through are interchangeable. Although scholars use different terminologies (e.g., Dunlap \& Goldman, 1991; Sergiovanni. 1992), these two concepts are related to the process of empowerment in leadership. As Blasé and Aderson (1995) describe: the power with empowers subordinates and other stakeholders to expect democratic participation as a right, rather than to view it as a privilege at the discretion of administrators. According to Fennell (1999), in the educational context, power with is "challenging to traditional, hierarchical approaches to power, and encouraging principals to develop closer relationships with teachers and support staff' (p. 25). Power through, as Goldman, Dunlap and Conley (1993) defined, is "the ability to help others achieve a set of ends that may be shared, negotiated, or complementary without being either identical or antithetical" (p. 70). Power through is manifested through someone rather than involving dominance over someone and key aspects of power through include enabling, negotiating, empowering based on the sharing power, and using power together with others to reach desirable ends (Fennell, 1999).

Instead of using the term power with, Sergiovanni (1992) suggests the term power to which is considered "a source of energy for achieving shared goals and purposes" ( $p$. 133). According to Sergiovanni (1992), when empowerment is successfully practiced, administrators exchange power over for power to and anyone who is committed to shared goals and purposes can practice power to. In school settings, when power to takes place, principals are free to lead. They worry less about whether 
they are using the right style and less about other process-based concerns and their leadership rests on the substance of their ideas and values (Sergiovanni, 1992).

Within the discourse of power with, the literature suggests that empowerment or shared leadership is a part (Dunlap \& Goldman, 1991; Fennell, 1999; Sergiovanni, 1992). In educational contexts, the discourse of empowerment is suggested as a teacher's opportunity for autonomy, choice, responsibility, and participation in decision-making processes (Lightfoot, 1986). A number of research studies suggest that empowerment is an important factor in building a strong and positive school environment. Vavrus (1989) when exploring the relationship between alienation and teacher empowerment found that teachers had been alienated from the workplace, and that they would overcome that alienation as they become empowered. Pickle's (1991) research on empowerment and motivation, found that highly empowered teachers were more motivated, and that this flowed over into teacher-student relationships. Wunder (1997) found that higher teacher empowerment, teacher efficacy and teacher morale are associated with higher levels of teacher attendance. It seems that empowerment exists and operates within the discourse of school effectiveness.

Studies in education suggest that school principals play an important role in empowering teachers (e.g., Edwards, Green, \& Lyons, 2002; Martin, 1990; Pollack \& Mills, 1997). In a study on exploring the relationships between personal empowerment, efficacy, and environment characteristics, Edwards et al. (2002) found that principals have the potential to influence teachers in order to help them increase their empowerment. For example, principals can work toward fostering a climate in which teachers feel safe and able to work together collaboratively and professionally. Principals also network teachers together so that they use each other as resources. Principals are in a position to share activities and resources to help teachers focus on learners. They encourage teachers to share strategies for focusing on learners, creating positive interpersonal relationships, honouring the student voice, and encouraging higher order thinking. Such managerial activities motivate and enhance the environment of empowerment in the school.

According to Bauer and Brown (2001), when teachers work in the environment of high empowerment, they realise that they can be leaders. This happens when school 
leaders are willing to empower teachers through the sharing of information, knowledge, and resources and then trusting that they will do the right thing and get the job done. When principals assume a more collegial role with teachers, giving them more opportunities to participate in decisions, teacher empowerment increases (Keedy \& Finch, 1994).

Shared decision-making is one of the key features of teacher empowerment. Shared decision-making offers people an opportunity to contribute to solving site issues and building a sense of community (Goldring \& Knox, 2002). Picucci, Brownson, Kahlert, and Sobel (2002) found that the principals in their research admitted that their initiatives would have more success if staff members felt that they shared responsibility for decision-making. When the principals share their authority/power, others are allowed to take ownership of the new direction for the school.

The idea of "shared leadership" operating within the discourse of empowerment is also confirmed by educational scholars (e.g., Blasé \& Blasé, 1997; Sergiovanni, 1992; Trites \& Weegar, 2003). School leaders can enhance the teachers' sense of empowerment through facilitative school leadership with shared governance or shared leadership (Blasé \& Blasé, 1997). Trites and Weegar (2003) emphasise the benefits of "shared leadership" as follows:

Shared leadership helps organizational change; it retains and strengthens decentralized management structure, giving an overall sense of empowerment as well as requiring extra effort from those individuals who step forward to take part in the process... Shared leadership fosters collaboration and relies on good communication; it emphasizes process and participations, and provides empowerment for employees, students and community members... Shared leadership balances workloads... Sharing leadership does ...help in understanding the needs of students and community members, and leads to overall empowerment of college staff, student, and community members in the affairs of the college. (p. 9)

\section{Societal cultures, power and leadership}

The relation between societal cultures and power in leadership has been widely discussed in literature. Power relationships vary in different cultures (Dimmock \& Walker, 2005; Hofstede, 1997). In some cultures, power is found to be distributed such as in New Zealand, Finland or Norway. In other cultures, power is believed to be concentrated such as in Malaysia, Philippines, Thailand or China. Hofstede (1997) offered the concept of power distance when he did a large-scale survey of 
employees' attitudes in 50 countries. This concept is used as a cultural dimension to explain the power distribution in various cultures (Dimmock \& Walker, 2005; Hofstede, 1997; House et al., 2004; Walker \& Dimmock, 2002). It aims to answer the question of how to handle the fact that people of a specific culture are unequal. House et al. (2004) defined power distance as the way cultures are stratified, thus creating levels between people based on power, authority, prestige, status, wealth, and material possessions. Researchers found that in societies where power is widely distributed (low power distance), inequity is treated as undesirable and effort is made to reduce it. In societies where power is concentrated in the hands of the few, inequities are often accepted and legitimised. People in power-concentrated societies tend to accept unequal distributions of power (Dimmock \& Walker, 2005; Walker \& Dimmock, 2002)

In the field of leadership, power distance is used to explain behaviours. Empirical studies suggest that there is a close relation between "power distance" factor and leadership style (e.g., Hofstede, 1997; House et al., 2004). In Hofstede's study (1997), the findings showed that in high power distance societies, organisations were hierarchically structured. Leaders and followers became either dependent or counterdependent. Leaders were entitled to privileges and contacts between leaders and followers were supposed to be initiated by leaders only. Leadership styles were likely to be more autocratic and coercive. In such societies, the ideal boss is a benevolent autocrat. On the other hand, in low power distance societies, organisations are structurally decentralised. The maintenance by leaders and followers encourages consultation and participation. While hierarchy in organisation of high power distance societies reflects the existential inequality between higher-ups and lowerdowns, in organisations of low power distance societies means an inequality of roles. Privileges for higher-ups are basically undesirable.

In Thailand, high power distance shapes the behaviour of administrators, teachers, students, and parents to show unusually high deference toward those of senior status in all social relationships. As a result, there is a pervasive, socially-legitimated expectation that decisions should be made by those in positions of authority. High power distance also creates a tendency for Thai administrators to lead by fiat. In the case of leading change, high power distance enables Thai leaders to achieve initial compliance more easily (Hallinger \& Kantamara, 2002). Such similar findings can be 
found in other studies conducted in societies of high power distance as Singapore, Hong Kong (Dimmock \& Walker, 2005), and China (Bush \& Haiyan, 2002; Law, 2009).

Power is associated with status and authority (Bass \& Bass, 2008). This means that power is related to the way people within a society perceive the concept of status and authority. As Hofstede (1997) argues:

There is an unspoken consensus that there should be an order of inequality in this world in which everybody has his or her place. Such an order satisfies people's need for dependence and it gives a sense of security both to those in power and to those lower down. (p. 38)

Status differentiation is often found in high power distance cultures (Hofstede, 1997). Power and status go together. In such cultures the powerful people are entitled to privileges. Their status is enhanced by symbolic behaviour which makes them look as powerful as possible. In a similar vein, House (1988) concluded that when social stratification (status differentiation) exists and the holders of authority feel strongly about their status, they will have fewer inhibitions against being coercive. The greater the social stratification, the more likely they are to be coercive in order to obtain compliance from subordinates. This is not likely to happen in low power distance cultures. In such cultures power and status need not go together. It is, as Hofstede (1997) points out, even considered a good thing if they do not. Consequently, leaders of such cultures may enhance their informal status rather than acting in a way that shows their high position.

\section{Building relationships}

\section{The importance of building relationships in leadership process}

Building relationships is important in leadership process (Fullan, 2001; Boyd, 1992). Fullan (2001) suggests a framework for leadership in which building relationships is one of the main components of effective leadership. He argues:

If moral purpose is job one, relationships are job two, as you can't get anywhere without them. In the past, if you asked someone in a successful enterprise what caused the success, the answer was "It's the people". But that's only partially true: it is actually the relationships that make the difference. (Fullan, 2001, p. 51) 
Fullan points out, "if relationships improve, things get better. If they remain the same or get worse, ground is lost" (2001, p. 5). Other scholars (Blasé, 1987; Picucci et al., 2002; Schein, 2004) also assert the importance of building relationships in terms of shaping and building a strong organisational culture.

In terms of management and leadership, the important role of school leaders in building relationships within a school is highly valued. Elmore (2000) emphasises that one of the primary roles of leaders is to "hold the various pieces of the organization together in a productive relationship with each other, and hold[ing] individuals accountable for their contributions to the collective result" (p.15). What is implied here is the importance of building relationships for effective leadership.

Similarly, in their study about "leadership behaviour of secondary school principals", Barnett, McCormick and Conners (2001) found that building relationships within the school community is central to school leadership. Through the relationships, school leaders establish and maintain leadership legitimacy, encourage commitment and effort towards making the goals of shared purposes. Cresswell and Fisher (1999) in a study on the topic "Assessing Principals' Interpersonal Behaviour with their Teachers" point out that an important aspect of most teachers' work is the relationship that they have with the principal. They emphasise that in all cases of the principal's leadership practice, the relationship that principals have with their teachers is significant in the eyes of the teachers.

The way school leaders build relationships with teachers affects teachers' motivation and behaviours towards tasks assigned. In a study about dimensions of ineffective school leadership, Blasé (1987) examined how principals build relationships with teachers and how they impact on teacher-student and teacher-teacher relationships. He identified a list of ineffective principal's personal traits that could affect the relationship building process. These include: lack of authenticity, lack of compassion, arrogance, unfriendliness, manipulation, insecurity, unintelligence, defensiveness, prejudice, immaturity, laziness, narrow-mindedness, and pessimism. Such forms of ineffectiveness made teachers feel depressed, angry, alienated, betrayed, impotent, and cynical.

Another factor of building relationships is collaboration. Rubin (2002) considers collaboration as 'democracy's mandate' and the only way to address a central 
problem. Collaboration is considered as an effective tool for leaders in leading and managing schools. It is the means by which leaders use their relationships with others to influence them to work toward a shared goal. To Rubin (2002), collaborative leaders are 'system thinkers' who know that changing systems requires changing people. He argues: "Tyrants bend systems, forcing people to follow. Collaborative leaders align the will and the work of people, causing systems to follow" (Rubin, 2002, p. 42).

Rosenholtz (1989) finds that the kind of leadership that principals provide influences the collegial norm structure of a school. He points out that teachers in highcollegiality schools described their principals as supportive and as considering problems to be school-wide concerns that provided opportunities for collective problem solving and learning. By contrast, teachers and principals in less collegial schools reported feeling isolated and alienated. Similarly, Little (1987) agrees that norms of collegiality are developed when principals clearly communicated expectations for teachers to cooperate. The principals offer themselves as models for collegiality by working directly with teachers in school improvement and rewarding expressions of collegiality among teachers. According to Little (1987) such principals provide recognition, release time, money and other resources, and they protected teachers who are willing to buck the customary norms of privatism and isolation by engaging in collegial behaviours.

It appears that from the educational literature leadership cannot exist without relationships within the organisation. School leaders play an important role in building relationships. What they do to improve relationships within school contributes to the school's improvement. They play an important role in building a strong school culture by what they do to build relationships.

\section{Cultural values, relationships and leadership}

Abosag, Tynan and Lewis (2002) make the point that different cultures value relationships differently and as a consequence, the establishment, development and maintenance of relationships vary across cultures. European perspectives on relationships mostly focus on the co-operative aspects of the exchange, while North American perspectives focus on power and conflict, and the Asian perspectives focus on connections through relationships (Abosag et al., 2002). The result of a substantial 
number of studies on cultural diversity is consistent with this argument (e.g., Dimmock \& Walker, 2005; Hofstede, 1997, 2001; House et al., 2004). Hofstede (1997) points out that values of individualism and collectivism affect the way people develop and maintain their relationships in the workplace or at school. In collectivist societies, the relationship between employer and employee is seen in moral terms. It resembles a family relationship with mutual obligations of protection in exchange for loyalty. In individualistic societies, the relationship between employer and employee is primarily conceived as a business transaction. As a result, a poor performance of the employee or a better pay offer from another employer are socially accepted reasons for terminating a work relationship. Whereas, the employee of collectivist societies may be seen as disloyal or unfaithful if he/she leaves the organisation or company to seek a better opportunity in other working places. Hofstede's study (1997) also reveals that different perspectives about relationships affect the management process of personnel affairs. Hiring relatives is given preference in collectivist societies where employee loyalty is emphasised. In individualistic societies, family relationships at work are often considered undesirable as they may lead to nepotism and to a conflict of interest. Relationships in collectivist societies prevail over tasks while in individualist societies people put tasks before relationships (Hofstede, 1997).

Different perspectives about the importance of relationships suggest different management strategies. In task-oriented cultures such as in Western countries, success in business is mainly based on "what you know" in terms of knowledge, capability, and value. In relationship-oriented cultures, people pay attention to "who you know". Relationships should be established first before launching business (Ashwill \& Diep, 2005; Hofstede, 1997; Law, 2009).

In an educational context, Dimmock and Walker (2005) reveal that school principals of different cultures have different leadership styles and managerial strategies for building relationships with teachers and staff. In the context of Hong Kong, principals employed a range of strategies to cultivate and preserve harmonious relationships with staff as a way to maintain performance, self-concept and loyalty to the school. Singaporean principals emphasised the strong belief in maintaining harmonious relationships with staff to facilitate the leadership and management process. In these countries, relationships were built and maintained in a non- 
confrontational way. Maintenance of harmony was key to performance, order, loyalty and the leadership function itself. Whereas, in Australia where harmony was valued but not emphasised, school leaders and staff were found to be willing to challenge harmony to change things. In terms of cultural perspectives, Dimmock and Walker (2005) argue that Hong Kong and Singapore principals reflect the AsianChinese cultural characteristics where collectivist values are given preference and the common good is served by harmony. In contrast, the Australian principals reflect the Anglo-American characteristic of individualism where egalitarian values are upheld.

Law (2009) also demonstrates that in relationship building in educational leadership and management, the impact of cultural values is significant. They found Chinese school leaders valued the importance of guanxi (relationship) in their leadership approach. Chinese school leaders had a strong tendency to build and cultivate relationship webs between leaders and teachers and among teachers as an investment to facilitate school leadership. Similar to their counterparts in Hong Kong and Singapore, they emphasised harmony as imperative for maintaining performance and quality leadership.

There is a close relationship between cultural values, strategy of relationship building and leadership approach. Each culture carries its own perspectives about relationships and its prevailing values determine the relationship styles. Such cultural values (or dimensions) as group-oriented/self-oriented, collectivist/individualist or holistic relationship/limited relationship (Dimmock \& Walker, 2005; Hofstede, 1997; House et al., 2004; Trompennaars \& Hampden-Turner, 1997) explain that in some cultures people appear to focus on their place within a group, while in others people focus on self when they establish and maintain relationships. These cultural values address how different societies or cultures adopt the styles of relationships and how they affect the process of relationship building in an organisation.

\section{Decision-making}

\section{Decision-making and leadership}

The word "decision" is defined in most dictionaries as a choice between several alternatives or possibilities (e.g., Cambridge Dictionary Online, Webster's Online Dictionary). If people have only one alternative, they do not have a decision. 
Decision-making is a fundamental managerial activity for leaders and managers and is core to any job description. Robbins (1999a, 1999b) describes decision-making as the essence of leaders' and managers' jobs and a critical element of organisational life. Leaders are decision-makers who must make decisions that significantly affect their organisations.

\section{Cultural influences on decision-making}

Many factors affect the decision-making process, such as the skills, knowledge, experiences and the personality of a decision maker (Palestini, 2005). Differences in the socialisation of leaders and the working environment that they live in may affect both their decision-making process and the choices that they make (Martinsons \& Davision, 2007). Scholars also agree that the context in which a decision is made, the way that the decision-maker perceives and understands the situation and what the decision maker values and judges are important (Rowe \& Boulgarides, 1993). Values influence the process of decision-making as they are integral to the thoughts and actions of an individual. According to England (1967), values influence the evaluation of both problems and potential solutions, and the processes used to make choices. Values affect how a decision-maker interprets and responds to a particular stimuli and set of conditions (Anderson, 1997; Cherrington, 1989). Regardless of cultural background, "goals and objectives are created by each person according to that person's value system" (Cherrington, 1989, p. 609) when making decisions, and the values of a certain culture motivate its members to behave cooperatively or competitively (Boyd \& Richerson, 1991; Yi \& Park, 2003).

People of different cultures have different values. A number of studies that have examined decision-making cross-culturally (e.g., Brew, Hesketh, \& Taylor, 2001; Hofstede; 1980, 1997; Martinsons \& Davision, 2007; Radford, Mann, Ohta, \& Nakane, 1993; Stewart, 1986; Wright, 1985) have found that societal culture has a significant impact on both decision-making style and the decision outcome. In their study on examining differences in decision-making styles in Japan and Australia, Radford et al. (1993) discovered that differences between the two cultures on decision-making styles were related to the values of individualism and collectivism. In a similar vein, Martinsons and Davison's study (2007) reports that American, Japanese and Chinese leaders have a distinctive decision-making style due to the 
differences in cultural values. They found that with scoring high on collectivism, the decision-making styles of both Japanese and Chinese leaders tended to focus on collective interests, emphasise relationships and intuition, and discourage conflicting views that would threaten group harmony or the individual's sense of "face". Alternatively, American leaders have a decision style that reflects a comparatively higher need for achievement. They tend to be more performance-oriented than their Japanese and Chinese counterparts. Such findings demonstrate the values of collectivism and individualism in different cultures. People from individualistic cultures tend to value personal goals over group goals and personal rights and needs over collective responsibilities and obligations (Gudykunst et al., 1992; Triandis, 1996). In contrast, people from collectivistic cultures tend to value group goals over personal goals, group concerns over personal concerns, and collective needs over personal needs (Ayyash-Abdo, 2001, cited in Yi \& Park, 2003).

Concepts such as hierarchy, face-saving, and harmony are important for Asian cultures as they have prescribed roles and relationships within relatively complex and stable social networks (Hofstede \& Bond, 1988). Such cultural values are found to be influential factors impacting on their willingness and involvement in the process of decision-making. Dimmock and Walker (2005) found that teachers in Hong Kong and Singapore were reluctant to contribute their opinions to the decision-making process as they were surrounded within the discourse of hierarchy, harmony and face saving. Their counterparts in Australia were willing to challenge or even to criticise their leaders. Their study also found that there was a difference between older and younger teachers in terms of involvement in decision-making, but such a difference was not found in the Australian context. Such findings indicate that people are embedded in their own cultural values when making decisions. As Yi and Park (2003) conclude:

Because people's behaviour is shaped by - and adjusted to - the particular culture in which they live and mature, cultural values might influence people to exhibit different behavioural patterns, including decision-making styles. (p. 36)

What has been reviewed so far indicates that decision-making is a culturally-bound process linked to the cultural values of a particular society. People of different cultures have different decision-making patterns that suit their own cultural values and beliefs. As Yi and Park (2003) point out, people of different cultural origin are likely to reveal different attitudes and styles of decision-making in negotiation, 
bargaining processes, and problem solving in various social settings. Decisionmaking is a universal phenomenon in leadership, but it is not necessarily the case that the principles of the decision-making process and their practices are universal, and that leaders act in the same way in all comparable cultural situations and contexts. Classical theories of decision-making are useful unless they are examined through the lens of cultural perspectives. Therefore, understanding how cultural values play in decision-making is important and well worth investigating in leadership in general and in school leadership in particular.

\section{Managing and solving conflict}

\section{Conflict and leadership}

Conflict is a universal phenomenon. It is considered "an inevitable condition of human existence" (Lee \& Rogan, 1991, p. 181). Conflict is seen as a perceived incompatibility of interests. It is caused by a misalignment of goals, motivations, or actions between two parties that can be real or only perceived to exist (Taylor \& Moghaddam, 1994, cited in Kaushal \& Kwantes, 2006). Although conflict has a negative meaning, it can be both functional (positive) or dysfunctional (negative) (Kaushal \& Kwantes, 2006; Palestini, 2005). Palestini (2005) points out that conflict is likely to increase when parties have the chance to interact, when the parties see their differences as incompatible, and when one or both parties see some utility in engaging in conflict to resolve incompatibility.

Dealing with conflict has been recognised as of particular importance in leadership (Bass \& Bass, 2008) as it is inevitable and it occurs whenever individuals or groups are not obtaining what they need or want and are seeking out their own interests. In an organisational context, if conflict is uncontrolled and unmanaged, it can demoralise employees and cause performance to deteriorate, increase tension and stress in an organisation. It increases the distance between people, hence a climate of mistrust and suspicion at work can arise (Palestini, 2005). According to Thomas and Schmidt (1976), in organisational life, the typical manager may spend $25 \%$ of his time dealing with conflict. Because leadership is a human interaction process which involves challenging people to do what they might not want to do for a defined organisational goal, conflict and leadership therefore go hand in hand. As Filson 
(2012) emphasises, "if you don't want to deal with conflict, leadership is not your thing" (p. 1).

\section{Conflict management}

Conflict management can be defined as behaviour aimed at resolving perceived incompatibilities (Boulding, 1963; Thomas, 1976). Yet, there has not been an allround approach to conflict management. Different scholars have different perspectives about conflict and offer different models of conflict management. Conflict management behaviour is believed to be a multi-dimensional construct.

Many scholars have made efforts to discover dimensions or strategies of conflict management styles (e.g., Blake \& Mouton, 1964; Frost \& Wilmot, 1978; Palestini, 2005; Rahim, 1983; Thomas \& Kilmann, 1974; Tinsley \& Brett, 2001). Five or so decades ago, Blake and Mouton (1964) proposed five different styles of managing organisational conflict. These included forcing, confronting, smoothing, avoiding, and compromising. Drawing upon these managerial styles taxonomy, Thomas and Kilmonn (1974)) proposed a model of two-dimensional taxonomy of conflict handling modes. Their model emphasises five conflict-handling modes which are classified by the two underlying dimensions of assertiveness and cooperativeness. Five conflict-handling modes include competing, collaborating, compromising, avoiding, and accommodating. For Pruitt and Carnevale (1993), they claim that conflict may be managed by three approaches: 1) joint decision-making: when parties deal with their conflict by negotiating with the goal of reaching a mutual agreement; 2) third-party decision-making: parties in conflict may turn to a third party for assistance in resolving the issues; or 3) separate action, including unilateral behaviours such as retreat, withdrawal, and tacit coordination. Similarly, Frost and Wilton (1978) identify four major conflict strategies that people employ based on the intensity of their responses to conflict, including avoidance, escalation, reduction, and maintenance.

In leadership and management, Palestini (2005) suggests five typical strategies that a leader might use for dealing with conflict. These strategies mostly overlap the five conflict-handling modes suggested by Thomas and Kilmann (1974). These strategies differ in the extent to which they satisfy a party's own and the other party's concerns. These strategies are described as follows: 
1) Avoidance: parties may withdraw from the conflict situation. This strategy works best when parties face unimportant or tangential issues, when they have little chance of satisfying their personal concerns, when the result will be likely to come with significant disruption, or when others can resolve the conflict more effectively.

2) Accommodation: parties use this approach to demonstrate a willingness to cooperate in satisfying others' concerns, while at the same time acting unassertively in meeting their own.

3) Compromise: this strategy is used when parties agree to reach an acceptable agreement although it does not maximise satisfaction of both parties. This strategy represents an intermediate behaviour on both the assertiveness and cooperation dimensions.

4) Forcing: using this mode, a party tries to satisfy its own while showing an unwillingness to satisfy the others' concerns.

5) Collaborating: this mode emphasises conflict solving with a goal of maximising satisfaction for both parties. People use this mode when they see conflict as natural, showing trust and honesty toward others, and encouraging the airing of every person's attitudes and feelings. (pp. 135-138)

Although these models have a significant contribution to the understanding of human behaviours in conflict management, they are, as Putnam and Wilson (1982) argue, plagued by conceptual weaknesses. They argue that the conceptual problems stem from the assumption that individuals have a characteristic mode of conflict management behaviour. According to them, a contingency model is more suitable than a trait model for studying conflict management behaviours across organisational situations. They suggested the Organisational Communication Conflict Instrument which proposes that conflict management behaviours can be clustered into three styles: 1) non-confrontational style: indirect strategies, avoidance, withdrawal, such communicative behaviours as silence, glossing over differences and concealing illfeelings; 2) solution-orientation style: open and direct communication about the conflict to find a solution, to integrate the needs of both parties, to compromise on issues; 3) control style: direct confrontation about the disagreement, taking control of the interaction, and advocating one's position.

Although these models generalise the typical behaviours in conflict management, they have been developed in an American-Anglo context and appear to exclude the cultural differences between Western and elsewhere. A number of empirical studies show that because people from different cultures hold different conflict management norms, they reach different outcomes when attempting to manage conflict (e.g., Lee \& Rogan, 1991; Leung \& Fan, 1997; Tinsley, 1998; Tinsley \& Brett, 2001). Such 
findings indicate the cultural differences in conflict style and cultural values account for these differences.

\section{Cultural variables in conflict management}

Lee and Rogan (1991) argue that although conflict and culture are two inseparable concepts, conflict may be seen as a culturally defined and regulated event. Each culture defines what constitutes conflict and the appropriate behaviours for dealing with conflict. While conflict itself may be an inevitable condition of human existence, the communication styles utilised to manage conflict could vary depending on one's cultural heritage. Other scholars claim that conflict management and culture have an interdependent relationship with one another (e.g., Chen \& Starosta, 1997; Lee \& Rogan, 1991; Ohbuchi, Fukushima, \& Tedeschi, 1999; Oudenhoven et al., 1998; Tinsley \& Brett, 2001). Cultural norms can affect conflict outcomes as they are standards for how people should behave (McGrath, 1984). As mentioned at the outset, societal culture generates variance on norms and it provides a common legal and institutional context that socialises, sanctions, and rewards conformity, norms can be expected to vary according to societal culture (Tinsley \& Brett, 2001). As Rabie (1994) reports that in the conflict management process, culture defines the values and interests that are at the core of each conflict, which in turn shapes people's perception of themselves and others, as well as the style by which one handles conflict.

A number of studies support the position that every culture distinguishes itself from others by specific solutions it chooses to certain problems and how it approaches these problems (Trompenaars, 1994). In their research on comparing conflict management strategies between the US and Hong Kong, Leung and Lind (1986) found that Americans demonstrated a preference for adversarial techniques over nonadversarial techniques whereas Chinese people did not. Ting-Toomey (1985) points out that differences are found in conflict management between low-context and highcontext cultures. People of high-context cultures tend to adopt a non-confrontational and indirect attitude towards conflicts, and tend to use an affective-intuitive style of conflict management. In contrast, people from low-context cultures tend to adopt a confrontational and direct style of conflict management. 
Many studies reveal that people of individualistic cultures have different approaches for dealing with conflict as compared with people of collectivistic cultures. As in Rahim's (1992) study, people from individualistic cultures were found to be more likely to resolve conflicts using a dominating or obliging style, whereas those from collectivistic cultures were more likely to use an integrating or avoiding style. Such findings are consistent with other studies which emphasise that people of individualistic cultures prefer to use active, assertive, and confrontational tactics for resolving conflicts, whereas people in collectivistic cultures prefer passive, collaborative, and avoiding tactics (Ohbuchi \& Takahashi, 1994; Trubisky, TingToomey, \& Lin, 1991). Some explanations for such cultural styles of conflict management have been suggested. For instance, researchers believe that in collectivistic cultures people dislike social disorganisation or disagreement. On the other hand, in individualistic cultures disagreement and conflicts are accepted as natural and an inevitable aspect of social life (Ohbuchi, Fukushima, \& Tedeschi, 1999). Triandis (1986) explains that individualistic cultures emphasise the individual's goals and autonomy, while collectivistic cultures emphasise goals, needs and views of the ingroup over those of the individual.

Hofstede's cultural taxonomy $(1980,1997)$ has added to the literature of conflict and its cultural dimension of individualism-collectivism helps to explain how conflict may be influenced by culture. Kaushal and Kwantes (2006) point out that, of the five of Hofstede's cultural dimensions, the constructs of individualism-collectivism have demonstrated the most promising theory in linking conflict behaviour with culture. People from collectivistic cultures such as Japan, China, Hong Kong and Singapore are more likely to utilise the avoidance strategy in conflict management with the goal of maintaining a positive relationship (harmony) (Dimmock \& Walker, 2005; Ohbuchi et al., 1999). Along with the collectivism-individualism dimension, Hofstede $(1980 ; 1997)$ also derived the dimension of power distance. This cultural dimension has been widely used in seeking the differences of conflict management of societies of different power distance. Lee and Rogan (1991) point out that pertinent to conflict management is the contention that members of high power distance cultures are fearful of disagreement with superiors, as subordinates consider their superiors to be different from themselves and vice versa. On the contrary, members of low power distance cultures not only respect each individual's quality but are less afraid of disagreeing with their bosses. 
The differences of conflict management are also found between egalitarian cultures and hierarchical cultures. Tinsley and Brett (2001) argue that egalitarian values (such as in American culture) encourage and legitimate the free expression of information about all participants' needs and concerns. By contrast, because the social divisions of a hierarchical culture (such as in Chinese culture) imply that differences are resolved based on social status rather on both parties' interests, hence people of hierarchical cultures tend to defer to those of higher status and authority in the process of conflict management. For such cultural characteristics, people in a hierarchical society tend to involve an authority figure in a conflict in order to gain power by association over the outcome (Tinsley \& Brett, 2001). Some scholars argue that by deferring a decision to a superior, both parties of conflict avoid the need to make concessions, respect status distinctions and also minimise social friction (Leung, 1997; Tinsley, 1997; Tinsley \& Brett, 2001).

In the case of Vietnam, there are few studies on relationships between culture and conflict management. Some scholars believe that Vietnam, like other Asian societies, is classified as a high-context society. Hence, it is suggested that in the process of conflict management and resolution, Vietnamese people may have different behaviours with people of different cultural backgrounds. This position is clearly reflected in the following story by Jamieson (1995):

I once saw an American point out to a Vietnamese employee that he had made a rather serious error. The American explained the situation earnestly and with great patience. The Vietnamese listened intently. When the American finished, the Vietnamese grinned from ear to ear and did not say a word. For a moment the American stared at him in amazement, then abruptly lost his temper. "Look at that son of a bitch! He thinks it's funny!" The smile had indicated embarrassment; the silence, agreement and acceptance of fault. The employee had understood the explanation, accepted responsibility for the problem, and would probably have corrected the deficiency at the earliest possible moment. But the American had expected some verbal response: an explanation, a denial, an apology, or even an argument. He interpreted the silence as disinterested and the smile as impertinence. (pp. 75-76)

As mentioned earlier, harmony is regarded as a centerpiece of Vietnamese interaction. Hence, maintaining and achieving harmony is essential in conflict management in Vietnam. Ashwill and Diep (2005) point out that Vietnamese people are reluctant to say no, it is because refusal threatens harmony. Third-party communication is utilised to avoid direct conflict. Face saving is highly valued by the Vietnamese as a way of maintaining respect and harmony in interpersonal 
relations. This explains why Vietnamese people will prepare very carefully what to say or do in order not to hurt others' feelings, thereby avoiding conflict.

The literature reviewed has shown that cultural values and beliefs are closely related to conflict behaviours. Cultural values provide individuals with the view of consequences of specific actions or attitudes and formulate their understanding of the world and how contingencies operate. Therefore, as Kaushal and Kwantes (2006) conclude: "Culture has a strong effect on individuals' understanding of what the results may be of a given choice of action, and it may be through this route that culture affects choices of conflict style management" (p. 584).

\section{Summary}

This review has covered the meaning of culture and leadership; provided a brief coverage of cultural knowledge and awareness and leadership theories; discussed the roles of the four pre-defined leadership functions and their relations with societal culture. The review of culture and leadership has demonstrated that societal norms and values shape, support and constrain leadership practice. Culture has effects on multiple functions of leadership. It is generally accepted that culture is the source of values that people share in a society. As such, values and beliefs impact the thinking and behaviours of leaders and individuals and the interactions among people. Furthermore, the review has also demonstrated that the practice and behaviour of leaders or leadership theories cannot be universalised because of the differences in people's cultural backgrounds and beliefs that could determine their behaviours and practices. It is becoming clear that leadership practice varies across different cultures. Hence, as Hallinger and Leithwood (1996) argue, there is much conceptual leverage to be gained from employing culture as a variable in a theoretical framework for educational leadership. This chapter has sought out the conceptual perspectives of culture and leadership and gathered knowledge that serves as a guide to inform my viewpoints for the research. The next chapter explains the adopted theoretical aspects of this study. 


\section{CHAPTER FOUR: METHODOLOGY}

\section{Introduction}

This chapter addresses the philosophical, theoretical and methodological aspects of this research. It explains the adoption of interpretivism as a research paradigm, phenomenology as a research framework and describes the research methods. The following sections are presented: (1) Interpretivism: A choice of research paradigm; (2) Phenomenology as a framework; (3) Research design; (4) Methods of data collection; (5) Data analysis; and (6) Summary of the chapter.

\section{Interpretivism: A choice of research paradigm}

Creswell (1994) points out that a good research undertaking begins with the choice of the topic, the research problem as well as the paradigm that the researcher uses as a cognitive guide for the whole research. Basically, a paradigm is defined as "a basic set of beliefs, values and technique...which acts as a guide or map, dictating the kinds of problems scientists should address and the type of explanations that are acceptable to them" (Sarantakos, 1998, p. 32). Patton (1990) simply puts it as a "world view". This view is supported by Denzin and Lincoln (2000) who believe that a paradigm is used to deal with first principles, ultimates or the researcher's worldviews. In this sense, a researcher is regarded as an interpretive bricoleur who seeks the meanings of human nature by constructing work from a diverse range of "taken for granted" things which happen to be available. The significance of a paradigm is that it shapes how a researcher perceives the world. A paradigm to which a researcher adheres has a deep influence on the whole research process. As Williams (1998) puts it, "within the research process the beliefs a researcher holds will reflect in the way the research is designed, how data are both collected and analysed and how research results are presented" (p. 2). In educational research, paradigms are termed in different ways, such as epistemes (Foucault, 1972) or traditions (MacIntyre, 1988) about how research data might be collected, understood, patterned, reasoned, and compiled (Morrison, 2007).

The philosophical assumptions of my research have come from an interpretive tradition (interpretivism). According to Weber (1968), this term "may refer to the actual existing meaning in the given concrete case of a particular actor, or to the 
average or approximate meaning attributable to a given plurality of actors" (p. 21). It implies a subjective epistemology and the ontological belief that reality is socially constructed. The epistemological stance of interpretive approaches (e.g., phenomenological approaches, interpretive phenomenological analysis and hermeneutics) is that the knowledge of reality, including the domain of human action, is gained through social constructions. Thus, there is no objective reality which can be discovered by researchers and replicated by others, as assumed by positivist science (Walsham, 1993). Proponents of an interpretive approach believe that social phenomena must be understood within the social contexts of the people who are being investigated. The basic perspectives of interpretivism are summarised by Sarantakos (1998) in Table 3:

Table 3: Perspectives of interpretivism (Source: Sarantakos. 1998, p. 40)

\begin{tabular}{|c|c|}
\hline Criterion & Perspectives \\
\hline Reality is... & $\begin{array}{l}\text { - } \quad \text { subjective, in people's minds } \\
\text { - created, not found interpreted different by people }\end{array}$ \\
\hline $\begin{array}{l}\text { Human beings } \\
\text { are... }\end{array}$ & $\begin{array}{l}\text { - } \text { creators of their world } \\
\text { - making sense of their world } \\
\text { - } \text { not restricted by external laws } \\
\text { - creating systems of meanings }\end{array}$ \\
\hline Science is ... & $\begin{array}{l}\text { - } \text { based on common sense } \\
\text { - } \text { inductive } \\
\text { - } \text { relying on interpretations } \\
\text { - not value free }\end{array}$ \\
\hline Purpose of research & 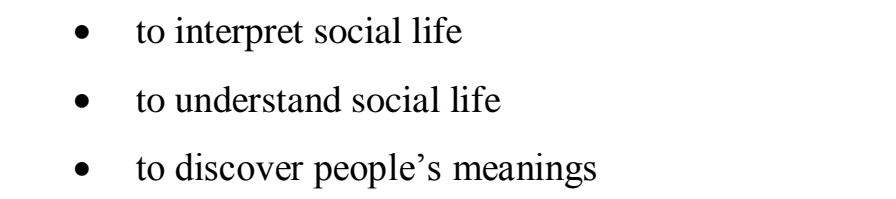 \\
\hline
\end{tabular}

In the domain of social research, interpretive researchers place emphasis on finding the meaning of a human action by studying and conveying the language that people use to describe the "reality" with the belief that the meanings of language lie behind their actions. As Taylor (1985) argues, "interpretation ... is an attempt to make clear, to make sense of, an object of study. This object must, therefore, be a text, or a text- 
analogue, which in some way is confused" (p. 15). This view is also supported by Boeckh (1985) who believes that, "of the varied signs and symbols in which human spirit expresses itself, the most adequate to express knowledge is speech" (cited in Muller-Vollmer, 1985, p.20). For an interpretive researcher, "there cannot be an objective reality which exists irrespective of the meanings human beings bring to it" (Morrison, 2007, p. 27). Therefore, according to Morrison (2007), in interpretive research, the significance of data collected and analysed is qualitative rather than quantitative.

This study assumes that people create and associate their own subjective and intersubjective meanings as they interact with Confucianism and school leadership in Vietnamese school contexts. The study attempts to understand the phenomena through accessing the assigned meanings of participants (Orlikowski \& Baroudi, 1991) and to explain the phenomena according to individual consciousness and within the frame of reference of study participants. The nature of this study is to explore and explain the phenomena of "the impact of Confucian values on school leadership.' In other words, the research is primarily exploratory.

\section{Phenomenology as a framework}

In this section, I present an overview of phenomenology and explain why phenomenology is chosen as a research method. Then, I discuss phenomenological techniques in practice. Finally, I explain how phenomenological research is designed in this study.

\section{Phenomenology: a choice of methodology}

Phenomenology began as a discourse over a century ago with its German philosophers Franz Brentano (1838-1917) and Edmund Husserl (1859-1917). Phenomenology has been widely spread and gained significant influence on social science in the last several decades (Sanders, 1982). One of the significant European philosophers who played a prominent role in the advancement of phenomenological movement is Herbert Spiegelberg (1904-1990).

Phenomenology "asks for a very nature of a phenomenon, for that which makes a some-'thing' what it is - and without which it could not be what it is" (Van Manen, 2006, p. 10). It is the study of conscious phenomena, exploring the way in which 
things or experiences show themselves (Sanders, 1982). This theory suggests that the social world is highly ordered, within which people are active creators, producing and maintaining a consciousness that communicates to them everyday experiences (Husserl, 1950; Sarantakos, 1998). People may not be aware of the fact that they are creating this ordered world. They take order as a natural phenomenon and do not question it (Sarantakos, 1998). Hence, phenomenology seeks to describe basic lived experience. In a phenomenological study the researcher must interpret the subject's experiences from his/her own perspective and to attain this, he or she must able to enter their inner world (Johnson \& Christensen, 2008). Since the aim of this research was to understand how Vietnamese school leaders exercised leadership by unveiling the impact of culture on their practices, beliefs and perceptions, a phenomenological theoretical framework was considered the best means for this study. In other words, the intention of this research was gather data regarding the perspectives of research participants about the phenomenon of cultural influence on school leadership. My epistemological position regarding the study I undertook can be formulated as follows: (1) data are contained within the perspectives of people that are involved in the practices of school leadership, either people are practitioners of leadership (school leaders) or people are informants on leadership practice (teachers) (this will be further explained in the section of this chapter: Selection of participants); (2) because of this I engaged with the participants in collecting data.

Following phenomenological perspective, I started the research by returning to my own experience and tried to describe my experience within the context where I lived and worked for years (as described in Chapter One). In a phenomenological approach, my personal experience was the starting point. It was from my own experience of leadership that I not only began to explore my own sense of meaning from the experience, but I began to wonder what it was like for others. Four phenomenological themes (exercising power, building relationships, decisionmaking, problem solving) emerged from my lived experience, which are reflected as experience of focus, the form of capturing phenomenon that I tried to understand. As Van Manen (1990) stated, "phenomenological themes may be understood as the structures of experience" (p. 79). 


\section{Phenomenological method}

In terms of practice, phenomenologists use method and analysis (techniques) in social science research to grasp the lived experiences of a phenomenon. By returning to lived realities, researchers obtain a comprehensive description of an individual's personal experience and perception to provide the basis for a reflective structural analysis. (Moustakas, 1994; Patton, 2002; Smith \& Osborn, 2003). To restate, a phenomenological approach acknowledges that reality exists independently of consciousness. However, the reality can only become "real" through a person's consciousness. Accordingly, the researcher's phenomenological task is to seek the understanding of the reality claims precisely as they are made by the research participants (Giorgi, 1994). This is achieved in three ways as follows:

(1) Adopt the phenomenological attitude;

(2) Encounter an instance of the phenomenon that one is interested in studying and then use the process of free imaginative variation in order to determine the essence of the phenomenon;

(3) And finally, carefully describe the essence that was discovered. (cited in Giorgi, 2008, p. 2)

With the advancement and spread of phenomenology, variations of principles and processes have emerged. These include seven Spiegelberg's (1994) steps of the phenomenological method, Giorgi's $(1994,1997)$ three Husserl-inspired interlocking steps, and Van Manen's (2006) and Moustakas' (1994) phenomenological techniques. Yet there are as many differences of the logic and steps of phenomenological methods among philosophers as there are similarities. There is no method that is neither exclusive nor exhaustive (Finlay, 2009; Giorgi, 1997).

As a method of study, the example by Giorgi's $(1994,1997)$ three interlocking steps is presented as follows:

(1) Phenomenological reduction: bracketing from all past theories or knowledge about the phenomenon in order to encounter it freshly and describe it precisely as it is intuited and withholding existential assent of the phenomenon;

(2) Description: describing the phenomena precisely as they present themselves, neither adding to nor subtracting from what is given; 
(3) Search for essence: describing the invariant characteristics and their relationships to each other based on intuition to make a fundamental meaning of the phenomenon without which a phenomenon could not present itself as it is.

Based on these basic steps, five Giorgi-inspired practical stages were undertaken in my study as follows:

(1) Collection of data: data were collected by interviews, observation, questionnaires and documents. The questions were designed broad and openended;

(2) The reading of the data: I read through all of the data to get the "global sense" before beginning analysis;

(3) The dividing of the data into parts: this was the process that I discriminated meanings of data. It aimed to constitute "meaning units" with the help of Nvivo 8 software program;

(4) Organization and expression of raw data into disciplinary language: I examined, probed, and re-described the meaning units so that the disciplinary value of each unit could be made more explicit;

(5) Expressing the structure of the phenomenon: I determined the essences of the phenomenon based on free imaginative variation (the process that I determined the integrated meaningful units which were essential for, and were made up of, a fixed identity for the phenomenon that was being studied).

Regarding the process of data analysis in a phenomenological study, Moustakas (1994) offered the four primary phenomenological principles (steps), based on which the understanding of the meanings and essences of a phenomenon that are being investigated can be disclosed and elucidated. The four primary phenomenological principles are epoche, phenomenological reduction, imaginative variation and synthesis: 
(1) Epoche: is as an ongoing process of "looking inside" to become aware of personal bias, to eliminate personal involvement with preconceptions.

(2) Phenomenological reduction: is the process whereby the researcher describes in textural language what he/she sees, not only in terms of the external object but also the internal act of consciousness.

(3) Imaginative variation: is the process of seeking possible meanings through varying the frames of reference, employing polarities and reversals in order to obtain a structural description of the phenomenon.

(4) Synthesis of meanings and essences: is the process of integration of structural descriptions to provide a synthesis of the meanings and essences of the phenomenon.

According to Moustakas (1994), these procedures provide a direction and steps to be followed that help the researcher move a study into action. How these four steps of phenomenological analysis were used in this study will be further described in the next section of this chapter (Qualitative data management and analysis).

\section{Phenomenological research design}

Methodologically, according to Patton (2002), "our understanding comes from sensory experience of phenomena, but that experience must be described, explicated, and interpreted" (p. 106). The phenomenological research design is aimed at exploring in detail how participants experience and make sense of their personal and social worlds. More particularly, in my research the phenomenological design helps me seek an understanding of the influence of Confucianism on school leadership by revisiting my experience of these phenomena in order to seek new emerging meanings (Gray, 2009; Smith \& Osborn, 2003). The design also helps research participants perceive, describe, feel about, judge, and talk about the phenomena (Patton, 2002). People are surrounded by many phenomena which they are aware of but may not fully understand, partly because these phenomena may exist but they have not been overtly described or explained or they have ignore or not paid attention to them. 
According to Smith and Osborn (2003), phenomenological research places emphasis on sense-making by both participants and researchers. They note that there is a twostage interpretation process: "The participants are trying to make sense of their world; the researcher is trying to make sense of the participants trying to make sense of their world" (p. 53). Therefore, a phenomenological researcher must pay great attention to and interpret "a chain of connection between people's talk and their thinking and emotional state" (Smith \& Osborn, 2003, p. 54). It is because, according to Smith and Osborn (2003), participants struggle to express what they are thinking and feeling. There might be reasons why the participants are reluctant to selfdisclose.

In this study, case studies have enabled me to understand the phenomena of the impacts of Confucianism upon school leadership within Vietnamese contexts. As Gray (2009), Hoepfl (1997), Miles and Huberman (1994) and Smith and Osborn (2003) point out that phenomenological research design is best suited to complex issues and aims to produce "thick descriptions" of people's experiences or perspectives within their settings. In contrast, a quantitative approach is conducted with a large number of participants. This approach easily minimises the richness and meaning of the data. As it is noted at the outset, school leadership is a socio-political process of complexity, which is not easily or fully understood with "thin descriptions". Therefore, a variety of methods of data collection can be used with the phenomenological research design.

The limitations of phenomenological design need to be acknowledged. In this way, potential threats to truth and difficulties of the research can be anticipated. The phenomenological literature (Gray, 2009; Hoepfl, 1997) suggests some of the following limitations:

1. Generalizability: a phenomenological design is often based on a small number of cases; hence, its generalisability is limited;

2. Validity: a phenomenological design uses relatively unstructured methods of data collection. As a result, the research outcome may be difficult to replicate. Furthermore, subjectivity and the indetermination of meaning between individuals are potential difficulties for data analysis (validity issues will also be discussed in the next chapter). 
How phenomenological research design was conducted in this study will be described in detail in the next section.

\section{Research design}

\section{Qualitative research - The choice of research method}

To restate, this research explores how school leadership is exercised as a cultural phenomenon in Vietnamese schools. The focus of the study is to explore and examine the relations between two objects: school leadership and Confucian values. An important emerging question confronted me: "What research method is the best for this study?" To answer this question, two sub-questions were tackled: "How is the chosen method suitable for the study? And what are its advantages?"

In choosing a method for the study, much depends upon what researchers are trying to find out. No method of research, quantitative or qualitative, is intrinsically better than another and no specific method can be privileged over any other. Each research approach has its own advantages and limitations (Berg, 2004; Denzin \& Lincoln, 2000; Morrison, 2007; Silverman, 2005).

My research aimed to explore the phenomenon of the impact of Confucian-affiliated values on school leadership in detail rather than making standardized and systematic comparisons or accounting for variances. A qualitative methodology was chosen as a suitable approach for examining and exploring the essence and nature of the phenomenon. In terms of theoretical perspectives, a qualitative research is associated with interpretivism and phenomenological research design.

Certain experiences cannot be meaningfully expressed by numbers or described in a statistically aggregated fashion (Berg, 2004). We can describe a girl in numbers by measuring her height, weight, and other variables. But numbers of her measurements cannot be used to describe or define a complete picture of how beautiful the girl is. In scientific research, a qualitative approach is used to avoid this limitation. Using qualitative research strategies is to provide perspectives that can prompt a recall of the common experiences and helps to discover the phenomenon of interest, particularly social phenomena where people are the participants (Berg, 2004; Maykut \& Morehouse, 1994). According to Berg (2004), qualitative research "refers to the 
meanings, concepts, definitions, characteristics, metaphors, symbols, and descriptions of things" (p. 3).

My research is a form of human science research. It seeks the meanings given to human phenomena of Confucianism in order to understand the practice of school leadership, construct social reality and cultural meanings by focusing on interactive processes and using thematic analysis. This approach is distinct from natural science studies that taxonomize natural phenomena, or explain behaviours in terms of probabilities, by using a large number of cases and statistical analysis (Berg, 2004; Denzin \& Lincoln, 2000; Neuman, 2003; Van Manen, 2006). Dimmock and Walker (2005) point out that school leadership is culturally and contextually bounded. The conceptual and practical complexity of leadership which is inextricably intertwined with its larger environment should not be simply understood by using statistical analysis or countable measurements. The unquantifiable facts of school leadership should be investigated in depth and in detail in order to illuminate not only the essence of leadership but also its subtle and dismissed facts.

The case study design was applied in my research. It is an approach that "involve[s] systematically gathering enough information about a particular person, social setting, event, or group to permit the researcher to effectively understand how it operates or functions" (Berg, 2004, p. 251). It is appropriate for this study because the research focus is on contemporary rather than historical events (Yin, 1994). The case study design was selected for the following main reasons. Firstly, Confucian values and school leadership is a common topic of a nation-wide phenomenon in Vietnamese contexts. With a period of six months for data collection, the case study design was the best choice to deal with time limitations. Secondly, case studies are believed to lead to better understanding, perhaps better theorising, about a larger collection of cases (Stake, 2000). Finally, the case study design allowed me to gain an in-depth understanding from rich, detailed and in-depth information, retain holistic and meaningful characteristics of real-life events, and improve understanding of the complex social phenomenon of school leadership and Confucian values (Berg, 2004; Maykut \& Morehouse, 1994; Yin, 2009). Burns (2000) suggests, the case study approach is a method of discovery rather than confirmation. The purpose of this research project is to discover the phenomenon of how school leadership is exercised 
within Confucian values in the Vietnamese context rather than confirm what this phenomenon is.

\section{Mapping research procedures}

The research procedures encompassed three main phases (illustrated in three different colours, see Figure 2). The "theory-before-research" model suggested by Berg (2004) was employed. This model is described as "begin with an idea, gather theoretical information, design a research plan, identify a means for data collection, analyse the data, and report findings" (Berg, 2004, p. 19). The research process was not a linear progression in a single, forward direction, rather, it was a spiralling progress. With this approach, as Berg (2004) suggests, I went two steps forward, and then took a step or two backward before proceeding with any other steps. The purpose of the spiralling progress was to provide the researcher with chances to reconsider, refine the idea, and re-examine the theoretical assumptions.

During Phase 1, my research problem was defined, which shaped the initial ideas for research development and strategies. The research proposal was developed, in which initial research-related literature was reviewed to set up a theoretical research framework. As Jankowicz (1991) and Keeble and Kirk (2007) point out, our knowledge only has value in relation to other people's. My research should not be seen in isolation. The literature review helped me clarify the "research gap"; refine the focus of inquiry; and provided a context within which to interpret my findings. The methods of data collection which were based on phenomenological design were outlined, including interviews (semi-structured individual interviews and focus group interviews), questionnaires, observations, and documents. All the interview questions and questionnaires were composed based on the focus of inquiry and within the constraint of a phenomenological research design. Hence, they were framed broadly and openly. "Yes/No" questions were avoided. Open-ended questions were designed in order to gain "thick descriptions" from participants. During this phase, the ethical issues were also sketched, considered and approved in order to ensure that the research was carried out properly. The ethics applications and research proposal were sent to the Ethics Committee of the Faculty of Education, Victoria University of Wellington for consideration and to request approval for the research. All content of letters to the Provincial Education and Training Services (PETS) and District 
Education and Training Services (DETS) was carefully discussed with my supervisors in relation to the ethical issues before they were translated into Vietnamese (see appendices 2, 3, and 4).

During Phase 2, the first thing I did when I returned to Vietnam was to seek permission to conduct research from PETS, DETS and administrative school boards. As Dimmock (2007) advises, researchers should be aware of difficulties of access due to some cultural and socio-political aspects. In Vietnam, undertaking research projects requires the permission of relevant government authorities. In terms of the administrative educational structure, all high schools are under the direct management and governance of PETS, whilst all secondary schools are under direct administration of DETS. To seek permission, I sent letters and all research-related information to PETS and DETS. Once permission was granted, I began the research. I received two referral letters from PETS and DETS in which I was allowed to conduct research in a high school and a secondary school around the town. These referral letters were used as an introduction to school leaders and helped me build trusted-cooperative relationships with them when I came to visit schools for the first time. For the third case, I sought permission directly from the School Principal Board because this school belongs to the tertiary education system. In Vietnam, schools belonging to the tertiary education system are more independent and have more administrative autonomy. 


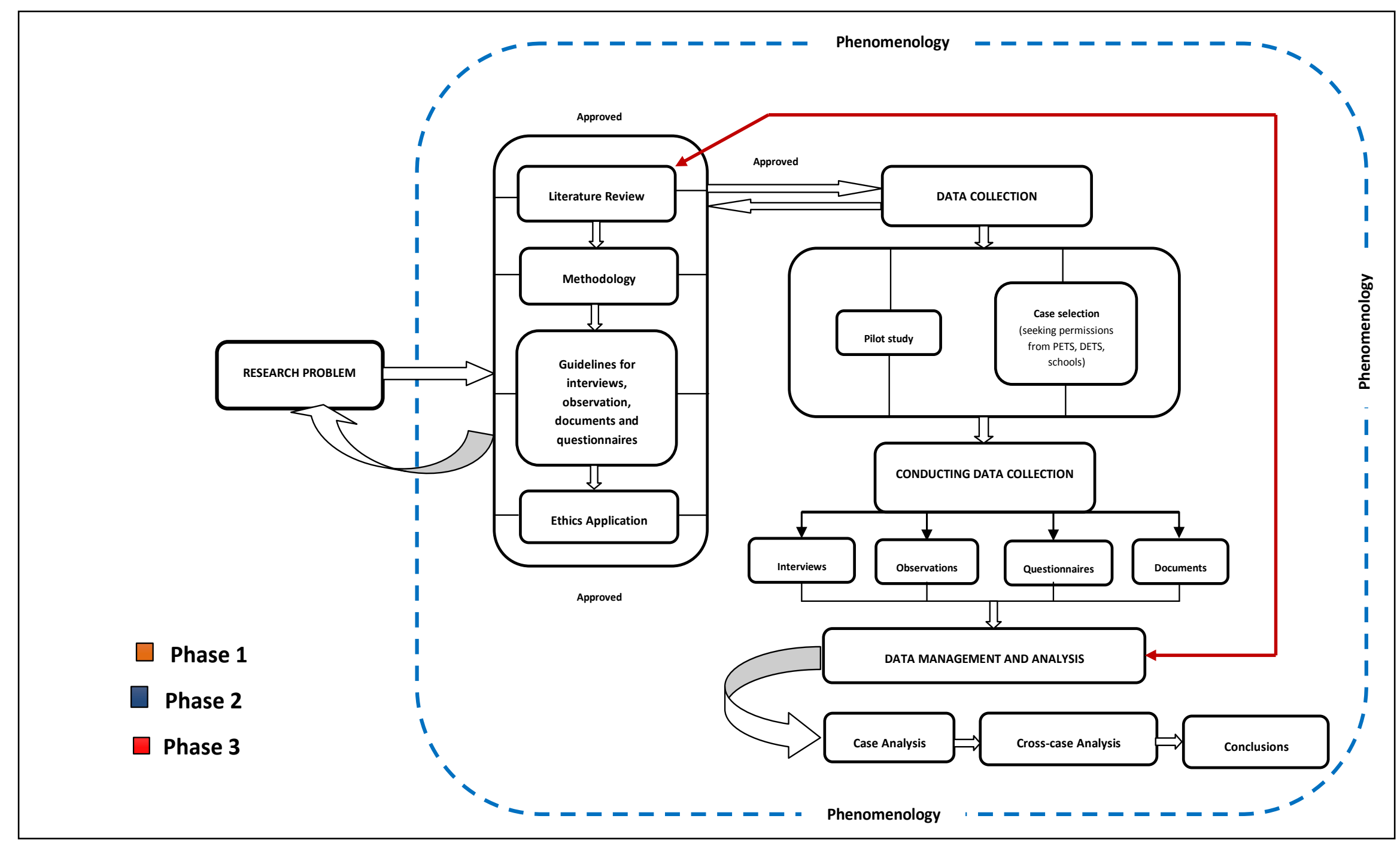

Figure 2: Mapping research procedures 
A pilot study was conducted in the first case study to test the research instruments before data collection was officially conducted (see more in the section: Piloting interview questions and questionnaires in this chapter).

During Phase 3, the data was collected in Vietnamese and then transcribed into texts, which were translated into English for analysis (see more in the section: Data management and analysis in this chapter). During this phase, data was managed and analysed. Simultaneously, literature was re-examined, refined, and developed.

As illustrated, this research project is best understood in terms of three phases. The research process was designed based on a spiralling "theory-before-research" approach with the purpose of creating fluidity as the research process unfolded.

\section{Sample strategies}

\section{Case study as a research method}

In my study, the goal was not to build a random sample, but rather to present the range of experiences of the phenomenon of Confucianism and school leadership in which I was interested (Maykut \& Morehouse, 1994). The sample was purposively designed and case studies were used as a research method.

The application of case study approach was also based on its acknowledged advantages in social research (Berg, 2004; Cohen, Manion, \& Morrison, 2000; Yin, 2009): (1) Case studies provide unique examples of real people in real situations and these can penetrate real situations in ways that are not susceptible to numerical analysis, thereby making it strong in reality; (2) Case study methods involve gathering enough information about a particular case (e.g., a person, an organization), hence, this provides an extremely rich, detailed, and in-depth information description; (3) Applying case studies enables a researcher to capture various nuances, patterns, and more latent elements that other research approaches might overlook.

In this phenomenological study, three schools were selected as multiple case studies. Multiple-case studies served the purpose of seeking the replication or producing 
contrasting results but for predictable reasons from one phenomenon. The advantage of multiple-case design is that it not only produces replications or contradictions among cases but also maintains the holistic picture of each case (Yin, 2009). The decision to choose three case studies rather than a large sample size "allows sufficient in-depth engagement with each individual case but also allows a detailed examination of similarity and difference, convergence and divergence" (Smith \& Osborn, 2003, p. 57). Small sample size is a factor of phenomenological research. The aim of the phenomenological study is to seek "thin description" rather than trying to claim generalisation of a phenomenon. My decision to choose a small sample size of cases follows the suggestion by Maykut and Morehouse (1994) and Patton (2002), that the sample size depends on the limitation of time, resources, and other factors that impinge upon the research enterprise. In this study, three schools representing three educational levels were selected: a college, a high school, and a secondary school. I chose these school types to find out if there were any similar results or contrasting results at various educational levels.

The schools, rather than the individual school members (working within the schools), were deliberately selected as the cases. This is because school leadership (my research focus) is an influential process, in which school members are interconnected. School leadership process takes place within a school community rather than within a single individual. As Skrla et al (2001) point out, "If leadership is occurring, someone is following. You can't lead in an empty room" (cited in Murphy, 2006, p. 3).

\section{Selection of cases}

The following criteria were applied in selecting the cases: school locations, types of school, principal's experiences and gender of principals.

School locations: The three schools are located in a province in the central area of Vietnam, where I live and work. Time was limited and therefore valuable; hence, school location was an important criterion of selecting to ensure access.

Types of schools: The three cases selected were state-run schools. State-run schools were selected over private schools because most of teachers in state-run schools are employed 
predominantly fulltime, whereas all private schools employ part-time teachers. The fulltime teachers have more commitment to school activities and are directly influenced by leadership practice. Furthermore, the full-time teachers were selected as participants for stable participation in the six-month involvement in the project.

Principal's experience: This selection criterion was based on the belief that a less experienced principal might not be a rich-information participant. Lashway, Mazzarella and Grundy (2006) highlight the importance of school leaders' experiences: "School leaders do not operate from scientific principles or rigid rules, but from informal 'rules of thumb' that have been tested in the fires of real life" (p. 70). Consequently, schools with principals of at least two years experience were selected.

Gender of principals: Gender role is also a cultural factor reflected in Confucian values. Gender was taken into consideration for participant selection to ensure that there should be at least one female principal in the three selected schools.

The first case study was conducted in a state-run teacher training college (School A) for students who are being trained to become teachers of nursery, primary, and secondary schools. The second case study was conducted in a high school (School B). This school teaches students between the ages of 16 to 18 years, and consisting of grades 10 to 12 . The third case study was conducted in a secondary school (School C), which teaches students between the ages of 12 to 15 years and consists of grades 6 to 9 .

\section{Selection of participants}

According to Hycner (1999), "the phenomenon dictates the method (not vice-versa) including even the type of participants" (p. 156). Hence, participants in my research were purposively selected as the most important kind of non-probability sampling. In a phenomenological study, selected participants are those who "have had experiences relating to the phenomenon to be researched" (Kruger, 1988, p. 150). Three main stakeholder groups of participants were selected, including principals, vice-principals, and teachers. Principals, vice-principals, and teachers interact most significantly with school leadership. These groups of participants are therefore in an advantageous 
positions and likely to provide rich sources of information on how leadership is exercised within schools.

Principal participants were selected as the practitioners of leadership. In the Vietnamese context, principals are considered to be the most powerful figures in school leadership (Thang, 2004). The literature suggests that principals are considered people who are associated with the highest positions of authority and seniority in schools (Murrihy, 2002; Sergiovanni, 2001). The number of principal participants invited to participate in the study were three, including one female principal from the college, and two male principals from the high school and the secondary school.

Vice-principals were selected as another main stakeholder group within the sphere of school leadership. This selection is based on the fact that they are both practitioners of leadership and informants on leadership practice. There were two vice-principals in each selected case. However, four vice-principals were selected due to their availability, including two vice-principals from School A, one from School B and one from School C.

Teachers are also involved in school leadership. Teacher participants were selected as the groups of informants on leadership practice. Some basic criteria for selecting teacher participants were as follows:

- Teacher's genders: three female and three male teachers were selected to balance gender voices;

- Teacher's age: younger and older teachers were selected to balance age;

- Teacher's experience: teachers who have worked for at least two years rather than novice ones were selected. In this way, better informants due to their rich experience in leadership practice were invited.

Six teachers selected for each case met all pre-determined criteria. The statistics on cases and participants are presented in Tables 4, 5, and 6 . 
Table 4: Statistics on School A (Case 1)

\begin{tabular}{|c|c|c|c|c|c|c|c|}
\hline \multirow[t]{2}{*}{ CASE 1} & \multicolumn{2}{|c|}{ Gender } & \multicolumn{3}{|c|}{ Age (years) } & \multicolumn{2}{|c|}{ Experience (years) } \\
\hline & Male & female & $25-39$ & $40-49$ & $\begin{array}{l}50 \text { or } \\
\text { over }\end{array}$ & in leadership & in teaching \\
\hline PC1 & & $\mathrm{x}$ & & & $\mathrm{x}$ & 24 & 29 \\
\hline VP1C1 & $\mathbf{x}$ & & & & $\mathrm{x}$ & 10 & 30 \\
\hline VP2C1 & & $\mathrm{x}$ & & $\mathrm{x}$ & & 6 & 17 \\
\hline C1MT1 & $\mathrm{x}$ & & $\mathrm{x}$ & & & & 10 \\
\hline C1MT2 & $\mathrm{x}$ & & & $\mathrm{x}$ & & & 12 \\
\hline С1MT3 & $\mathrm{x}$ & & & $\mathrm{x}$ & & & 28 \\
\hline C1FmT4 & & $\mathrm{x}$ & & & $\mathrm{x}$ & & 29 \\
\hline C1FmT5 & & $\mathrm{x}$ & & $\mathrm{x}$ & & & 22 \\
\hline C1FmT6 & & $\mathrm{x}$ & $\mathrm{x}$ & & & & 7 \\
\hline
\end{tabular}

(Keys: $C 1=$ Case $1 ; P=$ Principal $; V P=$ Vice-Principal $; M T=$ Male teacher $; F m T=$ Female teacher)

Table 5: Statistics on School B (Case 2)

\begin{tabular}{|c|c|c|c|c|c|c|c|}
\hline \multirow{2}{*}{ CASE 2 } & \multicolumn{2}{|c|}{ Gender } & \multicolumn{2}{c|}{ Age (years) } & \multicolumn{2}{c|}{ Experience (years) } \\
\cline { 2 - 8 } & Male & female & $25-39$ & $40-49$ & $\begin{array}{c}50 \text { or } \\
\text { over }\end{array}$ & in leadership & in teaching \\
\hline PC2 & $\mathrm{x}$ & & & & $\mathrm{x}$ & 15 & 31 \\
\hline VP1C2 & $\mathrm{x}$ & & & & $\mathrm{x}$ & 17 & 32 \\
\hline C2MT1 & $\mathrm{x}$ & & & & $\mathrm{x}$ & & \\
\hline C2MT2 & $\mathrm{x}$ & & $\mathrm{x}$ & & & & 23 \\
\hline C2MT3 & $\mathrm{x}$ & & & $\mathrm{x}$ & & & 15 \\
\hline C2FmT4 & & $\mathrm{x}$ & $\mathrm{x}$ & & & & \\
\hline C2FmT5 & & $\mathrm{x}$ & & $\mathrm{x}$ & & & \\
\hline C2FmT6 & & $\mathrm{x}$ & $\mathrm{x}$ & & & & \\
\hline
\end{tabular}

$\underline{\text { Keys: }} C 2=$ Case 2; $P=$ Principal $; V P=$ Vice-Principal $; M T=$ Male teacher $; F m T=$ Female teacher) 
Table 6: Statistics on School C (Case 3)

\begin{tabular}{|c|c|c|c|c|c|c|c|}
\hline \multirow[t]{2}{*}{ CASE 3} & \multicolumn{2}{|c|}{ Gender } & \multicolumn{3}{|c|}{ Age (years) } & \multicolumn{2}{|c|}{ Experience (years) } \\
\hline & Male & female & $25-39$ & $40-49$ & $\begin{array}{l}50 \text { or } \\
\text { over }\end{array}$ & in leadership & in teaching \\
\hline PC3 & $\mathrm{x}$ & & & & $\mathrm{x}$ & 29 & 32 \\
\hline VP1C3 & & $\mathrm{x}$ & & $\mathrm{x}$ & & 10 & 18 \\
\hline C3MT1 & $\mathrm{x}$ & & & $\mathrm{X}$ & & & 26 \\
\hline C3MT2 & $\mathrm{x}$ & & & $\mathrm{x}$ & & & 21 \\
\hline C3MT3 & $\mathrm{x}$ & & $\mathrm{x}$ & & & & 8 \\
\hline C3FmT4 & & $\mathrm{x}$ & & & $\mathrm{x}$ & & 29 \\
\hline C3FmT5 & & $\mathrm{x}$ & $\mathrm{x}$ & & & & 12 \\
\hline C3FmT6 & & $\mathrm{x}$ & $\mathrm{x}$ & & & & 5 \\
\hline
\end{tabular}

(Keys: $C 3=$ Case 3; $P=$ Principal $; V P=$ Vice-Principal $; M T=$ Male teacher $; F m T=$ Female teacher)

\section{Going into the field}

In conducting qualitative research, anxieties, hopes, blindspots, prejudices, class, race or gender, location, age, historical positions, emotions, the past, and people's sense of possible futures are not left behind (Wengraf, 2001). These factors can affect the research process; affect the interpretation of participants' statements, and the phenomenon that we are concerned with. In McLeod's words, these "can shape the way that research is conceived and carried out" (2001, p. 199). Plummer (2001) argues that if we wish to understand a researcher's story, we need to know where the researcher is coming from, what kind of relationships the researcher and the story teller are having together and how it fits into the wider social order. In this sense, conducting research requires the researcher's awareness of the "world" in which he/she is living and operating. The researcher has to be attentive to and conscious of cultural, political, social factors such as norms and values that have been absorbed as part of life experience during the research process (Morrison, 2007; Patton, 2002). Plummer (2001) concludes 
that "research knowledge only makes sense if we can acquire understandings about active processes through which such knowledge becomes produced" (p. 208).

The section below depicts my voice about the research process. I display multiple layers of my consciousness and connect my personal experiences to the culture in which I am living in. This section is a reflexive account of the conduct of the research. The four questions suggested by Plummer (2001) are used as guiding questions for this reflexivity: How does the researcher present himself/herself? How is a relational self built up with the subjects of research? How is the interaction embodied? And how are the feelings presented and managed? (p. 213). In order to answer these questions I consider them within the two themes: (1) Building relationships for the culture of research and (2) Power and ethics in the culture of research.

\section{Building relationships for the culture of research}

The first thing I did when returning to Vietnam was to seek the permission of "gatekeepers" before "going into the field". My Vietnamese friend who was doing PhD in TESOL warned me that "your fieldwork must be challenging and tough because the main subjects of communication in your research are leaders! It might not be so easy to get access to leaders if you have no relationships with them". I soon found these comments true. My research focus was on school leadership. School leaders were my main stakeholder groups of participants. They were also the "gatekeepers" whom I had to contact to ask for permission before conducting the research in their schools. Ashwill and Diep (2005) in their book "Vietnam Today" comment that in Vietnam "relationships come first, work second", and "relationship that precedes all else". From the experience of a man who was born in, grown up in, and has been living and working in Vietnam for over 35 years, I accepted their remarks. From my own lived experience, building relationships is crucial to getting things done. It is not just the way to "make friends" but a strategy to build trust amongst people. I took these ideas into consideration seriously before starting my academic journey.

After I received the two nomination letters from PETS and DETS, I contacted the schools where I was to conduct the research. The first one was a high school located in a 
city centre where I was living. I felt that accessing the leaders of this school would not be so easy because I did not have any prior relationship with them. However, I decided to select this school because it happened to be a good case based on the general information provided by PETS. My own judgement was right. I had a casual meeting with the principal to provide him with the research information and seek permission to conduct the research. He promised "to create favourable conditions" for me to conduct the research in his school but "not so sure to participate in my research". In the Vietnamese cultural context, when someone says "I am not sure to do something for you", it might show the speaker's reluctance or it can be understood as an indirect refusal, which is used to avoid the direct one that can hurt other people's feelings. He asked me to meet the first vice-principal to discuss in detail before offering permission because he was "quite busy these days". I had a 30-minute meeting with the first viceprincipal. I provided him with detailed information about my research and discussed my research plan. He agreed that I could conduct the research in his school by introducing me to teachers in order that I could select research participants. However, he refused to participate in my research because he thought that he was just nominated to this leadership position for some months, hence, he was "still less experienced in leadership". During that time, the second vice-principal was also not available for the research participation because she was busy writing her Master's thesis. The entry was simply and indirectly denied because it was impossible for me to conduct the research without the school leaders' participation. Finally, I decided to quit conducting the research in this school. The lesson I learnt was that my failure was partly derived from "poor relationships" with leaders in this school. I did not have any opportunities to build relationships with them before seeking permission. I did not have any people who could offer me "sponsorship" to make connection between the researcher and school leaders. As Ashwill and Diep (2005) describe, work relationships in Vietnam begin through introduction, but introduction in Vietnam is more like sponsorship. Borton (2001), an American writer who has worked in Vietnam for many years, also advises that the "newcomer" should have a sponsor who acts as a guide or an introducer to help the "newcomer" build relationships and trust with relevant authorities. 
Johnson (1975) affirms that "the achievement of successful entree is a precondition for doing the research" (p. 312, as cited in Patton, 2002). He suggests that there are two reasons why the entry stage is so important:

Firstly, no entrée, no research;

Secondly, the conditions under which an initial entree is negotiated may have important consequences for how the research is socially defined by the members of the setting. These social definitions will have a bearing on the extent to which the members trust a social researcher, and the existence of relations of trust between an observer and the members of a setting is essential to the production of an objective report, one which retains the integrity of the actor's perspective and its social context. (p. 312, as cited in Patton, 2002)

I changed my strategy for securing and maintaining access to cases by looking for a "sponsor" to gain access to and build good relationships with "gatekeepers" and research participants. As Patton (2002) suggests, "the best approach for gaining entrée is the known-sponsor-approach" (p. 312). I had a sponsor in the second high school (School B). The sponsor was my cousin who had been working in the school for over 20 years and had a close working relationship with the school leaders. She had had a preliminary conversation with school leaders to talk about my research plan and helped me make an appointment with school leaders before I came to school to have an official meeting with them. With her sponsorship, it was much easier for me to access school leaders to discuss my research plan and to ask for permission. The willingness of school leaders and teacher participants was inspired by her introduction and relationships.

Similarly, I accessed the secondary school (School C) with my brother's introduction and sponsorship, who had been working for the province's educational system for over 25 years and had a wide circle of acquaintances. He knew the principal of the school. He introduced me to the principal in a courtesy meeting with him in a coffee shop. Over cigarettes and cups of coffee, the connection was set up. The principal said that it was his pleasure to help his friend's brother conduct the research in his school. He also promised to create "the best conditions" for me to conduct the research successfully. On reflection, I wonder how challenging the research process would have been if I did not have my brother's help. 
Accessing the fourth school (School A) was much easier because I knew the school leaders and we had worked together for many years. I had no trouble with carrying out the research in this school, in terms of asking for permission and selecting participants.

In building relationships with participants, Dimmock (2007) advises that it is important for a researcher to cultivate good relationships with participants for their willingness to participate. I think that it is also a good strategy for establishing "trust" between the researcher and the researched. Building a research climate of trust enables the participants to willingly and freely participate and co-operate in the research process. Without trust, participants are likely to keep to themselves, rather than share their thoughts or offer their cooperation. As a result, I was conscious of being well prepared before conducting the research. To that end I:

- Provided the participants with as much information as I could about the research prior to data collection and honoured the principle of informed consent.

- Made an appointment to have an informal meeting with all participants in order to discuss general issues about the research and develop 'good' relationships with them.

- Visited schools to meet school staff and develop relationships with them.

In my research, I was embedded in a web of relationships as follows:

- Relationships among acquaintances: There were 10 participants whom I had known previously;

- Relationships between a teacher and a student: There were two participants who used to be my students in the college;

- Relationships between a stranger and a stranger: There were 13 participants whom I had never met before.

I did not need to spend much time building rapport with my acquaintances or former students; however, I had to build rapport with 13 'strangers'. There were two cultural 
factors that had a positive influence on the process of building relationships with the research participants: My age - I was not too young to make friends with older people. I wondered what would happen if I was a very young researcher or an inexperienced man? Would people look down on me with their "common" thinking: "The egg cannot be as clever as the duck" (Vietnamese saying)? My status was also an advantage. I was a college teacher who was obtaining a PhD in New Zealand. Te (no date) states that the Vietnamese common people seem to have a great love for knowledge and learning. They have particular respect and admiration for learned people. This seemed to be true in my situation. It was quite interesting that the participants admired and acknowledged my opportunity of living and learning in New Zealand. They acknowledged that I had shown great effort to win the government scholarship for my study. They believed that it was not easy to "get a good chance to study abroad" without a great effort. Their sincere acknowledgement and admiration made me feel more confident when building relationships with them.

I made full use of any opportunity to build relationships with my research participants. I began my research during the time Vietnamese people were busy preparing for their Tet holiday. ${ }^{4}$ The Tet holiday is an opportunity for Vietnamese people to meet each other, to make friends and to pay a visit to their friends' homes. Taking advantage of this opportunity, I spent three days visiting participants' families during Tet. They all welcomed me warmly as a 'special' visitor. In this way, I got close enough to the participants to build relationships with them and promote their willingness for participation. Even now as I am writing this thesis, I still feel their warm hospitality.

"Be discreet!" I took this suggestion by Bogdan and Biklen (2003) into my research with the purpose of building good relationships. Choosing suitable clothes was therefore important. As Vietnamese people say, "quen sọ dạ, lạ sọ áo quần" (We admire our acquaintance by their wisdom; we admire the strangers by their clothes ${ }^{5}$ ). I often went to school research sites in a smart suit. This was not just a simple way to make a good impression on people, but I also felt more comfortable and confident when I was well

\footnotetext{
${ }^{4}$ Tet holiday is a traditional national holiday. Vietnamese people often have 10-day leave. Tet starts on the first day of the first lunar month.

${ }^{5}$ This saying emphasizes the importance of how we dress to make good impression on the person whom we meet in the first time.
} 
dressed. I believed that an initial good impression could help me in building good relationships with participants. Bogdan and Biklen (2003) admit that appearance is an important factor that could facilitate the research process. They suggest, "People choose to wear clothes that communicate who they are. We do not suggest that you desert your personal style, but that you be aware of what your dress means to subjects" (p. 89). "Be discreet!" I was also aware that it was important "not to display too much of [my] knowledge while talking with [participants], since they [might] feel uncomfortable being in the presence of a 'know-it-all' (Bogdan \& Biklen, 2003, p. 89). I showed them that I was really interested in what they were saying and I demonstrated that I appreciated their knowledge and experience rather than showing off my knowledge. I did acknowledge that all participants in my research should receive my utmost respect for their willingness to share their time to help me obtain their lived experience for my research. For that reason, after interviews, I sent thank-you letters to all participants to express my deep gratitude to them.

\section{Power and ethics in the culture of research}

Power and ethics are reflected in the culture of the research. I exercised my power through my multi-roles: interviewer, observer, investigator and facilitator. These multiroles were employed under the influence of the cultural values and the ethical guidelines for social research. The participants exercised their power through their willingness, cooperation, attitudes and behaviours towards the researcher and the research. In this section, I discuss how power exercised by both researcher and the researched were connected to the ethical issues to form the culture of research.

I exercised the power of a researcher within ethical guidelines. Bouma (2000) warns that, "It is essential that you [researchers] be aware that there are always ethical issues involved in doing research" (p. 201). Ethical concerns should always be in the researcher's mind when the research is being conducted because ethical issues can arise at any stage of a research project. These are the guidelines that the researcher has to follow or strategies for problems that the researcher has to anticipate in order to avoid or at least minimise potential risks and disadvantages for the researched, a community or 
the society as a whole. Minimally, most of us, novice or experienced researchers, follow the six ethical principles suggested by Kirsch (1999) as follows:

- obtain informed consent in writing from participants;

- make sure that participation is entirely voluntary; that is, participants must be allowed to withdraw from the research at any time without any negative repercussions;

- inform participants of any risks involved in the research and ensure that potential risks and benefits are proportional;

- protect the confidentiality of all participants;

- ensure that participants' well-being, reputations, and employment are not affected by their participation in the research (or lack thereof);

- ensure that selection of participants is equitable. (as cited in Plummer, 2001, pp. 226-227)

The first ethical concern that I took into account was 'informed consent' during the participant selection process. The fundamental principle of informed consent is to empower the research participants to agree or refuse to participate in light of comprehensive information concerning the nature and purpose of the research (Homan, 1991). At the stage of teacher participant selection, one of the school leaders offered to help me select participants. He said to me "just tell me whom you want to invite, I will come to ask them to participate. No worries about that". I had to refuse his "kind" offer because I knew that if he was involved in the process of participant selection, his "power" would have conflicted with the rights guaranteed for all participants: the fundamental democratic rights to freedom and self-determination (Cohen et al., 2000). I acknowledged that the key principle of ethical issues is that of voluntarism by the participants when engaging in the research. In this sense, the research participants were guaranteed to be free from coercion or bribery to take part in the research (Burns, 2000; Busher \& James, 2007).

To put this into practice, I arranged a meeting with all potential participants from each case study to give them detailed information about my research: the purpose, processes, intended outcomes of the research and all potential risks were carefully explained; invitation letters, information sheets and participant consent forms with stamped 
addressed envelopes were provided; all questions were answered to their satisfaction. The potential participants were also allowed to have "one week of consideration" before they made the final accepting or declining decision, then they could post the consent forms to the researcher. "One week of consideration" was offered to ensure that participants understood well the purpose of the research and were fully aware of what risks they could face so that they had reasoned judgement to participate (Busher \& James, 2007). Table 7 presents the result of the participant selection process:

Table 7: Participant selection process

\begin{tabular}{|c|c|c|c|c|c|}
\hline School & $\begin{array}{c}\text { Numbers of } \\
\text { invited } \\
\text { participants }\end{array}$ & Agreed & Declined & $\%$ & $\begin{array}{c}\text { Numbers of } \\
\text { selected } \\
\text { participants }\end{array}$ \\
\hline A & 31 & 25 & 6 & 80.6 & 9 \\
\hline B & 27 & 25 & 2 & 92.5 & 8 \\
\hline C & 24 & 18 & 6 & 75.0 & 8 \\
\hline
\end{tabular}

Power and ethical issues were also reflected in the culture of the interviews. As Wengraf (2001) points out, " $[\mathrm{A}] \mathrm{n}$ interview is an interaction between real people and [that] there are issues of both power and emotion involved" (p. 76). Most of the participants appeared comfortable and confident about being interviewed. However, some of them were not. It seemed that they were still obsessed by the image of 'losing face', which might happen if they were not good at answering the questions, or if they spoke out in ways that were not permitted by the discourse of right behaviour. Young participants had a tendency to be more reserved than the older ones in the focus group interviews. They talked less than the older ones and hesitated to give their own opinions. It seemed that they were still haunted by the saying "the egg cannot be as clever as the duck" (Vietnamese saying). To encourage a "democratic" research climate, I had to give occasional prompts to encourage young participants to actively engage in the focus group interview process. All participants were also allowed to ask me to stop the interview for a break if they felt stressed or tired. The democratic climate was also reflected in participants' rights to access data. All participants were guaranteed the right 
to read the interview transcriptions if they wished. I acknowledged that the participants had rights over the data collected from them.

One of my concerns was that confidentiality must be maintained during and after my research. I understand that researchers are responsible for providing research subjects with a high degree of confidentiality. To that end, I removed or disguised any details from the research records that might inadvertently expose the participants' identities. For example, the real names of all cases and participants had been changed to pseudonyms or case numbers when reporting data. I did not describe the exact locations of schools such as the names of streets or the names of districts. Ensuring confidentiality of information obtained through the use of focus group interviews was quite challenging. Berg (2004) raises a question to warn researchers: "although it is easy to ensure that the researcher will maintain confidentiality, what can be done among the participants" (p. 58) in focus group interviews? According to him, it is necessary to have every member of the focus group sign a statement of confidentiality. Apart from signing the consent form for participation, every member of the focus groups was asked to sign the "Group Agreement for maintaining confidentiality" to indicate that they agreed not to talk about any information from the interview (including names of other members) with anyone outside of their focus group and the researcher. This procedure made participants uneasy as they believed that mutual trust among participants does not need building by signing an agreement like people do with their business. They felt reluctant because they thought people sign such an agreement only when they don't trust each other. I had to explain to them that this procedure was not used as a means to build or guarantee "mutual trust" among participants; it was just a research procedure that allowed participants an opportunity to have a second thought about issues of confidentiality before joining the focus group; thereby ensuring confidentiality. The enforcement of this agreement was then acknowledged by all focus group participants and their signatures were eventually obtained willingly.

Last but not least, I believe that the thoughts and experiences that participants were willing to share with me are worthy. On completion of the study, I sent each participant a letter expressing my appreciation for their contributions. I believe that "ethical 
researchers" should do that kind of acknowledgement to show the utmost respect for the participants.

In summary, no perfect checklist can be relied on to guide all aspects of fieldwork. My lesson from the fieldwork is that everything, either positive or negative, can happen during the process of fieldwork. Hence, researchers should have a good sense so as to take full advantage of any available opportunities. Researchers should not forget to anticipate any problems or challenges that might happen during the research process and need to remain flexible and creative during the fieldwork. I agree with Lareau (2000) who stated that going into the field means learning to live with uncertainty, ambiguity, and confusion.

\section{Piloting interview questions and questionnaires}

All interview questions and questionnaires in my research were originally developed in English. They were then translated into Vietnamese language because the data collection process was conducted in schools where all research participants use Vietnamese as their mother tongue. My intention was to test the comprehensibility of interview questions and questionnaires. To ensure all translation versions of interview questions and questionnaires were comprehensible and incorporated a natural use of language, I sent the interview questions and questionnaires in both English and Vietnamese to five colleagues, who were teachers of English in Vietnam to check and provide feedback. A meeting with the five teachers was organised in order to discuss their feedback. The results suggested that some changes had to be made in order to make the translated versions easier to understand. For example, changes were made to several concepts such as "authority", "interpersonal skills", "hierarchical structure", "collectivism", and "individualism". These were technical and ambiguous for participants when they were translated into Vietnamese. My colleagues also suggested that these concepts could be defined or explained to participants before the questions were asked. In this way, the participants could keep track of the meaning of a question to have a direct answer, rather than wasting time elucidating the meaning of these technical concepts. 


\section{Methods of data collection}

\section{Triangulation and validity issues}

To restate, this phenomenological study investigated the influence of Confucianism on school leadership in the Vietnamese context. My primary research question was "How is Vietnamese school leadership influenced by Confucian values?" A number of methods of data collection were employed in order to capture rich descriptions of phenomenon and its settings. In the phenomenological investigation the interview was the main method through which data was collected (Moustakas, 1994). Other methods were also combined in order to strengthen and improve internal validity (Burns, 2000). It was the triangulation technique. When I carried out this research, triangulation was seriously taken into consideration. There were two kinds of triangulation. The first was "data triangulation", in which data were collected from three different kinds of informants (principals, vice-principals and teachers). The second was "method triangulation" in which four different methods of data collection were used to collect data (Burns, 2000). Through triangulation, the research design was strengthened (Burns, 2000; Patton, 1990, 2002; Yin, 2009). Patton (2002) illustrates the term 'triangulation' with a picture in which a man is using a fishing line with three hooks to catch a fish. This implies that researchers could have more opportunities to access the 'phenomenon' that they would like to study if they apply multi-methods of data collection. Triangulation was used in order to "contribute to verification and validation of qualitative analysis by: checking the consistence of findings generated by different data collection methods; and checking the consistency of different data sources within the same method" (Burns, 2000, p. 419). Let us look at the following tale which appears to support the triangulation technique: Four fortune-tellers were describing an elephant on the street. The first one touched the elephant's trunk then he said, “The elephant looks like a big leech". The second touched its leg then he claimed, "The elephant looks like a big pillar". The third touched its tail then he described, "The elephant looks like a big broom". The last fortune-teller touched its ear then he affirmed, "The elephant looks like a big paper fan". This tale implies that if the four fortune tellers knew how to combine all parts of the elephant they touched, they could have had a more perfect picture of the elephant. 
The four main methods of data collection used in my research were interviews, questionnaires, observations, and documentation. By using a combination of multimethods of data collection, I was able to use different data sources to validate and crosscheck findings (Patton, 2002). Moreover, using a combination of data types increased validity as the strengths of one approach can compensate for the weaknesses of another approach (Patton, 1990). Each type or source of data has strengths and weaknesses; no single source has a complete advantage over all the others (Burns, 2000; Patton 1990, 2002; Yin, 2009). The four methods of data collection used in this study are described in the next section.

\section{Interviews}

\section{Purpose of the interviews}

The most important data collection method I used was the interview. Patton (2002) points out a pertinent rationale for why we use interviews as an effective method of data collection:

...[W]e cannot observe everything. We cannot observe feelings, thoughts, and intentions. We cannot observe behaviours that took place at some previous point in time. We cannot observe situations that preclude the presence of an observer. We cannot observe how people have organized the world and the meanings they attach to what goes on in the world. We have to ask people questions about those things. (p. 341)

Yin (2009) claims that the interview is one of the most important sources of information. It requires the researcher to operate on two levels at the same time: satisfying the needs of the line of inquiry while simultaneously putting forth friendly and non-threatening questions in open-ended interviews. In phenomenological study, the interview is the best way to collect data, especially semi-structured interviews (sometimes called "semistandardised interviews") with open-ended questions (Smith \& Osborn, 2003). This form of interviewing is important in phenomenological study because it allows the researcher and participants to engage in a dialogue whereby initial questions are modified in the light of the participant's responses. The researcher is permitted to probe interesting and important areas which arise (Berg, 2004; Smith \& Osborn, 2003). In this 
study, all types of interviews designed were based on the format of a semi-structured interview.

\section{Types of interviews}

Three types of interviews were employed in this study: individual combined interviews, individual semi-structured interviews and focus group interviews.

Individual combined interview approach: This approach was applied with the purpose of offering the researcher flexibility in probing and in determining when it was appropriate to explore information in greater depth, or even to pose questions about new areas of inquiry that were not originally anticipated in the interview instrument's development (Patton, 2002). Each principal participant was interviewed in the following manner:

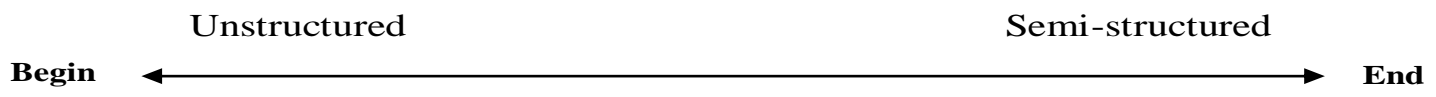

The interview started with an informal conversation and was then followed by a semistructured engagement. This design aimed to elicit as much information about the background or biography of each principal participant as possible by using informal conversations at the beginning of the interview. This information helped the researcher identify how the principal had established his/her own social values and beliefs through his/her life. The interview process was gradually turned into a semi-structured format, which was conducted under the guidance of a set of the pre-formulated questions focusing on the research inquiry. Each interview took up to approximately one hour and a half (see Appendix 7).

Semi-structured interviews: These were used to gather data from vice-principal participants. To avoid questions being insufficiently comprehensive to elicit from participants, semi-structured interviews were used. This allowed the researcher to ask each vice-principal participant questions in a systematic and consistent order and also gave the researcher freedom to digress with the purpose of getting additional information (Berg, 2004). Each semi-structured interview took up to around one hour and a half (see Appendix 8). 
Focus group interviews: The focus group interview was employed to gather data from teacher participants. Focus group interviews were used as a means for a sort of bracketing of discussion topics in this phenomenological study. In bracketing, people hold some phenomenon up for close and careful inspection. It is removed from the natural world where it occurs and is then examined. Discussions and interactions among participants under the guidelines of the moderator (the researcher) aimed to unmask, define, and determine the phenomenon's basic elements and essential structure (Berg, 2004).

According to Patton (2002), the focus group interview is neither a problem-solving session nor a discussion. It is an interview. In a sense, I did not seek any kind of consensus nor disagreement from participants. Focus group interviews were employed in this study for these reasons. Conducting a focus group interview was not only to elicit information by asking participants questions but giving participants chance to hear each other's responses and to make additional comments in further response (Patton, 2002). Applying a focus group interview could significantly increase the sample size of teacher participants in comparison with conducting the individual interview. In a given amount of time, I could gather information from a number of people instead of from only one (Patton, 2002). Applying this method costs less and was more likely to obtain richer data due to interactions among participants (Flick, 2002; Patton, 2002) (see Appendix 9).

\section{Interview procedures}

Interviews with the school leader participants: There were three principals and four vice-principals that were invited to participate in this research.

Prior to the interviews, I arranged an informal meeting with each school leader participant to discuss the general issues concerning my research such as the interview process, and issues of confidentiality and anonymity. The meeting provided a good chance to provide them with further information about the research. The rapport between the researcher and the school leader was established through "marginal conversations" about our life, families and also issues about Vietnamese education that concerned the school leader. During these meetings, the school leader participants shared general 
information about teaching and learning activities in their schools as well as their beliefs about Vietnamese education ideology. The information obtained during the meetings was also valuable data that could be used for the research.

My original intention was not to distribute the interview questions prior to the interviews. However, the school leader participants suggested that they should have them to know what exactly they would be asked so that they could brainstorm the ideas and prepare answers. All interview questions were distributed to them before the interviews were conducted. Their feedback showed that reading questions some days before the interview helped them feel more confident in taking part in the interview and their answers were deeper and "on track".

Appointments with school leader participants for interviews were a big concern for me because they all had busy schedules during my fieldwork. I had to cancel the interview with the School B principal six times. Some appointments were made for an interview on a Sunday given how occupied they were. The School A principal promised to have an interview with me before the Tet holiday, but the interview was delayed one month until after the Tet holiday. Only the interviews with the School C principal and other viceprincipals took place as they were scheduled. Selecting a location for an interview with a school leader was also a problem. I expected that the best location for an interview should be a place where the interview could be carried out without interruption as far as possible. All school leader participants preferred their own offices for interviews where (as they said) they felt most comfortable. I accepted their suggestions although I understood that a school leader's office was not a best choice for conducting an interview because the interview process might be interrupted at any time by the noise from playing children in the school yard or noise from door-knocking of an unexpected visitor. In terms of ethical dimensions, a researcher has to make sure that the location of the interview is somewhere the participant feels most comfortable (Berg, 2004). In some interviews, the process was interrupted by the office telephone ringing or by a staff member who came to report something to the school leader. In these cases, I had to pause the audio-recorder and wait a little while until the school leaders felt ready to be interviewed again. 
The interviews always started with an "ice-breaker activity" in which I spent some minutes chatting with participants such as talking about our daily life, our families or discussing a piece of "hot news" of the day. This activity was to set the participants at easy and establish a warm and comfortable rapport. The interview then followed by protocol and procedures that were described in the previous section: Types of interviews (individual combined interview approach for interviews with principal participants and semi-structured interviews for interviews with vice-principal participants). All interviews were recorded using a digital voice recorder. Each interview file was then copied and stored on my laptop with its own information for identification. All files were secured in a password-protected folder.

Interviews with teacher participants: There were six teacher participants invited for the focus group interview from each case. Before conducting the focus group interview, I had a general meeting with all teacher participants from each school to answer any questions that they may have about the research process. During this time I talked about the general nature of the interviewing process and how the interviews were going to be conducted. These discussions covered areas of confidentiality and anonymity, the motives and intentions of the researcher and how the information would be used. The five ethical issues were mentioned during these discussions, including: promises and reciprocity; risk assessment; confidentiality; informed consent; and data access and ownership (see Patton, 2002). Other issues discussed included time arrangement for the interviews, method of recording the interviews and interview locations.

During the discussions, I suggested to the participants that they could make decisions to choose time and locations for the interviews whenever or wherever they felt most comfortable. All teachers preferred Sunday because many them had classes during the week. They discussed two kinds of locations for the interviews: at school and in a coffee shop. All teachers agreed that the interviews could be held in a quiet coffee shop where they would feel at ease and therefore more comfortable to have a "talk" (They preferred using "talk" to "interview" because "interview" seemed to be more serious). Whereas, the interviews conducted at school, according to them, would not be good enough for recording purposes because of the noise from children. 
One or two days before conducting an interview, I phoned all participants to confirm the time for the interview. This was important because the focus group interview depended on the availability of each individual participant. If someone was absent, the interview could not be conducted. In School A, the schedule of the focus group interview had to be changed three times. In School B, the schedule had to be changed two times. This was because some participants were busy and had assignments which came unexpectedly.

Similar to school leader participants, all teacher participants suggested that the interview questions be given to participants before the interview. The focus group interview questions were sent to all teacher participants one week prior to the interviews. Three focus group interviews took place in a reserved private 8-square metre room of a quiet coffee shop where participants could enjoy a cup of coffee or fruit juice while talking about their own stories or asking about their families before the interview. Doing this helped the participants and the researcher feel more relaxed as well as establishing rapport and trust.

Unlike focus groups conducted in market research (normally in marketing research), the teacher participants in these groups knew each other well as they work together in the same school. The advantage was that I did not need to spend time building rapport among them or doing an "introductory activity" to break the ice before starting the interview. Their familiarity with one another made the process more open, comfortable and affable.

The control of the interviews was well maintained. I played the dual-role of an interviewer and a moderator. The interviewer asked the questions; the moderator helped the interview run smoothly. One of the most difficult tasks for my role as moderator was that I had to control dominating respondents or keep the discussion moving in the right direction while simultaneously encouraging passive group members. This was accomplished without the embarrassment of completely shutting down dominating participants. I used appropriate verbal and nonverbal feedback to the person being interviewed. For example, I used verbal feedback such as 'tell me more', 'what else?' 'yeah', 'yes' or gestures such as a 'nod', or a 'smile'. By doing this, the interviewee 
could be encouraged and motivated and he/she would know that I was interested in listening to him/her.

The interviews took on average 90 minutes and were recorded. Each interview file was then copied and stored on my laptop with its own information for identification. All files were secured in a password-protected folder.

\section{Questionnaires}

\section{Purpose of the questionnaires}

Questionnaires were employed in conjunction with the focus group interviews to gather more information from teacher participants. I wanted to explore teachers' perspectives about the research topic but focused on the issues that could be "sensitive" if discussed in the focus group interviews in which mixed-gender participants joined together. I anticipated that these issues could make the teacher participant reluctant to participate in discussion or the participants would not be willing enough to expose their candid thoughts. Using questionnaires appeared to be the solution to this problem. Teachers felt free and more comfortable about answering "sensitive" questions when they were on their own with the questionnaires. The respondents could complete the questionnaires at their convenience and offered greater assurance of anonymity. The purpose of the questionnaires in this study was different to the purpose for which questionnaires are used in survey methods. The questionnaires were designed with open-ended questions in order to supply a frame of reference for respondents' answers, coupled with a minimum

of restraint on their expression. Respondents felt unrestricted in both the content and manner of their reply. Open-ended questions were used to facilitate a richness, depth, honesty, authenticity and intensity of response (Burns, 2000; Cohen et al., 2001).

\section{Design of questionnaires}

The questionnaires were designed to explore the four main pre-defined themes of the research (see Appendix 10). The questions in the questionnaires specifically focused on the issues of gender, building relationships with school leaders and ineffective leadership in terms of influential cultural factors, which I anticipated might not be 
suitable for discussion in the focus group interviews. Each questionnaire included 9 open-ended questions. I was aware that the size of the questionnaire was important. The smaller the size of questionnaire, the more likely it was to be completed (Sarantakos, 1998).

The questionnaires were carefully typed and enveloped. Each questionnaire was provided sufficient space for recording the respondent's answer. The questionnaires included the researcher's phone number and the suggestion: "If you have any questions about the questionnaire, please contact me at..." In case teachers were not sure about the questionnaire, they could contact me to ask for an explanation. The questionnaires were disseminated after the completion of focus group interviews. Teacher participants were also asked to discuss the "due date" for completing the questionnaires. They all agreed that they should have at least 10 days to complete them. The questionnaire was designed to take approximately one hour to complete.

\section{Method and result of return}

Each teacher participant was provided a stamped addressed envelope with which to return the questionnaire when they had completed it. I also suggested that if they were "lazy" mailing them, I would be willing to come to their school to pick up the questionnaires. Eighteen questionnaires were distributed and the response rate was $100 \%$. The feedback from the participants indicates that the size of the questionnaire was adequate, not too large, nor too small. It took the respondents approximately one hour to complete. However, some questions in returned questionnaires were not answered. The respondents explained that some issues had already been discussed in the focus group interview; hence, they did not need to re-mention them in the questionnaires. Their feedback also indicated that respondents preferred multiple-choice questionnaires to questionnaires with open-ended questions, which took time and made them "rack their brains" to answer. 


\section{Observations}

\section{Purpose of the observations}

As a method for data collection, observing allows for better understanding of the context of a study. This is achieved through the following: by permitting the researcher to see things that interviews and documents do not show (allowing triangulation and thus increasing reliability); by providing the researcher with direct experience and potential access to personal knowledge; and by allowing the researcher to examine relevant behaviours and environmental considerations (Moyles, 2007; Patton, 2002; Yin, 2009).

Observation helps the researcher better able to understand the context in which his or her interest is being explored. He or she has the opportunity to see things that no one has ever really paid attention to. In reality, there are things that may routinely escape awareness among the people in the setting. Patton (2002) explains that "participants in those routines may take them so much for granted that they cease to be aware of important nuances that are apparent only to an observer who has not become fully immersed in those routines" (p. 263). Observation offers first-hand information/data when respondents are unable to provide it.

There are, however, some limitations to the observation approach that have also been recognised as follows:

- The observer may affect the situation being observed in unknown ways;

- Observations are limited focusing only on external behaviours;

- The limited sample of the programme activities may affect the observational data (Patton, 2002).

When researchers make decisions about what to observe, they first need to be clear about what their purposes are (Moyles, 2007). The purpose of applying the observation approach was particularly to collect and describe how school leadership activities were actively occurring. School leadership is an observable phenomenon in which leadership activities can occur at any moment when interactions amongst people within a school 
take place. As Gardner (2007) states, leadership is a two-way communication process. I assumed that leadership might be reflected in people's behaviours (nonverbal and verbal), formal and informal activities, working lives, and everyday communication within a school case. The observational approach grasped the interactional setting (e.g. the interactions that are taking place, formal, informal, planned, unplanned, verbal, nonverbal) that took place within the case. Furthermore, the observational approach was used to collect enough information/data for the physical setting of the case (the physical environment and its organization). In a case study, the holistic image of a case should be built with the employment of direct observation to describe what is going on within a case. Morrison (1993) argues that with the employment of observation "not only will the salient features of the situation emerge and present themselves but a more holistic view will be gathered of the interrelationships of factors" (p. 88). Observation also aimed to facilitate the generation of "thick description" (Cohen et al., 2001) which is considered a feature of the phenomenological study (see Appendix 11).

\section{Method of the observation}

The use of observation can be described in three terms: direct, semi-structured and nonparticipant. Direct observation is described as the process in which observation involves the subject that was being studied (Sarantakos, 1998), such as observations of meetings, sidewalk activities, classrooms and school sites. Direct observations were made through a field visit, including any occasions during which other evidence was being collected, such as an interview or an informal conversation with participants (Yin, 2009).

Semi-structured observation is described as a process in which an agenda of issues are pre-defined but data are gathered to illuminate these issues in a far less pre-determined or systematic way (Cohen et al., 2000). In my research, four pre-defined themes of school leadership (as discussed earlier) and two main variables of observation (discussed in the next section) were selected for observation approach. Observation categories were not defined in advance. I did not pre-determine what kind of communication or behaviour was to be observed. Semi-structured observations were for the collection of data that reflected the nuances of school leadership but focused on the research topic. 
Non-participant observation was employed in order to influence the flow of observed events as little as possible. I was an observer who was not part of the environment I studied. I was "invisible, unnoticed and outside" the group I observed (Sarantakos, 1998). It is argued that being observed can make people self-conscious and generate anxiety or stress. People may behave differently under conditions where an observation is taking place (Patton, 2002). To avoid or limit the "reactions to being observed", the non-participant observation, known as a measure made without the knowledge of the people being observed, was used as a strategic method.

\section{Variables of observation}

Two main variables of observation employed in my research included school meeting observations and school site observations. I observed school meetings for the following reasons:

- The school meeting was an event gathering people to disseminate information or discuss plans, strategies or find solutions for a problem. It was an ideal environment for me to investigate the variables of leadership such as power and the negotiation process, decision-making, and planning process through people's interactions and communication during the meeting;

- Time for school meetings was always pre-scheduled and I did not need to negotiate or arrange time with participants.

School site observations captured information pertaining to the live reality of the physical setting of each case school. It was also used to obtain relevant data reflecting the meanings of school leadership exposed to the researcher through people's conversations and behaviours taking place in any situations at a place of work, such as in the waiting room, in the principal's office, in the school yard or in a meeting room. 


\section{Procedures of observation}

\section{School meeting observations}

Meeting observations were used after I had asked the principal in each case for permission. Gaining access to school meetings was challenging even though I had good relationships with gatekeepers who play a key role in either granting or denying access. The school meeting was a place where "internal issues" are often addressed and discussed; its content, hence, needs to be kept confidential within school.

In School A, I asked the school authorities for permission to conduct observations in three school meetings. They allowed me to attend school meetings whenever the meetings were available and whenever the school meetings were suitable for my research schedules. I had four sessions of school meeting observation in this case.

In School B, I had planned to observe four school meetings. However, I was only allowed to attend two school meetings for observation. The school authorities explained that the school leaders and staff might not feel comfortable with the presence of a "stranger" in all their meetings. In addition, the meeting, such as the Principal Board meeting, was not to include someone else except for its members. Some meetings were held for "private purpose", so its content needed to remain confidential.

In School C, I was offered permission to attend one school meeting although seven meetings were held during my fieldwork in this case. The same reasons were explained as in School B. A school meeting observation took approximately 90 to 150 minutes, on average.

\section{School site observations}

The school site observations were aimed at collecting data for physical setting of each case as well as looking at the various aspects of daily working lives within a case, which were expected to expose the nuances of school leadership to the researcher. I observed people's interaction (including communications and behaviours) in both informal and formal situations such as in a waiting room, the school leader's office, or school yard. 
An observation took me approximately 120 to 150 minutes on average and five observations were conducted in each case.

\section{Methods of recording data}

Taking detailed notes on observed events or the observed's words is important in observational method. Maykut and Morehouse (1994) highlighted the importance of field notes that "the keen observations and important conversations one has in the field cannot be fully utilized in a rigorous analysis of the data unless they are written down" (p. 73). Gray (2009) argues that one way of reducing the unreliability of the observational method is to record the observed events in some way so that the data can be reviewed or re-interpreted. Taking field notes is important because it reduces the danger of human error in the recall of events. To that end, I kept a research diary to take detailed field notes during or after the observations to keep observational information correct and "fresh". I took detailed notes during the school meeting observation or during activities if the activity permitted, while at other times I waited until afterwards to record notes such as after an informal conversation with school leaders or teachers in the meeting room. Field notes contained the basic information about the event or situation, when and where the observation took place, who was present, what social interactions occurred and what activities took place. I also took notes on what people said as well as their responses in formal and informal conversations. The research diary included analytical memos, or end-of-a-field day summary, which contained my own feelings, reactions to the experience, reflections about the personal meaning and progress reviews. In phenomenology, taking field notes (keeping a research diary or log writing in Van Manen's words) is important because it is the process of phenomenological reflection, the purpose of which is to try to grasp the essential meaning of phenomena. It is also a

source that contains reflective accounts of human experiences that are of phenomenological value (Van Manen, 2006). 


\section{Documents}

\section{Accessing documentary sources}

The final data sources for this study were documents. In my research, documents were collected as secondary sources, which were done in conjunction with other methods discussed earlier in this chapter.

The three main kinds of "open" documents collected during the research process were annual school reports, school disciplines and regulations, and school working statutes. These documents were regarded as open sources because they were open to all school staff and student and school members. Although I expected to collect "personal" documents for analysis, they were not open for accessing, such as school leaders' working diaries and school decisions. When I asked school leaders for permission to access these "closed" or "restricted" documents, they hesitated to provide these as they were personal documents. They were surprised because of my research-purposed requirement as it was the first time they had been asked to provide their daily working diaries which they regarded as "very personal documents". However, the school leaders were very willing to help me collect the "open" documents. Official workers were asked to prepare the original documents before I had them copied.

Annual school reports were collected as they are expected to reveal the main school activities and achievements of the year which might reflect the cultural aspects and to a certain extent expose the meanings of school leadership. They were also expected to provide enough data for "thick description" for the case background.

\section{Qualitative data management and analysis}

Qualitative studies tend to produce large amounts of data that are not ready for analysis until they are condensed and made systematically comparable (Berg, 2001; Yin, 2009). Qualitative fieldwork in the three schools, which included 10 recorded interviews (individual and focus-groups), inevitably yielded a large amount of data in the form of field notes, questionnaires, and the collected documents, all of these sources of data made me enormously confused the first time I had access to them. Managing the data 
properly would help me to "get a sense of the whole" (Patton, 2002, p. 440) for the data analysis process and also ensure the validity and rigour of the research.

In this study, data from interviews and questionnaires were expected to provide the main sources of data with in-depth information, covering the four pre-defined themes. Facts and incidents obtained from observations were used as a complementary data source to provide the background information of case settings and to examine theme 1 (exercising power), theme 2 (building relationships) and theme 4 (decision-making). Data obtained from documents were used as a complementary source to provide background information of case settings and to examine theme 3 (problem-solving) and theme 3 (decision-making).

The raw data from various sources for each of the cases was assembled separately to establish a case story. All recorded interviews were translated by myself as I understood that doing my own interview transcriptions (instead of having them done by someone else) provided me an opportunity to become familiarised with the data and an experience to generate emergent insights (Patton, 2002). The transcriptions and data from the other sources were translated from Vietnamese into English.

For the process of single case analysis, a case database was constructed for each case, allowing for data to be organised, classified, edited, and coded into a manageable and accessible file with the help of the NVivo 8 software program. In this way, I was able to gather comprehensive, systemetic and in-depth information about each case. Once a complete case database had been loaded into Nvivo 8, the data were then coded under four main different nodes, namely "exercising power", "building relationships", "decision-making", and "conflict managing and solving". Within each main node, subnotes were created as presenting the themes and categories that emerge from the data of each source. A diagramatical representation of the process is as follows: 


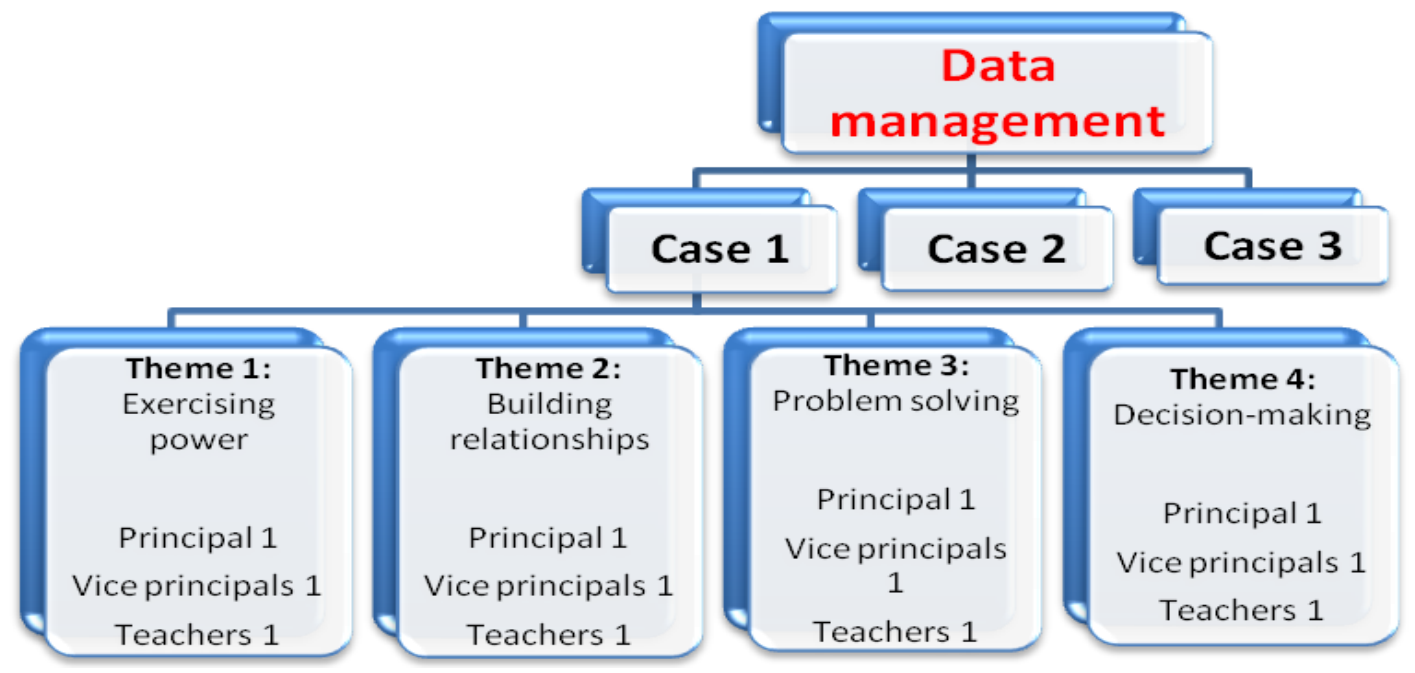

Figure 3: Process of data management

Each case study was then analysed independently of the other cases in order to preserve the distinctiveness and holistic entity of each case before cross-case comparisons were made.

As stated at the outset, this study adopted phenemenology as a research framework. Hence, phenomenological analysis was undertaken to grasp and elucidate the meanings and essence of the phenomenon of each case. The process of phenomenological analysis involved a "structural description" that contains the "bones" of the experience for the whole group of people (Patton, 2002). The four primary steps of phenomenological analysis (discussed in the Chapter IV) adopted from Patton (2002) and Moustakas (1994) were undertaken. These four steps can be summarised as follows:

1. Epoche: In this process, I repeatedly read the database of each case to achieve a sense of the whole, then identified and catergorised data aspects into four pre-defined themes.

2. Phenomenological reduction: I re-read the raw data and identified relevant meanings from irrelevant meanings. This was a critical phase of explicating the data to illuminate the research focus (researched phenomenon) by coding into 
free nodes (nodes reflecting the research meaning but I was not sure what that might be at that stage) with the help of Nvivo 8 program.

3. Imaginative variation: I identified the data obtained from various sources and categorised them into the four invariant pre-defined themes (see Figure 3) by re-examining the free nodes to identify the "units of significance", and then coding into tree nodes via the four pre-defined themes.

4. Sysnthesis of texture and structure: I paid close attention to the cluster of meanings within each pre-defined theme to elicit the essence of phenomenon. This process involved an integration of structural descriptions, providing a synthesis of the meanings and essences of the phenomena of each case.

Cross-case analysis was made after the findings of each case had been represented and understood. Cross-case analysis was aimed at examining and comparing cases by themes and patterns in order to seek commonality and dissimilarity.

\section{Summary}

In this chapter I have mapped out the theoretical assumptions and discussed the issues that flowed from the process of identifying the beliefs that underlay the choice of methodology. Interpretivism and phenomenological perspectives were chosen as the lens through which the data analyses and discussions of the research findings were viewed. A phenomenological research approach uses relatively unstructured methods of data collection because of its emphasis on details rather than on making more general claims. In this respect, the questions of this phenomenological research were broadly and openly-oriented. This was because this research was not aimed at testing a predetermined hypothesis; rather, the aim was to explain, to describe and to explore the area of concern flexibly and in detail (Smith \& Osborn, 2003). To restate, this research laid an emphasis on "how" rather than to confirm "what" with regards to the phenomenon of the "impacts of Confucian values on school leadership". Furthermore, a qualitative methodology approach was considered as the best choice for data collection as this research aimed to study the phenomenon of Confucianism and school leadership in detail rather than make standardized and systematic comparisons and accounts of 
variance. In other words, the use of the qualitative approach in this research was intentional to produce "thick" rather than "thin" descriptions. The triangulation of data was purposely utilised to improve the internal validity, including "data triangulation" (data collected from different kinds of informants) and "method triangulation (data collected from different methods of data collection).

The next chapter presents the data description within-case. 


\section{CHAPTER FIVE: CASE DESCRIPTION}

\section{Introduction}

In this chapter, I describe the data from mixed data sources, including interviews, questionnaires, observations and documents, from phenomenological perspective. The data description is presented within each case by the four pre-defined themes in order to capture the distinctive features of each case and gather enough data for the comparative analysis in the next chapter. The data of each case will be presented in the following structure: (1) The background of the school; (2) Leader participants; (3) Exercising power and authority; (4) Building relationship; (5) Decision-making; and (6) Managing and solving conflict.

\section{School A}

\section{Background of school: A reflection on power and administration structure}

This school was located on the outskirts of the city where I lived and worked. It had a history of over 50 years of development. It was first established as a teacher training high school which primarily functioned to train teachers for primary schools, supplementing the shortage of teaching staff for local schools during the war time (Vietnam-America war). After peace restoration in $1975,{ }^{6}$ the school continued its educational mission of training primary school teachers and pre-school teachers for the locality (See Appendix 1). Only local students were enrolled and they were required to attend the two-year fulltime course for their graduation. The school was then upgraded to a teacher training college in 1997 to meet the educational development needs of the province.

The school served as a multi-disciplinary college with the functions of training teachers for pre-school, primary and secondary schools and other educational sectors. It also provided refresher courses to managerial staffs at all levels from nursery to primary

\footnotetext{
${ }^{6}$ The Vietnam War is known as a prolonged struggle between nationalist forces attempting to unify the country of Vietnam under a communist government and the United States (with the aid of the South Vietnamese). Vietnam was reunited as a communist country (the Socialist Republic of Vietnam) when South Vietnam officially surrendered to communist North Vietnam on April 30, 1975.
} 
schools as well as conducting research for the socio-economic development of the locality. Depending on which types of degree programme that students pursue, they were required to complete a junior college programme (chuơng trinh trung cấp) or a college programme (chuoong trìh cao đẳng). The junior college programmes required two years of study and led to a Junior College Diploma, whereas students were required to spend three years to complete a college programme and granted an Associate Degree. Short-term training courses (chuyên tu) for students who had completed two years of junior college education were also offered. Annually, there were approximately 2000 students enrolled in full-time and in-service courses. There were over 150 teachers and school staff working full time with females accounting for over $57 \%$. Over $53 \%$ of the teachers obtained their $\mathrm{PhD}$ and MA degrees.

This school belonged to the national tertiary educational system. It was under the direct administrative management of the Provincial People's Committee (PPC- Ủy Ban Nhân Dân Tỉnh) in terms of personnel affairs and socio-political activities, whereas its professional activities were under the state management of the Ministry of Education and Training (MOET). The distinctive division of administrative management and state management is clearly stated in Article 4 of The Statute of Colleges (issued on 28 May, 2009 by Vietnam MOET). Accordingly, MOET was the competent authority that had the power to make decisions over establishing or dissolving a college. MOET was authorized to manage professional activities and teaching and learning quality of the college, in which all training programmes adopted in the college must be developed according to the general curriculum framework recognized and promulgated by MOET. The number of annual enrollments were determined and approved by MOET.

The PPC was authorised to manage the school in terms of personnel affairs and sociopolitical activities. The number of employees (school workforce) of the school was approved by PPC and all members of the Principal Board (including principal and viceprincipals) were decided and assigned by the Chairman of PPC.

The school had 17 different functional units, including six departments, seven faculties, three professional divisions (tổ chuyên môn), and an informatics-language center (ILC), all of which were under the direct political leadership of the Standing Board of the 
School Communist Party Committee (Đảng ủy - CPCO Standing Board) and the administrative management of the Principal Board (see Figure 4).

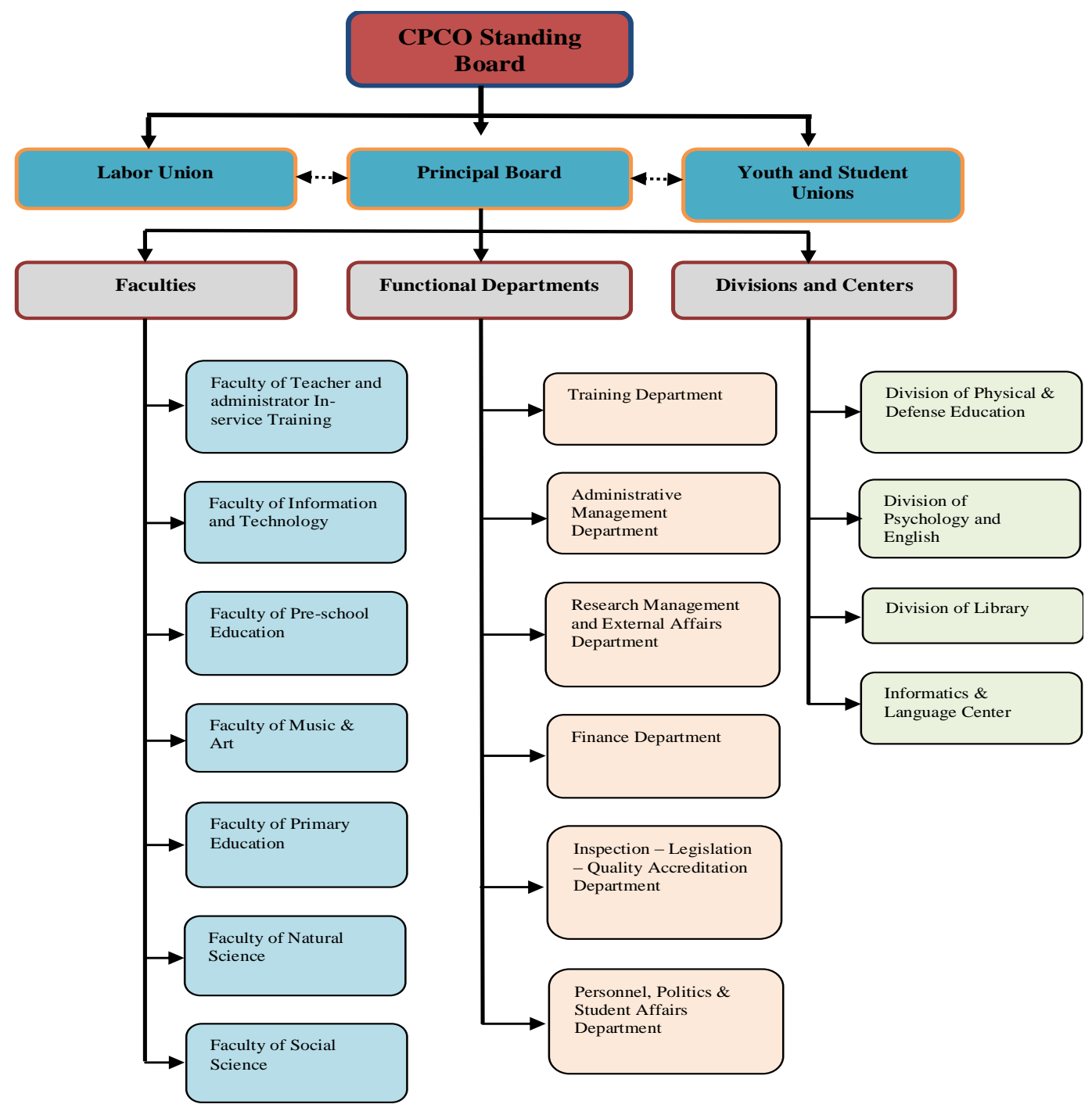

Figure 4: The Power and Management Structure of School A (source: The college's administrative information)

CPCO (Đảng bộ) was considered a supreme political organ in the school. Its membership included all school communist party members. Although acting as a political organization, its political leadership had a significant impact on all school activities, particularly on personnel affairs. The CPCO played an absolute political role in directing the school. All school members, with or without political affiliation, must 
obey and implement its policies and directives. The CPCO was led by the Standing Board whose members included a CPCO secretary, a vice-secretary and a commissioner. In this school, the principal (PC1) also held the position of the CPCO secretary, whereas the first vice-principal (VP1C1) was a vice-secretary and the second vice-principal (VP2C1 in this study) was in the position of the commissioner. With this political power structure, all members of the Principal Board played the "dual roles" and held all political and administrative power, in which the principal was the most powerful figure.

The School Labor Union was a socio-political organisation which was believed to represent the rights and interests of the cadres, teachers and officials, whereas, the Youth and Student Unions were the socio-political organizations representing the rights and interests of the students. These organizations were believed to have "independent roles" and were to "coordinate relations" with the Principal Board, but under the political direction of the CPCO. Despite this framework, in reality, these organizations were also under the direction of the Principal Board because of the "dual role" held by the principal and vice-principals (as explained above).

Since its foundation, the school has been through eight principal generations, in which seven male principals (87.5\%) and only one female principal (12.5\%) had been appointed. The percentage of females holding the positions of vice-principal were also relatively low: six vice-principals had been appointed, in which males accounted for $83.34 \%$ (five persons) and females accounted for only $16.66 \%$ (one person). The proportion of female participation in the Principal Board since its establishment accounted for $14.28 \%$ (See Table 8).

Table 8: Statistics of the Principal Board of the School A from its establishment up to the present (Source: The college's administrative documents)

\begin{tabular}{|l|c|c|c|c|}
\hline \multicolumn{1}{|c|}{ Positions } & Number & Female & Male & $\begin{array}{c}\text { Percentage of female } \\
\text { staff }\end{array}$ \\
\hline Principals & 8 & 1 & 7 & $12.5 \%$ \\
\hline Vice-principals & 6 & 1 & 5 & $16.66 \%$ \\
\hline Total & 14 & 2 & 12 & $14.28 \%$ \\
\hline
\end{tabular}


Although the proportion of females holding the current leadership positions in the Principal Board was quite high (66.66\%), the low percentage of female leaders could be found in the current lower administrative levels (See Table 9). With over 150 full-time working employees, of whom females accounted for approximately two-thirds, the number of women holding leadership position in all administrative levels made up only $35 \%$. However, this proportion was believed to be a "relatively high rate of female participation in leadership in comparison with other local schools" (PC1).

Table 9: The gender statistics of the current management staff of School A (Source: The college's administrative documents)

\begin{tabular}{|l|c|c|c|c|}
\hline \multicolumn{1}{|c|}{ Positions } & Number & Female & Male & $\begin{array}{c}\text { Percentage of female } \\
\text { management staff }\end{array}$ \\
\hline Principal Board & 3 & 2 & 1 & $66.66 \%$ \\
\hline $\begin{array}{l}\text { Leaders of faculties, } \\
\text { departments, } \\
\text { divisions, center }\end{array}$ & 17 & 5 & 12 \\
\hline Total & 20 & 7 & 13 & $29.41 \%$ \\
\hline
\end{tabular}

\section{Leader participants}

From the perspectives of the study participants, the term "school leader" only refers to those who were in the position of principal or vice-principal. In other words, the term was used to describe the members of the Principal Board who possessed the highest responsibilities and power in the school. The term did not refer to any other leadership positions in the school, such as the head of department or the dean of faculty.

In this school, all three members of the Principal Board were invited to participate in the research: a female principal, a female vice-principal, and a male vice-principal. The percentage of female school leaders of School A (66.66\%) was significantly higher in comparison with School B and School C, which accounted for $25 \%$ and $33.33 \%$ respectively. Their educational qualifications were also higher than their counterparts in 
School B and School $C^{7}$ (See the backgrounds of leader participants of School B and School C in the next section).

The female vice-principal (VP2C1) was the youngest among 14 school leaders since the school was established. She was appointed to vice-principal when she was in her late thirties. This appointment was known as a "breaking-through event" in personnel affairs of the school because during its history of establishment and over 50 years of development, no school leaders had been appointed before they reached their forties. The principal commented:

It proves that the (high-ranking) leaders have changed their leadership attitudes and increased their confidence to delegate more responsibility to the young generation. (PC1)

\section{Exercising power and authority}

The participants were asked how they perceived the concepts of power and authority before they were asked to discuss the school leaders' power exercise within their school context. The purpose of the question was to explore the participants' beliefs about school leadership which might be reflected in their own perceptions about power and authority. The data revealed how diverse participants perceived these concepts. Despite their different explanations for these terms, the participants had a common perception of power and authority. They believed that power and authority came with the position of a leader. However, power was deemed to be related to the personal competence and personality of a school leader, whereas authority was associated with the roles and responsibilities of a school leader and was clearly defined in the legitimate documents. Some of the participants explained their views as follows:

I see authority as "legitimized responsibilities" that a leader has to fulfill to lead a school, a state-run company or an organization. (VP2C1)

Authority is a kind of authorized power. I mean that it is your rights or duties which are defined by law or regulations of your school. (VP1C1)

Authority is a kind of duty of an individual. (C1FmT5)

\footnotetext{
${ }^{7}$ According to the Statute of College issued in 2009 by the MOET, a person who is in the position of the principal or vice-principal must have an MA degree or higher (Article $39 \& 42$ ).
} 
Authority is the right to which we are assigned to perform our tasks. (C1FmT4)

They believed that authority was constantly attached to the roles, responsibilities and position of a leader because, as PC1 explained, without authority, she could not perform her managerial tasks. The position of a leader was believed to provide legitimacy and to create the expectation that he/she was entitled to make certain decisions or to make an impact on teachers, students, and parents.

What participants saw as authority can also be referred to as legitimate power, one of the five distinct types of power, which as explained by French and Raven (1960), refers to the expectation of people for someone to be officially in charge. Even when formal leaders are not respected as individuals, others will tend to defer to them simply because the organization has granted them the right to make certain decisions. On this point, PC1 gave an example as follows:

I have the right to go to a class to check a teacher's work; find out how well he/she controls and manages the class, whether the students make a lot of noise or not. If I have no such rights, I cannot run the school. I cannot manage and lead the activities of the school in the right way to achieve to the defined goals. (PC1)

Participants also saw power as having a broader meaning, as follows:

Power exists along with your working position, your social position, your social status, your morality, your educational level and knowledge, your relationships with other people and so many other factors can bring you power. (VP1C1)

Power is closely related to some factors such as professional knowledge, morals, and even age. For example, a dean of a faculty will lose his leadership power and managerial ability if his/her professional knowledge is not highly acknowledged by his/her staff. In reality, a dean with a BA degree will encounter difficulty when giving a professional assessment to a lecturer with an MA. An educational degree might make a school leader more or less powerful. (VP2C1)

I mean there are many factors which bring power with them, such as your position, your gender, your social or academic knowledge. (C1FmT5)

I think the higher position he holds, the more power he has. Power depends on the position and status of an individual. (C1MT3)

Of course, in our society, the position or a social status of a person brings with it power. (C1MT3)

The term "power" mentioned by participants in school A was similar to the concept of "power over" as defined in Western literature. They emphasised power as something 
that leaders used to control and coerce subordinates to follow their instructions and directives in subordinates' playing of roles and duties. Participants saw power and authority as 'tools' that a school leader needed to have in his/her hands to manage, lead and run a school. They highlighted that a school leader without power or authority would not run or manage a school effectively. They saw school leaders as figures of authority and accepted this as a natural part of the society.

Data obtained from interviews and school site observations revealed that the power of a school leader was embedded in the values of the hierarchical system in the Vietnamese context. It was reflected in the way that people named the school leaders. Participants in school A called the school leaders "Thầy/Cô" (teacher) ${ }^{8}$ - even though they were their colleagues. Some older teachers called them "Anh/Chi" (older brother/older sister), ${ }^{9}$ even though these words were often used by a younger person to address someone older. This kind of language reflects the respect from followers towards their seniors. It reflected the way in which people took up the positions offered by the discourse as a natural structure of society. For the participants, the principal was unquestionably acknowledged as the most powerful figure in the school due to her managerial roles and responsibilities granted by the government and the Party. When asked about power sharing with the principal, two vice-principals affirmed the "supreme role" of the principal as follows:

The principal has the highest position in the school, so she has full power to make decisions. (VP1C1)

I have to obey the principal's decision and execute my managerial roles according to the task allocated by the principal. In certain cases, I can execute my managerial roles independently, but mostly I have to ask the principal's opinions for reference before making a managerial decision. (VP2C1)

From the above, it would seem that a "highly-expected obedience" was embedded in the leadership of this school. It appeared that this school was likely to highlight power as a kind of traditional power, used to oppress, prohibit, impose, and to coerce subordinates. Although teachers did not use the terms as categories of power in the educational literature, they described these in their answers about school leaders' exercising of

8 "Thầy/cô" (teacher) is used by students to call their teachers in everyday life.

9 "Anh" (for man) and "Chi?" (for woman) are used by younger people to address someone older. 
power. They stressed power as coercive in the ways school leaders managed the school. They accepted that school leaders must be ready to use power at their disposal to enforce policies that were essential to the school's mission.

School leaders admitted that discipline or punishment was never a pleasant task when executing their managerial roles especially in "sensitive situations" such as when dealing with older staff or with those who were tender-hearted or those with whom they had close relationships. At times, discipline needed to be undertaken so as to keep order for the school. As the principal explained:

I consider 'discipline' as a final solution to solve problems. In reality, conducting discipline on someone is not easy because we live in a very complicated web of relationships. But we have to carry it out to keep the disciplines and rules of the school. (PC1)

Teachers pointed out that abusing too much discipline when exercising power could produce constraints for the work climate. They admitted that discipline or punishment should be applied when an employee has constantly shown uncooperative attitudes or when an individual has not responded to the benefit of the school community. Teachers expressed that for reason of both fairness and benefit to the school community, school leaders had to exercise coercive power to deal with such situations.

The interviews and documents indicated that reward power was often used in school administration. Yearly, the school held meetings to select the "good teacher" or "good official" awards based on individual's annual achievements. A teacher who gained the title of 'good teacher' would be given an honor certificate and an amount of money as a reward. Participants stated that using reward power was a good managerial strategy of encouragement and motivation in leadership. As the vice-principal explained:

I think we work not only for earning money but for our fame also. We work and we wish our contribution and effort to be recognized by leaders and by our colleagues. When our effort is recognized and acknowledged by other people, we feel encouraged and motivated. Hence, I consider failing to gain the title of 'good teacher' as a kind of discipline. So during the school year, there are 'inexplicit competitions' among teachers and departments. (VP1C1)

When discussing the factors that might affect the process of exercising power, a significant factor from the data of School A was that "moral quality" was a very 
important factor. Both leaders and teachers believed that "moral quality" was a kind of power that was indispensable to the school leader and was integrated into the effectiveness management and leadership of the school. Participants also believed that high moral quality of a school leader significantly contributed to the school leader's success in managerial performance. A school leader's high standard of morality was considered the "number one" criterion for leadership promotion and delegation. Morality was even ranked higher than the criteria of competence and performance. In interviews, participants admitted that in Vietnamese culture, moral quality was deemed more important than other things, as shown below:

"Talent" or "professional ability" can be obtained through formal training and through education. And it may not take lots of time to train a person to "know how to work". But "moral quality" is not. It takes a long time for a person to cultivate his/herself to be a good person. It's difficult to change "bad manners" to "good manners". Training and educating a person to have good "moral quality" does not depend on other people's will. It depends on him/herself. (PC1)

In reality, some leaders are really good at management and leadership skills, but they don't obtain the admiration and respect from people because their moral quality is not highly appreciated. (VP2C1)

We always expect our leaders to set a good example for all staff. So the leader should show that he/she is righteous, generous and diligent. Without these moral standards, he/she cannot lead or can lead but ineffectively because he/she loses prestige. Misconduct of an individual is blamed not only for himself, but also on his parents. Misconduct of a leader is blamed not only for himself but also on his organisation. He sets a bad example for his employees. (C1MT3)

It appeared from the interview data that "moral quality" was the foremost factor when assessing a school leader or a leader-to-be. When asked about criteria for a leadership promotion, participants admitted that "moral quality" should be ranked first although they also expressed a strong preference for performance-based criteria for selecting a school leader. The principal explained:

"Moral quality" in our society is always placed first when assessing someone to be a leader. Nguyen Du said that "the heart/intention is worth three times that of talent". ${ }^{10}$ Like our ancestors, we now consider "moral quality" a characteristic of a person more important than his/her professional ability/quality. A man of great talent without moral quality means he lives and works for himself or for his family's interest, not for the organisation or society. "Morality" here means

\footnotetext{
${ }^{10}$ Nguyen Du is a famous Vietnamese poet (1766-1820). He is also known as a famous Confucianist. This saying is quoted from his epic poem The Tale of Kieu.
} 
someone is considerate, thoughtful, understanding other people. Someone scarifies his/her own interest to his/her organisation. People only support a leader who can bring the benefits to his/her organization and people in it. People "boycott" a leader who only looks after his/her own benefits. (PC1)

This participant continued:

If a leader has talent but the community believes that he/she cannot bring benefits to the organisation, he/she will have low confidence in the community. (PC1)

Why is "moral quality" so important in the process of exercising power? This question was raised to explore participants' social beliefs. In general, they agreed that "moral quality" was important for a school leader because it accompanied a leader's prestige. The prestige of a school leader comes from many different factors and a leader's prestige was inextricably linked with his/her moral quality. According to participants, to exercise power effectively, a leader should not only know how to lead and manage people with his/her managerial roles and responsibilities, but he/she should also know how to win his/her subordinates' hearts by his/her dignity and righteousness. Participants emphasised that the moral quality of a school leader always accompanied by the "power productivity" in which moral quality was in direct proportion to the power of a leader. As some of participants explained:

A good moral quality brings prestige to the school leader. If I have low moral quality, nobody will believe what I promise, what I sy to them and what I do. A leader's good moral quality goes with prestige. A school leader without good moral quality will not be able to lead people no matter how talented he/she is. (PC1)

A leader's power is in direct proportion to his/her professional and moral qualities. I mean, when one of these factors is not highly appreciated by subordinates, his/her power will be exercised ineffectively. (VP1C1)

A leader of good moral quality will receive much more respect from people than one of good specialist knowledge but his/her moral conduct is not highly appreciated by people. The first things that make staff have a liking for a leader are his/her dignity, personality or moral quality in general speaking.... It's not difficult for a leader to make his/her staff submissive, but it must be more difficult to make his/her staff respect and admire their leader. Ho Chi Minh said, "A man of talent without righteousness is useless, a man of righteousness without talent does whatever with difficulties". Ho Chi Minh's ideology was deeply influenced by Confucianism, so he always considered "talent and righteousness" as two standards for evaluating a person. But "righteousness" is always the first. (VP2C1)

Teachers affirmed that followers only listened to, looked up to or obeyed their principal when he/she had a good personality and dignity. They explained that to gain respect 
from followers or to exercise power effectively, school leaders must be ethical. This was important because subordinates wanted to be led or guided by those they respected and trusted.

All school leaders as well as teacher participants in School A asserted that being a good role model was very important for the effectiveness of exercising power and the leadership process. They explained that when the school leader served as a role model, he/she would inspire the followers to emulate what he/she was doing. According to the teachers, the important thing in being a role model was that "a leader must do what he says or what he promises to his followers" (VP1C1). Teachers explained that they admired leaders who were eloquent in their speeches. Participants emphasised that eloquent speeches from leaders were not nearly enough. They wanted to see the leaders' daily actions because they believed leaders' words and deeds must be consistent to determine how serious they really were about what they said and demonstrated how deeply they were committed to their beliefs.

Leaders and teachers believed setting a good example was an effective way to build trust with followers, to create the confidence in leadership for the school community and to stimulate followers to a greater awareness of the organizational mission and higher levels of performance. They argued that if the followers did not trust or lacked confidence in their leaders, then they were uninspired. Teachers emphasised that when they were deciding if they respected someone as a leader, they did not think about his/her attributes, rather, they observed what he/she did so that they could know who he/she really was.

Leaders admitted that school leaders had to convince their followers by setting good examples because the followers must not only hear what they were expected to do, but they also observed what their leaders did in real situations. The vice-principal gave the following example:

A leader cannot direct his employees to implement the movement of "building the cultural family" if he/she has a spoilt child or he/she has a bad marriage relationship. A leader who breaks the "law of family planning" cannot tell or expect his/her staff to follow and implement the family planning programme. (VP1C1) 
The interviews also revealed some other factors that participants believed to influence school leaders' exercising power:

- Leader's expertise and educational level: Participants said that they respected and admired leaders who had good qualifications or who achieved high educational levels. They agreed that a good qualification or a high educational level brought school leaders charisma and prestige. One of the teacher participants stated that: "a good qualification is a prerequisite for a person who wants to become a leader. Of course, it cannot be denied that the managerial competence of a leader in real situations is important; however, his/her qualification or educational level is important too because it demonstrates a leader's professional knowledge. I respect my principal because she has a $\mathrm{PhD}$ degree". Natural power was believed to come from a leader's expertise. Participants explained that teachers were more inclined to listen to leaders with deep knowledge and well-practiced skills. In contrast, teachers were likely to be disrespectful of the leader's authority (instructions or guides) if they believed their expertise was better than their leader's or if they obtained higher educational degrees than their leader. One of the school leaders admitted that he would feel less confident to give managerial instructions to teachers if teachers had higher qualifications than him.

- Leader's age and experience: These two factors were found to be intertwined. The interviews with participants suggested that the available subject position offered by the hierarchical structure of Vietnamese society offered aged and experienced people the right behavior, obligations, and possibilities for action. Teachers agreed that although "older leaders" might be less active and more conservative than "young leaders", teachers still preferred "older leaders" because they believed that the experience, wisdom, and maturity of older leaders can bring peace of mind for employees and they felt more secure under the leadership of "older leaders" than younger ones. Teachers explained that they felt easier to be submissive to instructions given by leaders who were older than themselves. In the same vein, when asked about difficulties that she had 
encountered in her work due to her young age, the VP2C1, the youngest leader participant in this school, admitted that her young age could be a disadvantage for her leadership in terms of exercising power. She explained: "It's more difficult to work with older staffs. I had the feeling, and I think other young leaders too, that I did not feel confident enough to exercise power over older staff, particularly with staff over 50. They are like my older brothers or sisters, or in some cases, their ages are quite similar to my parents' age, so we cannot behave the way we behave towards the younger staff. For example, I hesitate or avoid criticizing them even though their work is not as good as we leaders expect. We respect them because of their age, so we often yield (dêe dãi) to them. When we assess their teaching, we do not do as strictly as we do with younger teachers. Honestly, the age factor can affect my managerial psychology".

\section{Building relationships}

Interviews with participants indicated that they all recognized the importance of cultivating relationships. Leaders affirmed that building relationships was one of the most important managerial tasks. The most salient reason for building relationships was to build, maintain and foster the harmony and the solidarity for the school community. One of the leaders stated:

Lack of solidarity in people's relationships will spoil work or leads to a toxic working environment and poor productivity. I think that when disunity exists in the school community, it does reflect that the leaders are unsuccessful in fulfilling their managerial roles. (VP2C1)

Leaders revealed that they considered handling school's external relationships as being important as internal relationships. The hierarchical structure of vertical administration has not significantly changed the relationship between the school and state for several decades. In Vietnam, the education bureaucracy guaranteed government officials' power not only over education policy, but also other major areas such as school policy, internal management and deployment of human and financial resources. The school was not even authorised to determine the number of students in annual enrolment. Leaders revealed that senior government officials such as within MOET or the People's Committee officials played important roles in decision-making for short-term and long- 
term development plans for their school. Findings showed that leaders had a tendency to build and cultivate relationships with government officials for practical reasons, needs and benefits of the school. They believed that building and maintaining good external relationships with government was an investment essential for its support for school development in terms of both human and financial resources. In a formal conversation with her during the school site observation, the principal explained:

The school has recently received more attention and support from the MOET and local government. I think it is because the school plays a significant role in the local educational system and partly because we have built and maintained close relationships with government officials. (PC1)

As the interview responses indicated, school leaders highly emphasised their strict and faithful implementation of the central and local government policy with the purpose of cultivating their task-oriented relationships with the government. One of the viceprincipals remarked:

We hold a monthly school meeting to increase staff and teachers' awareness of the Party's resolutions and the government directives. (VP1C1)

Apart from cultivating relationships with government officials to enlist their support for school development, teachers revealed another reason why their leaders cultivated relationships with government officials, who were believed to "hold the political destiny of others". They believed cultivating close relationships with government officials was to ensure school leaders' career paths. As they explained, although the appointment of school leaders was based on specific criteria defined in legitimate documents such as moral quality, managerial capacity, and professional competence, having close relationships with local government officials was crucial because local government controlled the recruitment and appointment of school leaders.

School leaders expressed that creating and maintaining caring relationship webs between leaders and teachers and among teachers was regarded as an investment to facilitate school leadership. They highly valued various aspects of mutual relationships between leaders and subordinates, including respect, personal care and concern, trust, and confidence. They considered creating such a caring working environment as one of their major leadership concerns and their managerial responsibilities and it was seen as 
complementary to their management and leadership. The leaders admitted they did not have much time for cultivating relationships with teachers and staff because of their busy daily managerial work. However, they took full advantage of available occasions to show their care towards teachers and staff. For example, the principal often paid visits to teachers' and staff's private houses on the occasion of the Tet holiday (New Year holiday). She explained that her managerial work took her so much time that she did not have many chances to be close to her subordinates. Hence, the Tet holiday was a "perfect occasion to show a leader's care towards subordinates". The principal said:

I do the opposite. Other leaders might expect their teachers to visit them on this special occasion, but I prefer taking this occasion to visit my teachers. In this way, they are able to feel my care and concern about them. (PC1)

Two vice-principals also mentioned their other types of caring to build relationships with their subordinates, such as having frequent individual conversations with teachers or helping them solve their family or personal problems. Leaders and teachers admitted that subordinates felt a "bond to the school", motivated and self-actualised when they worked in a caring working environment.

It appeared that the dominant discourse of Vietnamese culture as "hierarchical structure' (discussed in the Chapter Two) was intimately connected to how people built relationships or behaved towards each other. Although school leader participants generally believed that building a good relationship must be based on mutual respect, understanding, caring and "leaders should be close to staff to understand their thoughts, feelings and aspiration" (VP1C1), they considered "recognising one's social position in the organization" an important way so as to have proper behaviors and build harmonious relationships among people, particularly between leaders and subordinates. The two vice-principals explained this with their examples as follows:

Let me give you an example. In a meeting, the chairman is a young leader presiding over the meeting with other older members. These members just see him as a young, less experienced man rather than their leader, so how can he chair the meeting and how can he exercise his leadership? I think that we build good relationships based on our mutual respect and understanding, but it does not mean that we are the same or we are fair in terms of social positions. We should know who we are and which social positions we are in. In that way, we recognize our roles and duties at work and have proper behaviour towards each other. (VP2C1) 
We should know our position in the organization to fulfill our responsibility. For example, students must respect and obey teachers; young staff should respect the older and experienced staff; leaders and teachers should respect each other; subordinates should execute their leader's instructions and decisions, meanwhile, leaders should understand subordinates' aspiration. When we know exactly which position we are in, we will do our job well and be able to avoid conflicts. A student cannot be on par with a teacher and behave the same way the teacher does. (VP1C1)

While leaders highly appreciated building close relationships with subordinates "to understand their thoughts, feelings and aspiration", they expressed that they should keep a "safe distance" in relationships with subordinates because an intimate relationship might affect their managerial work. For example, one of the vice-principals admitted that it was difficult for her to exercise power over a subordinate whom she had an intimate relationship with. Other leaders agreed that the distance in relationships did not mean that they had a tendency to discriminate social status between leaders and subordinates, but distance here meant the allocation of social status or position among people, which helped them understand their duties and roles in the organization in order to fulfill their assigned tasks.

Similarly, teachers revealed that they had difficulties in building relationships with their leaders although their leaders were "heartfelt, open-minded, generous, and caring" (C1FmT6). They described relationships between leaders and teachers as "hierarchical", whereas relationships among teachers were described as "collegial". They felt an "invisible obstacle" existing in building relationships with their leaders due to the difference in status, power and organizational positions. This "invisible obstacle" was more obvious in relationships between young teachers and leaders. As one of youngest teachers confessed:

Although the principal is quite out-going and open-minded, I still have a feeling of nervousness when having a talk with her. I don't feel confident enough to say anything that I would like to say, such as making a suggestion or request. (C1FmT6)

Older teachers did not have the same feelings as the young ones, but they admitted that the difference in power, authority and position between leaders and teachers was obviously an obstacle for building relationships and they granted the truth of unequal relationships as a natural phenomenon embedded in Vietnamese society in general and 
in their school in particular. The high power distance also impacted on the behaviour and attitude of teachers towards school leaders in terms of building relationships. One of teachers explained:

I rarely witness someone saying "no" directly to school leaders when they do not agree with leaders' opinions. A direct disagreement with a leader can ruin the relationships for sure. (C1FmT5)

Teachers admitted that "direct disagreement" or "disobedience" could displease their leaders and might demolish relationships with them. This explains why they tried to avoid using "critical voice" or "direct disagreement" with their leaders. They avoided voicing their opinions or expressing their aspirations, in case it displeased their leaders or harmed their relationships and put them at potential risk. Subordinates showed strong tendencies to humility to keep harmonious relationships with their leaders.

Cultivating leaders' good relationships with subordinates was affected by gender difference. Female leaders admitted that they did not encounter any difficulty in building relationships with male staff and teachers. In contrast, one male leader admitted that he sometimes felt uncomfortable showing care and concern to female teachers because he was not used to doing so. Besides that, he believed an intimate relationship between a male leader with a female teacher might be "sensitive" and would affect a leader's prestige if other people misunderstood it. This may partly explain why he preferred to build and maintain "moderate relationships" with his female colleagues to keep a "safe distance".

Age was seen as a factor challenging the process of building relationships. Young teachers admitted that besides the differences in power and position that hindered their building relationships with leaders, there were invisible barriers between generations. Participant C1FmT6 admitted that she often sought advice or opinions from the female vice-principal, the youngest school leader, when she needed to rather than asking other school leaders because she felt easier and more comfortable to express her own ideas with the leader of the same generation as her. Leaders admitted that they felt challenged when building relationships with older staff because they had to play two "conflicting roles" simultaneously: senior to them in working position but junior to them in age. This could explain why leaders claimed that they had to be very careful about choosing the 
appropriate words and showing correct behaviours when giving instructions or allocating a task to older teachers. The youngest vice-principal explained:

They are like my older brothers, sisters, or in some cases, their ages are quite the same as my parents' age. So when working with them, I cannot behave towards them the way I do with the younger staff. (VP2C1)

When discussing how to keep good relationships in order to create a friendly working environment, most of the participants suggested a variety of ways, in which "hard" and "soft" approaches were believed to be compatible with Vietnamese cultural values. They affirmed that leaders needed to balance "hard" (lý) and "soft" (tình) approaches to manage employees. The former were based on rigid procedures, rules, and regulations clearly defined in legitimate documents, whereas the latter was seen as an art of leadership which allowed flexibility in handling things and humanistic elements. As one of the vice-principals explained:

Balancing Lý and Tình is really important. I don't always use my power as a viceprincipal, rules, disciplines or law to impose upon the people in all situations. My experience shows that inflexibility in management or strictness in matters of principle is not efficient in all situations. We are living and working in a complicated web of relationships and we face multifaceted behaviours of people on a daily basis, $l y$, hence, is not always an effective management measure. In some cases, we need to use tinh (human love) to manage the school and to solve problems. It may not be a good idea that we always apply a type of discipline on a staff or a teacher who breaks the school rules. What we need is to use our colleagueship and comradeship to admonish him/her, give him/her a chance to put right his/her faults rather than conducting a kind of punishment. I think that in this way, we are able to build good relationships among people and create a strong school community. (VP1C1)

However, participants agreed that allowing flexibility in handling things and depending too much on humanistic elements or relationships could cause unfairness in the working environment. When two teachers committed the same kind of mistake but two different types of disciplines were applied, "unfairness" occurred.

Despite the "distance" existing in leader-subordinate relationships that participants regarded as a "natural phenomenon", the participants agreed that to guarantee good relationships between leaders and subordinates, mutual respect must be built and maintained. As a teacher explained: 
Respect is not a one-way behaviour. We respect our leaders and we also need to be respected by them. (C1MT3)

They emphasised that relationships could be ruined for lack of mutual respect among people, particularly between leaders and subordinates. Teachers mentioned that "arbitrariness" in leadership was a barrier to building good relationships with their leaders. According to them, "arbitrariness" was reflected in the way that a leader used his/her positional power to make commands, or to force subordinates to do things regardless of the consequences, reactions or feelings of the subordinates on the matter. Arbitrariness in leadership was believed to make a working environment stressful and the school culture toxic. Teachers emphasised that when leaders were thought to be arbitrary, democracy in the school must be decreased because "our voice or opinions are not highly valued; our suggestions are not taken into consideration; we don't have a chance to be involved in the school decision-making process" (C1FmT5). They believed that when the school was led by an arbitrary leader, relationships among people were fragmented; teachers were demotivated and their bonds to the school were weakened.

\section{Making decisions}

With the hierarchy of power structure and the dual role of school leaders due to the political attachment (as discussed in the background of the school), the members of the Principal Board had full power in the decision-making process. From the interviews, managerial decision-making was an "exclusive process" belonging to the members of the Principal Board, in which the principal, who was ultimately accountable to the government, played the biggest role. Participants admitted that their principal's decision was the "highest" and "the most authoritative" and it was always expected to be carried out with highest compliance on the part of subordinates. One of the teachers told a joke in the interview to describe the principal's power in decision-making process as follows:

It cannot be denied that the principal's decision is the "biggest". There is a joke like this. Article 1: the boss is always right; Article 2: if the boss is not right, refer to Article 1. (C1MT1)

Teacher participants revealed that they were expected to accept the principal's decisions without question even if they did not totally agree with it. They could be considered a "resister" if they showed their disagreement with or disobedience towards their leader's 
decision. Leaders showed high expectations for decision implementation because they believed that "the obligations and duties of staff are to implement leaders' decisions strictly and seriously" (PC1). The two vice-principals said that they felt hurt and disrespected if their decisions were not strictly implemented by teachers and staff. It was clear from the interviews that teachers rarely challenged their leaders' decisions. They had a strong tendency to avoiding conflict with their leaders. They obeyed and executed leaders' decisions strictly and faithfully.

Teachers expressed that they seemed not to be involved in the decision-making process because their main concern was accomplishing professional activities such as teaching, doing research and other teaching-related activities. A teacher explained this as follows:

I was only interested in teaching and learning activities and trying to fulfill my teaching tasks and complete other assignment delegated by leaders. (C1FmT5)

Teachers believed that decision-making was "not their job but the job of school leaders". Teachers were not used to participating in decision-making processes and they did not see their contributions of opinion as an "information channel" that school leaders might use for their reference. This may explain why leaders admitted that teachers and staff "are not fully aware of their roles and responsibilities in the decision-making process" (VP1C1). For example, before the principal made an official decision on promulgation of the Annual School Expense Statute, a draft version of Stature was sent to all teachers and staff for reference and they were asked to give feedback or opinions if they found any discrepant points or if they wished to offer suggestions for adjustment. However, as one of the leaders stated, school leaders rarely received responses from teachers and staff for such things although they were very welcomed to do so. Most responses or feedback were often from people who held a certain managerial position in faculties or departments, such as heads of departments or deans of faculties.

The interviews with leaders indicated that they were not familiar with and willing to give, subordinates responsibilities for making decisions about important tasks and discretion on deciding how to carry them out. They explained that school leaders, particularly the principal, were the people who were ultimately accountable to the Party and the government for all school activities. They were not willing to take risks by 
giving subordinates responsibilities for making important decisions. They were not even willing to delegate important tasks to subordinates whom they believed to be competent or experienced. The principal stated that "an approval must be confirmed by school leaders before an important task is implemented by subordinates".

When asked about how they were delegated in the decision-making process, the viceprincipals revealed that theoretically they could use their authorities to make decisions on what they were in charge of, but this did not mean that they were completely empowered to make managerial decisions with autonomy. An approval made by the principal was always needed. One of the vice-principals explained:

I am authorized to make managerial decisions on what I am in charge of. However, I don't play a decisive role in decision-making processes. I just work as a managerial assistant for the principal. In case I make a decision, it must be within the entrusted jurisdiction of the vice-principal and it must be ensured not to be contrary to the principal's opinions. (VP2C1)

In a similar vein, leaders of faculties and departments were not free to make decisions. In terms of decision-making, departments and faculties acted as professional counselors for the Principal Board and they executed their tasks under the directions of the Principal Board. Faculty-level leaders were seen as "decision implementers" rather than "decision makers". As a participant explained:

The leaders of departments and faculties are empowered and authorized to make decisions that have the sphere of influence within their departments or faculties. But they are always requested to refer to the senior school leaders (principal and viceprincipals) for approval before making a decision. All their decisions must be under the instructions and guidelines of the Principal Board. (VP2C1)

This could explain why seeking approval from school leaders was considered a must when leaders at department/faculty level made decisions or plans. Data from documents indicated that all "annual implementation plans" (kế hoạch hoạt động năm) of departments and faculties always included a signature from a school leader (the principal or vice-principal) with a school seal under the signature of department/faculty leader before they could become effective. The principal participant explained that a school leader's signature with the school seal in a department/faculty-level plan meant that "the plan had been approved by a school leader, it, hence, is considered as an official document that requires every member of the department or faculty to implement 
strictly". The principal confirmed that a plan approved by a leader with his/her signature and school seal was more effective and people felt more responsible for carrying it out.

Delegation among school leaders was regulated and not hands-free. It seemed that delegation was not a complete shift in the locus of decision-making power from one level to another. Rather, it was a process in which the principal guaranteed leaders of different levels (from vice-principals to deans and heads) with some degree of autonomy to make decisions under monitoring at critical points of implementation. This explained why the principal considered "monitoring" or "checking" as an important managerial task of school leaders to ensure "everything goes smoothly and on the right track". Leaders agreed that "intervention" was also a good measure of prevention of the worsening of problems or conflict because they were accountable for all things that happened in school. School leaders could have trouble or even lose their jobs if anything was to go wrong.

Four main factors that impacted on teachers' involvement in decision-making processes were found as follows:

(1) The tendency to avoid conflict with leaders: While they indicated the importance of "including teachers' voice" in the decision-making process, teachers expressed their worry about the consequences of giving their own opinions in school meetings because "their opinions are not guaranteed to be accepted or agreed by leaders. It will be ok if their opinions are advocated by school leaders. But conflicts might happen if their opinions are thought to be opposing to leaders' points of view and not accepted by school leaders" (C1FmT5). This explained why teachers showed unwillingness in contributing their opinions in decision-making processes.

(2) Leaders' exclusive responsibility: Teachers strongly believed that decisionmaking was a kind of managerial assignment attached to leaders' responsibilities. They, hence, depended much on leaders' decisions rather than acting on their own initiative to have their voice in the matter. 
(3) Democratic working environment: Teachers admitted that their involvement in decision-making processes depended significantly on how democratic the working environment was. They explained that when leaders were arbitrary, complete submission was highly expected. This was unfavorable to the spirit of democracy and impacted on teachers' willingness for contributing their ideas.

(4) Age and experience barrier: Interviews revealed that age factor was seen as a barrier to the involvement in decision-making processes. Participants explained that experienced teachers' opinions were often considered "weightier" than the younger or less experienced teachers' opinions due to the prominence of experientialism in Vietnamese culture. This could explain why young teachers hesitated to express their opinions in school meetings. Data from four school meeting observations indicated that the contribution of young teachers aged between 25 to 35 accounted for only $13 \%$ while opinions given by teachers aged between 36 to 45 and teachers aged above 45 accounted for 33\% and 53\% respectively (See Table 10). 
Table 10: Opinion contribution in School A meetings

\begin{tabular}{|c|c|c|c|c|c|c|c|c|c|c|c|c|c|c|}
\hline \multirow{3}{*}{ Meeting } & \multirow{3}{*}{$\begin{array}{l}\text { Total No } \\
\text { of } \\
\text { attendants }\end{array}$} & \multirow{3}{*}{$\begin{array}{c}\text { Total } \\
\text { opinions }\end{array}$} & \multicolumn{4}{|c|}{ Aged from $25-35$} & \multicolumn{4}{|c|}{ Aged from 36-45 } & \multicolumn{4}{|c|}{ Aged above 45} \\
\hline & & & \multirow{2}{*}{$\begin{array}{c}\text { No of } \\
\text { attendants }\end{array}$} & \multirow{2}{*}{ Percent } & \multicolumn{2}{|c|}{ Opinions } & \multirow{2}{*}{$\begin{array}{c}\text { No of } \\
\text { attendants }\end{array}$} & \multirow{2}{*}{ Percent } & \multirow[b]{2}{*}{$\begin{array}{c}\text { No of } \\
\text { opinions }\end{array}$} & \multirow[b]{2}{*}{ Percent } & \multirow{2}{*}{$\begin{array}{c}\text { No of } \\
\text { attendants }\end{array}$} & \multirow{2}{*}{ Percent } & \multirow[b]{2}{*}{$\begin{array}{c}\text { No of } \\
\text { opinions }\end{array}$} & \multirow[b]{2}{*}{ Percen } \\
\hline & & & & & $\begin{array}{c}\text { No of } \\
\text { opinions }\end{array}$ & Percent & & & & & & & & \\
\hline 1 & 136 & 7 & 46 & $34 \%$ & 1 & $14 \%$ & 52 & $38 \%$ & 2 & $29 \%$ & 38 & $28 \%$ & 4 & $57 \%$ \\
\hline 2 & 143 & 8 & 49 & $34 \%$ & 2 & $25 \%$ & 53 & $37 \%$ & 3 & $38 \%$ & 41 & $29 \%$ & 3 & $38 \%$ \\
\hline 3 & 143 & 6 & 47 & $33 \%$ & 0 & $0 \%$ & 54 & $38 \%$ & 1 & $17 \%$ & 42 & $29 \%$ & 5 & $83 \%$ \\
\hline 4 & 145 & 9 & 47 & $32 \%$ & 1 & $11 \%$ & 54 & $37 \%$ & 4 & $44 \%$ & 44 & $30 \%$ & 4 & $44 \%$ \\
\hline Total & 567 & 30 & 189 & $33 \%$ & 4 & $13 \%$ & 213 & $38 \%$ & 10 & $33 \%$ & 165 & $29 \%$ & 16 & $53 \%$ \\
\hline
\end{tabular}




\section{Managing and solving conflict}

Leaders believed that managing and solving conflict was one of their managerial responsibilities. They showed great concern for all kinds of conflict that could occur within the school community. They believed that conflict threatened school solidarity. They explained, conflict could ruin relationships, demoralise and demotivate people and make the school culture toxic. The principal explained:

School leaders should keep an eye on any would-be conflict. A small conflict that we underestimate can become a bigger one and it might affect the school's solidarity. (PC1)

For teachers, conflict was dysfunctional. They believed that when a conflict occurred, the relationships between people were likely to be damaged; tension and stress in workplace were likely to be increased. None of the participants believed that conflict was beneficial.

Interviews revealed that because of the emphasis on harmony in the workplace, people had a tendency to avoid conflict with each other even when they had different points of view on a certain matter. One of teachers admitted that although she did not agree with her colleague about the teaching techniques he had applied in his lesson, she could not express her direct attitude to show her disagreement during the feedback session. She said that she had to "use well-chosen words" when giving feedback in order to avoid hurting his feeling and self-esteem. Participants pointed out that in order to keep harmony and avoid conflict, one should show due respect for others' feeling and act to save their face because any conscious act of making others lose face would damage one's own image and that conflict would then occur. It seemed that this was particularly true in the process of building relationships between teachers and leaders. Teachers pointed out that even when they did not agree with leaders on a certain matter they often avoided making criticism or showing their disagreement. As some teachers stated: "we try to avoid conflict by keeping silent" (C1FmT4) or "silence is golden" (C1MT2).

Teachers believed that putting too much emphasis on maintaining harmony with leaders by "keeping silent" might lead to the so-called "bằng mặt không bằng lòng" (one is willing to show his/her consensus by accepting other's opinion/instructions/directives 
but in fact he/she does not agree or support such things at all). They saw this as a potential threat that could challenge school leaders. They explained:

One of the reasons that causes managerial conflict between leaders and subordinates in our school is that leaders don't really understand staff aspirations because they don't get enough information. Why don't they get enough information? I think it is because subordinates are not willing to express their own opinions or aspirations to school leaders. They avoid conflicts that may happen in case their opinions are not advocated by leaders. (C1MT2)

Ironically, we all seem to try to maintain harmony by keeping silent and avoiding making criticism even when we don't agree with leaders about something such as a new plan or a decision. But this does not mean that we are working in a conflictfree environment. Conflicts are now "implicit". What will happen if subordinates are full of pent-up discontentment but they don't have a chance to voice their opinions? (C1FmT4)

It appeared that in conflictual situations such as a disagreement with leaders, teachers tended to use a strategy of not responding or ignoring rather than directly refusing, disobeying or making criticism. Teachers believed that to avoid the phenomenon of "implicit conflict", school leaders should create a more democratic environment in which subordinates were encouraged to express their opinions without any restraint. Besides this, school leaders could "learn to listen to subordinates' opinions" (C1FmT5) and "learn to accept different points of view" (C1MT3). This was confirmed by leaders that they were still not used to "listening to and accepting contrary opinions from staff due to the influence of traditional thinking" (VP1C1). As one of vice-principal admitted:

We try to build a more democratic working environment in which staff are encouraged to express their own opinions or make any questions they wish. To do this, we leaders have to change our traditional thinking; we have to learn to accept the different points of view from our staff. I think it's hard to do that because I know that generally leaders are not very willing to listen to staff criticism. But for better management, we have to learn "the way of listening". (VP1C1)

In managing conflict, both leaders and teachers emphasised that establishing a strong community and maintaining solidarity in people's relationships was a good way to reach a state of harmony in social interaction to avoid confrontation and conflict. If conflict was unavoidable, harmony was still the goal for reducing the negative impact of conflict by "saving face" and "protecting one's prestige". As participants commented:

Sometimes I cannot avoid conflict with teachers. For example, when a teacher made a mistake, I cannot ignore it. Being a leader, I must offer the suggestions or 
make criticism in order to help him improve teaching quality because I am responsible for managing teaching and the learning quality of the school. However, offering suggestions or making criticism depends on who the person is. For example, for an older teacher, I use "mild comments" to avoid hurting his selfesteem and to protect his prestige. For a young teacher, I can offer him a direct suggestion or make a direct criticism. However, the most important is that our comments should be sincere, frank and constructive. (VP2C1)

Once I had a problem with another teacher. The principal knew the situation, so she asked me to have a private meeting with her. In the meeting, she said: "I know your problem and I understand the situation. That is not your own fault. But I think it would be better not to make a lot of noise about this. We are comrades and colleagues, so you should put up with each other to keep our solidarity". I think that the principal did not want to displease anyone between us. Her main aim was to maintain harmony rather than resolve the conflict thoroughly. (C1FmT5)

School leaders were believed to play a key role in managing and solving conflict. Findings indicated that when a conflict occurred and it could not be solved by the insiders themselves, or when it appeared to get worse, people tended to seek the involvement of school leaders as intermediaries. Teachers explained that by deferring a decision to a leader, people in conflict avoided the need to make concessions. They believed that leaders with their authority, power, prestige and knowledge could conciliate conflicts between people.

\section{School B}

\section{Background of school: A reflection on power and the administrative structure}

School B was a high school for gifted children. It was established in 1994 from the upgrading of a specialised division of a local high school aimed at teaching and training gifted students of the province. As it belonged to the national high school system, students were aged from 15 to 17 with grades from 10 to 12 . It provided for talented students with optimum conditions to develop their talents. One of the key factors that differentiated School B from other local high schools was the quality of specialised teachers. Students must take an entrance exam at the start of grade 10 and then were grouped into different specialised classes: mathematics, physics, chemistry, biology, literature, and English.

Approximately 200 students were enrolled annually. This school was considered to be the best high school for teaching and learning among the 32 local high schools. Its fame 
also rested on its high rate $(78 \%-95 \%)$ of students to pass the national university entrance exam in comparison with other local high schools (from 10\% to 35\%). It had over 70 teachers and staff working full-time. Female teachers and staff accounted for over $62 \%$. The teachers were "highly-qualified" as they were university graduates with distinction or were selected as teachers with teaching excellence or "experiential thickness of teaching" at other local high schools.

The power and management structure of the school is described in Figure 5. The schoolparty secretary, who headed the Executive of the School Communist Party Cell (CPCE Chi U'y), concentrated on ideological and political work and supported school leaders in administration. The principal and vice-principals were responsible for administration. The principal also held the post of the school-party secretary. The internal power hierarchy reinforced the political and administrative power of the principal. Respectively, participants confirmed that the power of leadership was highly concentrated in the principal's hands.

The school was part of the national high school system and was legislatively under direct administration of the Provincial Education and Training Service (PETS) in terms of personnel affairs and professional and socio-political activities. The Principal Board had overall responsibility for the school, including managing learning and teaching activities, responsibility for teaching and learning quality, property and financial management, but ultimate authority for teacher appointment and employment rested with PETS. All of the personnel decisions regarding the recruitment of school teachers were decided and approved by PETS officials. The members of the Principal Board were nominated and appointed by PETS, but the final decision was made by the Chairman of the Provincial People's Committed (PPC). PETS was believed to play a very important role in the process of school leader appointment.

The school had 10 different professional and administrative divisions, including five divisions of natural science subjects; four divisions of social science subjects and one administrative division. All divisions were under the direct political leadership of the Executive of the School Communist Party Cell (CPCE) and the administration of the Principal Board. 


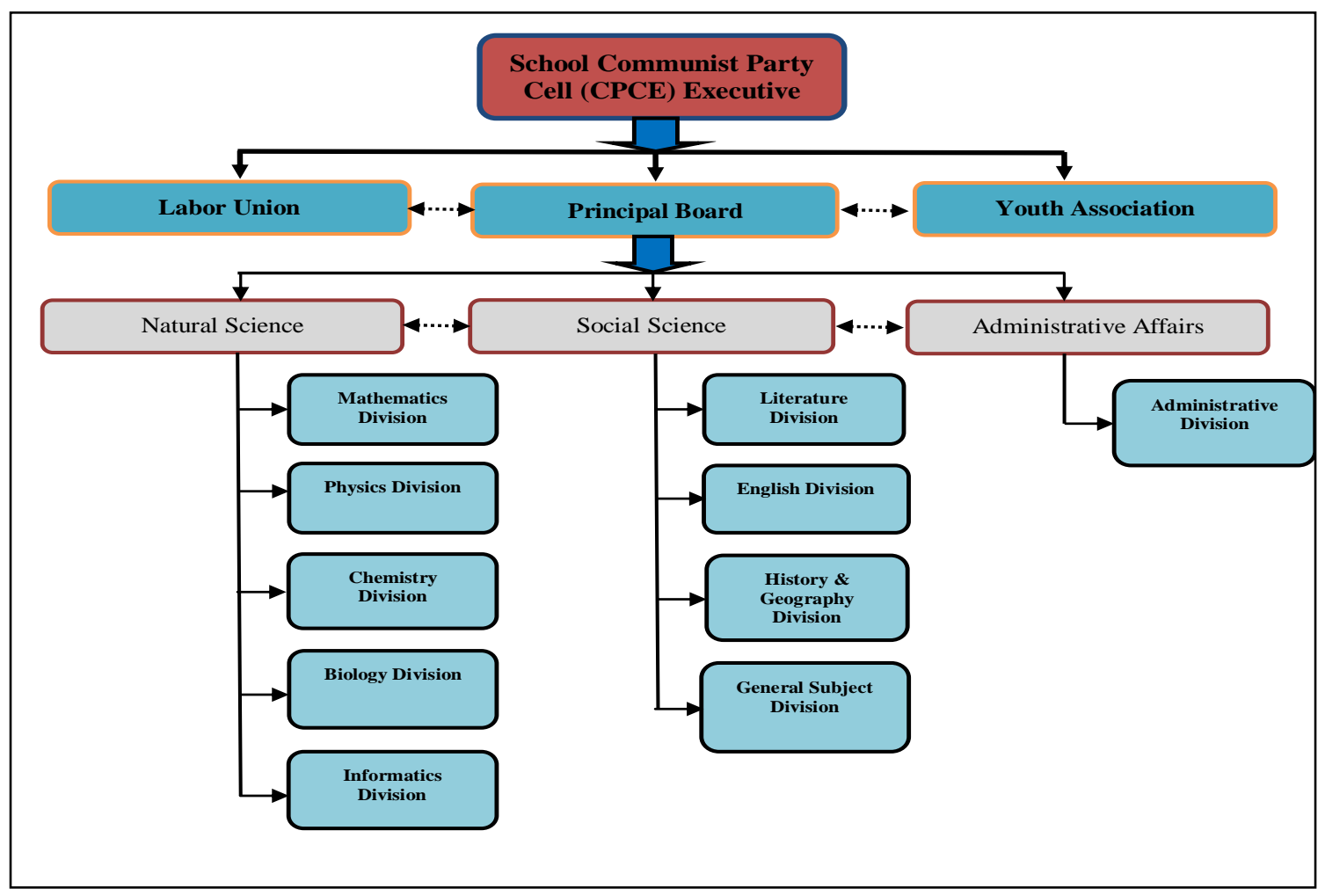

Figure 5: The Power and Management Structure of School B (Source: The school's administrative documents)

In School B, statistics on leadership show that the proportion of women holding positions in the Principal Board were relatively low. Two principals and six viceprincipals had been assigned since its establishment. Female leaders accounted for only $12.5 \%$ overall (see Table 11 ).

Women made up over $62 \%$ of the whole number of 72 officials and employees. The percentage of women involved in current leadership positions at other administrative levels accounted for $37.5 \%$. Female leaders at all administrative levels in this school made up only $33.33 \%$ (see Table 12 ). 
Table 11: Statistics of the Principal Board of School B from its establishment until the present (Source: The school's administrative documents)

\begin{tabular}{|l|c|c|c|c|}
\hline \multicolumn{1}{|c|}{ Positions } & Number & Female & Male & $\begin{array}{c}\text { Percentage of female } \\
\text { staff }\end{array}$ \\
\hline Principals & 2 & 0 & 2 & $0 \%$ \\
\hline Vice-principals & 6 & 1 & 5 & $16.66 \%$ \\
\hline Total & 8 & 1 & 7 & $12.5 \%$ \\
\hline
\end{tabular}

Table 12: The gender statistics of the current management staff of School B (Source: The school's administrative documents)

\begin{tabular}{|l|c|c|c|c|}
\hline \multicolumn{1}{|c|}{ Positions } & Number & Female & Male & $\begin{array}{c}\text { Percentage of female } \\
\text { management staff }\end{array}$ \\
\hline Principal Board & 4 & 1 & 3 & $25 \%$ \\
\hline Head of Division & 8 & 3 & 5 & $37.5 \%$ \\
\hline Total & 12 & 4 & 8 & $33.33 \%$ \\
\hline
\end{tabular}

\section{Leader participants}

Four members of the Principal Board were invited to participate in the research. Two accepted (including one male principal and one male vice-principal) and the other two (including one male vice-principal and one female vice-principal) declined. The female vice-principal accepted the invitation and promised to "share any managerial experience with the researcher". She then withdrew from the research as she explained that she was busy preparing for her Masters course examinations.

The principal (PC2) had worked for School B for over 16 years. He had been working as a vice-principal for seven years before he was appointed to the role of principal. He admitted that "I never thought that I would be a school principal when I was a young teacher. I never set out a target for this position". He revealed that his promotion was due to his great effort and competence: 
I think my leadership position comes from my efforts and competence that I have demonstrated at work; it does not come from my good luck. I don't mean that good luck is not necessary because everyone always expects good luck in their lives. But if you want to become a leader, your efforts as well as your competence are two important factors contributing to your success. No one expects to nominate an incompetent person to a leadership position. (PC2)

He revealed that he was encouraged and supported by his former principal and that his achievement was due to his former principal's support and recommendation.

The vice-principal participant (VPC2) had worked for the school for four years. Prior to the role he worked as head of a professional department for PETS. When asked why he decided to quit the post of the head at PETS to become the vice-principal, he confirmed that it was not his own decision. He had not expected to change his job. He accepted the nomination and appointment decided by the leaders of PETS. He confirmed that "all government officials must abide by the assignment approved by the party and government leaders. I am not an exception".

\section{Exercising power and authority}

Participants perceived power and authority as "exclusive privileges of school leaders". Teachers believed that power and authority were attached to the position of school leaders because school leaders were decision and policy makers. They could influence rules, regulations, procedures and school policies that other school members could not. Teachers admitted that their school leaders were the most powerful figures and exerted influence over others because of the authority associated with their jobs.

All participants in school B perceived power in the conventional way that power was the capacity to bring about certain intended consequences in the behaviour of others and to avoid outcomes which were not desired. Participants emphasised that power was connected to dominance, control and hierarchy. Similarly to School A participants' perception of power and authority, School B participants viewed power as "power over"; an indispensable tool every school leader held to execute managerial tasks and to fulfil their leadership roles. According to participants, leaders' power was embedded in daily managerial tasks of decision-making, checking subordinates' work, making plans, instructing and allocating tasks. Power was exercised to compel subordinates to comply 
with the school regulations or the Party and Government's resolution. Some of teachers commented:

They [school leaders] have the right to check how well I carry out my work or how well the others carry out their work. They are authorized to have full power to discipline someone who breaks the school rules. They have the right to make decisions and require other people to implement their decisions strictly. (C2FmT4)

Another teacher:

Power is synonymous with controlling. Power is used to control others. Our school leaders, for example, can give direct instructions to professional divisions, establish guidelines for their decision-making, approve or reject subordinates' decisions or opinions, or allocate resources. (C2MT2)

The concept of power perceived by participants referred to power resources of position power, coercive power, reward power, and expert power. Position power, in educational literature, is based on the perception that leaders have the right to exercise influence because of their position/role (Hales, 1997; Handy, 1993). They referred to this kind of power resource as they believed that school leaders had the right to check someone's work, to make decisions, to order someone to do something, or to conciliate conflict between people. Reward power and coercive power were defined as the leader's control over rewards and disciplines. These were discussed when the participants mentioned forms of rewards and discipline/punishment in the school. Participants viewed reward power in a positive way. They believed that reward power was positively associated with job satisfaction and performance. As some of the participants stated:

I think that people work harder and better if they are encouraged by offering a reward when they do their job well. I believe that teachers feel appreciated and proud of themselves whenever they receive a reward. Reward is not just money, a present or something like that; it can be a compliment from the leaders or even a promotion. (PC2)

I think that it is a kind of motivation that encourages teachers, students and school staff to work harder to contribute to the school's development. (C2MT1)

A reward also reflects our efforts and attempts in work. It also means that we are valued by other people. (C2MT3)

According to participants discipline was viewed as 'coercive power'. They saw discipline as a "tool" of power that school leaders used in some situations. Leaders revealed that they did not prefer "discipline" when performing their management and 
leadership because it was negatively associated with subordinates' satisfaction and could make the working environment more stressful. All leaders agreed that in some cases they could use "discipline" as a solution to increase their subordinates' compliance and enhance their influence on subordinates. As the vice-principal stated:

Discipline is an effective tool that might be applied to enforce people to follow the school rules and execute leaders' directions. (VPC2)

Teachers agreed that the school's discipline should be tightened to make people more responsible for their work. They confirmed that when school discipline was slack, staff tended to be less responsible. For example, the school had a rule which stated that any staff member who was absent more than three times from school meetings without permission would be disciplined. The form of the discipline for this was "cảnh cáo" (a warning and then informing the offence in the school meeting). A teacher who was subjected to "cảnh cáo" would not gain the title of "good teacher" at the end of the school year. The principal revealed that:

People feel more responsible for their work when such disciplinary measures are applied. No one wants their offence to be informed in the school meeting as they might lose face and lose prestige. (PC2)

"Expert power" was mentioned in interviews. Participants discussed how special knowledge of the school leader influenced the power exercise process. They were more compliant to a school leader whom they believed to be experienced and have special knowledge in a given area. As some of them stated:

A leader must be "taller one head more than" their subordinates. I mean their knowledge and their managerial experience should be highly acknowledged if they want to be respected and admired by their staff. No one wants to be led by trivial leaders, those they don't respect and admire. (C2MT1)

The power of a leader comes with his professional prestige (uy tính chuyên môn). His voice is less weighty in the school community if his professional competence is not acknowledged. (C2FmT4)

For exercising power, leaders acknowledged the importance of establishing order and obedience among staff. According to leaders, when order and obedience among staff were established, the school would operate smoothly; conflict was avoided and managerial work was easier to deal with. They argued that strictly following school 
rules, implementing leaders' instructions and decisions were seen as the way that staff showed their obedience and respect to school leaders and their authority. The principal stated:

I always expect my staff to strictly follow school rules as a way to show their respect for me and other school leaders. My managerial experience indicates that when school rules are strictly followed, order within the school community will be established. (C2P)

Findings indicated that the school carried out "regular inspections" and "internal teaching assessments" to guarantee school leaders' directives. Such managerial approaches were to ensure everyone followed school rules strictly. As the principal affirmed that teacher accountability was enhanced by the implementation of regular inspections. The regular inspections were carried out in order to raise teacher anxiety, which helped teachers take more responsibility for their work. Some common regular inspections emphasised checking teachers' personal profiles and teaching documents (such as lesson plans, self-studying notebooks) to find out how well teachers fulfilled their teaching assignment. For teaching assessment, each teacher was required to have at least two teaching sessions under the observation of the school education bureau to assess their teaching performance. Participants agreed that carrying out such measures was necessary. Reasons included:

To put pressure on teachers with the purpose of making them work harder for better teaching quality. (PC2)

When carrying out an inspection we look at the strengths and weaknesses of the individual teacher. We encourage teachers to develop their strengths and help them overcome their weaknesses. (VPC2)

Teachers indicated that not all teachers supported managerial measures. Four out of six teachers expressed that teachers should have more autonomy and freedom in their teaching activities. Teachers should not waste their time with regular inspections and teaching assessments which could make them feel stressed and harassed. They argued that without the close supervisions and regular inspection of their leaders, they were still responsible for their own work. The other two teachers agreed that they felt a little bit annoyed with such managerial measures. However, they believed that regular 
inspections were necessary because teachers' work should be checked and assessed to guarantee quality and keep teachers' work on the right track. As two teachers stated:

Sometimes I feel a little bit uncomfortable when being checked. However, carrying out an inspection is a way to discover weak points of the teacher in order to help and support him/her to work better. No one is perfect, so we need to be supported by each other. (C2FmT6)

Not all teachers and staff have high responsibility for their work. Hence, regular inspection and assessment, in my opinion, can be seen as a reasonable way to increase teachers' awareness and accountability for their work. (C2MT3)

Setting an example was seen as an effective strategy for exercising power and the leadership process. All participants believed that being a good role model encouraged subordinates to respect and obey leaders' authority and power. Teachers emphasised that they always expected their leaders to set good examples so that they could follow. School leaders must be exemplary people as what leaders did could positively or negatively affect subordinates' motivation at work. Some teachers explained as follows:

The leader must be exemplary if he expects others to listen to his directions or instructions. If the leader "nói một đàng, làm một néo" (says one thing and does another), no one will trust him. He will lose his prestige. And of course, a leader without prestige is a powerless leader. (C2MT1)

I like leaders of "walking your talk", I mean "setting a good example". I trust them because they do what they say. When leaders walk their talk, they demonstrate how deeply they are committed to their work. They convince subordinates by their actions rather than words. They do much more than they talk. In that way, they set a good example for subordinates. (C2FmT5)

Leaders strongly agreed that setting good examples was an effective strategy of exercising power. They admitted that when they set good examples, subordinates were more likely to be compliant. As the principal stated:

Everything I do gets people's attention. I consider myself as a "daughter-in-law of one hundred families" who is constantly watched by teachers, students and parents. What I do, how I behave, what communication style I use and so on send powerful messages to teachers and students. Hence, setting a good example is a way of setting standards and rules for teachers and students. For example, when I expect my subordinates to come to school on time, I must be never late for work. When I deployed the Government' instruction on banning smoking at school, I was the first person who stopped smoking. (PC2)

The vice-principal explained: 
Our ancestors said "Thuợng bất chính, hạ tắc loạn" (when superiors are unrighteous, juniors must be in disorder or fish begins to stink at head). I consider this saying as a reminder that all leaders must take into consideration. If you ask your staff to follow a government decree or school rules, you must follow it first. For example, I used to be a heavy smoker but I had to stop when the government issued a decree of banning smoking at working places. Who would be willing to listen to my instructions if I kept my smoking habit? We cannot ask them to come to school on time if we leaders are sometimes late for work. If we leaders set bad examples, then we cannot blame them for their mistakes. (VPC2)

When asked about the factors that could have an impact on school leaders' power exercise, all participants agreed that "building up prestige" was an important factor. Prestige was a type of power and leaders could have a significant influence even when they did not use coercive power. The principal revealed that he considered prestige to be key to a leader's success and enhanced power. According to participants, prestige was the quality and capacity of a leader acknowledged by his subordinates. They confirmed that the high degree of a leader's prestige was reflected in the following concepts:

The leader's instructions and directives are strictly followed by subordinates without delay or objection. (C2MT3)

School work goes smoothly even when a leader is absent. (C2FmT4)

High credibility and voluntary obedience of subordinates. (C2MT1)

The appreciation of superiors and the admiration of colleagues (C2MT2).

People expect the presence of the leader when dealing with problems or conflicts. The dependency is on the leader to make all decisions. (C2FmT6)

Participants confirmed that "building prestige" was inextricably linked to the two most important qualities of the leader: moral quality and professional knowledge (expert). The relationship between these two qualities and compliance was believed to be positive and significant. Teachers admitted that their compliance to their leader increased when these two qualities of the leader were believed to increase. A teacher stated:

To be prestigious, the leader must have wisdom, deep knowledge of the field assigned, frugal lifestyle, integrity, public-mindedness, "walking their talk", compassionate heart, selflessness, generosity, and so on. He leads and manages people by his good example and high prestige rather than using the power to govern and impose subordinates. Such a leader obtains subordinates' compliance and submission by his dignity rather than by his power. (C2MT1) 
Teachers mentioned that some factors could damage the prestige of the leader and reduce the credibility of subordinates. The importance of leadership style and the process of exercising power were emphasised. Some stated:

I don't like the leader who is imperious towards subordinates, who does not respect subordinates' opinions. An arbitrary leader might make subordinates fearful and compliant but not in admiration of their leader. (C2MT2)

A leader will lose his prestige and reduce the credibility amongst his subordinates when he relies on his leadership position to impose his rules on subordinates. (C2MT1)

The social values of hierarchy and position were important factors that impacted on the process of the exercise of power. Leaders were more challenged when working with someone who was older, whereas, teacher participants preferred working with older and experienced leaders. They explained some reasons as:

We have respect for elders, that's our culture. This is reflected in our working relationships. If your leaders are older or more experienced than you, it is much easier to go along with things that they expect you to do. You respect them, so, of course you respect their orders. (C2MT2)

I find it difficult to relate to someone who is older than me. I know that within hierarchical values and our culture of "respect for elders" there is an invisible tension between the younger leader and older staff. It may be a very difficult situation for the younger leader when he is required to fulfill his managerial role by checking or assessing an older teacher's work. It's not as easy as when we do the same with younger teachers. (VPC2)

It's not easy to criticize someone who is older than you even if you are their leader. For example, when I saw an older teacher coming to school late, I just gave him a gentle reminder rather than showing him a bossy attitude or criticizing him for his lateness. (PC2)

\section{Building relationships}

All participants stressed that cultivating and preserving harmonious relationships were imperative for maintaining the school's performance and culture. They clarified that cultivating and preserving harmonious relationships was the best way to promote solidarity among school members. This could help bind school members in order to "strive for the shared goal". Leaders saw "building and maintaining solidarity" as their most important managerial mission because solidarity had a significant influence on the school's achievement and accomplishment. Internal discord demotivated and lowered 
employees' morale and increased distrust among the school community. The viceprincipal explained as follows:

When people are working in a close-knit environment, they share responsibilities and interests; they share joys and sorrows; they work for the same purpose and they have a singleness of mind when doing things. As carrying a heavy object, one cannot carry it but many working together can. An effective leader is one who has the capability to bind people together into a united block in order to have enough strength to carry a heavy object. (VPC2)

Teacher participants stressed the ideas of building solidarity and maintaining harmony in organisational relationships was a key to performance and loyalty. When harmony was established and maintained, the school operated smoothly and people worked more cooperatively with trust. Teachers were more loyal to their school when they worked in a harmonious working environment. One of the teacher participants stated:

I love my school because I love the people in it. Will you think of looking for another job in another school if you don't love your school? I'm sure you will. (C2MT2)

Teachers admitted that their bonds to their school were strengthened and they felt more responsible for their work when a high degree of harmony and solidarity in relationships was maintained. In contrast, they had low morale when they worked in a distrustful and conflicting atmosphere where people's relationships were fragmented. In the words of one teacher:

I feel motivated and comfortable when working with people who I have good relationships with. It is because when harmony is well maintained, people feel easy to come to a consensus rather than confrontation. Just imagine what will happen when you work with other teachers who have different points of view and don't cooperate with each other at work? One will do this, others will do that and people won't reach a consensus. If that happens, I am sure that the quality of performance would be low. (C2FmT5)

For leaders maintaining harmony in relationships was not only to promote the school's working environment productively, but also to preserve the school's fame and prestige. The principal expressed:

I don't expect to live in a perfect world because relationships among people are so complicated, but at least we have to build and maintain a harmonious environment where people are encouraged to work cooperatively and effectively to achieve the same goal. Failure in building and maintaining such an environment will not only 
undermine teachers' morale but also destroy the fame and prestige of the school. Parents don't trust a school which they know its people "prefer" lawsuits when dealing with work. (PC2)

When asked about the relationships between leaders and teachers, both leaders and teachers admitted that the social value of hierarchy significantly impacted on their relationships. These values were deeply embedded in everyday communication and human behaviours and were seen as social standards. Teachers said it was not easy for them to build a close relationship with their leaders because of the various working positions, power and status. As a teacher said: "we are teachers and they are our leaders. We are not the same. They can exercise power over us but the other way round is not acceptable" (C2MT2). The meaning embedded in this explanation referred to the power inequalities that were accepted as natural and were legitimized in customs and relationships. Teachers took their "inferior positions" for granted and accepted it as standards for building and maintaining relationships with their leaders. Leaders described their strategies to improve relationships with teachers and this reflected the features of hierarchy. The principal described:

It is important to make the people understand that in their eyes I am not always a principal. I would like them to see me as a friend, a brother, a colleague or a comrade rather than a powerful principal. I try to break the gap between me and school members as much as possible because I know that close relationships with them help me run and manage the school more smoothly. (PC2)

The hierarchical gap between leaders and young teachers was significantly large. In the words of the vice-principal:

Even though I try to break the gap between me as the leader amd my teachers, particularly young teachers, it seems that there is a barrier for doing that. They are always welcome to come to my office to have a conversation with me if they want, but in reality, young teachers seldom do that. Older teachers sometimes come to have a chat with me in my office, but young teachers never do that. They just come to meet me when they want to ask for my managerial opinions relating to their work. (VPC2)

To build and maintain leader-teacher relationships, participants adopted a range of strategies, aimed at cultivating and preserving harmonious relationships. Participants revealed that leaders and teachers showed a great concern about conflict, which was dangerous to harmony, whether it was at a deep or surface level. Leaders tried to avoid doing things that could cause conflict as much as possible although they confirmed that 
it might be difficult because they played the role of "the daughter-in-law of hundreds of families who cannot cook a perfect meal to satisfy all kinds of taste" (PC2). Leaders indicated that "criticizing someone in front of others" was not preferable because it was believed to destroy harmonious relationships. The principal claimed that he was extremely reluctant to criticise a teacher, especially an older teacher in front of others because it could hurt the teachers' dignity and make them lose face. The concept of face was also mentioned by teachers. They explained that in exchange for obedience and conformity, leaders must care for and protect their subordinates. This meant that leaders could not openly criticize teachers in order to save face (discussed more in the section: Managing and solving conflicts).

Leaders also stressed that "showing caring" was an important factor in building relationships with staff in order to facilitate school leadership. Staff were more responsible for the school and were more compliant and loyal to school leaders if they worked in a caring working environment. The principal explained:

An encouraging word, statement or caring behaviour from me to people is really important. It is important in terms of intellectual life and in terms of a sense of responsibility. When I asked a teacher who was ill for some days "How do you feel now? Do you need to have some more days off?" I could see the gratefulness in her eyes. I knew that she highly appreciated my words. Teachers need encouragement and motivation in that way to enhance their bond to the school and boost their responsibility for work. (PC2)

\section{Decision-making}

The interviews with leaders and teachers revealed that school leaders played supreme roles in decision-making. What participants described reflects the concept of "bosscentered" developed by Tannernbaum and Warren (1958). Under the boss-centered style, leaders made the decision themselves and then announced it to teachers and staff, sometimes with an explanation. Teachers believed that they did not have roles in the decision-making process because they were not involved in any managerial positions in the school. They considered themselves as "decision-implementers" who were always expected to carry out leaders' decisions with high compliance and loyalty. Some participants admitted that they were not interested in participating in the decisionmaking process because they were not willing to take risks while contributing their own 
opinions. They could face troubles in case their opinions were incompatible with leaders' opinions. Teachers emphasised that school only relied on a small number of decision-makers, including members of the Principal Board.

When discussing the process of decision-making, leaders appeared to advocate and acknowledge the trend towards teachers more active involvement in decision-making, whereas they saw themselves as key decision-makers in the school. The principal explained:

Working as a principal, I understand that I am the person who has the highest responsibility for everything happening around the school. I am accountable to the government and parents. So all school decisions must be approved or decided by me before they become effective or come into practice because the principal is supposed to be answerable for all things that happen in school. However, teachers' opinions are always welcomed. (PC2)

The principal expressed that teachers expected him to be the chief decision-maker with minimal input from others. He stated:

I believe that teachers don't like working with an indecisive principal. They expect me to be strong and decisive in decision-making. My managerial experience indicates that a leader must be decisive and determined in decision-making if he expects his decisions to be carried out by subordinates with their high compliance. (PC2)

Leaders revealed that decentralised governance in education had increased when the government issued the new policy on management and leadership. According to them, "organizational/grassroots democracy" was encouraged and expanded with the purpose of "encouraging employees to participate more in management and supervision". The shift toward more participative management seemed to have a slow uptake and school leaders continued to have difficulty in getting teachers involved in decision-making. In the words of the vice-principal:

Teachers and staff still play a passive role in the process of decision-making. They are still familiar with hierarchical management form in which they would rather follow orders and always expect their principal to be the chief decision-maker. Teachers and staff remain very unwilling to express ideas and opinions in school meetings. (VPC2)

Factors such as "respecting authority" and "avoiding conflicts" were viewed as barriers to teachers' involvement in decision-making as well as the "age factor" which was 
believed to impact on teachers' willingness. Both teachers and leaders revealed that older teachers seemed more willing than their younger colleagues to challenge and openly contribute in whole-staff meetings. Of the two school meeting observations, the contribution of young teachers aged from 25 to 35 years accounted for only $20 \%$ while opinions given by teachers aged from 36 to 45 and teachers aged above 45 account for $45 \%$ and $35 \%$ respectively (see Table 13 ). 
Table 13: Opinion contribution in School B meetings

\begin{tabular}{|c|c|c|c|c|c|c|c|c|c|c|c|c|c|c|}
\hline \multirow{3}{*}{ Meeting } & \multirow{3}{*}{$\begin{array}{c}\text { Total no } \\
\text { of } \\
\text { attendants }\end{array}$} & \multirow{3}{*}{$\begin{array}{c}\text { Total } \\
\text { opinions }\end{array}$} & \multicolumn{4}{|c|}{ Aged from $25-35$} & \multicolumn{4}{|c|}{ Aged from 36-45 } & \multicolumn{4}{|c|}{ Aged above 45} \\
\hline & & & \multirow{2}{*}{$\begin{array}{c}\text { No of } \\
\text { attendants }\end{array}$} & \multirow{2}{*}{ Percent } & \multicolumn{2}{|c|}{ Opinions } & \multirow{2}{*}{$\begin{array}{c}\text { No of } \\
\text { attendants }\end{array}$} & \multirow{2}{*}{ Percent } & \multirow[b]{2}{*}{$\begin{array}{c}\text { No of } \\
\text { opinions }\end{array}$} & \multirow[b]{2}{*}{ Percent } & \multirow{2}{*}{$\begin{array}{c}\text { No of } \\
\text { attendants }\end{array}$} & \multirow{2}{*}{ Percent } & \multirow[b]{2}{*}{$\begin{array}{c}\text { No of } \\
\text { opinions }\end{array}$} & \multirow[b]{2}{*}{ Percent } \\
\hline & & & & & $\begin{array}{c}\text { No of } \\
\text { opinions }\end{array}$ & Percent & & & & & & & & \\
\hline 1 & 69 & 11 & 21 & $30 \%$ & 2 & $18 \%$ & 29 & $42 \%$ & 5 & $45 \%$ & 19 & $28 \%$ & 4 & $36 \%$ \\
\hline 2 & 68 & 9 & 21 & $31 \%$ & 2 & $22 \%$ & 28 & $41 \%$ & 4 & $44 \%$ & 19 & $28 \%$ & 3 & $33 \%$ \\
\hline Total & 137 & 20 & 42 & $31 \%$ & 4 & $20 \%$ & 57 & $42 \%$ & 9 & $45 \%$ & 38 & $28 \%$ & 7 & $35 \%$ \\
\hline
\end{tabular}


The principal captured this phenomenon:

Young teachers are encouraged to contribute their opinions, but every time in the meeting you'll find that they are so quiet and passive. They will not speak unless we leaders appoint someone to share ideas or report something; otherwise they will keep silent through the whole meeting. (PC2)

While expressing the need for teachers' participation in decision-making, the principal admitted that he preferred an autocratic approach. The key reason was a deep concern about the principal's role within an accountable environment. The principal explained that the current managerial and power structure passed all the responsibility to the principal.

Leaders confirmed that democracy was more open at an administrative level. This involved participation between the principal and other administrators such as viceprincipals and heads of divisions. Before making major decisions, the principal always called for a meeting with other administrators to discuss the issues to seek out their opinions. The vice-principal admitted:

There's a lot of collaboration among school leaders. The principal always discusses the important things with us [vice-principals]. He listens and respects our opinions. There's plenty of opportunity for people to have their say and eventually for decisions to be discussed. (VPC2)

Leaders used their senior staff as intermediaries to collect opinions and aspirations from teachers and staff. According to leaders this was preferred by both teachers and school leaders. They revealed that meetings at the division level were held monthly so that teachers had an opportunity to give their opinions to the head of division who then reported the results to the principal. This process seemed to work well in the hierarchical management system. The principal explained for this preference:

Teachers are more willing to express ideas and opinions, or even criticism, to their head or their colleagues in division meetings, than to the school leaders in whole-staff meetings. This is a very good information channel that helps school leaders understand teachers' needs, aspiration and feelings. (PC2)

Teachers indicated that they felt free to express their ideas in small-group forums without the presence of school leaders. Some teachers stated that:

It's hard to express my ideas with the presence of school leaders. Hence, whenever I want to contribute my ideas, I talk to the head of division or discuss with other teachers in my division rather than go to see the school leaders. I prefer this way because I feel free to talk to them. (C2FmT6) 
I have never expressed my ideas in the whole-staff meetings. It does not mean that I am an irresponsible teacher. But I agree with teacher C2FmT6 that we have more freedom when we express our ideas within our division. (C2FmT5)

Even though the shift towards a more participative management was slow and the teachers' role in the decision-making process was "dim", both leaders and teachers revealed a change in their perception of school leader-teacher relationships. Leaderteacher relationships were open and "more democratic". Teachers tended to be more confident in expressing ideas and opinions and more teachers were willing to contribute "straightforward ideas" in whole-staff meetings and have "straight talks" to leaders. Leaders captured the essence of this shift:

School leaders used to be "big bosses" who held the most power in decisionmaking. But now we can't be like that. We must respect teachers' opinions and have to understand their legitimate aspirations and meet their needs. (PC2)

In the annual meeting of selecting emulative titles through discussion, teachers are quite frank about what they don't like about school. Their spirit of criticism and self-criticism (phê bình và tụ phê bình) is also quite forthright. They are not just saying things to please you. You must also be respected for your ability and managerial performance; it's not that your teachers respect you because of your position. (VPC2)

There was a change in school-parent relationships in decision-making. This change was believed to "have a positive influence on the implementation of school policy" and "to tighten the bond of solidarity between school and parents". The school was open to parents' participation in the school policy-making process. Participants revealed that the school held parent meetings twice a year to report on their children's academic achievement, announce the school's new policy and plans and call for parents' opinion contribution and consultation before introducing important school policies. Leaders revealed that parents had previously been excluded from school management. However, this was seen as changing. The principal stated:

Parents need to know what is happening around school where their children spend most of their time during the day. They also need to know the school policies which, when implemented, have significant influence on their children's learning. We invite parents to have their voice in school management with the purpose of tightening their bond to school and enhancing their sense of responsibility to their children. (PC2)

Teachers stated that the role of parents had moved from "passive to active" in the decision-making process. One of the teachers said, "In the past, parents just did whatever the school requested, but now the school has to listen to parents' opinions and try to please their demands" (C2MT3). 


\section{Managing and solving conflict}

As in School A, participants in School B believed that conflict was serious, dysfunctional and should be avoided to maintain harmonious relationships among people and the school community. A vice-principal linked conflict to harmony and solidarity:

When conflicts happen, harmony and solidarity are broken. No one says "I can work well with a person whom I don't like". Never and never. If there is any conflict taking place, the working climate could be very stressful and affect our performance for sure. I cannot work effectively when having a dispute or a quarrel with other people. (C2VP)

Leaders and teachers identified that conflict avoidance was in their school culture. They confirmed that open arguments and conflict were extremely rare, especially in school meetings or with school leaders. A teacher admitted that during his 23-year career, he never witnessed teachers having arguments with leaders. In his words:

Argument with leaders? I don't think so. Even if you disagree with your leaders about something, I dare say you don't want to have an argument with them. (C2MT3)

Teachers revealed that they avoided giving opposing opinions to their leaders. Within the discourse of hierarchy and the culture of highly-expected obedience, giving opposing opinions meant disagreement or criticism, and could upset school leaders, especially in public meetings. Avoiding expressing their contradictory opinions or criticising leaders was a way to save leader's face and prestige. Similarly, leaders believed that in a meeting, disagreements were not vocalised in order to avoid confrontation and loss of face by either party. Some participants explained:

Criticising a person in public can be seen as an insult. How do you feel if your leader criticises you in front of your students? It would be a very bad situation. Such behaviour could make your students think of bad things about you, for example, "oh, our teacher must have done something wrong". You will lose face and prestige. (C2FmT6)

I try to avoid criticising a teacher in front of others, particularly in front of students or parents. It's like an insult if a leader behaves in such a way. It hurts teachers' feelings and self-esteem and makes them lose face. It is advised that "keep the door closed when giving advice". That's the way to protect prestige of each other. Nobody wants their faults discussed in public because they don't want to lose face and prestige. (PC2)

Leaders believed that controlling emotion and temper was another strategy used to maintain harmony and protect face. The principal commented, 'I'm a hot-tempered 
father at home, but an imperturbable leader at work". The vice-principal revealed that he could sometimes get angry with subordinates, but he "never shouted at teachers". He commented:

Hot-temper is not a criterion used to select a leader! Want to be a good political leader? If so, you must be a person of "nobody ever knows when you cry, nobody ever knows when you're sad"! It's just a joke but it's true. An emotional person cannot be a good leader. At work, even when I get so angry with someone [teachers], I try to control my emotion and hide my anger. It's not necessary to show my anger. I just talk to them in a way to show that I am not happy with their work. In such a way, you don't hurt their feeling; you keep their face and protect their prestige, and of course your charisma (in their eyes) is also enhanced. (VPC2)

In order to protect individual or collective prestige and save face, people tended to hide personal issues and disputes and attempted to apply the strategy of "internal resolution". Teachers explained that they tried to resolve conflicts themselves rather than report to school leaders because when leaders knew of their conflict, not only was their personal prestige negatively affected but the prestige of the whole division was also affected. A teacher explained:

It's bad if the outsiders know your conflict. They might think that you are not united and your relationships are not harmonious. It affects not only you but other members also. (C2FmT4)

Some teachers agreed that hiding problems or conflict could protect face and prestige but could lead to "surface harmony" because problems or conflict were not thoroughly resolved the illusion of harmony to outsiders was projected to other people.

"Surface harmony" was mentioned by leaders when they discussed strategies for managing and solving conflict. The vice-principal commented: "Calm sea does not mean that it has no waves; calm water does not mean that there is no ferment below the surface". The principal described this phenomenon as "surface harmony", in which people concealed their problems or disagreement to avoid conflict. The principal admitted that:

Leaders should be careful about this phenomenon. Sometimes we are so selfsatisfied with the illusion of surface harmony that we forget to anticipate problems. Do not think that "when our decision or a new plan is strictly followed and implemented by teachers" means "they completely agree and support us". Back stage, people might have lots of criticisms. They might keep quiet because they respect your authority and they don't want to displease you. (PC2) 
Leaders indicated that the effort of solving conflict sometimes posed a dilemma for leaders. Leaders pointed out three common dilemmas. The first dilemma derived from a conflict between cultural values and legitimate regulations. The principal called it a "tình - ly" dilemma. If a leader dealt with a problem or conflict by using the "tình" approach, he was using relationship-based strategy to solve problems to maintain harmony with subordinates. If he deployed the "ly" approach, he used the power-based strategy to fulfill his leadership role and managerial responsibility. However, the way to deploy these approaches in a way that the harmony could be preserved and at the same time the school regulations were followed and authority was respected could pose a dilemma for leaders. The principal explained:

How to keep harmony with subordinates but at the same time complying with the responsibilities and roles of a leader is not easy at all. Sometimes it makes me headachy. For example, how do we deal with a teacher's fault? Discipline her? Yes, it's simple. We leaders are authorized to do that. But our discipline decision might ruin the relationship. Just warn her and ignore her fault to keep harmony and save her face? Yes, we can. But we are not fulfilling our leadership roles and managerial responsibilities that we have been assigned. We break the law for preserving relationships. (PC2)

Leaders confirmed that these types of dilemmas occurred when they had to use their power to solve problems with a teacher or student, whom they had a close relationship with. One example was that the vice-principal had a problem with his nephew, who was accused of cheating in an exam at his school.

The second dilemma was mentioned when leaders discussed the strategy for dealing with the "surface harmony" phenomenon. Leaders agreed that to minimise such a phenomenon in order to avoid "implicit conflicts", leaders should build a more democratic working climate for people to express their opinions without constraint. However, as leader participants admitted, people in their school were reluctant to confront others. The principal pointed out that disclosure and critical arguments were avoided in meetings or in interpersonal interactions even though they were encouraged because they might be perceived as a threat to authority and the hierarchical relationship. They were also believed to lead to confrontation and ruin solidarity amongst people. The need for "total openness", in leader participants' perspectives, may not fit neatly with their school situations. It appeared that school leaders were faced with a dilemma as to how to build a suitable working environment in which both implicit and explicit conflicts were controlled. As the 
principal added: "we try to avoid "implicit conflicts" but "explicit conflicts" are more likely to happen".

The third dilemma occurred when leaders respected senior officials' authority to maintain harmony with them while making an effort to reconcile their decision with staff benefits and aspirations. Leaders confirmed that they sometimes saw themselves in a no-win situation: to make a decision that strictly complies with senior officials' directives, which could conflict with staff interests and benefits. As in the example of the vice-principal:

I was asked to deploy "the campaign on raising money for the poor" requested by PETS, in which each teacher was asked to donate an amount of money equivalent to at least two days of their wages. I knew that teachers were not very happy with this campaign because they thought they should have donated money with their charity voluntarily. How could we leaders deal with this? If we had deployed, the teachers would have felt uncomfortable with our decision; if we hadn't, senior officials would have been very unhappy with us and we would have been criticised for not fulfilling our leadership roles. (VPC2)

Leaders admitted that they were sometimes under a lot of pressure when implementing senior officials' instructions. This was because they had to follow the senior official's instructions strictly to show their respect for authority and avoid conflict as well as maintain harmonious relationships with senior officials even when the instructions/directives were not suitable for their school. The principal stated:

We had to follow their instructions although sometimes we did not want to follow them at all. If not, we might be accused of not executing the Party's lines and policies or not respecting their authority. I am sure that conflicts would then be inevitable. (PC2)

To illustrate the dilemmas that he faced, the principal gave the following example:

One of my young teachers who got a $\mathrm{PhD}$ degree wanted to quit his job in my school to find another job in a bigger city. I supported his decision because I thought that he would prove his ability better in a more challenging environment rather than working as a normal teacher in my school. But PETS officials did not agree. They told me, "don't let him go. We need to keep staff with high qualifications". It was a big dilemma for me: to do what PETS wants will disappoint my staff; to sign a decision for him will oppose PETS's directives and will disturb harmony with senior officials. In the end, I had to respect PETS's instructions. (PC2) 


\section{School C}

\section{Background of school: A reflection on power and administration structure}

This school was established in 1994 to address the increase in secondary school students. This school recruited local students aged between 11 to 15 years for grades 6 to 9. Annually, it had approximately 1,100 students enrolled. Sixty teachers and other staff worked fulltime, in which the percentage of female teachers and staff accounted for $76.78 \%$. The teachers held either an associate degree $(42.8 \%)$ or a university degree (BA) $(65.2 \%){ }^{11}$

The school was under the direct administration of the District Education and Training Service (DETS). Teachers and staff were recruited and employed by DETS. The school did not have a role in teacher and staff recruitment. The school leaderresponsibility system had not changed the relationship between the school and state. The need for "autonomy" and "self-determination" on the part of the school management system was evident and increasing over time. The education bureaucracy had power over educational policy, staff establishment and allocation of human and financial resources. The principal stated:

We use human resource but we don't have any rights to make personnel decisions. It's quite funny, isn't it? Because I am a school leader but my teachers and staff are selected and recruited by DETS. In some cases, DETS recruits a teacher who majors in a certain subject that our school does not need at all. For example, we now have six teachers of English, but five is enough. It's similar to wanting to eat rice, but your mother only feeds you bread. (PC3)

DETS was not authorised to make personnel decisions for the leadership position of the Principal Board. All members of the Principal Board were approved and appointed by the Chairman of District People's Committee based on the recommendation of the head of DETS. ${ }^{12}$ School leaders explained that although DETS was not authorised to make a final decision on the appointment of a school leadership position, it had de-facto power to nominate and recommend a person to a leadership position.

\footnotetext{
${ }^{11}$ Teachers at secondary school level are required to have an associate degree (three years of training in a college) or a BA (four years of training in a university)

12 Article 18 of the Statute of the primary school, high school and the school with multi-level issued by Vietnam MOET in 2007.
} 
School C had a similar organisational power structure to Schools A and B although these schools belonged to the three different educational levels (see Figure 6). The school had eight different functional units under direct political leadership of the Chi uy (the Executive of the School Communist Party Cell - CPCE) and the administration of the Principal Board. The top-level political power was held by the Executive of the School Communist Party Cell.

Unlike Schools A and B, the vice-principal of School C held the position of the CPCE secretary, whereas the principal was in the position of the vice-secretary. The principal was responsible for administration and the CPCE secretary concentrated on political and ideological work. The CPCE had more power than the principal. However, the de-facto power of leadership was highly concentrated in the principal's hands due to an unclear power division in the organisational structure of the school. As the vice-principal revealed, the influence of the Party in a small organisation was less significant than its influence in a bigger organisation. With this political power structure, the educational politics and administration were not separated, but were structurally integrated. The advantage of the connection of administration and political work was that the Party's politics could be thoroughly embraced amongst school leaders. This arrangement for the school leaders' dual role facilitated the process of "bringing the directives and the will of the Party into the administrative work" (PC3).

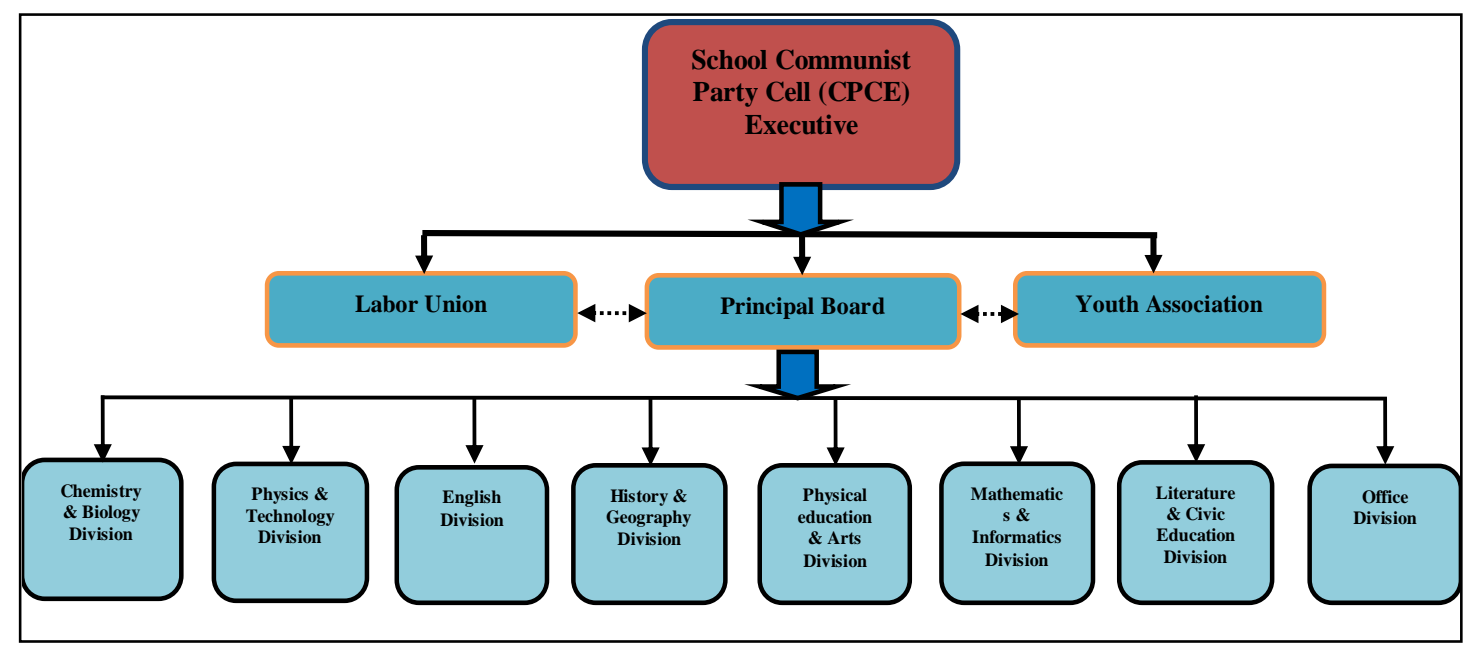

Figure 6: The Power and Management Structure of School C (Source: The school's administrative documents)

The leadership and management system of the school had experienced three generations of school principals since its foundation. No female had ever been appointed to the position of principal. There had been four vice-principals since the 
establishment of the school, in which the percentage of females holding this leadership position was relatively high (50\%) in comparison with Schools A and B (accounting for $16.66 \%$ for these two schools, see Table 8 and 11). The proportion of female participation in the Principal Board since its establishment accounted for $28.57 \%$ (See Table 14). The statistics show that most leadership positions on the Principal Board had been held by males since its establishment.

Table 14: Statistics of the Principal Board of School C from its establishment until the present day (Source: The school's administrative documents)

\begin{tabular}{|l|c|c|c|c|}
\multicolumn{1}{|c|}{ Positions } & Number & Female & Male & $\begin{array}{c}\text { Percentage of } \\
\text { female staff }\end{array}$ \\
\hline Principals & 3 & 0 & 3 & $0 \%$ \\
\hline Vice-principals & 4 & 2 & 2 & $50 \%$ \\
\hline Total & 7 & 2 & 5 & $28.57 \%$ \\
\hline
\end{tabular}

Compared to Schools A and B, School C had a significantly high percentage of women's participation in leadership at lower-level administration (see Table 15). With approximately 60 teachers and staff working full-time, of which females account for $76.78 \%$, the proportion of women holding leadership positions at lowerlevel administration accounted for $62.5 \%$. Women's participation in leadership at all administrative levels made up $54.55 \%$. These percentages show that the proportion of women's participation in leadership at all administrative levels in this school was relatively high in comparison to Schools A and B (accounting for 35\% and $33.33 \%$ respectively).

Table 15: The gender statistics of the current management staff of School C (Source: The school's administrative documents)

\begin{tabular}{|l|c|c|c|c|}
\hline \multicolumn{1}{|c|}{ Positions } & Number & Female & Male & $\begin{array}{c}\text { Percentage of female } \\
\text { management stafi }\end{array}$ \\
\hline Principal Board & 3 & 1 & 2 & $33.33 \%$ \\
\hline Heads of Division & 8 & 5 & 3 & $62.50 \%$ \\
\hline Total & 11 & 6 & 5 & $54.55 \%$ \\
\hline
\end{tabular}


When asked if this significantly high proportion of female participation in leadership meant that women and men were equal in positions of power, leaders explained that the high percentage of women involved in leadership position at lower-level administration was evident in secondary schools, primary schools and nursery schools as female teachers dominated the numbers. In this school, some divisions had all female teachers. This explains why the principal did not have any other choices in terms of gender when personnel decisions were made. In the principal's words: "among all female teachers in a male-absent division, we have to nominate one who is believed to be the best for such a leadership position" (PC3).

\section{Leader participants}

The Principal Board had three members; two of whom accepted to participate in this research, one male principal, and one female vice-principal. One vice-principal could not participate due to his unavailability.

The male principal had had 29 years of experience in school management and leadership. He was assigned to hold the position of principal in this school for six years (at the time of writing this thesis) in accordance with the leader rotation plan of DETS. ${ }^{13}$ Prior to this, he worked as a principal in other local schools.

The female principal had had a teaching career of over 18 years. After 10 years of working as a teacher, she was assigned to the vice-principal position in this school. She considered her appointment as a "special case" as she was assigned when she was 32 years old, "so young to become a school leader". She described her feelings and obstacles when she became the vice-principal:

Normally, a teacher becomes a school leader when he/she is at the age that shows enough maturity in his/her actions, behaviour and thinking. I mean that he/she should be "old enough" so that everyone can respect his/her managerial position and accept his/her as their leader. I became the vice-principal at the age of 32. At that time I still felt that I was so young to be a leader. Many teachers were much older than me; some teachers used to be my former teachers. I considered the "age" factor an obstacle for my new leadership position. Just imagine that you used to be their students or their colleagues for a while, then one day you become their leader! As a result, I was very worried about my new leadership position. The school entrusted me with managerial roles, however, I was not sure that I would be able to fulfill my managerial roles as they

${ }^{13}$ According to the Statute of General Education (issued in April, 2007 by Vietnam MOET), a school principal term is five years. A school leader holds the position of principal for no more than two terms. 
expected. I was quite young, lacked managerial experience and was still not familiar with the new position... These feelings remained me for quite a long time. (VPC3)

Her primary responsibilities included managing and directing the school's extracurricular activities and being in charge of managing the professional activities of the social science subjects.

\section{Exercising power and authority}

Similarly to the participants' perceptions in Schools A and B, it could be inferred that the participants in School C also considered 'power' as a tool that the principal needed for "control[ling] what people do, when they do it, and how they do it" (Sergiovanni, 1992, p. 133). All participants believed that power and authority were attached to a leadership position. Participants believed that the leader's power derived from the position he/she occupied in the hierarchy. They emphasised that the leader's power was coercive; failure to follow orders subverted the entire community and usually led to discipline or dismissal. In the words of a teacher:

\footnotetext{
Leadership means giving directions or instructions to subordinates to fulfill a certain task and observing all school activities to make sure that they are under control and people do the right things. If a school leader does not give directions, does not control activities, teachers and staff can do what they want to do. For example, they might go to school late; they might not make lesson plans; they might not fulfill their assigned tasks and so on. I mean that they do not do the right things. Hence, leadership means using power and authority to direct, control, and manage people to go the right way. (C3MT3)
}

Teachers agreed that power had two sides: negative and positive. It was positive when power was rationally exercised to set up a good habit of working for the school community. It was negative when power was abused by school leaders in order to set up the habit of obedience without considering subordinates' opinions, aspirations and feelings. Teachers believed that when the habit of obedience or order was highly emphasised, it resulted in the school's working climate being more stressful as well as limiting the creativity and imagination of teachers and staff. Due to obedience, teachers always expected school leader's instructions to carry out a task. They explained that they felt more secure when following school leaders' instructions rather than proceeding with it in their own way.

Teachers agreed that school leaders had to be ready to use coercive power to reinforce policies essential to the school's mission or to reestablish the order in case 
conflicts arose. Similarly, school leaders saw power as coercive enabling things to get done. They believed that not all teachers and staff were self-motivated and selfdisciplined. For the reasons of fairness and efficiency, school leaders used power in a coercive way to establish a good habit of working, especially for those who were slack or undisciplined. Coercive power was used to make teachers and staff become aware of their own daily work. As the principal explained that people did not want the leader to impose his ideas on them, but he used his positional power to impose what he thought was right with the purpose of achieving the school's goals. He stated:

For example, teachers might not want me to check their lesson plans, markrecording notebooks, ${ }^{14}$ or other kinds of things. However, I have to carry out my monthly inspection to check these things to see how well they do their work. I have to do that for the benefit of the school. (PC3)

In School C, the leaders had the power to carry out a monthly inspection of teachers' work. For example, they could check a teacher's lesson plan and observe a teacher's lesson to see how well the teacher was carrying out his/her work. An "unscheduled inspection" (kiểm tra đột xuất) was sometimes carried out with the belief of "preventing a teacher from becoming lazy". The leaders confirmed that a managerial strategy was effective in establishing the habit of self-discipline for teachers. Leaders explained:

Sometimes teachers are lazy, they teach a lesson without preparing a lesson plan. Hence, when we carry out the unscheduled inspection, teachers don't really know when they will be inspected. In that way, we make sure that teachers are more responsible for their work. (VPC3)

My responsibility is to manage and direct people to follow the school rules strictly. For example, teachers have to make lesson plans before teaching; students have to complete their homework as a requirement for their study progress; office staff have to do their office work well to support teaching and learning activities and so on. From my experience, no guidance, no checking, and no inspection can make people lazy or do things perfunctorily. As people say "when the cat is away, the mice will play". This proverb describes exactly what will happen if the leader does not keep an eye on people's work. (PC3)

Moral power which was described as 'the leader's influence comes from followers' respect for his or her personal quality, expertise, or position" (Lashway, 2006, p. 84). This idea was emphasised when the participants discussed how the school leaders built up and protected their prestige in order to gain respect from followers.

\footnotetext{
${ }^{14}$ A mark-recording notebook is used by a teacher to record all marks that a student obtain during a school year.
} 
Participants emphasised that the leader's prestige comes from his/her social and professional knowledge, charisma, moral quality, and personality. The leader's prestige was not believed to come from his/her managerial position. According to participants, prestige was "extremely important for anyone who is in the position of leadership" (VPC3). Some participants explained as follows:

Without it [prestige], you will lose half of your power! You cannot exercise your authorized power effectively if you are not prestigious in your subordinates' eyes. (VPC3)

To exercise power effectively, the leader must be respected by subordinates first. How to be respected? He/she must be prestigious. (C3FmT6)

Participants differentiated the concepts of "prestigious leader" and "autocratic leader". The prestigious leader sought submission from his/her subordinates by setting a good example, self-cultivation (in terms of morality and professional knowledge), and respecting teachers' opinions. The autocratic leader sought teachers' submission by using his/her managerial position to impose ideas and taking action that would accomplish objectives in an authoritarian style. Teachers admitted that their school leaders tended to be more autocratic when they were in the role of a decision-maker or when giving instructions. They relied on their prestige when dealing with conflicts or building relationships with teachers.

The establishment of order and obedience among teachers and staff was clearly reflected in the process of leadership. Teachers and staff did not play an active role in the decision-making process and relied on school leaders' instructions when carrying out an assigned task. They avoided challenging the logic of managerial directives and were not willing to make their own decisions. They were not allowed to be involved in making decisions about curriculum and had to strictly follow DETS' professional instructions. Teachers and staff had to implement plans or decisions made by DETS without any argument. The following quote indicates the high expectation of obedience in the school leadership process:

Annually, DETS promulgates a standardised lesson plan sample and requires all teachers to follow it. Lots of teachers complain about it because teachers of different subjects need to make the lesson plans in their own format rather than copy the same sample. It's quite ridiculous because all lesson plans look the same. Teachers are not allowed to make it different and if we do, we might be blamed for "not following DETS' professional instructions". We don't want to take risks, we just follow the instructions. (C3FmT4) 
Leaders saw "sharing power" as a delegation process in which the principal delegated important tasks to other vice-principals with some degree of autonomy and accountability. The leaders agreed that delegation was inevitable and must be employed for better school management and leadership. Delegation, as participants confirmed, aimed to share responsibilities among school leaders and to reduce the load of work on the principal. However, delegation was not a complete shift of empowerment. The principal showed a willingness to delegate tasks to other viceprincipals but he stated that his own accountability prevented him from providing the vice-principals with total autonomy. He was concerned about "complete delegation". He had to keep an eye on other school leaders' work to ensure that everything went well and wrong decisions were avoided. He stated:

If a vice-principal makes a wrong decision, the principal will suffer consequence. I will be blamed for irresponsibility. I think that when the principal exercises a complete delegation, he take a risk. (PC3)

The vice-principal said that most decisions were made by the principal. She perceived her role as an "assistant" who helped the principal complete the managerial work rather than as a "full power leader" who made decisions with complete autonomy. As she stated:

To a certain extent, I can make decisions but my decision must be in line with the principal's direction. Normally, we [vice-principals] have to ask the principal's opinions before making decisions. If he agrees, we can do it, if not, then we have to follow his opinion. (VPC3)

What leaders perceived as their managerial roles and emphasising the principal's accountability could have been influenced by the regulations in educational governance as defined in the Statute of the School of General Education ${ }^{15}$ (Article 19: Tasks and authority of principal and vice-principal). The Statute explicitly spelt out that "the principal is fully accountable to senior leaders for all things happening within the school", whereas "the vice-principal is accountable to the principal for tasks and duties assigned by the principal". This explained why school leaders attached importance to accountability in exercising leadership and why delegation was not treated as a complete shift of empowerment.

School leaders identified three main factors that impacted on the delegation process. These were the vice-principal's competence, experience, and the relationships

15 The Statute was issued in April, 2007 by the Vietnam Ministry of Education and Training. 
between the principal and the vice-principal. The principal preferred using competence-based criteria when delegating important tasks to a vice-principal. Evidence of the vice-principal's ability and performance and his/her record of experience were important. The principal admitted that the more trust he placed in the vice-principal's competence and ability, the greater the degree of delegation was guaranteed. However, competence-based criteria were not enough for enhancing the delegation process amongst school leaders. The maintenance of good relationships among school leaders was believed to stimulate the willingness to delegate. The principal was more willing to delegate important tasks to vice-principals when good relationships were maintained. He explained that if he had vice-principals to delegate an important task to, he would choose someone who had a closer relationship with. In that way he was more "secure". The principal explained:

A good relationship with a vice-principal can guarantee his/her commitment to the delegated task and his/her loyalty to the principal" and "it is easier to share a mission and vision of the task when implementing it. (PC3)

When discussing the factors that could affect the process of the exercise of power, participants said that the professional knowledge, experience, age, and moral quality of school leaders could either enhance or lessen their power. As teachers confirmed that they showed more respect and felt more submissive to an older and experienced school leader than a younger one. Teachers agreed that the prestige of a leader was linked to moral quality and professional knowledge. A school leader with good professional knowledge and moral quality (at least in the teacher's eyes) gained more support and respect from teachers.

With regard to gender, teachers preferred being led by males. Teachers used a number of adjectives to explain why "male leadership" was more preferred over "female leadership". For example:

Male leaders are more decisive, assertive and firm than females. (C3FmT5)

Male leaders are stronger and much more decisive in terms of power exercise. They seem to be more appropriate in leadership positions than females. (C3FmT4)

Females are usually meticulous and emotional in work. (C3MT3)

Apart from the prevailing norms of femininity as described by teachers that could affect a women's leadership, the everyday "heavenly mandate" attached to a 
woman's role also challenged women in their daily managerial work. This was indicated in the following quote from a female participant:

Apart from fulfilling office work, we [female leaders] have to fulfill our role as a mother and a wife at home. I have two children aged 5 and 11 . So I have to spend lots of time looking after them. We are expected to look after our home, do house work, and spend hours and hours doing domestic chores. My husband is also an official. He sometimes helps me with housework, but I do most of it. Sometimes we feel stressed because we have a lot of work to do. It seems to me that women leaders must work twice as hard as men to balance their multiple roles. This is the reason why women don't want to strive for a position of power. They are happy in the role of "normal people" who work eight hours a day and still have time to look after their families. Women are also limited in building relationships and making connections with other people, particularly with senior officials who have a strong influence on the school because they don't participate in social activities outside working hours due to their busyness in housework. A male leader can enjoy such activities but we cannot. I think this also limits our managerial work. (VPC3)

\section{Building relationships}

The hierarchical values were reflected not only in the school structure and in the exercise of power but also in people's perspectives on relationships. People built relationships based on their own place determined by duties, responsibilities and status. For example, participants believed that the principal should be respected due to his status and authority. Teachers stated that teachers could not be an par with school leaders because of the difference in authority, responsibilities, and roles. Teachers had good relationships with their school leaders, but this did not necessarily mean "close relationships". This explained why teachers emphasised the existence of a "gap" in relationships with their school leaders. Leaders confirmed that this gap existed in relationships with teachers and staff and agreed that hierarchical values impacted on the process of building relationships. The vice-principal said:

Staff seem to keep a "secure distance" with their leaders even though we leaders are open and out-going. I think it is because people acknowledge and attach much importance to social positions and authority in the work-place. (VPC3)

The interviews with teachers indicated that the existence of traditional values of respect for authority and the tendency to preserve harmonious relationships with leaders was reflected in the following typical behaviour patterns of teachers towards leaders:

- Teachers often showed humble attitudes towards their leaders; 
- Teachers tended to comply with leaders in the interests of harmony, even if they disagreed with them. If a teacher disagreed with the leader, he/she also agreed with what had been said and avoided voicing their disagreement in a direct way or his/her disagreement could be voiced but in an indirect and private way;

- Teachers could use "strong language" when giving feedback on their colleagues' work, but usually used "mild language" when they were asked to give feedback on their leader's work;

- Teachers tended to avoid complaining to their leaders directly when they encountered a certain problem. Instead they voiced their complaint in an informal channel, such as with their colleagues, their heads, or even with their relatives.

Although teachers believed that respect for school leaders accompanied their position, status and authority, they also believed that school leaders had to earn respect by building and maintaining good relationships.

Leaders considered "preserving and cultivating harmony" with staff as a strategy for facilitating their school leadership. Leaders explained that building and maintaining good relationships with staff was an effective strategy to ensure teachers' loyalty and commitment. Maintaining good relationships with staff helped leaders "run and manage the school more smoothly", "build trust", "consolidate the leader's prestige/power", "reinforce teachers' support" and "strengthen teachers' bond to school". Leaders said that teachers seemed to be more "submissive" if harmonious relationships were maintained.

Leaders adopted a range of strategies aimed at cultivating and preserving harmonious relationships with staff, in which leadership style had significant influence on the relationship building process. They stated:

Be open-minded, willing to listen to and respect their [staff's] opinions, be strict at work but out-going in social life, as close to them as possible to understand their thoughts and aspirations. If I always behave towards them in a bossy mood, I will make the gap with them more sizable. As you know, staff are often afraid of having conversations with leaders and avoid expressing their opinions if you don't make the working environment friendly enough. (PC3) 
My principal is quite open, sociable, out-going and accessible. Although he is the school "boss", he is close with subordinates. He is not stuck-up. He leads the school in a democratic style: He listens to staff opinions; he acknowledges other school leaders' suggestions. (VPC3)

Teachers placed emphasis on leadership style when they were asked how school leaders built relationships with staff. As one of them revealed:

I have worked under the regimes of three principals, so I have the comparison between the principals in mind. The present principal makes a good impression on me through the way he works and behaves towards his followers. He's close to his followers, friendly and collaborative in work. (C3FmT4)

For teachers, their principal's leadership was not focused on power. He liked meeting and talking with teachers during the break times, having tea and joking with them when he had free time. It was a way of building relationships and minimising any "gap" between teachers and the principal.

Communication was an important factor that impacted on relationship building and the prevailing view about "attitude toward age" was still highly valued. Older teachers deserved respect because of their teaching experience and knowledge. This explained why leaders had to be careful over how they communicated with older teachers. The vice-principal explained:

I have to be very careful when communicating with older teachers. While I can say directly to a younger teacher what I disagree with him/her about, I never make derogatory remarks towards older teachers because it can hurt their selfesteem. Older teachers tend to be more sensitive. An acrimonious remark or criticism may be a severe hurt to their self-respect. (VPC3)

The principal claimed that he was reluctant to criticise older teachers as public criticism from a leader towards a younger teacher was acceptable, but it was seen as an insult when an older teacher was involved. To reduce the risk of conflict and preserve harmony with older teachers, leaders tended to avoid bringing the issue into the public arena to save face of older teachers. When leaders were not satisfied with an older teacher's work, they preferred to have a private conversation and use "mild language" to dilute criticism.

Some activities were also highly appreciated by the participants when they discussed the process of relationship building. All teachers and staff contributed a small amount of money from their salary to set up the school's welfare fund each month. This fund was used for helping school members with illness or difficulties in life, and 
for supporting teachers' social activities, such as buying presents for young teachers' weddings, teachers' birthdays, or organising a New Year party. It was also used for organising short visits for teachers during the summer holiday. Participants believed that these activities created caring relationship webs amongst people and "knotted people together".

Collaboration in work was highlighted when participants discussed people's relationships. The school created a collaborative environment for professional development. For example, teachers participated in a colleague's lesson to observe their teaching method. After the observation, they had a discussion to identify "good points" and "things needing improvement". This activity was expected to establish a collaborative environment. However, according to participants, teachers found it difficult to offer "candid feedback" in these activities because they could lose face if the feedback was "too blunt" or "too candid". As a result, teachers' comments on performance were sometimes "superficial" to avoid displeasing people.

Interviews indicated that building and maintaining external relationships with senior officials was a concern for school leaders. The principal revealed that he had good, close relationships with DETS officials and the relationships helped his work. For example, he could call a DETS official to ask for opinions instead of "taking time to write a formal letter" or "making an appointment for a face-to-face meeting". $\mathrm{He}$ revealed:

Everything becomes possible and work can proceed rapidly, sometimes faster than you expect if you have close relationships with them [senior officials]. If you don't maintain good relationships with them, you may find that things take longer than they ought to. (PC3)

\section{Decision-making}

Interviews indicated that the process of decision-making relied heavily on the authority of school leaders. Teachers confirmed that they did not have a role in the decision-making process and the role of school leaders was as decision-makers. They stressed that the school relied on a small number of decision-makers, such as the principal and the vice-principals. They depended on school leaders to make all of decisions. They stated:

The principal's decision is the highest. Everyone must accept, obey and execute it. (C3MT3) 
The principal is the person who has the highest power in the decision-making process because he is responsible for all school activities. The most power is in the principal's hands. (C3FmT4)

This was also confirmed by leaders. Leaders supported the maintenance of autocracy in terms of the decision-making process because of the demands of accountability for whatever happened in the school. The principal explained that he felt a need to assert his prerogative as a final decision-maker because everything occurring within the school was his responsibility. The principal stated:

In the decision-making process, I have full power to make decisions, to accept or refuse other people's opinions because I am responsible all of the school's activities. I am supposed to be answerable for all things that happen in the school. I may face criticism from senior leaders if anything is to go wrong. (PC3)

Given their preference for maintaining autocracy in the decision-making process, leaders expressed the importance of seeking teachers' consensus and participation. Leaders encouraged teachers and staff to participate in school or group meetings. They agreed that encouraging teachers to participate in decision-making was a way to share responsibility and to attain a high degree of unanimity amongst leaders and teachers. The principal confirmed:

The leader's decision seems to be more convincing if a discussion is open for all teachers so that school leaders can know what teachers think about it. (PC3)

Although leaders emphasised the importance of teachers' involvement in the decision-making process and employed a number of strategies to get teachers involved, they admitted they continued to have challenges in getting teachers involved. As in Schools A and B, teachers in School C showed their strong reluctance at being involved in the decision-making process. Leaders admitted that teachers very rarely offered opinions or confronted leaders because it may be seen as disrespectful. In the words of the vice-principal:

Teachers are quite reserved in expressing their ideas, particularly to school leaders and in school meetings. Although we leaders are quite open and we encourage the democratic attitudes of all school members in discussions, it seems that it is difficult for them to "break the ice" to express their ideas. (VPC3)

Participants believed that the working environment had become more democratic and open but they were still reluctant to contribute their opinions because of the following reasons: (1) This could lead to some type of conflict if their opinions 
displeased school leaders; (2) Teachers felt that their opinions were not so important for school leaders and that they did not have much influence in the decision-making process; (3) Teachers felt that they lacked managerial knowledge and experience necessary to make a worthwhile contribution, consequently keeping silent was a strategy for "saving face"; and (4) Teachers' involvement was affected by hierarchical and etiquette values.

There was more active involvement in smaller group settings such as in division meetings or professional group meetings. Teachers confirmed that they were more able to contribute their ideas in monthly meetings within their division or professional groups. One of the teachers revealed:

Within our division, we could argue with each other for hours and hours because people have different points of view about something. It seems to me that teachers feel much more confident to confront each other and they are not afraid of speaking up about their ideas. They are even willing to express their disagreement. But in the meeting with the presence of school leaders, things are so different, people are so reserved. (C3MT1)

The trend toward more involvement of teachers was evident in the decision-making process. Participants revealed that the recruitment of secondary school principals did not involve teachers and staff much because DETS and the District People's Committee controlled the recruitment and appointment process. The recruitment of principal was more democratic than it was in previous times because teachers and staff were invited to participate in the recruitment process by casting their votes on a "prestige index" (phiếu tín nhiệm). The procedures for conducting a poll on the prestige index can be described as follows: (1) DETS nominates a school leader candidate who is believed to be the best for the principal position; (2) Teachers and staff are asked to cast their votes for the prestige index; (3) The final result of the prestige index is used as a reliable source of information for considering the eligibility and appointability of a leader. A leader candidate with a high ranking of prestige index (more than two-thirds of teachers' agreement) is more likely to be nominated as a principal. Teachers confirmed that although a leader's prestige index was not used for the final decision and they did not play a decisive role in the recruitment of principal, they felt more responsible and empowered through such a recruitment process. This kind of internal assessment could at least increase the transparency and recognition of the teachers' role in the personnel decision-making process. As teachers revealed that in some cases the person who had a low-rank on 
the prestige index could also be recruited. Teachers thought that this could explain why leaders cultivated and maintained good external relationships with local government. And this could explain why school leaders admitted that having a good relationship with the local government was important. Teachers acknowledged that it was difficult to eliminate the influence of relationship factors on leader promotion and appointment. However, the teachers' involvement in such a promotion and appointment process could help school leaders with a low prestige index "adjust their leadership style", "cultivate relationships with teachers" and "make more effort for the school's development" to "regain prestige".

Leaders indicated that the bureaucracy in the educational system continued to have a significant influence on the school decision-making process. Leaders had to implement the instructions from the local government or educational senior officials. Failing to do this could lead to potential conflict between school leaders and the local government. If the conflict occurred, it could be a "potential risk" for the school given the allocation of financial and human resources relied heavily on the local government's decisions. The principal stated:

Sometimes I feel that we school leaders seem to be the instruments of state policy. It's quite difficult to refuse instructions from above. When we receive an instruction from above, we have to implement exactly what we are instructed without refusing it. The problem is that not all instructions or decisions are suitable for the school, but we have to put it into action. (PC3)

This was confirmed by teacher participants who stated that:

They [school leaders] obey and execute any decisions made by higher officials such as DETS, PETS or MOETS. Last year we started the campaign "Each teacher is an example of morality and self-learning" launched by MOET. We were not very happy with some of the content of the campaign. We know that the school leaders weren't either, but they had to implement it. They don't have any other choice. They just do what senior officials ask of them. (C3FmT5)

People were predisposed to accept the unequal distribution of management power in the hierarchical educational system. School leaders were tolerant of hierarchical management styles and positions of authority. Consequently, they did not openly state that they did not agree with decisions from senior officials. One of the teachers remarked:

School leaders never dare to openly question the reasoning behind the directive of senior officials such as PETS and DETS. (C3MT2) 
At the school level, leaders were considered to be authoritative decision-makers. All school members were to respectfully obey school leaders' decisions. The viceprincipal confirmed: “A decision made by the principal is considered as a 'must' that every school member has to obey and follow" (VPC3).

It would seem that two main factors affected the decision-making process:

(1) Age and experience: Similar to Schools A and B, participants in School C admitted that older and more experienced teachers seemed to be more willing to express their ideas than their younger colleagues. Participants pointed out two main reasons. First, younger teachers' opinions were not considered as important as their older colleagues because they were thought to have less experience. Secondly, people had typically been raised to respect their elders and seniors and were reluctant to offer opposing opinions. A teacher stated: "Younger teachers are not willing to do so because if they do, other people may think that they "offer to teach fish to swim", whereas, older teachers seem to be proud that with their age comes wisdom" (C3FmT4). In terms of personnel appointment, experience seems to be overaccentuated. As in a teacher's illustration: “Two vice-principals were selected as candidates for the principal position (in case the present principal retired soon). The person who was more experienced (in terms of age and working experience) was more likely to be recruited" (C3MT2).

(2) Relationships: Relationship was believed to have a significant impact on the decision-making process. School leaders identified two crucial factors that they had to think of when making a managerial decision, namely getting things done and preserving harmonious relationships with staff. Teachers admitted that the closeness in working relationship between a school leader and teachers could result in school leaders making biased decisions. For example, as teachers stated, school leaders tended to have a priority for a teacher whom they had a close relationship with.

\section{Managing and solving conflict}

Leaders placed emphasis on "managerial conflict", which was likely to arise when school leaders could not balance the needs of the organisation (with an emphasis on 
tasks and outcomes) and the needs of individuals (with an emphasis on maintaining harmonious relationships). Interviews indicated that while school leaders made efforts to pursue the school goal and focused on the outcomes, they kept an eye on potential conflict, which could destroy the school solidarity. A school leader explained:

In management, I don't think that attaining a goal at any cost is a good idea. Although seeking the school goal is of the utmost importance, it does not mean that we must sacrifice all other things to achieve it. (PC3)

However, leaders revealed that "managerial conflict" rarely occurred in their school. This was also confirmed by the teachers. It seemed that teachers avoided challenging school leaders for the following reasons:

(1) Teachers assumed that they had to respect school leader's decisions because of their authority. It appeared that school leaders were granted respect by virtue of their superior position. A teacher pointed out: "We respect their decision because they are our leaders. I think no one in this school is willing to challenge school leaders' decisions. We just follow what they ask us to do rather than talk back to them" (C2FmT4).

(2) Teachers believed that challenging school leaders would risk disrupting harmonious relationships and it might put them at potential risk. A teacher said: "It is not easy for you if you don't maintain good relationships with them [school leaders]" (C3FmT5). According to teachers, open arguments or conflict between teachers and school leaders were rare.

Maintaining harmony was important in conflict management. Apart from listing some important strategies for preserving harmony and avoiding conflict such as "being careful when communicating, particularly with older teachers and school leaders", "avoiding direct criticism", "avoiding discussing sensitive issues" as in criticising someone's personality, or "respecting leaders' opinions and decisions", participants also emphasised the importance of the avoidance of emotional displays. For example, the principal saw "endurance" as an effective strategy to minimise the possibility of conflict. He explained:

Sometimes I feel angry if a staff member causes trouble or a teacher makes a mistake. In that case I just show him my displeasure rather than shouting at him in front of others. It's an insult and he will lose face if I do that. The leader 
should know how to hide his emotion, remain serene and know how to restrain himself not to lose temper even when something wrong is happening. (PC3)

Leaders emphasised that when they dealt with the daily work, they had to suppress their emotions to be "not too angry", "not too worried" and "not too anxious" in order to create the image of an imperturbable leader to set a good example. They believed that "quá giận mất khôn" (when a man grows angry, his reason rides off). Consequently, the suppression of emotion was not only to preserve harmonious relationships with staff but also to save the leader's prestige. This related to the notions of face and respect for both teachers and leaders which remained very important in public.

Participants strongly agreed that when conflict occurred within a group, group members avoided unveiling the "true story" to "outsiders". It was an unfavorable loss of face to insiders or the whole group when the "true story" was leaked to someone outside the group. Participants admitted that although they were not directly involved in the conflict, they felt shameful when the conflict occurred within their group. Concealing the conflict was to save insiders' face and protect the group's prestige. This was illustrated in the following example:

If a conflict, such as a quarrel, occurs between two group members, it not only destroys the insiders' own prestige but negatively affects the prestige of other group members also. The whole group may lose face if someone outside the group knows the story. We all might then be blamed for "mất đoàn kết nộ bộ" (internal disunity). That's why we are told over and over again that to "protect an individual's prestige is to protect the collective's prestige". (C3FmT5)

Teachers confirmed that they preferred to solve conflict by themselves or look for "giải quyết nội bộ" (internal resolution) to seek school leaders' involvement because they could lose face if school leaders knew their "true story". Teachers agreed that they tended to leave small issues (conflict) unsolved or ignore them to preserve harmonious relationships. Teachers explained:

A small issue can become a bigger one if two parties don't try to restrain themselves. When I have a problem with someone, I try to seek to make peace rather than argue with them for hours and hours to find out "who is right and who is wrong". If we do that, we might make matters worse. Sometimes "right or wrong" does not matter; the very matter is how to keep harmony with each other. (C3MT1)

Or as in a teacher's story as follows: 
Staff never quarrel with each other if there's the presence of school leaders. Let me give you an example. Two teachers were arguing noisily in the staffroom with the presence of other teachers. No one could stop them quarrelling. Someone saw the principal coming and then shouted out "stop, stop, he's [the principal] coming!" The two teachers stopped quarreling immediately and they kept silent as if nothing had happened. They did not want to let the principal know what was happening because they did not want to lose face. (C3FmT3)

Teachers sought out school leaders' involvement in their conflict when the conflict was "too serious" or when the problem seemed to be worse and both parties were not able to reach a final agreement to solve the conflict. Teachers said that in such a situation, school leader intervention was necessary because leaders could play the role of "a referee at the match who can make the final decision that everyone should follow".

Teachers also sought out school leader's involvement when they had personal problems such as a family problem. They believed that school leaders were good mediators because their opinions were significant due to their prestige and leadership position. This partly explains why school leaders placed an emphasis on the importance of prestige in the process of conflict resolution. The principal mentioned:

I am emphasising the prestige of a leader because people only listen to or accept the suggestions and advice from a mediator who is prestigious in their eyes. The voice of a prestigious mediator is always weighty and respected. (PC3)

It also seemed that seniority played an important role in the conflict management process. When a conflict occurred within a group, older members were the "prestigious mediators" to conciliate the discord. Seniority was believed to be connected with credibility due to their experience and imperturbability. A young teacher confirmed that she tended to seek older teachers' advice when she encountered a problem or when she was faced with a conflict. Other teachers believed that the experience, maturity and prestige of an older colleague could serve as powerful tools in a process of persuasion.

\section{Summary}

This chapter described how the four leadership functions, namely exercising power, building relationships, decision-making, and managing/solving conflict, were exercised in three selected schools in Vietnam. Data from four data sources was mixed and described within each case with the purpose of building up and exposing 
an idiosyncratic and complete picture for each case. Four leadership functions as predefined themes were used to form the structure of the descriptions. The next chapter presents a cross-case analysis. 


\section{CHAPTER SIX: CROSS-CASE ANALYSES}

\section{Introduction}

As this is a multiple case study using a phenomenological research design, a crosscase analysis is applied to integrate composite structural descriptions and provide a synthesis of the meanings and essences of the experience. This step is conducted as a phase of illumination in phenomenological study, which helps to expand awareness and deepen meaning of the data to bring new clarity of knowing.

The integrated data is analysed against the four pre-defined categories that arose from the research questions: (1) exercising power; (2) building relationships; (3) decision- making; and (4) managing and solving conflict. Within these categories, subcategories that arose from the analysis process are used as pattern analyses.

\section{Exercising power}

\section{The hierarchical administrative system}

In these schools educational administration and politics were not separated, but structurally amalgamated. The three schools belonged to three different educational levels, but their administrative systems had similarities in political and administrative structures. The administrative systems were structurally hierarchical and vertical in which the CPCO or CPCE held the most political power with an absolute role in directing the school. The school-party secretary concentrated on ideological and political work, while the principal was responsible for administration. These roles were separately established with the belief that they could balance power and against abuse of power by school leaders. In reality, these roles were not separated. Despite the division of power among the principal and school secretary, most of the principals played both roles. The principals were also school-party secretaries. In this study, the principals of School A and School B were the school-party secretaries, while in School C, the principal was the vice-secretary. The political and administrative power was highly concentrated in the principal's hands. Most participants admitted that the "voice" 16 of the principal represents the "voice" of the Party (politics) and the "voice" of the State (administration). School leaders believed

\footnotetext{
${ }^{16}$ Voice here means the directive
} 
that a principal's dual role facilitated the managerial process. As one of the leader stated, "it helps bring the directives and the will of the Party into the administrative work" (PC2).

All leaders in these schools were Communist Party members. Consequently, their beliefs reflected the ideology of the Party which is clearly defined in the 1992 Constitution of the Socialist Republic of Vietnam as follows:

The Communist Party of Vietnam, the vanguard of the Vietnamese working class and loyal representative of the interests of the working class, the working people and the whole nation, who adheres to Marxism-Leninism and Ho Chi Minh's thought, is the force assuming leadership of the State and society. (Article 4)

Interview findings revealed the CPCO/CPCE had a strong political influence on school leadership and administration. School members were expected to implement the policies and directives promulgated by CPCO or CPCE. The school leaders expressed their strong belief in the role of CPCO and CPCE in directing the school. They emphasised the importance of faithfully implementing the CPCO/CPCE policy and demanding all school members to strictly observe the CPCO/CPCE's rules and directions. The absolute role of the CPCO/CPCE was also admitted by the teachers without any political affiliation.

The hierarchical administrative structure reinforced the position power for implementation of new policies or plans. The directives made by senior leaders were always expected to be implemented by junior leaders. Participants in Schools B and $\mathrm{C}$ revealed that they had to implement the plans or programmes made and directed by PETS or DETS even though school leaders and teachers did not support them. The administrative structure and educational bureaucracy's external control also limited school leaders' powers over school policy and management, particularly the deployment of human and financial resources. In terms of personnel affairs, leaders in Schools B and C did not have any powers to make personnel decisions. Such decisions were completely concentrated in PETS or DETS officials' hands. All teachers in these two schools were recruited and employed by PETS or DETS. In School A, school leaders had more power in the deployment of financial and human resources. Generally, however, the administration of tertiary educational institutions was controlled by senior authorities. Prior to officially advertising employment 
vacancies, the schools' recruitment proposals had to be submitted to senior authorities for consideration and approval.

These findings suggest that the paternalistic culture of obedience and respecting authority, as dominant features of Confucian values, have been extended into the contemporary politico-administrative structure of schools. With such a politicoadministrative structure, the school's internal power hierarchy has reinforced its culture of obedience and respect for authority. The schools were configured with legitimised hierarchal power and authoritarian leadership. Owing to the continuing efforts of the Vietnam Communist Party to institutionalise and enhance its political role in all social and political aspects, the values of obedience to authority in management was reinforced. The documents of $11^{\text {th }}$ Vietnam National Party Congress such as Decree 71/1998 on the regulation of the implementation of democracy in social institutions emphasises its absolute role in leadership and governance as follows: "Expansion of democracy must be associated with ensuring the leadership of the Vietnam Communist Party based on the principle of democratic centralism" (Decree 71/1998, Article 2). This could explain why the extension of a culture of obedience has prevailed and seemed to be dominant in all three school cases. The vertical hierarchy of the administrative structure and the integration of educational administration and politics have further strengthened the Communist Party's power in the contemporary educational leadership.

\section{Participation of women in school leadership}

Gender statistics for the leadership and management staff in the three schools indicated that the percentage of women's participation in leadership was lower than men's. Overall, the percentage of women in senior positions (principal or viceprincipal) was significantly lower than men. The statistics on women's participation in the principal board from their establishment to the time of the study in the three schools showed that $14.28 \%$ of women held senior positions in School A, $12.5 \%$ in School B and $28.57 \%$ in School C (see Tables 8, 11 \& 14). At lower levels of power, the representation of women was higher. In School A, $29.41 \%$ of women were holding leadership positions in faculties, departments and divisions; while $37.5 \%$ of women were holding leadership positions in divisions in School B. The percentage of 
women holding leadership positions in divisions in School C is significantly higher, representing $62.50 \%$ (see Tables $9,12 \& 15$ ).

This implies that there were challenges for women's participation in school leadership. Interviews and questionnaire results further indicated that traditional cultural beliefs and practices have contributed to the under-representation of women in school leadership. Most teachers in the three schools showed that they preferred being led by male leaders. They believed male leaders are more appropriate to leadership positions than females due to their "masculine traits" such as decisiveness, rationality, assertiveness and being highly regulated. Such long-entrenched gender stereotypes have challenged women in seeking opportunities for participation in leadership.

Apart from the prevailing norms of masculinity and femininity, participants emphasised that one of the obstacles challenging women in participation in leadership was the everyday "heavenly mandate" attached to women's roles. In Schools A and C, all three female leaders believed that prevailing gender stereotypes did not influence their managerial work. They did believe that the heavenly mandate roles (such as giving birth, teaching children, and fulfilling housework) had impacted on their work. They had to perform a lot of "heavenly mandate roles" in addition to their full-time employment. According to them, such "taken-for-granted" roles have limited women's participation in leadership.

\section{Leadership styles}

When comparing the findings across the three cases, one of the significant points that emerged was that of an autocratic leadership style in exercising power. Participants perceived power as "power over" defined as being concerned with dominance, control, and hierarchy. In the process of exercising power, school leaders relied heavily on positional power and expected obedience from staff. In all three cases, findings indicated that "highly-expected obedience" was embedded in the domain of school leadership. Particularly, teachers and staff were always expected to obey and execute leaders' decisions and opinions. Leaders were traditionally expected to act autocratically. Teachers accepted that school leaders must be ready to use power or make decisions at their disposal to enforce policies in support of the missions of the schools. In some cases, participants supported the deployment of discipline and 
punishment as an effective approach to keeping order and discipline at school. In School A, participants agreed that discipline should be applied in order to prevent uncooperative attitudes and when an individual did not respond to the "quyền lợi của tập thể" (collective interests). In School B, participants agreed that school discipline should be tightened to make people more responsible for their work. In School C, participants believed that discipline could create a good working habit for the school culture. Cross-case findings indicated that school leaders believed that they used discipline as a solution to increase their subordinates' compliance and enhance their influence over subordinates.

An autocratic leadership style was also reflected in how school leaders perceived and practised their positional power. Cross-case findings indicated that all leaders supported the practice of positional power to influence staff as well as to impose their will or viewpoints on staff to achieve the school's mission. The leaders argued that although imposing viewpoints on staff seemed to be undemocratic, in some cases leaders needed to use their positional power to impose their ideas on staff to establish order and obedience. They believed that once order and obedience were established, schools would run smoothly and managerial work would be easier. The maintenance of obedience and order is in line with what participants saw as traditional beliefs about the different positions, status, responsibilities and roles delegated to different people in the school. It was generally agreed that a subordinate's responsibility was to submit to a leader's instructions or directives. Acting against this would lead to conflict or disharmony. Even staff obedience, in School B, was seen as a way that staff displayed their respect for school leaders. This explains why teachers in the three schools saw themselves as "inferior" and school leaders as "superior".

School leaders in all three cases believed that power was used to control what people did, as well as when and how. They emphasised that they used power as a "tool" to manage, lead and run their schools. Leaders and teachers supported the deployment of "coercive power", which was believed to "enforce policies", "get things done" and "keep order and discipline for the school". In School C, leaders agreed that coercive power was used to prevent teacher laziness or to make slack and undisciplined staff work harder and be more responsible. In Schools B and C, leaders tended to carry out more regular inspections such as checking teachers' personal profiles, teaching 
documents and observing teaching sessions to raise consciousness with the purpose of making staff aware of their daily work. Although the frequency of inspections in the three schools was different (generally every three months in School A, monthly in Schools B and C), school leaders generally agreed that carrying out regular inspections was to put pressure on teachers to make them work harder and be more responsible.

\section{Concentration on discipline and enforcement of rules to establish managerial order}

Concentration on discipline to establish managerial order for school effectiveness was emphasised as an important managerial approach in all three cases. School leaders regarded discipline as a way of establishing a moral order and cultivating staff responsibility. The interviewed leaders of all three cases revealed that they preferred using regular and unscheduled inspections to cultivate responsibility amongst staff. Their argument was that not all staff were self-motivated and selfdisciplined. Regular or unscheduled inspections were used to establish good habits and to get things done. Leaders used discipline as a solution to increase staff compliance and enhance their influence on staff. In School C, leaders admitted that they used unscheduled inspections to prevent teachers from becoming lazy. Leaders were authorised to check any teacher's work without prior announcement. They identified that this managerial strategy was effective in establishing the habit of selfdiscipline for teachers. Similarly, leaders of Schools A and B confirmed that when regular inspections were carried out, staff were more responsible and became more aware of their own daily work. PETS and DETS sometimes carried out regular or unannounced inspections in Schools B and C. They checked the schools' work to make sure that government policy, school discipline and rules were strictly enforced.

On one hand, teachers in all three schools admitted that the application of discipline as a managerial approach could be associated with subordinates' dissatisfaction; thereby making the working climate more stressful. On the other hand, they agreed that school discipline should be tightened to make people more responsible for their work. When the school lacked discipline or the enforcement of rules was inconsistent, the managerial order of the school was not maintained. Such a working 
environment made people "irresponsible" or "disregarded discipline" and "were unmotivated".

\section{The importance of leader's prestige and charisma in the process of exercising power}

Most participants emphasised the importance of leader's prestige and charisma in the process of exercising power. They agreed that the more prestigious a leader was, the more compliant, loyal and respectful subordinates were to the leader. Some participants viewed prestige as a source of power or key to a leader's success and enhanced the leader's power. Most participants emphasised that a leader's prestige was inextricably linked to the two most important qualities of the leader: moral quality and professional knowledge or competence.

Participants viewed the moral quality of a leader as more important than the other qualities and as the number one criteria for leadership delegation. For example, School A participants believed that the moral quality of leaders was more important than their competence. They mentioned that moral quality was important in assessing a school leader or a leader-to-be. In School C, participants agreed that leaders should have good moral quality (at least in teachers' eyes) if they sought more support and respect from teachers. In School B, the importance of a high standard of morality as a prerequisite for anyone who was in a position of leadership was emphasised. Generally, participants from the three cases believed that the good moral quality of leaders was reflected in the way they set examples for subordinates. When supervisors were unrighteous (setting bad examples), juniors were in disorder (doing bad things). Hence, leaders were required to be role models to cultivate a culture of trust in the school community. It was agreed that school leaders' words must match their actions. A leader's high standard of morality facilitated his/her exercising of power. The cross-case findings indicate the contrary features of high standard of morality and low standard of morality. These features are described and compared in Table 16: 
Table 16: The attributes of low and high standard of morality in leadership

\begin{tabular}{|l|l|}
\hline Leader of high standard of morality & Leader of low standard of morality \\
\hline $\begin{array}{l}\text { Leader was prestigious in school } \\
\text { community }\end{array}$ & $\begin{array}{l}\text { Leader was less or no prestigious in } \\
\text { school community }\end{array}$ \\
\hline $\begin{array}{l}\text { Subordinates were more compliant and } \\
\text { loyal }\end{array}$ & $\begin{array}{l}\text { Subordinates were less compliant or } \\
\text { "superficially compliant" }\end{array}$ \\
\hline $\begin{array}{l}\text { Leader gained more support from } \\
\text { subordinates }\end{array}$ & $\begin{array}{l}\text { Leader lost support from subordinates } \\
\text { Subordinates put trust in their leader } \\
\text { confidence in their leader }\end{array}$ \\
\hline $\begin{array}{l}\text { Subordinates showed their strong } \\
\text { willingness } \\
\text { implementing leader's directives or } \\
\text { instructions }\end{array}$ & $\begin{array}{l}\text { Subordinates might be submissive to } \\
\text { leader's directives or instructions but } \\
\text { they did not respect the leader }\end{array}$ \\
\hline
\end{tabular}

In the process of exercising power, professional knowledge and the competence of the leader were seen as the second most important qualities of leadership. For example, in School A, teachers were more inclined to listen to leaders whom they believed to have deep knowledge and good managerial competence. Teachers were likely to be disrespectful of leader's authority if they believed their own expertise was better than their leaders. This was similar for Schools B and C. In these schools, teachers' compliance to their leaders increased when the leaders' professional knowledge and expertise were acknowledged.

\section{Role models}

Setting good examples or role modeling emerged as an important trait of leadership in the three schools. Teachers expected their leaders to set good examples as they believed that staff were more affected by what their leaders did than what they said. Teachers considered that example setting was a process of building trust and stimulating staff to respect and obey leaders' authority and power. Similarly, leaders strongly agreed that setting good examples was an effective strategy of exercising power. They argued it was a way of setting standards and rules for staff and for reinforcing their power and authority. Cross-case findings indicated that staff were likely to be more compliant when leaders set good examples. Failure to set a good example might lead to losing leaders' prestige and charisma and diminishing the 
level of trust among the school community. When implementing government policy, a plan or a programme of the school, leaders were always expected to be exemplary as role models. Interviews with teachers from the three schools revealed that if a school leader succeeded in setting a good example, such as with morality, personality and knowledge, he/she would gain considerable respect and support from his/her followers.

\section{Delegation}

Most of the interviewed principals and vice-principals perceived "sharing power" as a delegation process in which the principal delegated important tasks to other viceprincipals with some degree of autonomy. Delegation was inevitable and was aimed at sharing responsibilities among school leaders and to reduce the principal's workload. All interviewed principals showed a willingness to delegate tasks to viceprincipals but they also emphasised their own accountability that they were responsible for all things happening in their schools. This explains why viceprincipals in School A confirmed that they were not completely empowered to make decisions because all their decisions must be approved by the principal before implementation. Similarly, vice-principals of Schools B and C admitted that they had to refer to their principals' opinions and sought their approval before making a managerial decision or implementing an important task. Delegation, as school leaders acknowledged, was regulated. It was the process in which the principal delegated tasks to vice-principals and guaranteed them a degree of autonomy for the process of implementation and decision-making but within or under the principal's monitoring and supervision. Most of the vice-principals preferred seeking their principal's opinions or agreement before making decisions rather than making decisions based on their own judgments. This reduced the possibility of erroneous decision-making which the principal would assume responsibility for when dealing with potential consequences.

Leaders in these schools were found to prefer using competence-based criteria for delegating tasks. They acknowledged that competence was the first criterion for delegation, but also emphasised the importance of experience and relationships. However, some participants emphasised the relationship-based criteria for the delegation process. They agreed that within the values of Vietnamese culture, 
relationship-based criteria were sometimes more important than competence-based criteria. They believed that school leaders had a tendency to delegate tasks to someone they trusted and had a close relationship with. This was also confirmed by the principals of Schools A and C. The principal of School C admitted that he was more willing to delegate important tasks to someone whom he had a good relationship with. A good relationship could guarantee their commitment to the delegated task and their loyalty to the principal.

\section{The dilemma of respecting hierarchy and promoting democracy}

While school leaders sought to increase democracy for the school community such as broader participation in decision-making processes or promoting openness in discussions, they acknowledged the value of hierarchy. Cross-case findings indicated that the encouragement and enhancement for broader participation in these schools was evident, but remained bound by traditional norms of hierarchy. For example, while leaders expressed that they encouraged teachers to be more active in decisionmaking participation, they supported the maintenance of autocracy, obedience and compliance. As the principal of School A stated: "The obligations and duties of staff are to implement leaders' decisions strictly and seriously" (PC1). Interview responses indicated that the organisational democracy was emphasised as a feature of "modern" leadership. Its purpose was to encourage staff to express opinions and to participate more in school management and leadership. However, the fact remained that the shift towards more participative management seemed to have a slow uptake. Values of hierarchy still impeded the process of promoting democracy in schools. All leaders admitted that they continued to have difficulty in getting teachers involved in decision-making. Interviews with teachers indicated that most of them were still familiar with hierarchical forms of management in which they would rather follow leaders' orders and decisions. They were not very willing to express their own opinions.

The trend of promoting democracy was a challenge in student evaluations of teaching. In 2009, in recognising the need to provide a mechanism for students to have their say in improving teaching and learning, the Vietnamese Ministry of Education and Training encouraged schools to involve students in the evaluations. Student evaluations of teaching were compulsory for all tertiary education 
institutions. Interviews indicated this new policy encountered some difficulties in the implementation process in all three cases. Not all teachers supported this new policy as they believed that being evaluated by students was seen as offensive and not suitable in Vietnamese culture and tradition. Most teachers were still influenced by the traditional view that teachers were regarded as the masters, the knowledge carriers for students and higher than students in terms of social position and status. In Schools B and C, participants agreed that the student evaluations of teaching should not be conducted in primary, secondary or high schools as they believed students were "not mature enough" to evaluate teachers' teaching. Interviews with participants from School A indicated that there was a hesitancy to implement students' evaluation of teaching. They confirmed that this was considered to be a new practice. Hence, it required time for teachers to familiarise themselves with the new evaluation system. Leaders of this school revealed that most teachers did not support this new policy when it was first launched as they believed it was antithetical to prevailing social values. During the implementation process, teachers called for students' evaluations not to be published in order to preserve teachers' prestige in case they received poor assessments.

Involving staff in the evaluation of leaders was also seen as promoting and expanding democracy for school management and leadership. Participants revealed that the staff evaluation of leaders was initiated by the Vietnam Communist Party as an approach to "expand democracy within the Party". Leaders in these schools agreed that this approach could promote democracy but it might destroy harmonious relationships between leaders and staff or ruin school solidarity in case they were poorly rated. Most teachers in the three cases supported this approach but they also pointed out some obstacles when it was implemented. First, leaders pointed out that they were reluctant to apply this approach as they did not want to be evaluated by their staff. Second, teachers thought that the results of the evaluations might not be accurate because relationships in schools might affect the results of assessments. As teachers in School B pointed out, a competent leader may get a poor assessment if he/she was not able to maintain good relationships with staff. Teachers in School A revealed that teachers tended to say "good things" about leaders to avoid conflict when they did the assessment; thereby leading to inaccurate results of assessment. 


\section{Building relationships}

\section{Preservation of harmony within a hierarchical sphere}

Cross-case findings indicated that the preservation of harmony among school members was seen as very important. Although the meaning of harmony differed among participants, all believed that it was extremely important for the school's working climate and imperative for maintaining the school's performance and culture. Participants argued that harmony among school members was inextricably connected to the nature of solidarity, which had a significant influence on school achievement and accomplishment. Hence, cultivating and preserving harmonious relationships was the best way to promote solidarity among school members.

Preservation of harmony was exercised differently among people. Teachers in all three cases agreed that they avoided open argument and confrontation. Open argument and confrontation were rare, especially between teachers and leaders. Teachers claimed that they were extremely reluctant to confront their leaders in discussion, school meetings or forums. They tried to avoid criticising leaders to keep the harmony with leaders even if they were not happy with their leaders. Most teachers did not expect to confront their leaders as they believed they might be at risk if they displeased their leaders. This explains why leaders in all three cases claimed that teachers avoided giving opinions or feedback in school meetings or forums even when they were encouraged to do so. Cross-findings indicated some common strategies for preservation of harmony between teachers and leaders. These included avoiding direct disagreement, disobedience, voicing opinions or expressing aspirations in school meetings or forums. It was evident that teachers in these schools showed strong tendencies of humility to leaders to preserve harmonious relationships with leaders. It was clear, regardless of whether harmony was real or superficial, that the preservation of harmony was seen as important.

School leaders had great concerns about whether conflict was dangerous to harmony. Leaders tried to avoid doing things that could cause conflict. Leaders confirmed that they avoided criticising teachers in front of others because it could hurt teachers' dignity and make them lose face. They were very reluctant to criticise older teachers because of the culture of "kinh lão đắc thọ" (respect for the elder). They admitted that they never shouted at older teachers or talked to them in an angry manner when 
they were not satisfied with their work. Such behaviours could be considered "insolent" to older teachers and might seriously harm their relationships. Leaders claimed that they had to be very careful when communicating with older teachers in ways which ensured older teachers felt respected. The concept of "face" ensures the maintenance of the importance of all people. Maintaining "face" was very important for older teachers. As participants explained, "making someone lose face" was synonymous with "destroying people's dignity and self-esteem". In the three cases, older teachers were always respected by other school members. This respect was expressed in both attitude and behaviour and the use of certain language.

\section{Relation-centered leadership: preservation of harmonious relationships as investments}

School leaders showed a considerable concern in building harmonious relationships with staff although they all acknowledged the prevailing value of hierarchy. All leaders believed that building and maintaining harmonious relationships could benefit the school. The leaders saw the maintenance of harmony as a way of ensuring teachers' loyalty and commitment. Teachers in these schools were more likely to be loyal to their leaders or schools when they maintained harmonious relationships with leaders and other school members. They felt "safe and comfortable" in the school. On the contrary, teachers felt demotivated or had a weak attachment to the school if they worked in an environment that lacked solidarity and harmony amongst the people. Cross-case findings indicated that the maintenance of harmony built trust amongst people and strengthened teachers' bond to their schools.

School leaders believed that preserving and cultivating harmonious relationships with teachers and amongst teachers facilitated good school leadership. They pointed out that when harmony was established, the school operated smoothly and people worked cooperatively. When harmonious relationships with staff were maintained, staff submission and obedience to school leaders was enhanced. Harmony also minimised the possibility of conflict, open challenge and criticism with/from staff.

Principals in these schools had a strong tendency to maintain and cultivate good relationships with seniors. They acknowledged the importance of preservation of good relationships with seniors as a profitable investment for the school. For example, in School A, the principal revealed that her school received more attention 
and financial support for investing in the school's infrastructure from the local government as school leaders maintained close relationships with senior officials. In School C, the principal admitted that he received a lot of support from DETS as a result of cultivating task-oriented relationships with DETS officials. Consequently, his managerial work has been going smoothly. In School B, the principal believed that the big investment in school's infrastructure partly resulted from the school leader's effort in building and maintaining relationships with local government. Teachers also admitted that they preferred working with leaders who could establish a wide social network which, as they believed, could benefit school development. They believed that if their school leaders did not have good relationships with seniors, the development of their school would be affected. Most teachers considered "establishing good relationships with seniors" as one of the school leader's managerial abilities and competence. This suggests that school leaders built and maintained good relationships with seniors because of their demands on school benefits. They all considered fostering good working relationships with seniors as a profitable investment essential for their school development.

Teachers further believed that school leaders' close relationships with seniors also ensured their ambitions. The procedures for leader appointment had become more democratised over the years. For example, delegation criteria were publicly specified in legal documents or teachers were invited to participate in the delegation process by casting their votes for a "prestige index". However, the final decisions remained in the hands of CPC and senior officials, who were believed to hold the political destiny of others. This partly explains why leaders tended to establish tight relationships with seniors. All teachers in the three cases believed that close relationships with seniors helped their leaders ensure their career path.

The effort in building and maintaining harmonious relationships amongst people was closely connected to the preservation of school's popularity and an increase in social recognition. Interviewed leaders and teachers in these schools confirmed that the failure to build and maintain harmonious relationships amongst school members destroyed the prestige of the school. Leaders revealed that they might be reprimanded by senior leaders if lawsuits occurred in their schools. This may explain why leaders preferred "internal negotiation" if conflict occurred. The "internal negotiation" could be used to deal with conflict rather than with lawsuits in order to 
keep "disadvantageous information" from being disclosed to outsiders to preserve the school's fame and leaders' prestige. Leaders believed that lawsuits reflected problematic relationships amongst people and seriously affected the school's solidarity. Such findings explain why participants in these schools emphasised the importance of the preservation of harmony amongst people; even the maintenance of "surface" harmony.

\section{Power, position, status and age}

Position, status and age were three main factors impeding the process of relationship building. Within the discourse of hierarchical values and system, every school member had to identify their own positions and roles to have proper behaviours and build relationships. Staff were always expected to obey and respect leaders; students were expected to obey and respect teachers. There was a culture of highly-expected obedience. Participants agreed that such features were rooted in the values of Vietnamese culture of a hierarchical value-driven society. Due to the prevailing cultural discourses of hierarchy, relationships amongst school members remained at a "certain distance" although efforts had been made to narrow the gap. Teachers found that it was not easy for them to build close relationship with their leaders because of the existence of different working positions, power and status. Teachers felt the existence of "invisible obstacles" in building relationships with their leaders, although they admitted their leaders were "out-going", "open-minded" "sociable" and "friendly". They explained that positions, status, power and age were always acknowledged in relationship building to maintain harmony amongst school members, particularly with school leaders. The "invisible obstacles" seemed to be clearer in relationships between young teachers and leaders. The young teachers revealed that besides the differences in position and power; "age factor" and "generation gap" limited the process of relationship building. Gaps between the generations made it more difficult to build close relationships with leaders. Leaders in the three schools pointed out some common features of young teacher-leader relationships as follows: 1) Most young teachers had a tendency to avoid having face-to-face communication with leaders; 2) Young teachers were afraid of expressing their own ideas to leaders; 3) Young teachers displayed a tendency for humility in order to keep harmonious relationships with leaders; and 4) Young teachers played passive roles in building relationships with leaders. Although leaders 
of the schools appeared to make an effort to narrow the gap between leaders and young teachers, the prevailing cultural values of hierarchy still impeded their relationship building processes.

Leaders' perceptions and practices of power significantly affected the relationship process between leaders and staff. Leaders in all three cases saw power as "power over" which was used to control and manage people. They perceived power as dominance, control and hierarchy. As a result, in practice, they had to seek centralisation to assert control to ensure policy implementation. They believed that centralisation enabled leaders to impose order on the school so as to implement the government's policies and achieve the school's target. Such perceptions and practices may partly explain why leaders in all three cases, on the one hand, claimed that school leaders should be close to staff to understand their thoughts, feelings and aspiration. On the other hand, they tended to keep a "safe distance" with staff to

preserve the leader's power and authority. All leaders believed that keeping relationships with staff at a safe distance was to ensure the effectiveness of the leader's power exercise as intimate or close relationships could affect the leader's power exercise process.

\section{Decision-making}

\section{Hierarchical decision-making process: Habit of obedience}

Cross-case findings indicated that within the hierarchical power structure (discussed in the last section), school leaders played a major role in the decision-making process. School leaders demanded that staff strictly respect and obey leaders' decisions, especially decisions made by principals. In interviews, most of the leaders believed that staff had to implement leaders' decisions strictly although, as leaders admitted, in some cases their decisions were not always agreed with. Yet, leaders' decisions must be carried out with the full compliance of staff. Such leadership perspectives and practices have resulted from the Vietnamese government's continuing efforts to institutionalise and reinforce the values of obedience to authority in traditional Vietnamese management. The Vietnamese Government issued Decree 71/1998 on the regulation of the implementation of democracy in social institutions, which states that: 
While on duty, staff or employees must obey the directives and guidance of seniors. Staff or employees have the right to express their opinions and propose solutions to the problem within the scope of their responsibilities that can be different from the opinions of the person in charge, but they must still comply with the directives of the person in charge, and they may reserve opinions and report to their superiors. (Article 13)

Such hierarchical values can also be found in other legitimate documents such as "the Regulation on the implementation of democracy in schools" issued by Vietnam MOET, which highly emphasises the importance of staff's obedience to authority.

Findings further revealed that the Vietnamese educational system placed emphasis on accountability of the school principal and the power of leadership was highly concentrated in the principal's hands. This could explain why all interviewed principals supported the maintenance of autocracy in the decision-making process due to the demand on the principal's accountability. Principals asserted their prerogative as final decision-makers because they were responsible for everything occurring within their schools. In these cases, principals had the power to make decisions, to require other people to obey and implement their decisions, to accept or refuse other people's opinions contributing to the decision-making process.

In the interviews, most of the teachers admitted that the Vietnamese culture of respecting seniority and authority was highly reflected in the decision-making process. For example, teachers showed a high level of obedience in the implementation of decisions and they were reluctant to challenge school leaders' decisions. They believed that the subordinates' duty was to obey and implement leaders' decisions. The acceptance of decisions was important and considered as a degree of unanimity for the school community. Leaders believed that the extent to which staff accepted, obeyed and committed to the leader's decisions was crucial to the effective implementation of the decisions.

Leaders showed a strong belief in the importance of faithfully implementing seniors' decisions and government policy, particularly the CPC's directives. Within the sphere of hierarchy of cultural values and political and administrative structures, obedience in the implementation of decisions was reflected in the handling seniors' decisions and directives. It was not only school leaders that admitted they had to implement seniors' decisions faithfully; teachers in these schools were asked to perform seniors' decisions and directives unconditionally. 
The hierarchical structure, the prevailing cultural values of hierarchy and the existence of autocracy in leadership style created the "habit of obedience" in the working environment in these schools. Most participants recognised the value of having someone in charge and were willing to accept leadership from whoever was in the position of school leadership. School leaders as well as teachers agreed that staff often did not want to be bothered with the responsibility of making decisions because they believed that making decisions was not the responsibility of staff. What teachers did depended much on their school leaders' decisions and instructions.

\section{Teacher involvement in decision-making process: Obstacles of cultural values}

More active involvement of teachers in school decision-making was found to be encouraged and motivated by the schools. However, teacher and staff involvement in decision-making was likely to be impeded by values of hierarchy. Teachers and staff found it difficult to offer their opinions or they were reluctant to speak up or offer their ideas because these may lead to conflict. A willingness to contribute openly seemed more common in small group meetings or "internal forums", such as meetings or forums held within a faculty or in a professional group. Teachers commonly remained reticent to express themselves in larger meetings such as a school meeting. They would rarely express their opinions in front of school leaders. Most interviewed teachers admitted that they did not want to express their opinions in meetings. This was a way to reduce the possibility of conflict and to "save face".

In these schools hierarchical values were found to be obstacles for the teacher involvement in decision-making. Interviews and observational data showed that older or experienced teachers were more willing than their younger colleagues to contribute to decision-making. In these schools, older and experienced teachers' opinions were more influential in the decision-making process than their younger colleagues. Older teachers' social status, experience in teaching and professional knowledge, long-time contribution to school development influenced and were more outspoken than their younger colleagues. Younger teachers had to be careful with the way they expressed their opinions so that they were not seen as "know-it-all" or "teaching a fish how to swim" (múa rìu qua mắt thơ). Observational data of the two schools (see Table $10 \& 13$ ) showed that older teachers were more willing than their younger colleagues to challenge and openly contribute in the whole-staff meetings. 
The data from the three schools clearly indicated that the concept of harmony in Vietnamese culture had a significant influence on the decision-making process in all three schools. Factors such as "respecting authority", "avoiding conflicts", "nonconfrontation" and "saving face" were viewed as barriers to teachers' involvement in decision-making. The picture from the case findings was that because teachers respected authority, they avoided confronting or challenging leaders' decisions as it might lead to the possibility of conflict. Maintaining harmonious relationships with leaders was teachers' top priority and they avoided exposing opinions. Teachers were willing to raise issues or express opinions, but only in a non-confrontational style or in a respectful tone and manner.

\section{Democracy for the decision-making process}

The trend toward more involvement of teachers was evident in the decision-making process in these schools. Although hierarchical values were embedded and reflected in the decision-making process (as discussed above), most of the leaders acknowledged the importance of teacher's involvement in decisions. They agreed that school leaders should respect teacher and staff opinions, listen to their aspirations and encourage a more democratic environment for decision-making. When teachers' opinions were considerately encouraged and listened to by leaders, teachers were more aware of their responsibility and connectedness. Moreover, leaders agreed that encouraging teachers to participate in decision-making was a way to share responsibility and to attain a high degree of unanimity amongst leaders and teachers. Some leaders, such as the vice-principal A and the principal C, expressed that school leaders should learn to accept argumentative opinions or criticism from teachers and staff. The school working environment should be made democratic so that teachers and staff were more willing to contribute their ideas or even challenge leaders' decisions. Such perspectives reflect a fact that there was a change in the tradition of decision-making and tended to be taken into leadership practice. Such a change was evident in Schools A and School B. In School B, teachers were reported to be more confident in expressing opinions and more teachers were willing to contribute straightforward ideas in whole-staff meetings.

In comparison with the authority and management structures of schooling in the past, participants agreed that the climate of democracy had been enhanced. The evidence 
was that transparency was clear in management and leadership practice. Teachers and staff were invited to be involved in leader recruitment processes by casting their votes for the "prestige index"; annual school plans were discussed in the staff meeting to seek teacher and staff approval before it took effect; annual financial school reports were annually sent to individual teachers for reference (school A) or disclosed in the staff meeting (Schools B and C); regular parent meetings were held to seek opinions and encourage them involve in school management and leadership (in Schools B and C). Previously, such features of administration had not been highly acknowledged and parents had been excluded from school management.

Another factor identified as a trend of expanding openness and promoting involvement of teachers and staff in school decision-making was that teachers and staff were more willing to openly contribute their opinions in small groups. The trend toward more active involvement in decision-making was more prevalent in small group meetings such as meetings within a division or a faculty. Teachers showed a willingness to express their "hard" opinions or discuss sensitive issues without the presence of school leaders.

\section{Solving and managing conflict}

\section{Avoiding conflict and confrontation: The importance of harmony}

Conflict avoidance was embedded in the culture of these schools. Any forms of unpleasant confrontation that could upset relationships or cause conflict were avoided. Interviewed participants revealed that open argument and conflict were extremely rare. Most of the participants viewed conflict as dysfunction for their schools. They believed that conflict destroyed harmony amongst people and spoilt the solidarity of the school community. Such perceptions of conflict were clearly reflected in people's daily behaviour and practice. The strategies of avoiding conflict in these schools are summarised as follows:

- Avoid direct criticism, particularly towards older teachers and school leaders;

- Be careful when communicating, particularly with older teachers or school leaders; 
- Avoid discussing sensitive issues such as leader's decisions or leader's personality;

- Respect leaders' opinions and faithfully implement their decisions;

- Show obedience and loyalty to school leaders;

- Avoid giving bad feedback to people or reluctant to point out someone's weaknesses or problems, particularly on older teachers and school leaders, to save people's face;

- Keep silent or be reluctant to express opinions in school meetings;

- Keep silent or ignore rather than directly refusing or making criticism when disagreeing with leaders;

- Unwillingness to expose problems or weakness to "outsiders" to save face for people or group.

The centrality of maintaining harmony was a key feature in building school culture in these schools.

\section{The illusion of superficial harmony}

Open arguments were not evident in the schools' culture. People were reluctant to confront each other and direct criticism was avoided. Teachers and staff showed a strong reluctance to challenge school leaders or anyone who had higher status or social positions. This was to preserve harmony. For the reason of preserving harmony and avoiding conflict, people in these schools tended to hide their disagreement or "real thought", particularly with school leaders. Most discord remained hidden or was less blunt. This explains why interviewed participants in these schools pointed out the same phenomenon: the existence of superficial harmony. Conflict avoidance or non-confrontational style in no way indicated that there was no disagreement or conflict, but that it existed in implicit forms. As a result, avoiding conflict and confrontation led to the illusion of superficial harmony.

There was a trend of hiding conflict or problems that might affect people's prestige or the school's reputation. When a conflict or a problem occurred within a group, a 
division or a school, people tried to prevent the information from leaking out to "outsiders" to protect individuals' face and the prestige of the school community. Conflict or problems were often dealt with insiders or by using an "internal solution". When a teacher's problem was leaked outside, not only did that teacher lose face, but other teachers' prestige (for example teachers of the same division) was detrimentally affected. For example, teachers in School C admitted that although they were not directly involved in the conflict, they felt shameful when the conflict between members in their group occurred. Similarly, participants in School B admitted that when the information of a problem was leaked out, not only was their personal prestige negatively affected but the prestige of the whole division was spoilt. Leaders agreed that they were responsible for all things happening around the school. If a teacher or staff member made trouble, school leaders might be blamed for "letting the bad things happen". This explains why most leaders in these schools were very aware of "lawsuits" that might badly affect the school's fame and they all preferred an "internal solution" when dealing with conflict. However, cross-case findings indicated that hiding conflict or problems could protect face and prestige but could also lead to "superficial harmony" as the problems or conflict were not thoroughly resolved and people projected the illusion of harmony to outsiders.

\section{Lý and Tình approaches: A dilemma in solving conflict}

Cross-case findings indicated that ly-tình approaches were commonly applied to deal with conflict in these schools. Lý approach was based on rigid procedure, rules and regulations. Tình approach was seen as solving conflict based on humanistic elements or human relationships which allowed flexibility in handling things. Participants admitted that these approaches needed to be carefully balanced when solving conflict or problems. When lý approach was applied to solve conflict, leaders only used rules, regulations and law to solve conflict while ignoring other humanistic elements such as relationships. This approach was believed to protect fairness but might harm harmonious relationships between leaders and staff. When leaders deployed tình approach, they depended too much on humanistic elements or relationships when solving conflict or problems and it could preserve harmony with staff but might create unfairness for people. This explains why leaders emphasised their carefulness in balancing these approaches when dealing with work or solving conflict so that fairness was respected while harmony was preserved. However, 
leaders admitted that they were sometimes in a dilemma because they were reluctant to make a choice of these approaches.

\section{Leaders and older people as intermediaries for conflict}

Leaders had a key role in managing and solving conflict. When conflict occurred and could not be resolved by insiders, most staff tended to seek the involvement of school leaders as intermediaries. Leaders with authority, power and prestige could conciliate conflict among people because leaders' decisions and opinions had great influence on people-in-conflict. Leaders had power to create and enforce their resolution. As a result, their decisions or opinions were easily accepted by people-inconflict. Sometimes, people tended to seek school leaders' involvement in solving their personal and family problems. For example, teachers in Schools A and C revealed that they sought their school leaders' involvement in solving their personal problems as they believed school leaders' opinions were significant due to their leadership positions and prestige.

People tended to seek the involvement of older members in the resolution of conflict and paid deference to older people's opinions and advice as they were believed to be connected to credibility due to their higher status, experience and imperturbability. As in School C, teachers revealed that older members were "prestigious mediators" to conciliate discord as their experience, maturity and prestige could serve as powerful tools in a persuading process.

\section{Summary}

This chapter has presented the analyses of combined data from the three school cases, focusing on examining how school leadership practices were exercised within prevailing Confucianism-affiliated traditional values. The analyses have shown that the leadership practices and cultural values were intertwined. Cultural features embedded in Vietnamese cultures such as hierarchy, harmony, non-confrontation, face-saving, and collectivism were found to be important factors that exerted certain influence on school leadership behaviours and practices. Other factors such as hierarchy of political and administrative structures, were also found to combine with prevailing cultural values to configure leadership behaviours and practices. Cultural values, mainly related to harmony, relationships, and seniority, were prominent in 
interacting reciprocally to construct leadership behaviours and to impact on the choice of leadership strategies such as strategies for managing conflicts, building relationships, exercising power, and decision-making.

The following chapter discusses the study findings to expose the grounds and nature of school leadership in Vietnamese school contexts. 


\section{CHAPTER SEVEN: THE NATURE OF VIETNAMESE SCHOOL LEADERSHIP}

\section{Introduction}

In this chapter, the relationship between Vietnamese school leadership practices and Confucian values are further exploited. It answers the two research questions: (1) what are the nature and impacts of Confucianism on the four leadership functions (exercising power, building relationship, decision-making, and conflict management and solution) and (2) how effective is school leadership as perceived from Confucian values? The discussion is based on the recognition that the nexus between leadership and cultural influences leads to improvement in leadership practice. This is because improving leadership practice involves the particular characteristics and requirements of the context with which it interacts and is exercised (Dimmock \& Walker, 2005). The discussion of this chapter is presented in a three-component focus as follows:

(1) Demonstrating the nature and extent of Confucian influence on Vietnamese school leadership;

(2) Describing the particular nature of Vietnamese school leadership;

(3) Proposing a reconceptualisation of the Vietnamese "có uy" leadership.

The nature and extent of Confucian influence on Vietnamese school leadership

According to this study, Confucian values influenced the four functions of leadership in the Vietnamese schools. School leadership with cultural values was exercised as an integrated process. This section demonstrates how Confucian values influence these leadership functions by addressing the following emerging themes: (1) the reflection of hierarchy-penetrated mind in exercising power; (2) hierarchy-oriented relationship; (3) The influence of cultural values on decision-making; (4) perception of conflict; and (5) cultural expectations about gender in school leadership. 


\section{The reflection of hierarchy-penetrated mind in exercising power}

Participants were predisposed towards leadership and management behaviours that were traditionally associated with "power over". This emphasised hierarchical traits - controlling, coercing, obedience and domination. The concept of power, in participants' perceptions or in the practice of school leadership, indicated that Vietnamese people (no matter what working positions they were in), accepted the unequal distribution of power in their schools. School leaders generally worked according to managerial instructions and directives from senior officers and were not willing to openly question the reasoning behind the directives even though, in some cases, the directives or decisions did not work well. At their own level, they acknowledged and expected obedience and compliance from teachers and staff. They considered obedience and compliance as indispensable features of effectiveness in the process of exercising power. Showing obedience and compliance towards leaders was a fundamental obligation of subordinates. Seeking and reinforcing obedience and compliance from subordinates was considered the right or managerial duty of school leaders. This explains why school leaders and teachers showed a high acceptance of the unequal distribution of power and were more tolerant of hierarchical leadership styles and positions of authority.

Moreover, the unequal distribution of power among people was also accepted as a natural phenomenon because they believed that different people had different roles and positions in their own families, their organisations, and in the society. In other words, in the Vietnamese mind, power is intimately connected to one's roles and positions. This explains why the leader as well as teachers believed that the person in a superior position could exercise absolute authority and demand absolute obedience from the person in an inferior position. In this approach, managerial order is established for facilitating the management process. This study also indicated that in the Vietnamese context, school leaders must be ready to use power at their disposal to enforce policies and to demonstrate and maintain their status of superiority.

Such perceptions and practice of power can also be found in other contexts such as business. In their study about the influence of culture on managerial behaviour in the Vietnamese business context, Berrell, Wright and Hoa (1999) identified some patterns of behaviour in the process of exercising power, in which "unequal 
distribution of managerial power" was accepted as natural in relationships among people in companies. This phenomenon of uneven power distribution exists in other Confucian-influenced settings such as China, Singapore and Hong Kong (Dimmock $\&$ Walker, 2005), where hierarchical structures and values are prevalent and accepted in most social structures, including families, groups, organisations and the society in general. In contrast, in societies which can be classified as power-distributed, such as the USA and Australia, people are less inclined to accept unequal distributions of managerial power and view overbearing management styles as unacceptable and efforts are made to reduce it wherever possible (Berrel et al., 1999; Dimmock \& Walker, 2005).

The acceptance of unequal power distribution from the perspective of Vietnamese people and in leadership may be explained in terms of the strength of hierarchy existing in every aspect of life. Hierarchical values are believed to originate from Confucian ideology, which emphasises stability, order (against instability and chaos), and hierarchy as guarantors of that state of affairs (Bich, 1999). One of the main characteristics of power distribution in these schools was the ingrained respect for seniority (in terms of working position and age). This meant that leaders were always considered to be superior and subordinates' respect towards the leaders was generally granted through their high-ranking position, rather than because of their expertise or managerial ability. Similarly, older teachers were granted respect because of their age, regardless of their positions. Such hierarchical values have combined to promote unequal power distribution in the Vietnamese context and encourage the practice of "power over" (this will be discussed in the next section) in school leadership.

\section{Hierarchy-oriented relationship}

Hierarchical structures were recognised in this study, particularly in leader-teacher relationships or older teacher-younger teacher relationships. Although relationships were believed to be based on mutual respect; position and status were emphasised in relationships. The value of harmony was believed to be very important and carefully cultivated, but the preservation of harmony was found to be hierarchy-oriented. The concept of "equality" existed in relationships between colleagues of the same position and same age, but not in relationships between leaders and teachers and between school members of different generations. This indicates that cultures of 
these schools were bound by traditional norms of hierarchy. All teachers, regardless of their ages, believed that school leaders should be respected by other school members due to their leadership positions. Although in general leaders had to earn respect by showing and demonstrating their "leadership traits" such as good morality, good expertise, good managerial competence and charisma, respect for the leaders was also believed to be automatically accompanied with their leadership position and higher status. "Respecting authority" in participants' perspectives sounded like "obligatory" and "compulsory". It was understood as "subordinates" duty toward superiors". A variety of teachers' typical behaviour patterns which reflected the value of "respecting authority" in these schools was evident.

Teachers showed a strong tendency to avoid challenging leaders; teachers often showed humble attitudes towards leaders; and teachers avoided giving direct feedback about leaders' managerial decisions or performance. Such behaviours can be explained as the reflection of hierarchical values which emphasise strict principles of human relations in Vietnamese society. People build relationships within their roles and positions and these relationships were bound by the discourse of "respect" and "obedience". These behaviours might not be found in all Western societies where hierarchical values are not emphasised and power distance is found to be low. Dimmock and Walker (2005) found that in Australia, respect for the school leader does not automatically accompany an organisational and social position or status. "Respect" has to be earned rather than attained automatically by the higher position or status of the leader. Australian school leaders' perception of harmony is quite different from that of Vietnamese school leaders'. While Australian school leaders believed that "sometimes [there is a] need to challenge harmony to change things" (Dimmock \& Walker, 2005, p. 139), "challenging harmony" in Vietnam was believed to lead to conflict and disorder. Australian teachers in Dimmock and Walker's study placed value on harmony but they were not afraid to express their opinions and feelings at the expense of maintaining harmonious relationships. The Vietnamese teachers in this research showed their reluctance to express opinions and feelings to leaders so they could preserve harmonious relationships.

This study found that the relationships between leaders and older teachers were bound by hierarchical values. While leaders were granted respect by virtue of their higher organisational position and authority, teachers who were older were granted 
respect because of their age, regardless of their positions. Such values shaped the strategies of building relationships and impacted the choice of conflict management approaches (conflict-related issues will be discussed in the next section). The leaders of these schools were willing to give direct criticism to younger teachers and could use their positional power to force younger teachers to follow their instructions. However, they all agreed that they felt uncomfortable with criticising older teachers. Criticising an older teacher in public was considered an "insult" and could lead to brokenness in a relationship. By the same token, leaders in these schools often exercised power with older teachers in a persuasive manner rather than applying coercive approaches.

Leaders confirmed that the obligations and duties of a teacher and staff were to respect leaders' authority and implement leaders' instructions and decisions strictly and seriously. "Respecting authority" is officially legitimised and institutionalised in the government documents such as Decree 71/1998. This Decree states that "while on duty, staff or employees must obey the directives and guidance of seniors" (Article $13)$.

Large bureaucratic educational systems with a high degree of centralised control also reinforced the traditional values of "respecting authority". The Vietnamese educational system has traditionally been centralised. Schools are told what to do and the principal's job involves implementing decisions made by MOET or central offices (PETS or DETS). Participants had revealed that with the pyramidal structure of traditional bureaucracy, school leaders had little chance to review government policies or to decline senior administrators' decisions. Such leadership practices were the symbol of "power-concentrated", which was characterised as leadership from the top; respect for seniority; goals set by top management and acceptance of wide power and status differentials between school leaders and teachers (Dimmock \& Walker, 2000). In other countries such as Australia, New Zealand, the USA, societies are classified as "power-distributed" or low power distance (Trompenaars \& Hampden-Turner, 1997; Dimmock \& Walker, 2005; House et al., 2004; Hofstede, 1983, 1991), inequalities in power are undesirable and efforts are made to reduce it.

To sum up, traditional values of respect for authority and seniority impacted on behavioural patterns in building relationships. In Vietnamese contexts where 
hierarchical values remained dominant, school members were entwined in a web of relationships and defined by roles such as leader, older teacher, younger teacher, or student. These distinctive roles defined their responsibilities and obligations from which they must produce the "right speech" and "right behaviours" to build and maintain harmonious relationships with other people.

\section{The influence of cultural values on decision-making}

Cultural values, to some extent, might be seen as hindrances to involving the teacher in decision-making. In this study, all school leaders acknowledged the importance of teachers being involved in decision-making as a way to mobilise "collective brainpower", motivate teachers' autonomy, and expand "dân chủ co' sơ" (grassroots democracy). Yet teachers confirmed that their involvement was minimal. The encouragement and motivation of staff involvement in decision-making was legitimised in school documents and viewed as an important element in the process of expansion of "grassroots democracy". However, in reality, the prevailing traditional values challenged and impeded this process.

School decision-making infused a sense of hierarchy where teachers showed their reluctance to express their ideas and opinions or criticise their leaders. Teachers expected their leaders to set direction and make major decisions. They were more familiar with the hierarchical decision-making style than with the participatory one. In general, teachers were used to leaving school issues to school leaders. These traits of decision-making reflected a working environment of high power distance culture, in which people expected leaders to lead and they became uncomfortable with the delegation of decisions (Kirkman \& Shapiro, 1997).

Teachers showed a strong tendency to avoid challenging leaders' decisions. They accepted leader's decisions as "final" and "compulsory" which school members had to acknowledge and implement. Interestingly, these findings relate to a phenomenon found in other Confucianism-affected societies such as China, Hong Kong, and Singapore or high power distance-labelled societies such as Thailand. Some empirical studies (e.g., Bush \& Haiyan, 2002; Dimmock \& Walker, 2005; Hallinger \& Kantamara, 2002) indicate that school leaders in hierarchical value-dominated societies have a tendency to retain their hierarchical distance and positional authority in decision-making. Their decision-making styles were autocratic rather than 
democratic. Teachers in these cultures maintained their traditional reluctance to openly contribute to and challenge the decision-making process. As in these societies and in the Vietnamese context, decision-making styles were found to be characterised by the "so-called" traditional Asian values such as respect, nonconfrontation and embedded in the values of harmonious relationships. In contrast, in Western societies such as England, New Zealand, and Australia, cultures were symbolised as "low power distance" (Hofstede, 1980, 1991; House et al., 2004) and school leadership was characterised as "task-based" "self-oriented" and "democratic" (Dimmock \& Walker, 2005). Teachers showed strong willingness to express their opinions and ideas on school matters and expose opinions that might challenge their leader's perspectives.

Teacher involvement in the decision-making process was also affected by age. Older teachers were more willing to express their ideas and opinions than their younger colleagues. "Young age" and "less experience" were seen as barriers to involvement in decision-making. Young participants revealed that they seldom expressed their ideas in school meetings. This was a way to save face in case their opinions were not highly acknowledged by colleagues or challenged leaders' perspective. Their reluctance to be involved in decision-making was found to be impacted by "psychological factors" (Conley, 1991; Little, 1988). They believed that their opinions were not as appreciated as the older teachers' opinions or they were affected by cultural perspectives on "experientialism": "trúng mà đòi khôn hơn vịt" (egg cannot be as clever as duck - Vietnamese saying) or "múa rìu qua mắt thọ" (never offer to teach fish to swim - Vietnamese saying). Conley (1991) and Little (1988) suggest that there are relationships between psychological orientations and teachers' willingness to participate in decision-making. Such "psychological orientations" are significantly impacted by cultural norms and values. Cultural norms such as "face saving", "respect for elders and authority" and "non-confrontation" explain why young teachers showed their psychological orientations of "unwillingness" and "reluctance" to participate in decision-making. In contrast, in Australian contexts, culture is labeled as "high confrontation", "self-oriented" and "lower uncertainty avoidance" (Hofstede, 1980, 1991; House et al., 2004), and there are no distinctions between older and younger teachers in terms of decision-making involvement. All teachers, (whether young or old), are primarily driven by self-advancement and therefore willing to challenge and criticise school leaders' decisions (Dimmock \& 
Walker, 2005). The research findings contradict the research by Dimmock and Walker (2005), who found that in the contexts of Hong Kong and Singapore there is still a keen sense of retaining hierarchical values in society, but younger teachers were more willing than their older colleagues to challenge and openly contribute in school meetings. One explanation for this, as these authors point out, is that teachers of young generations have received a more liberal upbringing than older teachers and absorb more Westernised values. This is not the case in a developing country like Vietnam as its society is not as open as developed countries such as Hong Kong and Singapore. Its administrative and political systems are highly centralised and bureaucratic under the leadership of one single political party (The Vietnam Communist Party) (Ashwill \& Diep, 2005). Bureaucracy, as Davies and Harber (1997) claim, in terms of decision-making, is a rigid, closed, and non-participatory form of organisation.

The "age factor" was also found to affect leaders' attitudes towards information processing. School leaders displayed more trust in older teachers than younger teachers in terms of psychological maturity in decision-making. They believed that older or experienced teachers' opinions were valuable and respectable; their opinions were easier to receive. Leaders often took older teachers' ideas and suggestions more seriously. The leaders' attitudes contribute towards younger teachers developing a culturally disposed psychological orientation of unwillingness and reluctance in decision-making. These findings support Johnson's argument (1989) that when leaders fail to be receptive to and take seriously teachers' opinions and when they are exclusionary and controlling, teachers may be less willing to participate in decisionmaking.

Teachers' willingness to participate in decision-making reflected a high level of "non-confrontation" or "conflict avoidance". The teachers were more willing to say what was not harmful to their relationships and reluctant to express opposing ideas that could disrupt the harmony. The teachers at School B revealed that they were very willing to express opinions in decision-making related to "professional issues" or "classroom issues". They avoided expressing their opinions related to administrative and managerial decisions as they believed that such decisions were much more related to people's benefits and their opinions, hence, easily led to conflicts if they were opposite to or not accepted by others. These findings are 
consistent with the argument that teachers' willingness in decision-making varies across decision domains (Bacharach, Bamberger, Conley \& Bauer, 1990; Conley, 1991). Such variations, as this study's findings suggested, reflect the level of cultural dimensions such as "confrontation" and "conflict avoidance". In School A, the teachers revealed that there was a "common phenomenon" happening more often in school meetings: people avoided expressing "nhũng điều khó nghe" (things that are not easy for people to accept or agree), but they were willing to say things that make people happy or feel comfortable. The teachers often hid their real thinking if they were asked to contribute their opinions in decision-making. The participants called this cultural phenomenon "dĩ hòa vi quý" (harmony is the first prerequisite) ${ }^{17}$.

One important condition regarding involvement is that people possess a participative openness; that is, they feel free to give opinions and contribute ideas (Hiltrop, 1996). Given that people work in an environment of participative openness, the expectations for effective shortcuts to subordinates involvement in the context of Vietnam are naive because of the hindrance of cultural values as we have discussed. No doubt, the values of harmony and hierarchy were obvious obstacles for the promotion of involvement and empowerment in school management and leadership. It seems that the problem with involvement was less about openness but more about cultural impediment. The problem with involvement was also more about how opinions were handled. In the context of high power distance, leaders were expected to act autocratically without consulting subordinates (Vitell, Nwachukwu, \& Barnes, 1993). Subordinates' opinions were not highly acknowledged. This could demotivate subordinates to become involved in the decision-making process and hence establish their habitual reluctance. In countries with a high power distance such as Vietnam, the context of a richness of ideas (or high involvement) can be created if leaders are more willing to accept subordinates' divergent opinions.

\section{Perception of conflict}

As in collectivism-oriented cultures (see Brett, 2001; Carnevale \& Leung, 2001; Morris et al., 1999), conflict was typically viewed negatively, avoided, and even

\footnotetext{
17 This Vietnamese saying originally comes from Confucian teachings. Literally, it means that in everyday communication and social relationships, the different points of views are likely to cause conflict within society. So it advises people to take harmony as the first prerequisite in human endeavours.
} 
suppressed in school contexts. Although the participants accepted that conflict in schools was inevitable, they all appeared to perceive conflict in a negative manner. In this study, conflict was synonymous with a state of dysfunction or chaos. This perspective contradicts Western perspectives of conflict, which suggest that conflict can be functional or dysfunctional (Kaushal \& Kwantes, 2006; Palestini, 2005). Palestini (2005) argues that some conflict is beneficial. It can encourage school innovation, creativity and adaptation. Such perspectives would not likely be accepted in these Vietnamese schools where the participants showed a strong belief that conflict might "destroy relationships", "ruin school solidarity", "weaken cohesiveness among school members" or "lead to lawsuits". Particularly, as most of the leaders emphasised, conflict might destroy the reputation of the school which may take school members a long time to re-build and re-gain.

Although this study agreed that conflict was negative, different stakeholders had different reasons to explain why they viewed conflict as negative. School leaders emphasised the consequences of conflict related to their accountability for conflict management due to their leadership position. As a leader pointed out,

No leader expects conflict to occur in their school because they might be blamed for their weakness in management. It is commonly thought that conflict is bad. So if a conflict occurs, it is either a personal or work-related conflict; the leader must bear some responsibility for its turning out right. (VPC3).

Teachers placed emphasis on the impact of conflict on people's relationships. The reason why teachers perceived conflict as "negative" rather than "positive" was that conflict affected relationships, regardless of how well it was managed. The teachers confirmed that work-related conflicts were more likely to turn into personal conflict because people did not differentiate a clear boundary between a work-based relationship and an interpersonal relationship. As a teacher put it,

Whatever the conflict is, whether it is caused by different points of view in work or is due to differences in people's personalities, if it happens, conflict will always affect their interpersonal relationships. (C2FmT5)

Both leaders and teachers believed that their schools would be better to have less conflict to maintain the solidarity and unity of the school community.

In this study, the concept of conflict reflected that people's beliefs were constructed by the traditional value of harmony, a cardinal value that guided people to pursue a 
conflict-free relationship. This indicated the strong tendency to achieve harmony in communication to avoid conflict. As such, conflict was treated as an enemy of harmony rather than a common problem of communication.

\section{Cultural expectations about gender in school leadership}

This study supports Hang's study about women's leadership in Vietnam, in which she confirms that at higher levels of power, the representation of women is lower (2008). The National Strategy for the Advancement of Women in Vietnam (Vietnam Government, 2001) reports that the women's rate of participating in leadership is low especially in the state administration and local governments. The statistics on women's participation in leadership in these schools shows that the representation of women in school leadership positions was lower than that of men. All school leaders confirmed that low representation of women in leadership positions was a "general phenomenon" of all schools in the province. PETS' annual reports on the province's school administrative staff $(2008,2009,2010)$ indicated that approximately $20 \%$ of school principals (primary, secondary and high schools) were women. The percentage of women in deputy positions was slightly higher, accounting for over $30 \%$. This suggests that women continued to face difficulties and obstacles in participation in school leadership despite the Vietnamese Government's efforts to promote women's participation in leadership. The Vietnamese Government approved the National Strategy for the Advancement of Women in Vietnam, which calls for women to hold $50 \%$ of all positions in state agencies and socio-political organisations at all levels (Vietnam Government, 2001). In contemporary Vietnam, which has been under the Communist Party's leadership since 1945, the role of women in family and in society has changed considerably compared to their role in the past (Bich, 1999; Hang, 2008; ADB, 2005). Since the Communist Party took power, it has carried out a variety of programmes to revolutionise the role of women, including provisions for participation in government and leadership (Asian Development Bank, 2005). However, this research reconfirmed Hang's conclusion (2008) that there is a sizeable gap between verbal commitments to gender equality and actual practices.

Traditional cultural beliefs and practices have contributed to the under-representation of women in school leadership. Teachers preferred to be led by male leaders. They 
believed male leaders were more appropriate to leadership positions than females due to their "masculine traits". When asked about gender equality, the participants confirmed that women's status and role were considered to be equal to men and the patriarchal thinking "respect men and disrespect women" is fading in the present society; the women's feminine traits, such as "chân yếu tay mềm" (weak legs and soft hands) or "đàn ông nông nổi giếng khơi, đàn bà sâu sắc nhu cơi đụng trầu"18 (Vietnamese saying), were still embedded in people's thinking. Such feminine traits have existed and could explain why participants believed that male leaders were better than females in leadership. These traditional cultural beliefs, as Davies (1990) points out, are viewed as a contributing factor to the under-representation of women in school leadership roles in developing countries. This research supports the Vietnamese Government's claim about gender equality. In the National Strategy for Advancement of Women in Vietnam (2001), it confirms that despite the Communist Party and the Government's efforts to promote gender equality, cultural expectations about gender still affect the practices of gender equality (Vietnam Government, 2001). Vietnam has different mandatory retirement ages (55 for women and 60 for men). This affects the appointment of school leadership positions. School Statutes at all levels define that for appointment to the position of a school principal, men's age must not exceed 55 and women's age must not exceed 50. Such unequal treatment mandated by law limits women's opportunities for participation in leadership. This explains why women's participation in school leadership is considerably lower than for men.

This study also found that in the new socio-economic system, female school leaders were struggling to combine their traditional motherhood role with the fulfillment of leadership role in schools. Three female school leaders revealed that they were always expected (by themselves, by their family members and the society) to keep doing well with the roles of the "heavenly mandate" in addition to their full-time employment. Interestingly, whilst these female school leaders believed that their husbands were "modern men" (in terms of thinking) and supported their work, they all admitted that they sometimes felt stressed as they had to try to pursue a career as

\footnotetext{
${ }^{18}$ Literally translated, a man may act hastily but his thought is likened to a deep well whereas a woman may think deeply but her thought is just as narrow as the platter of betel. This saying shows a striking contrast between men and women in their thoughts and behaviours. It is said that men usually have more profound thoughts than women. The ancient people have taken two objects that are common in rural areas to illustrate the difference in a well and a betel container.
} 
well as support family commitments. They had to do most of the chores and their husbands did not help them with the housework. These "housewife roles" did not impact on their delegated authority but limited their leadership roles. They revealed that their heavenly mandate roles consumed much of their time and limited them in participating in social activities. This meant that they had fewer opportunities than their male colleagues to expand and strengthen working relationships, particularly with senior officials. It could also explain why teachers showed their preference for being led by male leaders, whom they believed able to establish good relationships between schools and higher-level administration for the school's benefit.

When asked about the influence of the leader's gender on the process of exercising power and authority, most of the participants believed that there was not much difference in leadership between men and women. However, teachers stressed that their leadership styles were slightly different. Teachers believed that male leaders were more decisive, aggressive and patriarchal, while female leaders showed their carefulness, detail, reluctance and hesitation in decision-making. The teachers believed that male characteristics seemed to be suitable for leadership positions while being too careful and detailed was not appropriate. These social prejudices, as Carli and Eagly (2001) claim, against women as leaders and potential leaders would interfere with women's ability to gain authority and exercise influence and would produce discrimination when it is put into practice such as personnel decisions or political structures. This suggests that despite the promotion of gender equality and the adoption of new cultural values of women's role and status, school leadership in Vietnam appears to be firmly identified with male dominance. The Confucianismaffected cultural heritage, which rigidly defined gender roles and behaviours and placed Vietnamese women in subordinate roles to men (Hang, 2008), appears to continue its influence on people's perspectives about school leadership. Although Vietnamese women are believed to be no longer subordinate to men and no longer confined to housework as in the traditional society, women have to make more effort to attain parity in leadership. This point to confirm Hang's comments (2008) about women's role in leadership: stronger efforts must be made to bridge the gap between national gender equality goals and everyday practices. 


\section{The particular nature of Vietnamese school leadership}

What has been discussed would have us believe that school leadership manifests itself in its own cultural setting. While we acknowledge universal leadership characteristics, we need to identify the particularities of leadership that are shaped by cultural and contextual conditions. For this reason, this section seeks the particularities of Vietnamese school leadership. Ten particular leadership features, belonging to the four pre-defined themes of the research, have been identified: (1) The preference for "power over" over "power with"; (2) Leader's role modeling in exercising leadership; (3) The combination of politics and sociocultural values in exercising power; (4) The reflection of high power distance in building relationships; (5) Building relationships as an investment in leadership; (6) Power-concentration and the reflection of collectivist values in decision-making; (7) Consensus-based decision-making; (8) Factors affecting conflict management strategies; (9) Harmonybased and face saving-oriented conflict approach; and (10) Seeking intermediaries for conflict conciliation.

\section{The nature of exercising power}

\section{The preference for "power over" over "power with"}

This study did not aim to explore the concepts of "power over" and "power with" and the way these power approaches were practised, but there was evidence of leaders' preference for "power over" over "power with". All study leaders displayed a strong belief in the importance of exercising "power over" subordinates as an effective approach to guarantee the power of leaders and establish managerial order and subordinates' obedience. They believed that, once this was established, their schools would operate smoothly and managerial work was easier to deal with. Such perspectives contradict Sergiovanni's (2001) view of power as an ineffective approach in leading a school. He believes that power over is concerned with dominance, control and hierarchy and is likely to produce resistance among subordinates. He believes that the "power over" approach is rarely effective in school leadership. Other empirical studies (e.g., Johnson \& Short, 1998; Hinkin \& Schriesheim, 1989; Rahim, 1989) have indicated that power over is negatively associated with empowerment and found likely to be associated with resistance or conflict. 
Within the influence of the hierarchical values of Confucianism and the features of the hierarchical structure of the school administration system, school leaders had preference for "power over" over "power with". Although the practice of "power over" (such as imposing leaders' viewpoints on staff or enhancing leaders' control and inspection over the work of staff) appeared to be undemocratic and could create stress, they supported the practice of positional and coercive power to influence staff and imposing their will or viewpoints in order to achieve the school's mission. In exercising power, they concentrated on discipline and the enforcement of rules to establish managerial order. In these schools, strict discipline was employed as a way of establishing a moral order and cultivating staff responsibility. Not only did school leaders support the deployment of strict disciplines, so did the teachers. Most teachers confirmed that "tightening discipline" was effective in establishing the habit of self-discipline for staff. They also believed that when the school lacked discipline and the enforcement of rules was not highly concentrated, people were "irresponsible", "disregarded discipline", and were "unmotivated". Such leadership behaviours depict some form of control over staff which Fennell (1999), Gill (1995), Hurty (1995) and Sergiovanni $(2001,1992)$ perceive as “power over”.

Empowerment, as the process that emphasised teachers' opportunity for autonomy, choice, responsibility and participation in decision-making in organisations (Lightfoot, 1986; Pawlas, 1997), was not found to be highly cultivated in these schools. The teachers confirmed that they did not have any opportunities for autonomy and choice. Their leaders expected the teachers to implement their decisions and directives strictly and faithfully. Teachers were familiar with traditional power approaches which concentrated on hierarchy, directives, command, and obedience. Whereas, "power with", which is typified by concepts such as increasing teacher involvement, sharing power, autonomy, and openness (Dunlap \& Goldman, 1991; Fennel, 1999; Sergiovanni, 1992, 2001), was not highly cultivated.

This study showed that "hard" strategies (power over, strict discipline, coercion, and assertiveness) exercised in leadership had a high level of acceptance. Not all participants viewed them as a positive type of influence on subordinates, but all of them viewed hard strategies as an effective way to exert influence on subordinates in order to establish managerial order. Such findings were found in the contexts of other Confucian-affected countries such as China and Hong Kong (e.g., Fu \& Yukl, 2000; 
Schermerhorn \& Bond, 1991). The leaders in this study had the same perspectives about hard strategies as Hong Kong leaders. In the study by Ralston et al (2001), Hong Kong leaders expressed negative views toward the hard strategies, but their acceptance of these strategies was the highest compared to the countries of Western culture such as the USA, Germany, and Italy. In Western countries, hard strategies are viewed as a negative type of influence; hence, the level of acceptance of hard strategies in these countries is low. Interestingly, while the participants in this study viewed "power over" as a way to enhance leadership effectiveness (such as establishing managerial order, cultivating staff responsibility and getting things done quickly and efficiently), Western people equate "power over" with resistance or conflict and viewed it as a negative type of influence (e.g., Johnson \& Short, 1998; Hinkin \& Schriesheim, 1989; Sergiovanni, 2001). This may reflect the fact that a culture in which power distance is high, the exercising of "power over" is widely accepted as an efficient tactic for leadership effectiveness, whereas "power over" is rejected and declined in a culture where power distance is low. The preferences of leadership strategies vary from culture to culture. A leadership strategy preferred in a situation or in a culture may not be preferred or is not automatically sufficient to ensure effective application elsewhere, especially in another country, as there are likely to be potential clashes of cultural values and other conditions (Thang, Rowley, Quang, \& Warner, 2007). As Schneider (1998) put it, preferences are "clearly linked to cultural attitudes" (p. 238).

The preference and dominance of "power over" practices over "power with" in this study can be explained with two reasons. Firstly, "power over" practices were supported by the existing hierarchical values embedded in the culture which have been transferred into the contemporary school management culture. While the teachers accepted inequalities in power distribution and recognised their roles as "inferior", the school leaders described themselves as "superiors" who used power to ensure work accomplishment and expected teachers to comply with their instructions. These hierarchical values lead to an emphasis on "power over" practice to maintain leaders' authority and high status. Respect for hierarchy was strongly emphasised amongst school leaders. Secondly, the dominance of "power over" practice in school leadership can also be explained as the result of the Vietnamese Communist Party's continuing efforts to institutionalise and reinforce its role as the "sole force leading the state and society" (1992 Constitution, article 4). The 
reinforcement of its leading role in all social domains encourages the practice of "power over" to maintain the Party's power and status (Porter, 1993). Its political philosophy and practice such as "power-based system", "power-centralised system", and the emphasis on leader accountability are compatible with the values of obedience and respecting hierarchy. This encourages the application of "power over" practice.

Within the discourse of "power over", there was evidence of McGregor's (1960) Theory $\mathrm{X}$ in exercising power. The main thrust of Theory $\mathrm{X}$ is that people must be coerced, punished and controlled to make them contribute to organisational objectives. It was not only the leaders who considered "strict discipline" a solution to increase staff compliance and enhance their influence on staff, but the teachers also agreed that their leaders should tighten discipline and use coercive power to make people more responsible for their work. These leaders tended to build management and systems with the purpose of directing the efforts of staff; controlling their actions; modifying their behaviours to fit organisational need and reinforce their political power. "Highly-expected obedience" and the "absolute role" of the schoolparty secretary and principal were embedded in the domain of school leadership in these schools. Participants' perceptions about leadership and leadership practices in these schools were opposite to a leader approach of a leader espousing Theory $\mathrm{Y}$ (McGregor, 1960), in which people are encouraged to seek responsibility; take risks; set ambitious targets and challenges (Whitaker, 1997).

Aside from the influence of politics and the traditional values of hierarchy in school leadership which reinforces the practice of "power over", the centralisation of administrative system also asserted control to ensure the government policy and the Party's directive implementation. This centralisation enabled the government to impose order on the school system and partly supported the practice of "power over" in school leadership.

\section{Leaders as role models in exercising leadership}

The leader as a role model was significant in this study. Setting a good example or role modeling emerged as an important trait of the process of exercising leadership in these schools. Leaders were always expected to set good examples in their leadership practice as a way of setting moral standards and working rules for subordinates to 
follow. When the leader set an example of appropriate behaviour or performing duties in a responsible manner and avoiding improper actions, subordinates were then inspired and motivated. Leaders as role models in leadership embraces the concept of Western transformational leadership theory, which emphasises that leaders do not only direct subordinates to complete tasks, but also motivate and inspire them via charisma, inspirational motivation, intellectual stimulation, and individualised consideration (Bass, 1985). It can be seen that among transformational leader behaviours, "high expectation of performance" - one of the five typical transformation leader behaviours (Chen \& Farh, 2001), emphasising the leader's expectations of subordinates' excellence, quality and high performance were embedded in leaders' perspectives about role modeling. As the school leaders believed that to encourage subordinates' high performance, they had to demonstrate their high performance in order to prove their leadership qualities. In that way they inspired subordinates to emulate and built trust in them. Leaders believed that whenever a certain practice was expected of subordinates, the school leaders should also follow the same practice. A leader participant explained that he pursued his $\mathrm{PhD}$ study despite his old age to set a good example for younger staff. In his words,

As old as I am, I am still willing to learn and upgrade my knowledge. Therefore, there is no excuse for the younger staff not being able to do the same thing. I also want to set a good example of learning for my children. My learning might inspire them to the greater efforts in their learning. (VP1C1)

In Vietnamese leadership, "high expectation of performance" had a strong attachment to the concept of "providing an appropriate model" in transformational leadership. The leader as role model was a factor in "fostering collaboration". Chen and Farh (2001) explain that "fostering collaboration" in transformational leadership is the "extent to which a leader promotes trust and cooperation among employees and gets them to work together toward a common group goal" (p. 108). Although this study did not focus on examining the transformational leader behaviours, there was evidence of leaders as role models in fostering collaboration. For the leaders, setting a good example was an effective way to build trust with staff and to create trust amongst school members. Sometimes participants called it "solidarity". 
The reinforcement of authoritarian leadership practice as a result of the combination of politics and sociocultural values

While the Vietnamese Government acknowledges that by implementing educational decentralisation, an enhancement of the autonomy and accountability of schools are to improve the activeness of schools and the efficiency of school administration (MOET, 2001), it seeks to strengthen the Party's leadership towards education and training. The education and training strategy issued by Vietnam MOET (2001) clarifies: "All Party Committees from central to local levels should regularly direct and monitor the implementation of education and training policies, especially the political and ideological education activities. Set up order and discipline and consider the development of education and training as a target for building up a healthy and strong Party committee." (p. 24). These political beliefs were embedded in school members' perspectives about political leadership and leadership practices. The leaders explained that the integration of politics into the school administrative system helped bring about the directives and the will of the party into the administrative work. The structure of power and management of the schools (illustrated in Figures $5,6, \& 7)$ indicates the "comprehensive leadership role of the party". This explained why all participants, with or without political affiliation, acknowledged the importance of implementing the party's policies and directives. Although the Communist Party works on the principle of "collective leadership" and "collective decision" (decision made by majority) (Lai, 2011), all participants accepted the "absolute role" of the school-party secretary and perceived his/her power as highest. The highest position of the school-party secretary was reflected in everyday school practices. One of participants explained how school members acknowledged the role of the school-party secretary: "In all school meetings, the co-ordinator should say: "Mr Secretary, Mr Principal ... when introducing important guests. The school-party secretary should be welcomed first as he/she is the person of the highest position in the school and then the others". Lai (2011) in his article on the role of the party secretary points out that that the secretary is "the head of the heads", who has wide power and holds the right to decide the leadership in an organisation. This explained why participants indicated their strong belief in the importance of faithfully and strictly implementing the Communist Party's policies and respecting the school-party secretary's directives and decisions. In reality, most of the principals concurrently held the post of school-party secretary, hence, the political and administrative power 
was concentrated in the principals' hands. The review of "the Statute of school administrative mechanism and operation" of the three schools also indicated that within one school, the functional relationship between school leaders and staff was hierarchically and vertically constituted. These legitimised vertical relationships and promoted the practice of authoritarian leadership.

The hierarchical structure of administration in the education system and the reinforcement of the power of the Communist Party emphasises its sole representation for the people and its role of leadership the state and society. In 1945, the independence and the formation of the Democratic Republic of Vietnam (now known as the Socialist Republic of Vietnam) were declared. This was a significant turning point in Vietnamese history and marks the rise to power of the Communist Party (Bich, 1999). Since this period Vietnamese society has been undergoing the fundamental socio-economic transformation in its history. Particularly, Vietnam has been more open to the world since it carried out the "Đổi móti" (Renovation) and "Mở của" (Open door) policy in 1986. The Communist Party continues to influence every social aspect as it is legitimised as the "sole force leading the state and society" (1992 Constitution, Article 4). Within the domain of the Communist Party leadership and its domination, the power and influence of the Party over the national education system has been reinforced. The Party union (Communist Party Cell - CPCE or Communist Party Committee - CPCO) is established in each school to ensure its leadership and enhance its political influence on all school activities.

The reinforcement of the political influence of the Communist Party can be viewed as a factor that has led people to be more accepting of the distribution of power. The situation of the one-party communist state as the "leading force" has important implications. In schools, everyone, either in political or non-political affiliation must accept the party secretary's power and decisions. The legitimised absolute role and power of the school party secretary encourages and reinforces the values of obedience to authority in school management. This means that unequal power distribution is legitimately reinforced and accepted. In this study, all leaders revealed that their fundamental duty was to persistently implement and comply with the directives and regulations of the Party. Similarly, teachers noted that they had to strictly execute the party's lines and policies as well as the directives and decisions of the school party. The evidence indicated that people were more power-centralism 
oriented, placed more worth on hierarchical structures, accepted the unequal distribution of power and took inequality for granted. This supports Jamieson's remark that in Vietnam, hierarchy itself has been made "part of the intrinsic structure of the universe, a state of affairs that was both natural and unalterable" (1993, p. 16).

What has been discussed suggests that the authoritarian leadership style had preference and was reinforced as a result of the combination of the hierarchical structure of political power and administration with the cultural values of obedience and respecting hierarchy. Despite having been exposed to Western values of leadership, practical needs and concerns such as the tendency and promotion of democracy and of empowerment as well as decentralisation in school administration, school leaders' views and their practices of leadership and management were still driven by their Confucianism-affected national culture and embedded in the discourse of hierarchical leadership. Traditional management values, such as respect for seniority and authority, were maintained and reinforced by the combination of politics and the cultural values of hierarchy. This implies that the expectations for effective shortcuts to implementation of decentralisation and grassroots democracy in the context of Vietnam are naive. Although it is likely that decentralisation, empowerment and grassroots democracy can grow on the base of Vietnamese cultural values, the effect of such endeavours will only be felt over time. It is important, therefore, to build a more open administrative system in which people are promoted to become involved in the management process, to raise their own voice (opinions) on school issues as an encouragement for involvement and empowerment.

\section{The nature of building relationships}

\section{The reflection of high power distance in building relationships}

Although Vietnam has not been included in Hofstede's cultural map, this study indicated that high power distance was one of Vietnam's cultural aspects. Power distance is the distance a person feels or keeps between themselves and a person in a position of power (Hofstede, 1980; 1991). Power distance indicates the degree of inequality in power distribution. In this research, high power distance was reflected in the leaders' support of the maintenance of a level of aloofness, which was believed to be necessary to retain leader's authority and power. In School A, the leaders believed that they had to keep a "safe distance" in relationships with subordinates 
because intimate relationships could affect their managerial work. The leaders created a distance with staff based on their power, authority and status. In School B, power inequalities were accepted as natural and rooted in customs and relationships. The teachers took their inferior positions for granted. Similarly, in School C, secure distance with the leaders was maintained as the participants believed that teachers cannot be on par with leaders because of the differences in authority, responsibilities and roles. This indicated that high power distance was dominant in the domain of relationship building and the exercising of leadership.

Analysis of the leaders' exercise of power showed a similarity with school leadership of other countries whose cultures are labelled as Confucianist and considered to have high power distance (House at al, 2004; Hofstede, 1983, 1991), as with Hong Kong, China, and Singapore. In Dimmock and Walker's study (2005), school leaders in Hong Kong and Singapore acknowledged the prevailing discourse of the respect for people in senior positions and the importance of the maintenance of hierarchical distance, positional authority, and aloofness. Bush and Haiyan (2002) found that in educational leadership in China, values of Confucianism-embedded national culture had a deep influence on the practice of school leadership, such as the absolute obedience of children to teachers, subordinates to leaders and the determination of positional power in the process of exercising power. Teachers showed a strong reluctance to challenge their school leaders' power and authority. The findings of the study showed a similarity with Vietnamese teachers who avoided challenging and confronting their leaders' power. Power was concentrated with school leaders or senior administrators. Inequalities were accepted as natural and were officially legitimised in relationships and policies.

The phenomenon of high power distance in this study can be explained as the influence of traditional values of respecting authority in the Vietnamese culture. A child is traditionally taught to be obedient and does not speak as much with authority; the younger has to respect the older; the junior has to respect and obey the senior; disagreement may be taken as a sign of disrespect (Bich, 1999; Aswill \& Diep, 2005). These attitudes have transferred to the leader-subordinate relationship in the workplace where the existence of autocracy, obedience and compliance was dominant. The phenomenon of high power distance was reflected in the way leader participants viewed their leadership roles. They supported the maintenance of 
compliance and order with what they saw as the necessity of determination of authority, and that a level of leadership distance was necessary to retain status and order. Leadership distance was rooted in how the participants viewed leadership and how it was reflected in the power practice of school leaders. Respect was traditionally given to the position of school leaders or other senior administrators. School leaders were expected to be the chief decision-makers; to act autocratically; to set instructions and directives for teachers and staff, whereas teachers and staff members were expected to respect seniority and authority. Teachers and staff might not disagree with their leaders but they did not want to "talk back" or disrespect their leaders (labeled as superficial harmony discussed in Chapters Six and Seven). They were obligated to just accept whatever their leaders said. Dimmock and Walker (1998) used the notion of power distance of Hofstede's model (1991) to conceptualise this differential authority in the educational context of high power distance as follows:

In societies with large power distance values... hierarchy means existential inequality, subordinates expect to be told what to do, and the ideal boss is a benevolent autocrat or a kind father figure. (p. 574)

Beliefs about seniority, harmony and hierarchy existing in Vietnamese school cultures combine to challenge the Western leadership values which emphasise the necessity of decentralisation, confrontation, empowerment, institutionalisation, stressing self-control and task-based management (Dimmock \& Walker, 2005; Lowe, 2003; Hofstede, 1980, 1983). These beliefs were supported by Confucian values which acknowledge people's places in the order of preference and the importance of harmony in relationships for the stability of the school community or the society. Although school leaders, in some cases, made efforts to reduce power distance between leaders and staff, empowered teachers by seeking their involvement in decision-making process, strengthened democracy in schools by encouraging school members to express, and contribute their ideas to the discussion, the traditional thoughts of "inferior and superior" impeded the process of empowerment and decentralisation. The direct implication is that the working environment of participative openness should be built and encouraged so as to develop subordinates' willingness to take more responsibility and authority in school management. School leaders should build a closer relationship with subordinates to reduce the power distance in the working environment. It is argued that when the working relationship 
among people, particularly between leaders and subordinates, grows closer and a certain level of trust is achieved, people show more openness, willingness, frankness, trust and cohesiveness.

\section{Building relationships as an investment of leadership}

Building and maintaining good relationships was perceived as an investment in the exercise of leadership. Firstly, in handling a school's internal relationships, although the social values of hierarchy created the distance that could hinder the leaders from establishing close relationships with subordinates, all leaders had a strong tendency to build and cultivate harmonious relationships with subordinates. The maintenance of harmony with subordinates was believed to ensure the subordinates' loyalty to leaders and a high commitment to their work. When harmonious relationships between leaders and subordinates were preserved and cultivated, subordinates were more likely to be loyal to their leaders and schools. Their commitment to work was also strengthened. The maintenance of harmony built trust amongst people and strengthened the teachers' bond to their school. On the contrary, subordinates felt demotivated or had a weak attachment to the school if they worked in an environment that lacked solidarity and harmony amongst the people or did not have good relationships with their leaders. One of the participants admitted that she used to consider changing her job because she did not have a good relationship with her former principal.

Cultivating relationships with subordinates also helped to facilitate school leadership. When harmonious relationships with staff were maintained, staff submission and obedience to school leaders were enhanced. Harmony also minimised the possibility of conflict, open challenge and criticism from subordinates. With harmony established, the school operated smoothly, people worked cooperatively and consensus among people was easily attained.

The effort in building and maintaining harmonious relationships amongst people was closely connected to the preservation of a school's popularity and social recognition. The failure to build and maintain harmonious relationships amongst school members destroyed the prestige of the school. Leaders revealed that they could be reprimanded by seniors if lawsuits occurred in their schools. This explains why leaders preferred "internal solution" if conflict occurred. The "internal solution" was used to deal with 
conflict in which parties tried to negotiate a possible solution within the school or within a group rather than filing a lawsuit against senior officials. This was to prevent "disadvantageous information" from being disclosed to outsiders to preserve the school's reputation and leaders' prestige. Leaders believed that lawsuits reflected problematic relationships amongst people and seriously affected the school's solidarity. This explains why participants in these schools emphasised the importance of the preservation of harmony amongst people; even they recognised that emphasising on the maintenance of harmony too much could lead to the phenomenon of "surface harmony".

Secondly, in handling school's external relationships, the leaders had a strong tendency to maintain and cultivate good relationships with seniors. They acknowledged the importance of preserving good relationships with seniors as a profitable investment for the school. In School A, the principal revealed that her school received more attention and financial support for investing in the school's infrastructure from the local government as school leaders maintained close relationships with senior officials. In School $\mathrm{C}$, the principal admitted that he received a lot of support from DETS as he had cultivated task-oriented relationships with DETS officials. As a result, his managerial work went smoothly. In School B, the principal believed that big investment in the school's infrastructure partly resulted from the school leader's effort in building and maintaining relationships with local government.

Not only did the school leaders believe that building a good relationship with government seniors was as an investment that benefitted their school's development, but so did the teachers. All teachers admitted they preferred working with leaders who could establish a wide social network with government seniors because they believed their leaders' good relationships with them was essential for their support for school development. These beliefs explain why most teachers considered "establishing good relationships with seniors" as one of the school leader's managerial abilities and competence. This suggests that school leaders built and maintained good relationships with seniors because of the demands on school benefits. 
School leaders' close relationships with seniors were also believed to ensure their ambitions. The procedures for leader appointment have become more democratised over the years. Delegation criteria were publicly specified in legal documents. Teachers were invited to participate in the delegation process by casting their votes for "prestige index". The result of voting "prestige index" was used to review how much percentage of staff agreed to promote their leader to a new leadership position. However, the final decisions were remained in the hands of CPC and senior officials, who were believed to hold the political destiny of others. This is why leaders tended to establish tight relationships with seniors. All teachers believed that close relationships with seniors helped their leaders ensure their career path.

What has been discussed here suggests that in a relationship-oriented community culture like that of Vietnam, maintaining a good relationship should be seen as an investment in leadership and management. Nevertheless, there are two sides of the same coin. The positive nature of a good relationship is that it could promote trust, mutual obligations and consensus among people. It also strengthened subordinates' loyalty to their school and leaders and enhanced their commitment to their work. A good relationship was perceived as a prerequisite for any business. Relationships came first and work came a close second. As Ashwill and Diep (2005) point out that in the Vietnamese context, when a good relationship is built and cultivated, the mutual trust that flows from it and work can proceed at a surprisingly rapid pace (Ashwill \& Diep, 2005). However, there are negative sides to relationships. By placing too much emphasis on relationships, leaders may find it hard to implement procedures that need to be scientific or fact-based. As the research indicated, a leader's decision on a personnel affair (delegation), for example, could be affected by the web of relationships he/she had with other people. While such a managerial decision should be fact-based or reason-based, close relationships could affect a leader's decision due to the phenomenon of cronyism. When relationships influenced the decision-making process, leaders' decisions could become biased, partial and prejudiced. Relationships sometimes put leaders in a dilemma as leaders did not know how to make a "right" decision that can balance the advantages between "tình" (relationship-based) and "ly" (rule-based) approaches. In the Vietnamese context, placing too much emphasis on "ly" can be perceived as cold-hearted or even brutal because it requires people to do the right thing according to the rule without considering other people issues. It could harm people's relationships. But if a leader 
relied too much on "tình" approach, he could disregard the school rules; make biased decisions as an "action of sacrifice" to protect a person with whom he had a close relationship. Moreover, relationship-oriented management could create a fertile ground for corruption. As participants revealed that there was staff whose success rested on their relationships with leaders rather than relying on their competence and ability.

\section{The nature of decision-making}

\section{Power-concentration and the reflection of collectivist values in decision-making}

In this study, school leaders' style of decision-making was found to be authoritarian. Some typical features in decision-making reflected the traditional values of the Vietnamese culture and the hierarchy of the administrative system. These features are reflected in the leader's behaviours and teachers' behaviour as illustrated in Table 17:

\section{Table 17: Behaviour in decision-making}

\begin{tabular}{|l|l|}
\hline Leader behaviour & Teacher behaviour \\
\hline $\begin{array}{l}\text { School leaders saw themselves as key } \\
\text { decision makers }\end{array}$ & $\begin{array}{l}\text { Teachers conceived themselves as } \\
\text { "decision-implementers" }\end{array}$ \\
\hline $\begin{array}{l}\text { Leaders always expected teachers to } \\
\text { respect, obey and implement their } \\
\text { decisions strictly and devotedly }\end{array}$ & $\begin{array}{l}\text { Teachers showed the belief in fulfilling } \\
\text { the duties and obligations of their } \\
\text { subordinate role }\end{array}$ \\
\hline $\begin{array}{l}\text { Leaders played the foremost role in } \\
\text { decision making process }\end{array}$ & $\begin{array}{l}\text { Teachers did not acknowledge the } \\
\text { importance of their roles in decision } \\
\text { making. They played a passive role in } \\
\text { decision-making }\end{array}$ \\
\hline $\begin{array}{l}\text { Leaders showed their preference for } \\
\text { power-based decision-making }\end{array}$ & $\begin{array}{l}\text { Teachers showed their reluctance to } \\
\text { challenge their leaders' authority in } \\
\text { decision making }\end{array}$ \\
\hline $\begin{array}{l}\text { Leaders displayed more trust in } \\
\text { older/experienced teachers than the } \\
\text { younger teachers }\end{array}$ & $\begin{array}{l}\text { Older teachers showed more } \\
\text { willingness to participate in decision- } \\
\text { making than their younger colleagues }\end{array}$ \\
\hline
\end{tabular}

People's behaviour in the decision-making process wase attached to collectivist values rather than to individualist ones. Gaenslen (1986) argues that in decision- 
making, people can be labeled as "collectivist" or "individualist". In the collectivist realm, subordinates are reluctant to challenge leaders, and leaders are reluctant to permit such challenges because they risk the collapse of a social order. By contrast, confrontations are normal in the culture of individualism where subordinates are willing to challenge leaders' opinions and perspectives. They are willing to say what is thought to be right as they value autonomy and criticism, they sense that their thoughts and actions are not determined by causes outside of their control or by confrontation (Gaenslen, 1986). In these schools, autonomy in decision-making was low. Teachers relied on leaders' instructions and directions. They found the notion of subordinate duties and obligations congenial. The idea of "subordinates must be obedient to leaders" was taken for granted. Moreover, the leaders showed their strong support for an autocratic decision-making style as they explained that they were ultimately accountable to the Government and superintendents. The teachers viewed "leadership" as being synonymous with "decision-making" whereas they saw themselves (subordinates) as "decision implementers". This indicated that teachers were happy to leave school issues to leaders rather than actively seeking their involvement in decision-making. As one of teachers confirmed "decision-making is not our job but the job of school leaders" (C1FmT2). Teachers developed a culturally disposed psychological orientation of dependence (Conley, 1991; Little, 1988; Smylie, 1992). They were used to relying on the decisions and instructions of their leaders and lacked a willingness in the decision-making process.

\section{Consensus-based decision-making}

The decision-making process appeared to be consensus-oriented. When a decision was made, seeking consensus seemed to be a concern for school leaders. Most of the leaders emphasised that when consensus was attainable, decisions were easily implemented. They also viewed the attainability of consensus in decision-making as an indication of the school's solidarity and unity. Disagreement or divergence in opinions were unfavourable or unexpected. Two school leaders stated that they felt hurt if their decisions were not advocated or not strictly implemented by their subordinates. The other leaders confirmed that sometimes they had to ignore others' opinions in order to "simplify the decision-making process" as they believed "lắm thầy thối ma" (literally means that too many cooks spoil the broth). Disagreement or divergence in opinion was viewed as a "problem" or "disunity" rather than being 
seen as a common phenomenon in the decision-making process as found in individualism-driven societies (see Gaenslen, 1986; Yi \& Park, 2003). Most of the leaders agreed that seeking consensus for decision-making and implementation was extremely important. Such features of decision-making, as Yi and Park (2003) argue, manifest the values of collectivist cultures in which consensus is considered most importance with emphasis on cooperation, harmony, solidarity, unity and interdependence in social life. When unanimity was not unattainable, conflict was more likely to happen. This explained why most of the teachers revealed that they avoided challenging leaders' opinions or decisions. In most cases, they showed their obedience to leaders' decisions rather than offering their opposing ideas even though they might not totally agree with their leaders. The teachers confirmed that their obedience was to show their consensus. This meant that in some cases their consensus did not mean that they completely agreed with their leaders' decisions. In these schools, "showing obedience" to school leaders was understood as "showing consensus". But "obedience" or "consensus" was not necessarily meant to be "agreement" or "supporting". Such behavioural patterns of decision-making are found to be uncommon in cultures of individualistic and low-power distance societies such as Australia, the USA and New Zealand (e.g., Ayyash-Abdo, 2001; Dimmock \& Walker, 2000; Triandis, 1996). People from individualistic cultures place more importance on independence and the self (Ayyash-Abdo, 2001; Triandis, 1996). Literature on cultural distinctions in decision-making styles indicates that although consensus is a desirable objective in individualistic cultures, it is not the overriding concern. The greater importance is the necessity to maximise individual interests as people from individualistic cultures value personal goals over group goals and personal rights and needs over collective responsibilities and obligations (Gudykunst et al., 1992; Triandis, 1996). This was not the case in Vietnamese schools where people emphasised the values of collectivism over the values of individualism.

The literature suggests that people's behaviour is shaped by cultural values which influence people to exhibit different behavioural patterns of decision-making (e.g., Martinsons \& Davison, 2007; Yi \& Park, 2003). Such an argument manifests a fact that cultural values are the reasons behind behavioural patterns of decision-making in Vietnam. Within the Vietnamese context, hierarchical and collectivist values are emphasised (as discussed in the Chapter Two). On the one hand, these cultural 
characteristics involve the need to maintain harmony, power, social order and status and emphasise collective needs over personal needs. On the other hand, they reject the values of independence and self-reliance. This is likely to lead to an emphasis on the importance of obedience, consensus, and non-confrontation in the decisionmaking process. The principals described themselves as in agreement with the concept of "autocratic leaders" who used positional power and legitimate authority to ensure work accomplishment and expected teachers to comply with their instructions and decisions. The teachers described themselves as "decision implementers" who showed strong willingness to respect and comply with leaders' instructions but were reluctant to challenge leader's decisions.

\section{The nature of conflict management and solution}

\section{Factors affecting conflict management strategies}

There was the use of harmony-based and face saving-oriented approaches in conflict management (this will be discussed in the next section). In some cases, people were ready to use confrontational strategies to deal with conflict. Participants believed that in terms of conflict management strategies, people made choices dependent on their status and power. The more powerful and high-ranking the person might be, the more likely he/she used a confrontational approach for conflict management. While subordinates used avoidance strategies when dealing with their leaders, leaders were ready to use confrontational strategies with them. This is consistent with Hofstede's (1980) expectation of high power distance behaviours. When experiencing conflict with subordinates, leaders were willing to exercise their power to influence the subordinates' behaviours in case this was necessary.

Similarly, the older teacher was more likely to challenge a younger colleague, but the other way round was unusual. They used more confrontational strategies with leaders than younger colleagues. It was true that as one's time in employment in the school increased, one was presumed to have more power (in terms of status, wisdom or expertise). This explains why experienced or older teachers were more willing to challenge leaders than their younger colleagues. Perhaps this was due to the fact that as an individual became more experienced; their expertise were highly recognised and acknowledged. Their voice exerted more influence over the decision-making and conflict management processes. 
Conflict was more likely to occur between teachers than between teachers and leaders. Teachers were more likely to resort direct communication and use confrontational styles when dealing with problematic issues with people of the same level. However, the direct styles were rarely found in solving conflict between people of different levels, such as between a leader and a teacher or a leader and a supervisor. Such findings suggest that people might change their avoidance strategies as a function of the power and status relationship. School members with a higher status were more likely to use confrontational styles than members with a lower status. This is a similar result to studies conducted in countries of high power distance such as China and Korea (e.g., Lee \& Rogan, 1991; Yu, 2002) where status and power are found to have significant impacts on conflict management strategies. But it shows a different result from studies in low power distance cultures. In their comparative study, Lee and Rogan (1991) found that US counterparts did not change their avoidance strategies as a function of the power relationship. The findings of this thesis suggest that in cultures of high power distance and exposed to hierarchical values, status and power are conditions for the applicability to conflict management behaviours. Particularly, Vietnamese school leaders are more sensitive in exercising power with their subordinates than with their supervisors.

Various empirical studies suggest that gender might affect the choice of conflict management strategies. For example, Korean males prefer using either integration or control strategies rather than avoidance to deal with conflictual situations more than Korean females. In contrast, the American males were found to prefer using avoidance style more than American females (Lee \& Rogan, 1991). However, this study found that gender did not impact on the choice of conflict management strategies. Most participants agreed that they did not find differences between the approaches of males and females. Although they confirmed that female colleagues were exposed to "gentleness" and males tended to be more aggressive in nature, the gender factor did not impact on the choice of conflict management strategies. As a participant in School B stated: "We think women are gentle in nature so they should be tender when dealing with a conflict? No, it's not true. Some seem to be more aggressive than men when confronting a conflictual situation" (C2MT3). Some participants agreed that male leaders might be more decisive than female colleagues when solving conflict. But they argued that "decisiveness" reflected in conflict 
management process depended mostly on the leader's personality rather than on the gender factor.

\section{Harmony-based and face saving-oriented conflict approach}

An important belief in establishing a harmonious relationship was the effort to avoid being involved in conflict. Participants described a large number of strategies that were commonly deployed to anticipate the occurrence of conflict in school settings, such as avoiding direct criticism, respecting leaders' opinions; keeping silent or concealing their sentiments in annoying situations; indirect expression of disapproval; having self-restraint; and saving people's face. All of these strategies indicate that people preferred to apply the harmony-based approach over the confrontation-based approach for conflict management and solution. Any form of unpleasant confrontation that could upset relationships or lead to conflict was avoided. Particularly, people tended to use the harmony-based approach in dealing with conflict with seniors or people of higher status. The following typical story illustrates how such conflict management strategies were utilised to maintain harmony between a person of lower status (a young teacher) and a person of higher status (a school principal):

The principle blamed me for not preparing well for the school meeting. He talked to me in an angry manner and went away. I soon recognised that he blamed me mistakenly. Another teacher should be responsible for that, not me. But I didn't dare to talk back to him. In such a situation, a young teacher like me should be patient. Getting mad with the leader might make a conflict more serious. (C3FmT6)

Most of the participants indicated that they preferred non-confrontational strategies to confrontational ones. This evidence supports the literature on the relationship between cultural values and conflict behaviours from different disciplines which suggests that people in low-context cultures tend to be more confrontational and direct in conflictual situations, while people in high-context cultures tend to adopt a non-confrontational and indirect style in conflict (e.g., Chung, 1996; Hofstede, 1995; Ting-Toomey et al., 1991;Triandis, 1994, 1995). Vietnamese culture is believed to be high-context, where collective values outweigh individualistic values (Bich, 1999; Borton, 2000). In a collective-oriented society such as Vietnam, people emphasise the values of interdependence, show a strong connection with other people and expect harmony (Ferraro, 2002). Such cultural characteristics could explain why 
people showed a strong belief in deploying a harmony-based approach for conflict management. These ideas supported the view that the cultural context provides the setting in which individuals view the consequences of specific actions or attitudes. It has a strong effect on an individual's understanding of what the results may be of a given choice of action and the choices of conflict style management (Kaushal \& Kwantes, 2006). It also links into other empirical studies conducted in the countries of collectivistic cultures (such as Japan, Hong Kong and China), that showed people from collectivistic cultures are more likely to utilise the avoidance conflict management strategy with the goal of maintaining a positive relationship (e.g., Jehn \& Weldon, 1997; Ohbuchi et al., 1999; Tinsley \& Brett, 2001).

In this study, conflict rarely occurred, particularly between leaders and teachers. Participants agreed that this did not necessarily mean that school was conflict-free, but conflict might be in implicit forms or be hidden by the illusion of superficial harmony. Superficial harmony could be constructed through two possibilities. Firstly, it might emerge in the process of avoiding conflict and maintaining harmony by the use of a non-confrontational conflict management strategy. Secondly, it might come out in the process of solving conflict in which two parties had to accept a "temporary" solution offered by a person of higher status (such as a leader or an older colleague) that they might not be satisfied with it. As a teacher explained,

If the conflict solution satisfies the two parties, it's ok. They may get along well again. But if the solution is not reasonable and they just accept it as a way of respecting the leader's decision, superficial harmony will eventuate. Bằng mặt mà không bằng lòng (willing speech but unwilling heart). (C2MT1)

When superficial harmony arose and the problem was not thoroughly solved, the conflict would be accumulated. Such a nature of conflict can be illustrated in Figure 7. Participants recognised the danger of superficial harmony, but they still preferred it to direct confrontation. 


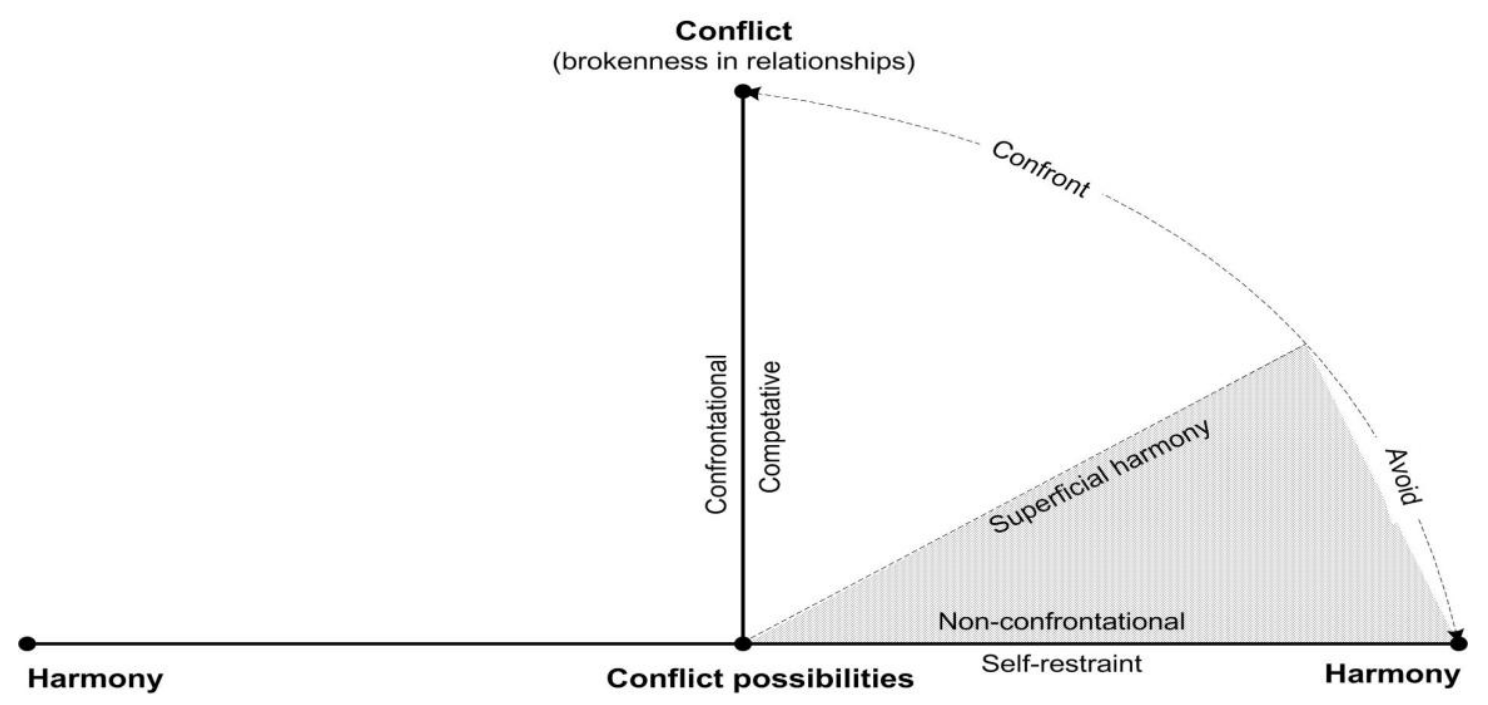

Figure 7: The nature of conflict management

When conflict occurred, the brokenness in relationships was inevitable and not easy to mend. This explains why most participants showed a preference for nonconfrontational approaches. However, participants agreed that the types of school conflict could affect how school members adopted conflict management strategies. Conflict was categorised into two types: task-related or personal conflict (non-task related). The subordinates were not willing to use confrontational strategies with their school leaders in any type of conflict, either it was task-related or personal. People at the same levels were more likely to be willing to get involved in taskrelated conflicts than personal conflicts. When people worked together, their divergent opinions could turn into arguments and could lead to conflict if they could not come to a "win-win solution".

Dealing with task-related conflict, even in the case of using confrontational strategies, was more comfortable than dealing with personal issues. In the workplace when people had different points of views, they might come up with a consensus to do the job better. In personal conflict, if people used the confrontational approach, conflict was deemed more serious. Such findings support the view that the type of organisational conflicts can play an influential role in the choice of conflict management strategies by organisational members (Andrews \& Herschel, 1996). The result of this thesis is generally consistent with other research which suggests that 
confronting styles are often used in task-related conflicts and non-confrontational strategies for personal issues (e.g., Phillips \& Cheston, 1979; Yu, 2002).

The concept of conflict was attached to issues of face. Saving face was viewed as an outcome in the process of conflict management. Participants revealed that when conflict occurred, people tried to prevent "disadvantageous information" from leaking to outsiders in order to protect face for all parties involved in the conflict and for the collective as well. Leaking "bad information" to outsiders was an embarrassing experience and it might damage one's own face or that of another. Leaders emphasised that when they solved a conflict, the best solution was the one that offered a good approach to preserve people's face. Conflict solution was viewed ineffective even if it brought fairness for people but not to save people's face. In Vietnam, face means one's prestige and dignity. Losing face means that the person loses his/her prestige and status and it hurts the person's self-respect. Participants agreed that "saving face" was important to people but it was extremely important to teachers who, if they lost face, suffered from the disrespect of their colleagues and students.

The face saving-based approach was commonly deployed in the process of feedback and appraisal to prevent the occurrence of conflict. Direct, open and even honest feedback might cause conflict. People avoided providing critical and direct feedback to each other even though they might have different points of view. They were reluctant to show their disagreement directly and publicly. One participant confirmed that she had to use "well-chosen words" when providing feedback in order to avoid hurting her colleague's self-esteem and self-respect. In feedback and the appraisal process, it was hard to "call a spade a spade" as it could lead to conflict and people could lose face. While in Western societies, honest and open feedback on performance to an individual being appraised is a key element to improve working quality (Dimmock \& Walker, 2005, Hostede, 1995). This did not relate to Vietnamese schools as people outweighed the importance of harmony and saving face over the quality of feedback. The cultural features of "saving one's own face" and "saving face of another" were very important. It discouraged frank and honest discussion in feedback and appraisal processes because people did not want to make their colleagues lose face. This happened if their critical feedback exposed any weakness in their colleagues' performance. This point supports Hofstede's argument 
(1995) that direct feedback destroys the harmony that is expected to govern interpersonal relationships in collectivist countries.

Saving face was strongly emphasised in managing conflict with people of higher status (either in terms of age or social position). Teachers tended to show their compliance with or avoided criticising leaders even if they disagreed with them. This was utilised not only to preserve harmony with leaders but also to enhance and save leaders' face. If the leader was publicly criticised no matter and what to extent the subordinate's criticism was right or wrong, the leader's prestige (or face) would be affected. This explains why teachers showed a reluctance to challenge leaders' opinions and avoided criticising leaders in public. Similarly, older teachers enjoyed their higher status in the conflict management process. When a conflict between an older teacher and a younger teacher happened, preserving older teacher's face was a priority. Younger teachers tended to accept "disadvantages" or even "unfairness" in order to maintain harmonious relationships. This supports Te's (nd) comment about the concept of age in the Vietnamese cultural context: "Age is an asset, not a liability". It indicates a clear reflection of the Vietnamese traditional culture that accepts the principal of social hierarchy to care passionately about face and status (Jamieson, 1993). They support the concept of equality in the Vietnamese context that equality does not imply the breaking down of the established hierarchy (Bich, 1999).

\section{Seeking intermediaries for conflict conciliation}

This study found that seeking intermediaries in school conflict was common. People might seek help from intermediaries in the following situations:

- When two parties did not want to confront each other directly or they did not feel comfortable with a confrontational strategy;

- When they believed there someone who was "prestigious enough" to conciliate the conflict better than they could;

- When their conflict was serious and they could not resolved it themselves;

The most important reason for seeking intermediaries was to reduce the negative consequences and conciliate the two parities. It indicated that people sought the 
involvement of school leaders in task-related conflicts as they believed that school leaders could play the role of referee who had full authority, power and prestige to make the final decision. In such a way, both parties could avoid the need to make concessions. Leaders were believed to have power to create and enforce their resolution. Hence, their decision or opinions, were easily accepted by people-inconflict. Leaders revealed that besides being involved in task-related conflicts, they were sometimes asked by subordinates to be involved in their personal conflicts such as a family problem. Most of the leaders admitted that such involvement in conflict was due to subordinates placing their trust in a person of authority whose opinions were highly acknowledged.

People also sought older people's involvement in the role of referee or conciliator in the conflict management process because older people's opinions and advice were believed to be connected to credibility due to their higher status, experience and imperturbability.

Dealing with conflict reflects the existence of the values of hierarchy in Vietnamese society in which the values of respecting authority and seniority are dominant. Seeking intermediaries for conflict management strategies emphasised the importance of cultural values of hierarchy in which people pay great deference to those of higher status, either in terms of their social position, age or organisational position. The hierarchical nature of Vietnamese culture has concern for authority and

seniority in conflict management strategies. Such organisational behaviours are supported by the view that members of hierarchical cultures tend to defer to those of higher status and authority in conflict management processes (Leung, 1997). As Leung (1997) points out, by deferring a decision to a superior or a person of higher status, both parties avoid the need to make concessions. The avoidance of making concessions might be understood as a way to preserve one's own face in the conflict because concession also means "loss in negotiation process" which, if it happened, might affect one's prestige or status (face).

\section{Reconceptualisation of Vietnamese có uy leadership}

The question now asked is: how is school leadership effectiveness reconceptualised in the Vietnamese context? This section offers a reconceptualisation of effective school leadership based on the findings of this study. 
As stated, there are two leadership styles in practice and in people's perspectives. These are authoritarianism (or hierarchical leadership) and "governing by virtues" (Đức trị - moral leadership). Authoritarianism is supported by the hierarchy of political line and hierarchical organisational structure of the school. Authoritarianism is also supported by the hierarchical values rooted in Confucian philosophy. The practice of "governing by virtues" (or moral leadership) is inspired by the cultural norms of ethics characterised by Confucian values. Such values include "tu thân" (self-cultivation), "làm guoong" (setting a good example), harmonious relationships, and "ngũ thưòng" (five common human virtues), including: 1. Nhân - benevolence and huminity; 2. Nghĩa - reciprocity and altruism; 3. Lêe - propriety; 4. Trí knowledge; and 5. Tín - integrity and faithfulness.

The sustained cultural core values are rooted in Confucianism, the philosophy of which concentrates on relationships and order. A person is defined by his/her relationships with others. There are rules and orders in operating these relationships. This study affirmed that recognising one's social position in the organisation ensures proper behaviour which builds harmonious relationships. This Confucian cultural heritage is reflected in the views of leader roles and leadership. For example, the study leaders saw the quality of relationship as one of the most important bases in their decision-making and exercising of power. While they stressed the necessity of the combination of strong discipline and authority in exercising power, they acknowledged the importance of showing care toward employee's well-being as a way to maintain harmonious relationships. They saw themselves as the "highest figures" due to their leadership roles, legitimate authority and accountability and treated employees strictly to establish managerial order. But, they also recognised the importance of leading by example to demonstrate their own high moral integrity. These perspectives and practices suggest that the leaders had a strong tendency to combine the autocratic/authoritarian leadership and moral (ethical) leadership in exercising power.

Authoritarian leadership involves absolute, authoritarian control over a group. It concentrates on establishing strong authority, compliance and obedience. Authoritarian leaders assert absolute control over subordinates and demand unquestionable obedience from subordinates (Bass, 1990; Russell \& Stone, 2002; Cheng, Chou, Wu, Huang, \& Farh, 2004). Moral leadership emphasises the leader's 
appropriate conduct through personal actions and interpersonal relationships, and the promotion of such conduct to subordinates through two-way communication, reinforcement, and decision-making (Brown, Trevino \& Harrison, 2005). From a Confucian perspective, moral leadership emphasises the role models of leaders whose actions are to be emulated by subordinates (Resick et al., 2011). Based on this study, the attributes of authoritarian leadership and moral leadership in the Vietnamese context are identified and summarised in Table 18:

Table 18: The attributes of authoritarian and moral leadership styles

\begin{tabular}{|c|c|}
\hline $\begin{array}{l}\text { Characteristics of authoritarian } \\
\text { leadership }\end{array}$ & Characteristics of moral leadership \\
\hline $\begin{array}{l}\text { Autocratic (recognising the importance } \\
\text { of obedience and compliance from } \\
\text { subordinates) }\end{array}$ & $\begin{array}{l}\text { Showing care toward subordinates } \\
\text { (recognising the importance of respect } \\
\text { from subordinates) }\end{array}$ \\
\hline $\begin{array}{l}\text { Using positional power and authority } \\
\text { to influence subordinates }\end{array}$ & $\begin{array}{l}\text { Using personal conduct and prestige to } \\
\text { influence subordinates }\end{array}$ \\
\hline $\begin{array}{l}\text { Using Lý (rules, regulations, discipline, } \\
\text { law) }\end{array}$ & $\begin{array}{l}\text { Using Tinh (focus on relationships, } \\
\text { caring subordinates' feeling and } \\
\text { aspiration) }\end{array}$ \\
\hline $\begin{array}{l}\text { Led by using authority and positional } \\
\text { power. Regulate subordinates' } \\
\text { behaviour by strict discipline and } \\
\text { regulations }\end{array}$ & $\begin{array}{l}\text { Led by setting a good example. Regulate } \\
\text { subordinates' behaviour by setting role } \\
\text { models (leader's self-cultivation, } \\
\text { fulfilling one's obligations) }\end{array}$ \\
\hline $\begin{array}{l}\text { Maintain a level of aloofness with } \\
\text { subordinates to retain leader's } \\
\text { authority and power, build the image } \\
\text { of "condescending leader" }\end{array}$ & $\begin{array}{l}\text { Tend to build close relationships with } \\
\text { subordinates to create the image of a } \\
\text { "sociable leader" }\end{array}$ \\
\hline $\begin{array}{l}\text { Emphasise assertiveness in working } \\
\text { relationships }\end{array}$ & $\begin{array}{l}\text { Emphasise harmony, face saving and } \\
\text { avoiding confrontation }\end{array}$ \\
\hline Status and power building & Prestige and reputation building \\
\hline Rigorousness in work & $\begin{array}{l}\text { Consideration and tolerance in work } \\
\text { (altruism) }\end{array}$ \\
\hline
\end{tabular}

Within the domain of authoritarian leadership, the school leaders built an image of "powerful and authoritarian figures", who established and exercised control and dominance over subordinates. They were familiar with and enjoyed the mechanism of the "top-down" - centralised decision-making system. Hence, communication between leaders and teachers was generally in a downward flow: the leaders made 
decisions, gave directives and instructions; while teachers and staff were expected to obey the leaders' decision and implement their directives and instructions. While the leaders saw themselves as key decision-makers, they considered teachers and staff as decision-implementers. The leaders exercised moral leadership by setting good examples and building harmonious relationships with subordinates to gain respect and create the image of prestigious leaders. Within the domain of moral leadership, the leaders used their personal conduct and prestige to influence their subordinates.

It can be argued that authoritarian and moral leadership styles were both used to influence subordinates for managerial purpose, but each style had its own strength and weakness. The study found that a strong leader who utilised an authoritarian style could establish managerial order for a smooth management process. However, the abuse of authority could be problematic as "bossy" or "dictatorial" behaviours of the leader could make the working climate more stressful, demotivating to subordinates, and lead to subordinates disliking the system. Moral leadership style was utilised to promote trust between the leader and subordinates. The exercising of moral leadership built and stimulated subordinates' respect and emulation toward the leader. Yet, while moral leadership could work out positively, especially in cultivating long-term mutual trust and personal relationships between the leader and subordinates, it could be problematic if the leaders abused the cultivation of relationships for managerial purposes. Unfairness or favouritism, for example, could occur at the workplace as a result of cronyism and camaraderie.

The interaction of the authoritarian and moral leadership styles was found to have positive effects on the responses of the subordinates. Leadership styles employing subordinates' compliance and respect simultaneously were found to improve subordinates' work attitude. While authoritarian leadership was used to establish subordinates' compliance, obedience and fear, moral leadership was employed to attain subordinates' respect, awe and emulation. The image of a có uy leader was built when a leader combined these two types of leadership. This study has shown that a leader was considered có uy only when his/her subordinates showed their compliance, obedience and fear combined with their respect, awe and imitation. Có uy was understood as the effectiveness of leadership. It was a result of the combination of authoritarian and moral leadership in order to attain two primary responses from subordinates: compliance and respect. Subordinates might show their 
absolute obedience, compliance with, and fear of their leader as a way to accept the leaders' authority and positional power, but it was not necessary that subordinates respect the leader and that it does not mean the leader was có uy. Hence, có uy leadership in the Vietnamese context can be defined as the art of leadership in which the leader is able to combine his/her legitimate authority with his/her morality in a high level of exercising leadership in order to achieve subordinates' obedience, compliance and fear combined with their respect, awe and emulation for the purpose of leadership effectiveness.

The study noted that low levels of exercising authoritarian leadership resulted in negative responses from subordinates. For example, when subordinates were irresponsible in their work, they disregarded the school discipline and they rejected the leader's authority and power. All of these subordinates' negative responses could lead to widespread disruption among people. Similarly, a low level of exercising moral leadership resulted in subordinates' disrespect and rejection towards the leader. From this discussion, the effective leadership or the image of có uy leader can be conceptualised and illustrated in the following model (see Figure 8).

The model provides an explanation of how leadership effectiveness is achieved and conceptualised in the Vietnamese context. The model indicates that when authoritarian and moral leadership approaches are exercised in a combined and integrated manner, four possibilities of leadership outcome can be attained. These possibilities are illustrated in the four quadrants:

- Quadrant 1: describes a leadership situation in which the leader exercises high authoritarian leadership and high moral leadership. The combination of these two approaches to leadership is likely to result in positive subordinate responses (obedience, fear, respect, awe, and emulation). Such an outcome indicates that leadership is exercised effectively and is perceived as có uy leadership.

- Quadrants 2: illustrates a leadership situation which is high in morality and low in authoritarianism. In such a combination, the result is potentially, ineffective leadership (non-có uy). 


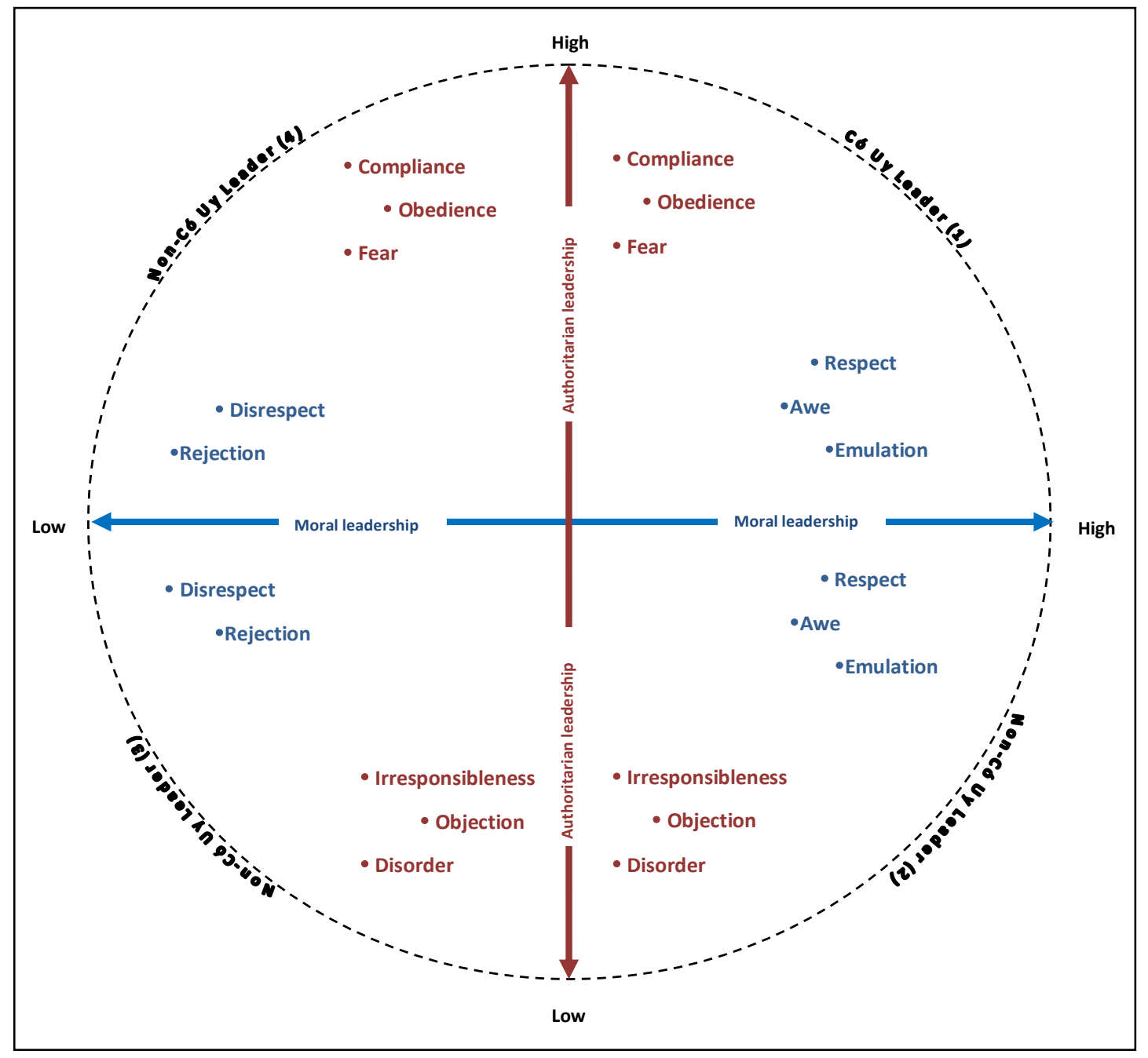

Figure 8: Model to conceptualise có uy leadership

- Quadrant 3: shows a situation where leadership is low in morality and low in authoritarianism. The resultant impact is ineffective leadership (non-có uy).

- Quadrant 4: illustrates a situation where there is high authoritarianism and low morality. Given this combination, leadership is likely to be ineffective (non-có uy).

Given the above description, the following equations summarise the possible options of có uy or non-có uy leadership in the Vietnamese context: 


\begin{tabular}{|c|}
$\mathrm{HA}+\mathrm{HM}=$ Có $u y$ \\
$\mathrm{HA}+\mathrm{LM}=$ Non-có $u y$ \\
$\mathrm{LA}+\mathrm{HM}=$ Non-có $u y$ \\
$\mathrm{LA}+\mathrm{LM}=$ Non-có $u y$ \\
$(\mathrm{~A}=$ authoritarian leadership $; \mathrm{M}=$ moral leadership $\mathrm{H}=$ high $\mathrm{L}=\mathrm{low})$
\end{tabular}

Lord, Brown, Harvey and Hall (2001) state that the values of societal culture influence the types of leader behaviour and characteristics that are endorsed within a particular culture. In Vietnam, the continuation of prevailing Confucian values and the qualities of hierarchical political and administrative structure could provide the reasons for the combination of these leadership styles.

On the one hand, Confucian values strongly concentrate on the importance of social order and hierarchy. Consequently, authoritarian leadership is encouraged. This study showed that school leaders acted autocratically and maintained strong authority. Subordinates were obligated to be obedient. Furthermore, the hierarchical values of political and administrative structures (discussed in the previous Chapters Six and Seven), which granted leaders strong authority and emphasised the importance of subordinates' compliance and obedience, encouraged the deployment of an authoritarian leadership style.

On the other hand, the moral values of Confucianism that concentrate on righteousness, benevolence, loyalty and harmony, encouraged leaders to act ethically by protecting subordinates' prestige, saving face, showing care toward subordinates and guaranteeing subordinates' well-being. Although the behaviours of these two types of leadership seem to contradict each other to a certain extent, the combination of these styles works well as it appears to respond to the cultural context and the political and administrative system. In the previous analysis and discussion, the relative effectiveness of authoritarian leadership and moral leadership is that the authoritarian leadership focuses on fostering subordinates' assigned roles, responsibility and performance abilities. The moral leadership focuses on developing relationships, fostering harmony among people, and being concerned about subordinates' personal feelings and needs. These two types of leadership are deeply rooted in the philosophy of Confucianism emphasising reciprocal interpersonal relationships between superiors and subordinates under hierarchically authoritative 
leadership and reciprocally humanitarian leadership (Lee, 2001). The combination of these two leadership approaches could help school leaders exercise their power and authority very effectively as this is congruent with Vietnamese cultural values such as hierarchy, social order (respecting elders and seniors, status preference), collectivism (harmonious relationships, face saving, avoiding confrontation), or morality (the importance of self-cultivation and role modeling).

What has been discussed implies that in the case of establishing managerial order for "smooth management process", authoritarian leadership enables leaders to achieve initial subordinate compliance and obedience more easily. For subordinate compliance, it is authoritarian leadership that has the largest effect. However, the authoritarian leadership can be problematic if subordinate compliance is in a superficial form. Superficial compliance may exist if subordinates show their compliance to their leaders as a way to accept the leaders' authority and power but they do not show their respect. This study showed that such a phenomenon could happen if a leader exercised a high level of authoritarian leadership but employed a low level of moral leadership. This also means that subordinate compliance would be a negative response if it was not combined with subordinates' respect. The subordinate compliance was only considered to be a positive response when the exercising of authoritarian leadership and moral leadership interacted at a high level (as showed in Figure 9). In other words, the exercising of authoritarian leadership must be combined with the exercising of moral leadership to attain leadership effectiveness. Leaders should not only see themselves as people of high authority who carry leadership responsibility, but also see themselves as the moral standard bearers for their schools, demonstrating consistently high standards of moral conduct to send a strong message to their followers. This conclusion is consistent with the widely-accepted philosophy of management from a Vietnamese perspective: "We need an iron hand, but the iron hand must be a clean hand"19 .

\section{Summary}

The discussion in this chapter has made the case that cultural values have an impact on four distinctive school leadership functions: exercising power, building

\footnotetext{
${ }^{19}$ Metaphoric meaning: the iron hand refers to a leader who severely utilises his/her authority and power to influence subordinates in order to establish managerial order; the clean hand refers to a leader who utilises his/her high standard of moral conduct to influence subordinates.
} 
relationships, decision-making and managing and solving conflict. In Vietnamese school contexts, Confucianism-affiliated cultural values, mainly related to harmony, obedience, face saving, respect for authority and seniority, are found to be prominent in interacting with these leadership functions to configure leadership behaviours and strategies. Literature about leadership suggests that the personal values of leaders are important in shaping their attention and behaviours in leadership practice (Hallinger \& Leithwood, 1998), this research has added clear evidence that school leadership behaviours and approaches are also shaped and significantly impacted on by cultural values. 


\section{CHAPTER EIGHT: RESEARCH IMPLICATIONS AND CONCLUSION}

\section{Introduction}

In this final chapter, five areas are covered: (1) a summary of the study is given, focusing on the research questions; (2) the implications of the findings are discussed, focusing on school leadership practices and policy-making; (3) the research limitations are reviewed, based on my reflections on this study; (4) the suggestions for future research are proposed; and (5) my concluding thoughts are provided.

\section{Summary of the study}

I have explored how Vietnamese school leaders exercised leadership within Confucian discourse. My interest in this aspect of leadership emanated from the fact that as a Vietnamese citizen who was living and studying in New Zealand, I had become aware of the significant differences in people's ways of thinking, expectations and behaviours. My training experience in leadership made me interested in cultural factors as I found that there was a missing variable in the Vietnamese training course books. The influence of Confucian values as a prominent feature of Vietnamese culture and its connection to school leadership had been neglected in academia. This deeply concerned me. Accordingly, this research set out to answer the question: How is Vietnamese school leadership influenced by Confucian values?

The four pre-defined themes of the research focused on four particular functions of school leadership: exercising power, building relationships, decision-making, and managing and solving conflict. Based on these pre-defined themes, three questions were asked:

1. What are the nature and impacts of Confucianism on the:

a) exercise of power?

b) building relationships?

c) undertaking decision-making? 
d) the nature of problem-solving?

2. How effective is school leadership as perceived from Confucian values?

3. What are the implications for school leadership in Confucian-influenced contexts?

A qualitative research approach was applied for this phenomenological interpretive study. Four methods of data collection were adopted, consisting of interviews (individual and focus-group interviews), observations, document analysis and questionnaires. School leaders and teachers from three schools participated. School principals and vice-principals participated in the individual semi-structured interviews. Six teachers from each school were asked to gather for the focus-group interviews. The teachers were also asked to complete the questionnaire (open-ended questions) individually. Most observations were undertaken in school meeting contexts. School documents (such as annual school reports, school discipline and regulations, and school statutes) were also collected.

The data provided evidence that in Vietnam Confucian values were reflected in participants' perception about school leadership and in the manner of everyday leadership and management practices, particularly under the four pre-defined leadership functions. Confucian authority chains, seen as the paternalistic culture of obedience and respecting authority or hierarchical values, have transferred into contemporary Vietnamese school leadership and management. These cultural values were reinforced by the political and administrative hierarchical structures to influence school leadership practices. The leadership and management practices were also found to be embedded in and shaped by the other cultural values such as harmony, collectivism and moral values and perspectives (such as self-cultivation and setting a good example). How these cultural values were transferred into school leadership and management practices will be summarised below.

\section{Exercising power}

Two significant trends of exercising power in the Vietnamese context were found. Firstly, schools continued to rely heavily on authoritarian leadership. The practices of power were embedded in social hierarchical values and the hierarchical structure of school administration. While acknowledging the need for and the trend of the 
expansion of grassroots democracy in leadership practice, school leaders continued to exercise their power within traditional parameters of respect for hierarchy and seniority. Subordinates' obedience and compliance were highly emphasised; discipline was enforced; subordinates were kept in line; decision-making was a "topdown" process. These hierarchy-oriented practices were used as a basis for establishing managerial order. Such practices were believed to respond well to the administrative structure of school and Vietnamese cultural values. For example, "power over" is viewed as negative in Western perspectives, but in the Vietnamese school context it was believed to be an effective approach for guaranteeing the power of leaders and for the purpose of creating a smooth management process.

Secondly, moral leadership, which placed emphasis on leading by setting a good example (self-cultivation, fulfilling one's obligation) and using personal conduct and prestige to influence subordinates, was found to be significant. In the Vietnamese context, moral leadership was used to moderate the negative effects of authoritarian leadership. The exercising of authoritarian leadership was combined with the moral leadership to attain leadership effectiveness. The combination of these two leadership approaches is conceptualised as the "có $u y$ " notion within Vietnamese culture.

\section{Building relationships}

Building relationships in schools was found to be embedded in two important cultural discourses. Firstly, relationships were built in a hierarchy-oriented course of action. Within schools, people acknowledged the prevailing discourse of respect for people in senior positions and the importance of maintaining hierarchical distance, positional authority, and aloofness. Hierarchical values remained dominant and were used as guidance for people's behaviours. The dominance of hierarchical values explains why in leadership practice, leaders emphasised the importance of attaining subordinates' compliance and obedience.

Secondly, harmony in building relationships was found to be the basis for school members' behaviour. Values of harmony affected the approaches that leaders chose to build relationships, deal with conflict and exercise power. Leaders and subordinates employed a range of strategies to cultivate and preserve harmonious relationships. Preservation of harmony was seen as being essential for leadership effectiveness. Hence, challenging harmony was believed to lead to conflict and 
disorder. This was why teachers were reluctant to confront leaders and why people preferred to use a non-confrontational approach for conflict resolution. Building relationships was seen as an investment in leadership. For internal relationships, leaders maintained harmony with subordinates to facilitate leadership and the management process. For external relationships, leaders cultivated relationships with seniors for the benefits of the school and to ensure their career path.

\section{Decision-making}

The Vietnamese school leader's style of decision-making was found to be authoritarian and decision-making was a consensus-based process. School members accepted and acknowledged the "top-down" protocol of the decision-making process, in which leaders were key decision-makers and subordinates were decisionimplementers. Accordingly, leaders showed strong support for an autocratic decision-making style and in turn subordinates showed a high level of compliance and obedience. This meant that subordinates developed a psychological orientation of dependence. They lacked willingness in the decision-making process and heavily relied on the decisions and instructions of leaders. The value of harmony (reflected in cultural factors such as respecting seniors, avoiding conflict, and saving face) was found to further impede teacher involvement.

The preference for an autocratic style of decision-making was promoted by two main factors. Firstly, the hierarchical power structure placed an emphasis on the leader's accountability in which power of leadership was highly concentrated in the leader's hands. The maintenance of autocracy was due to the demand on the leader's accountability. Secondly, cultural values of hierarchy encouraged the deployment of an autocratic style. Within the working environment of hierarchy (in terms of administrative structure and cultural values), the habit of obedient subordinates was established and the autocratic style in decision-making was reinforced.

\section{Conflict management and solution}

The strategies for conflict were found to be harmony-based and face saving-oriented. These two cultural features encouraged school members to choose nonconfrontational over confrontational approaches when dealing with conflict. Behaviour that could upset relationships and lead to conflict was avoided. 
Subordinates were reluctant to challenge their leader's decisions and leaders were not willing to confront their seniors. Avoidance strategies constituted the basis for maintaining harmony amongst people. However, people could change avoidance strategies as a function of power and status relationship. School members with higher status (in terms of age or working position) were likely to use confrontational approaches with people of lower status. The other way around was unusual. As in other cultural contexts, seeking intermediaries for conflict conciliation was found in the Vietnamese schools. Seeking intermediaries emphasised the act of paying deference to those of higher status due to the cultural emphasis placed on hierarchy.

\section{Implications}

Based on the findings of this study, the recommendations and implications for school leadership practices in the Vietnamese context are offered as follows:

\section{Implications for school leaders}

Firstly, school leaders must play an active role in supporting subordinate involvement in decision-making. Confucian values (such as hierarchical social order, face-saving and harmony) were found to challenge the decision-making process and constrained participative leadership, the philosophy of which emphasises the active engagement of teachers in solving problems and decision-making (Bass \& Bass, 2008; Lashway, 2006; Northouse, 2006). All leader participants in this study acknowledged that teachers' involvement in decision-making process could increase the quality of decisions and motivate subordinates' responsibility. However, subordinate involvement in decision-making was impeded by values of hierarchy or "habit of obedience". This study indicated that subordinate involvement and empowerment were low, which restrained the mobilisation of "collective brainpower" in the decision-making process and hindered the course of the expansion of grassroots democracy that the Government has been encouraging in the process of decision-making. Unless these obstacles to participative decision-making that are latent in Vietnamese culture are acknowledged and fully understood by school leaders, it is not easy to remove them. In a practical sense, however, this does not mean that subordinate involvement and empowerment cannot be enhanced. No one but leaders should play an active role in creating an environment of trust, in which subordinates believe that their opinions, either agreeable or opposing, would 
be taken into consideration and respected. This research indicated that no one would be willing to contribute their ideas if they believed that their opinions would not be accepted or acknowledged by leaders. In other words, subordinate involvement cannot be promoted in an environment of low trust between leaders and subordinates. At this stage, the problem with subordinate involvement seems less about openness and more about how subordinates' opinions are handled by leaders. Thus, attempts should be made to reduce apprehension or fear to make subordinates feel safe when being involved in the decision-making process. In the context of a richness of ideas, leaders should show that their ideas are taken into account and a choice of one over another could be explained. Moreover, close relationships should be made to build bonds among people. It is argued that when the relationship between leaders and subordinates grows closer or when groups build cohesiveness, subordinates are motivated to have a voice in discussion (Thang et al., 2007).

At an institutional level, school leaders might be encouraged to undertake an appropriate professional development programme. With their own peers, leaders can examine the issues closely and suggest ways to improve subordinate participation that is based on có úy leadership. Over time, appropriate systems-wide professional development may be instituted, using existing political and societal policy processes.

Secondly, school leaders must demonstrate an appropriate combination of authoritarian and moral leadership approaches for leadership effectiveness. Although authoritarian leadership, in Western perspective, is inherently coercive (Lashway, 2006), this approach appears to be implemented effectively and preferable in Vietnamese schools as it fits the context of hierarchical administrative structure and the long-established values of hierarchy in Vietnamese society. In a context where hierarchical values (in organisational and social levels) are emphasised and respected, authoritarian leadership is cultivated to establish managerial order. Discipline and rules are used as an effective way to establish an organisational order and cultivate responsibility. Consensus among subordinates can be attained if authoritarian leadership is exercised. But such consensus can be superficial because it is based on subordinates' fear and obedience rather on their acquiescence and acceptance. This can be dangerous because the superficial consensus, as a type of resistance underground, makes subordinates have low commitment to work and deject their responsibility. This implies that authentic consensus cannot be achieved 
through an obtrusive approach because leaders may come to believe they have achieved consensus where none exists. In addition, high application of an authoritarian leadership style might lead to an undemocratic and stressful working environment which might exterminate subordinates' motivation, creativeness, and willingness to participate in decision-making, and bond with the school.

However, this does not mean that the negative effects of authoritarian leadership approach cannot be reduced. In the Vietnamese context, as the research findings indicated, the negative effects of authoritarian approach can be moderated by moral leadership (as we discussed có uy leadership model in Chapter Seven). Moral leadership has a significant effect on subordinates. It appears to have replaced some outdated elements of authoritarian leadership. In this research, moral leadership is more probable than authoritarian leadership to induce subordinate influence through acts of high moral conduct and exemplary behaviour. This implies that school leaders should cultivate their moral leadership to facilitate the exercising of an authoritarian approach. Consequently, in the Vietnamese context, school leaders should employ authoritarian leadership and moral leadership an integrated and in a balanced-manner to achieve the best results and effectiveness.

This need for có uy leadership (which is authoritarian yet moral) highlights the importance of the personal integrity of the school leaders. Again, at an institutional level, through an appropriate professional development initiative, school leaders might be assisted to appreciate the newer understandings of có uy leadership (from this study) and helped with personal development tools to ensure and enhance their leadership effectiveness.

Thirdly, leaders can establish and encourage discussion panels to increase subordinate involvement. Subordinates were more willing to express their ideas and opinions to their peers and within their panel than to their school leaders or in wholestaff meetings. The trend toward more active involvement in decision-making was more prevalent in small group meetings such as meetings within a division or a faculty. Teachers showed a willingness to express their direct and sometimes confrontational opinions or discuss sensitive issues without the presence of school leaders. The key reasons for this were that people within a group had closer relationships and had the same working status. "Power distance" or remoteness 
amongst people was low. Trust was built through a lot of interaction amongst people. Such organisational features promoted people's willingness and enthusiasm to express their opinions or even criticism as they felt safe when doing so. In terms of a cultural perspective, Vietnamese people make a distinction between being "within" and "outside" a group. It is considered an unfavourable loss of face to a group or member when negative feedback or criticism comes from, or is leaked to someone outside the group. Yet, giving opinions or even criticism within a group is seen as acceptable because it is evidence of caring about another person (Thang et al., 2007). These organisational and cultural features should be taken into consideration for the purpose of creating discussion panels to encourage subordinates involvement in decision-making. School plans, programmes or policies should be best discussed within a group, department or faculty rather than within whole-staff meetings. This is largely due to people in groups knowing one another well through their close relationships. When people are in more intimate levels of relationships, they are more direct, frank, and honest with each other (Borton, 2000; Tuan \& Napier, 2000), the discussion is open and people feel more confident and free to discuss issues with people of the same working status. In this case, school leaders can build a network of senior staff whom they can trust to collect opinions and aspirations from the discussion panels. As a first line of assistance, school leaders might be supported to facilitate these newer ways of working within a school

Fourthly, school leaders must learn to use strategies that counter traditional norms of harmony to understand and reduce negative cultural effects for a better decisionmaking process. This research indicated that harmony involves "two sides of the same coin". Maintaining harmony was to maintain a conflict-free working environment, where people felt peaceful, cohesive, and united. Harmony was inextricably connected to the nature of solidarity, which had a significant influence on a school's achievement and accomplishment. The maintenance of harmony was seen as a way of ensuring subordinates' loyalty to the school employing them and commitment to their work. Challenging harmony in Vietnam was believed to lead to conflict and disorder. Yet, on the other side of the coin, the strong emphasis on harmony could become detrimental to school management. For example:

- Subordinates' reluctance to contribute to decision-making, being reserved in expressing their ideas; 
- Low willingness to give frank feedback (people did not want to hurt others by giving frank feedback)

- Low willingness to accept feedback on performance (people felt hurt and shocked if they received negative feedback from colleagues).

To preserve harmony, people tended to hide their disagreement or "real thought". Resistance and discord remained hidden or were less blunt. If this happened, leaders were unable to propose appropriate managerial strategies because they did not fully understand the situation. Resistance or disagreement is a natural by-product of decision-making process. It is, hence, something that leaders must learn to work with. As Maurer (1996) claims:

Often those who resist have something important to tell us. We can be influenced by them. People resist for what they view as good reasons. They may see alternatives we never dreamed of. They may understand problems about the minutiae of implementation that we never see from our lofty perch. (p. 49)

For leadership effectiveness and better outcomes for the decision-making process and conflict resolution, school leaders must understand the nature of harmony, both its positive and negative effects. As a school leader stated: "a calm sea does not mean that it has no waves; calm water does not mean that there is no ferment below the surface".

Again, without an initial institutional professional development, school leaders are unlikely to re-think the applications of harmonious relationships within Vietnamese contexts. As an initial strategy, institutional leaders might be supported to discuss the application, experiences and challenges relating to Confucian values and influences on harmonious relationships and decision-making in the Vietnamese school setting.

\section{Implications for policy-makers}

Firstly, the implications for the practice of grassroots democracy, autonomy and decision-making. The educational system of Vietnam has been in transition from centralisation to decentralisation. Its purpose is to hand more autonomy to schools and encouragement of grassroots democracy in order to "promote and mobilize the intellectual potentials of principals, teachers, learners, staff and employees" (Article 1, MOET, 2000). The Education Law of 2005 emphasises that the state should "implement decentralisation of management to local agencies and enhance the 
autonomy and accountability of grassroots education establishment" (Article 14). However, given the desire of the government for the grassroots democracy implementation in schools, the values of democracy is not likely to be put into practice if school leaders are not well prepared for their readiness to practice and implement grassroots participation in decision-making. This is because, as this study indicated, the cultural discourses of hierarchy as well as the leaders' "powercentralised" mentality circumscribed the implementation of grassroots democracy practices.

In a practical sense, a long-term plan for creating a new generation of leadership who are willing to practice democratic values should be instituted. This requires school leaders to be provided with education and training on how to perform grassroots democracy and decentralisation. This approach is different from the present one, based on a central government office mandating grassroots democracy and decentralisation in schools without offering school leaders with appropriate education and training.

Furthermore, as the study findings indicate, while the Government stipulates the idea of grassroots democracy as an enhancement of autonomy, decision-making and accountability of schools, the Party has reinforced its political role in school administration, requiring all school members to strictly execute and comply with the directives and regulations of the Party. This seems to be contradictory. Such a political approach is a reinforcement of the political influence of the Party in its "comprehensive leadership role". Doing so encourages the values of compliant obedience which is inconsistent with the practice of grassroots democracy and participative decision-making. The idea of obedience discourages the involvement of school members in the decision-making process. Given the wish of the Government for an enhancement of autonomy and decision-making in a highly politicalinfluenced system, a tripartite framework for a division of labour among three stakeholders (school-party secretary, school leaders, and teachers and staff) in school administration needs to be clearly defined and institutionalised in order to circumscribe any political power abuse, while stimulating subordinates' responsibility in decision-making process. Detailed job descriptions for these three stakeholders and working procedures within a school will need to be clearly defined and legitimised to represent different levels of power in different leadership domains. 
Moreover, if schools are encouraged to maximise the practice of grassroots democracy, autonomy and participative leadership, policy-makers should give way to more flexible policy guidelines for schools rather than standardise practices and outcomes to impose the Party's political will. This implies the need to shift from policies that attempt to standardise political practices and willpower to ones that permit greater variance in decision-making process.

Secondly and related to the major findings, leadership and cultural practices are not isolated. As a number of studies and education reports indicate (e.g., Ho \& Berg, 2010; Khanh \& Hayden, 2010; Vallely \& Wikinson, 2008), schools at all levels remain subject to a highly centralised system of control; the process of decentralisation has been delayed due to the fact that educational authorities have retained a strongly "power-centralised" view and displayed a "power-centralised" mentality in making policies or in policy implementation. Some reasons for this are "unfamiliarity with autonomous system", "unclear separation of powers between leading roles", and "the existence of bureaucracy" (see Ho \& Berg, 2010; Khanh \& Hayden, 2010; Vallely \& Wikinson, 2008). However, no cultural factors have been identified as a main reason for the resistance to change or delay in the decentralisation process. This study has confirmed that the hierarchy-penetrated mind and the "taken-for-granted" acceptance of unequal power distribution of Vietnamese people could be an obstacle for the implementation of institutional autonomy and for the decentralisation process. A leader who behaves with high levels of autonomy has a laissez-faire style, is passive and gives the subordinates freedom of action without participating in subordinate activity (Bass, 1990; Trevelyan, 2001). A leader with a hierarchy-penetrated mind prefers leading by directives and expects subordinates' obedience. The question now is that how can a Vietnamese school leader with a hierarchy-penetrated mind be stimulated to have a laissez-faire leadership style? Khanh and Hayden (2010) claim that the concept of institutional autonomy is widely understood in Vietnam as "referring only to a decentralisation of accountability for the management of resources" (p. 135) rather than freedom for an individual to act or function independently. In other words, autonomy and decentralisation for leadership and management may be stimulated in one respect, but is caught in the trap of hierarchy and power centralism in another. As this study findings have indicated, while school leaders perceived the importance of autonomy and decentralisation as an approach for expanding grassroots 
democracy and promoting the practice of self-governance, they retained the traditional norms and values of hierarchy. Power distribution in management is considered a new concept and practice in leadership in Vietnam. As long as the underlying key norms and basic values in society (hierarchy) remain unchanged, it is unlikely that the practice of autonomy in management and the process of decentralisation would be accepted and achieved. Consequently, the dogmatic adoption of a management model without the concern of possible cultural obstacles could lead to its failure. In other words, leadership and management as cultural practices are not isolated. In the process of policy-making, the adoption of a management model should be understood and interpreted in its own context with cultural sensitivity. Any attempts to promote and expand decentralisation in schools by importing ideas from other countries must consider the cultural differences to anticipate obstacles that may impede the management process. If these sociocultural obstacles are not fully understood and recognised by policy-makers, the practice of autonomy, decentralisation and grassroots democracy is unlikely to be achieved.

Thirdly, transparent procedures are needed to reduce the negative effects of relationships. The research findings indicated that maintaining good relationships was perceived as an investment in the exercise of leadership, such as promoting trust, mutual obligations and consensus among people. However, there were negative effects of relationships. For example, a leader's decision could become biased, partial and prejudiced when he placed too much emphasis on relationships. While a managerial decision should be a fact-based or reason-based, a leader's decision could be affected due to his cronyism. In order to eliminate the negative effects of relationships, overall transparency in working procedures (such as recruitment process or decision-making procedures) should be offered to school administration. Since transparency involves sharing of information, most decisions of school leaders, and important rules and regulations are in the public domain. When the decisionmaking process is completely transparent, it reduces chances of nepotism, favouritism, and the like by the impact of a good relationship or a good "connection" (Bac, 2001). When school leaders know that their decisions will be out in the open, then they will be less inclined to act with self-interest or their own connections. 


\section{Possible improvements for any further study}

If I were to conduct this study again, I would improve on two areas. Firstly, this research was conducted with a small sample of cases and participants due to the permitted scope of doctoral research. Methodologically, such a small sample size allowed sufficient in-depth engagement with each individual case and a detailed examination. It also responded to the particularity of the phenomenological study that emphasises a "think description". However, it was never my intention to draw any major generalisations across Vietnam. This study was conducted in one province in the centre of Vietnam and there was no intent to generalise the findings to other regions (such as the North and South of Vietnam) as regional differences exist. To combat this limitation, future research could be conducted with a larger sample and on a larger scale with a representative sample of populations from different regions to see if the influence of Confucian values on school leadership has any diversity in different regions. In particular, more empirical research is needed in Vietnamese context in order to make systematic cross-region comparisons possible.

Secondly, in terms of methodology, my choice of non-emergent research design although appropriate for this research also had limitations. The choice of nonemergent design was due to the fact that the research data was collected in Vietnam and then analysed in New Zealand. Consequently, I was unable to collect further information from the participants. This non-emergent research design was less open and responsive than an emergent design. It is a design in which "data is collected, then analysed" (Maykut \& Morehouse, 1994, p. 44). Future research could be conducted with the emergent design that allows for a broadening or narrowing of the focus of inquiry and identifying important leads in the early phrase of data analysis (Maykut \& Morehouse, 1994).

\section{Recommendations for future research}

There are three areas that could be explored further in future research. Firstly, the research examined the four functions of leadership under the influence of Confucian values. This means that the research focus was restricted to the four functions only and was not aimed at exploring how Confucian values impacted on the other leadership functions, such as motivation, planning, counseling, and evaluating. Although my intention was not to act as a "Pooh-Bah" who attempted to examine all 
leadership functions, the exclusion of other leadership functions in this study can be considered a research limitation. In any on-going research, these leadership functions could be included to see how they are exercised under the influence of Confucian values in the Vietnamese context.

Secondly, this study is limited by its research context. It, hence, did not aim to obtain comparative data across societies. It is apparent that leaders are increasingly working within globalizing policy environments that exert convergent forces on their leadership. Today school leadership is characterised by tension between forces of convergence and divergence (Dimmock \& Walker, 2002). Consequently, in the field of school leadership, a comparative research (between societies such as Vietnam and

a Confucianism-affiliated country or Vietnam and a Western country) should be carried out to understand how increasing inter-connectivity and inter-dependence between cultures impact the traditions and practices of school leadership in a global age.

Thirdly, the findings of this study indicated that there appeared to be interrelationships between Confucian values and the Communist Party ideologies and the influence each has upon leadership beliefs and practices. However, the interrelationships and connections between these cultural and political resources were not fully explored due to the scope and focus of the research. It may be useful to undertake a further research to seek a deeper understanding of how these two ideologies complement and challenge each other within the domain of school leadership. How Confucian values interact with political power needs to be fully studied in order to have a deeper insight of Confucian influence on school leadership beliefs and behaviours.

\section{Concluding thoughts}

Now that I have completed my research journey, I realise that my research is just the beginning of a life-long scholarship. Although this research has set a foundational stone for literature concerned with the influence of Confucian values on Vietnamese school leadership and provided empirical data to enrich literature on societal culture in the study of educational leadership, it needs to be continued to further explore relationships between school leadership and Vietnamese culture. A number of questions came up in my mind when I was writing these final words, which need to 
be answered in order to deepen and broaden my research insights: What are the cultural challenges presented to the Vietnamese educational system in the transition process from centralisation to decentralisation? How can the policies and practices of school improvement from other contexts be adopted by Vietnam with consideration of its cultural context? What cultural forces hinder the adoption of improvement mechanisms in the areas of school leadership and management? What cultural forces could be brought into play to improve the practices of school leadership and management? And in what ways do cultural values influence the process of educational policy-making?

I believe that the investigation into how Vietnamese culture influences the practices of school leadership and management is an ongoing process because one research cannot uncover the multiple cultural layers and influences on school leadership. This research, hence, is just the beginning of a longer journey. 


\section{REFERENCES}

Abosag, I., Tynan, C., \& Lewis, C. (2002, July 2-5). Relationship marketing: the interaction of cultural value dimensions. Paper presented at Academy of Marketingn Annual Conference, Nottingham Business School, Nottingham.

Anderson, C. (1997). Values-based management. Academy of Management Executive, 11(4), 25-46.

Andrews, P. H., \& Herschel, R. T. (1996). Organisational communication: empowerment in a technological society. Boston: Houghton Mifflin.

Armenakis, A. A., Harris, S. G., \& Mossholder, K. W. (1993). Creating readiness for organisational change. Human Relations, 46, 681-703.

Ashwill, M. A., \& Diep, T. N. (2005). Vietnamese Today: A guide to a national at a crossroads. Yarmouth, ME: Intercultural Press.

Asian Development Bank (ADB). (2005). Vietnam: Gender situation analysis 2005. Retrieved January 15, 2011, from http://www.adb.org/Documents/Reports/Country-Gender-Assessments/cgavie.pdf

Ayyash-Abdo, H. (2001). Individualism and collectivism: The case of Lebanon. Social Behaviour and Personality, 29, 503-518.

Bac, M. (2001). Corruption, connections and transparency: Does a better screen imply a better scene? Public Choice, 107, 87-96.

Bacharach, S. B., Bamberger, P., Conley, S. C., \& Bauer, S. (1990). The dimensionality of decision participation in educational organisations: The value of a multi-domain evaluative approach. Educational Administration Quarterly, 26, 126-167.

Bajunid, I. A. (1996). Preliminary explorations of indigenous perspectives of educational management: The evolving Malaysian experience. Journal of Educational Administration, 34(5), 50-73.

Baker, C., Wuest, J., \& Stern, P. N. (1992). Method slurring: the grounded theory/ phenomenology example. Journal of Advanced Nursing, 17, 1355-1360.

Bandiho, H. (2009). Status of educational leadership and female participation: The case of Tanzania. In H. C. Sobehart (Ed.), Women leading education across the continents: Sharing the spirit, fanning the flame (pp. 43-48). Plymouth: Rowman \& Littlefield Education.

Banks, J. A. (1994). Multiethnic education. Washington: Allyn and Bacon.

Barnnet, K., McCormick, J., \& Conners, R. (2001, December 2-6). Leadership behaviour of secondary school principals: what do principals and teachers say. A paper presented at the Australian Association for Research in Education Annual Conference, Fremantle, Sydney. 
Bass, B. M. (1985). Leadership and performance beyond expectations. New York: Free Press.

Bass, B. M. (1997). Does the transactional-transformational leadership paradigm transcend organisational and national boundaries? American Psychology, $52,130-139$.

Bass, B. M., \& Avolio, B. J. (1994). Introduction. In B. M. Bass \& B. J. Alovio (Ed.), Improving organisational effectiveness through transformational leadership (pp. 1-9). Thousand Oaks, CA: Sage.

Bass, B. M., \& Bass, R. (2008). The Bass handbook of leadership: Theory, research $\&$ managerial applications $\left(4^{\text {th }}\right.$ ed.). New York: Free Press.

Bauer, A., \& Brown, G. (2001). Principal leadership in an inclusive school. Retrieved July $16^{\text {th }}$, 2011, from http://www.newhorizons.org/spneeds/inclusion/staff/bauer.htm.

Bennis, W., \& Nanus, B. (1985). Leaders. New York: Harper and Row.

Berg, B. L. (2004). Qualitative research methods for social science (5th ed.). Boston: Pearson Education, Inc.

Berrel, M., Wright, P., \& Hoa, T. T. V. (1999). The influence of culture on managerial behaviour. Journal of Management Development, 18(7), 578589.

Bich, P. V. (1999). The Vietnamese family in change: the case of Red river delta. Richmon: Curzon Press.

Black, J. S., \& Mendenhall, M. (1990). Cross-cultural training effectiveness: A review and theoretical framework for future research. Academic of Management Review, 15, 113-136.

Blake, R. R., \& Mouton, J. S. (1964). The managerial grid. Houston: Gulf.

Blasé, J. (1987). Dimensions of ineffective school leadership: The teacher's perspective. American Educational Research Journal, 24(4), 589-610.

Blasé, J., \& Blasé, J. (1997). The micropolitical orientation of facilitative school principals and its effects on teachers' sense of empowerment. Journal of Educational Administration, 35(2), 138-64.

Blase. J., \& Anderson, G. L. (1995) The micropolitics of educational leadership: from control to empowerment. London: Cassell.

Bodley, J. H. (2011). An anthropological perspective from cultural anthropology: tribes, states, and the global system ( $5^{\text {th }}$ ed.). Plymouth: AltaMira Press.

Bogdan, R. C., \& Biklen, S. K. (2003). Qualitative research for education: An introduction to theories and methods. Boston: Allyn and Bacon. 
Borton, L. (2000). Working in a Vietnamese voice. Academic of Management Executive, 14(4), 20-19.

Borton, L. (2001). To be sure...: Work practices in Vietnam. Athens: Ohio University Center for Southeast Asia Studies.

Boulding, K. (1963). Conflict and defence. New York: Harper \& Row.

Bouma, G. (2000). The research process ( $4^{\text {th }}$ ed.). Melbourne: Oxford University Press.

Boyd, V. (1992). School context: Bridge or barrier to change. Austin: Southwest Educational Development Lap.

Brett, J. M. (2001). Negotiating globally. San Francesco, CA: Jossey-Bass.

Brew, F. P., Hesketh, B., \& Taylor, A. (2001). Individualist-collectivist differences in adolescent decision-making and decision styles with Chinese and Anglos. International Journal of Intercultural Relations, 25, 1-19.

Brown, M. E., Trevino, L. K., \& Harrison, D. A. (2005). Ethical leadership: A social learning perspective for construct development and testing. Organisational Behaviour and Human Decision Processes, 97, 117-134.

$\mathrm{Yu}$, A. C. (2005). Enduring change: Confucianism and the prospect of human rights. In E. M. Bucar \& B. Barnett (Eds.), Does human rights need God? (pp. 104134). Michigan: Eardmans Publishing Co.

Burn, J. M. (1978). Leadership. New York: Harper and Row.

Burns, R. (2000). Introduction to research methods. French Frost NSW: Longman.

Busch, P. (1980). The Sales Manager's Bases of Social Power and Influence upon the Sales Force. Journal of Marketing, 44(3), 91-101.

Bush, T., \& Haiyan, Q. (2002). Leadership and culture in Chinese education. In A. Walker \& C. Dimmock (Eds.), School leadership and administration: Adopting a cultural perspective (pp. 173-186). New York: RoutledgeFalmer.

Busher, H., \& James, N. (2007). Ethics of research in education. In A. R. J. Briggs \& M. Coleman (Eds.), Research methods in educational leadership and management (pp. 106-122). London: Sage.

Cac, P.V. (2005). An approach to Confucianism in the context of regional area and modern time. Retrieved 25th December, 2008, from http://chungta.com/Desktop.aspx/ChungTa-SuyNgam/Suyngam/Nghien_cuu_nho_giao_Viet_Nam/

Carli, L. L., \& Eagly, A. H. (2001). Gender, hierarchy, leadership: An introduction. Journal of Social Issues, 57(4), 629-636. 
Carnevale, P. J., \& Leung, K. (2001). Cultural dimensions of negotiation. In M. A. Hogg \& R. S. Tindale (Eds.), Blackwell handbook of social psychology: Group processes (pp. 482-496). Massachusetts: Blackwell.

Chen, C. C., \& Lee, Y. (2008). Leadership and management in China: Philosophies, theories, and practices. Cambridge: Cambridge University Press.

Chen, G., \& Starosta, W. J. (1997). Chinese conflict management and resolution: Overview and implications. Intercultural Communication Studies, 7(1), 117.

Chen, X. P., \& Farh, J. L. (2001). Transformational and transactional leader behaviours in Chinese organisations: differential effects in the people's republic of China and Taiwan. Advances in Global Leadership, 2, 101-126.

Cheng, B. S., Chou, L. F., Wu, T. Y., Huang, M. P., \& Farh, J. L. (2004). Paternalistic leadership and subordinate responses: establishing a leadership model in Chinese organisations. Asian Journal of Social Psychology, 7, 89117.

Cheng, K. M. (1995). The neglected dimension: Cultural comparison in educational administration. In K. C. Wong \& K. M. Cheng (Eds.), Educational leadership and change: An international perspective (pp. 87-104). Hong Kong: Hong Kong University Press.

Cherrington, D. J. (1989). Organisational behaviour: The management of individual and organisational performance. Needham Heights, MA: Allyn \& Bacon.

Chuan, N. T. (2007). The exploitation of traditional values of Confucianism for national development in the context of globalization. Retrieved 25th December, 2008, from http://chungta.com/Desktop.aspx/ChungTaSuyNgam/Suy-ngam/Nghien cuu nho giao Viet Nam/

Chung, J. (1996). Avoiding a "Bull Moose" rebellion: Particularistic ties, seniority, and third-party mediation. International and Intercultural Communication Annual, 20, 166-185.

Cohen, L., Manion, L., \& Morrison, K. (2000). Research methods in education ( $^{\text {th }}$ ed.). RoutledgeFalmer.

Coleman, M. (2005). Theories and practice of leadership: An introduction. In M. Coleman \& P. Earley (Eds.), Leadership and management in education: Cultures, change and context (pp. 6-25). Oxford: Oxford University Press.

Conley, S. C. (1991). Review of research on teacher participation in school decisionmaking. Review of Research in Education, 17, 225 - 266.

Cresswell, J., \& Fisher, D. (1999). Assessing principals' interpersonal behaviour with their teachers. International Studies in Educational Administration, 27(1), $29-44$.

Creswell, J. W. (1994). Research design: Qualitative and quantitative approaches. Thousand Oaks, CA: Sage. 
Cuong, N. M., \& Ha, N. T. H. (2007). Nho giáo đạo học trên đất kinh kỳ. Ha Noi: Culture \& Information publish house.

Dahl, R. A. (1957). The concept of power. Behavioural Science, 2, 201-215.

Đại Việt sủ ký toàn thu (Complete historical Annals of Dai Viet). (1993). Translated from Chinese into Vietnamese by Le Van Huu, Phan Phu Tien, Ngo Sy Lien. Hanoi: Publishing House of Vietnam Institution of Social Science.

Dalton, R. J., Hac. P. M., Nghi. P. M., \& Ong. N. N. T. (2001). Social relations and social capital in Vietnam: The 2001 World Values Survey. Retrieved April 15, 2009, from http://www.worldvaluessurvey.org/Upload/5_viet.pdf

Dam, Q. (1999). Nho Giáo xưa và nay. Ha Noi: Information and Culture Publish House.

Davies, L. (1990). Equity and efficiency? School management in an international context. London: Falmer Press.

Davies, L., \& Harber, C. (1997). School management and effectiveness in developing countries: the post-bureaucratic school. London: Cassell.

de Bary, W. T. (1988). East Asian civilization: A dialogue in five stages. Cambridge, MA: Harvard University Press.

Deal, T., \& Kennedy, A. (1982). Corporate cultures: the rites and rituals of corporate life. Mass: Addison-Wesley.

Deal, T., \& Peterson, K. (1990). Symbolic leadership and the school principalship: shaping school culture cultures in different contexts. Washington, DC: US Department of Education.

Deal, T., \& Peterson, K. (1999). Shaping school culture: the heart of leadership. San Francisco: Jossey-Bass.

Denzin, N. K., \& Lincoln, Y. S. (2000). The discipline and practice of qualitative research. In N. K. Denzin \& Y. S. Lincoln (Eds.), Handbook of qualitative research (pp. $1-28$ ). California: Sage.

Dimen-Schein, M. (1977). The Anthropological Imagination. New York: McGrawHill.

Dimmock, C. (2007). Cross-cultural differences in interpreting and conducting research. In A. R. J. Briggs \& M. Coleman (Eds.), Research methods in educational leadership and management (pp. 53-68). London: Sage.

Dimmock, C., \& Walker, A. (2000). Cross-cultural values and leadership. Management in Education, 14(3), 21-24.

Dimmock, C., \& Walker, A. (2002). Connecting school leadership with teaching, learning and parenting in diverse cultural contexts: Western and Asian perspectives. In K. Leithwood \& P. Hallinger (Ed.), Second international 
handbook of educational leadership and administration (pp. 395-426). Dordrecht: Kluwer Academic Publishers.

Dimmock, C., \& Walker, A. (2005). Educational leadership: Culture and diversity. London: Sage.

Doan. D. H. (2005). Moral education or political education in the Vietnamese educational system. Journal of Moral Education, 34(3), 451-463.

Duiker, W. (1995). Vietnam: Revolution in transition. Boulder: Westview Press.

Dunlap, D., \& Goldman, P.(1991). Rethinking power in schools. Educational Administration Quarterly, 27(1), 5-29.

Edwards, J., Green, K., \& Lyons, C. (2002). Personal empowerment, efficacy, and environmental characteristics. Journal of Education Administration, 40(1), 67-87.

Ellis, C. (1995). Culture shock! Vietnam. Portland, Or: Graphic Arts Center Pub. Co.

Elmore, R. F. (2000). Building a new structure for school leadership.Washington, D.C: Albert Shanker Institute.

England, G. W. (1967). Personal value systems of American managers. Academy of Management Journal, 10, 53-68.

Englehart, N. A. (2000). Rights and culture in the Asian values argument: The rise and the fall of Confucian ethics in Singapore. Human Rights Quarterly, 22, 548-568.

Fayol, H. (1916). General and industrial administration. London: Pitman.

Fennell, H. (1999). Power in the principalship: Four women's experiences. Journal of Educational Administration, 37(1), 23-39.

Ferguson, M. R. (2001, Spring). Teaching and learning: Inside the Korean culture. International Education, 16-23.

Ferraro, G. P. (2002). The cultural dimension of international business ( $^{\text {th }}$ ed.). Upper Saddle River, NJ: Prentice Hall.

Filson, B. (2012). Conflict, leadership and leadership talk. Retrieved April 20, 2012, from http://ezinearticles.com/?Conflict,-Leadership-And-The-Leadership$\underline{\text { Talk\&id }=156329}$

Finlay, L. (2009). Debating phenomenological research methods. Phenomenology \& Practice, 3(1), 6-25.

Flick, U. (2002). An introduction to qualitative research. London: Sage Publications.

French, J. P. A., \& Raven, B. H. (1960). The bases of social power. In D. Cartwright \& A. Zander (Eds), Group dynamics (pp: 607-623). New York: Harper and Row. 
French, J. R. P. (1956). A formal theory of social power. Psychological Review, 63, 181-194.

French, J. R. P., \& Raven, B. (1959). The basis of social power. In D. Cartwright (Eds.), Studies in social power (pp. 50-67). Ann Arbor: University of Michigan, Institution for Social Research.

Frenier, M. D., \& Mancini, K. (1996). Vietnamese women in a Confucian setting: The causes of the initial decline in the status of East Asian women. In K. Barry (Ed.), Vietnam's women in transition (pp. 21-37). New York, NY: ST. Martin's Press, INC.

Frost, J., \& Wilmot, W. W. (1978). Interpersonal conflict. Dubuque, IA: W.C. Brown.

Fu, P. P., \& Yukl, G. (2000). Perceived effectiveness and use of influence tactics in the US and China. Leadership Quarterly, 11(2), 251-266.

Fullan, M. (1991). The new meaning of educational change. New York: Teachers College Press.

Fullan, M. (2001). Leading in a culture of change. San Francisco: Jossey-Bass.

Gaenslen, F. (1986). Culture and decision-making in China, Japan, Russia, and the United States. World Politics, 39(1), 78-103.

Gardner, J. W. (2007). The nature of leadership. In Jossey-Bass (Ed.), The JosseyBass Reader on educational leadership (pp. 17-26). San Francisco: JosseyBass.

Geertz, C. M. (1973). The interpretation of cultures. New York: Basic Books.

Gerstner, C., \& O’Day, D. (1994). Cross-cultural comparison of leadership prototypes. Leadership Quarterly, 5, 121-134.

Getzels, J., Lipham, J., \& Cambell, R. (1968). Educational administration as social process. New York: Harper \& Row.

Giddens, A. (1989). Sociology. Cambridge: Polity Press.

Gill, B. (1995). Educators and visionaries: women educational leaders in action. Paper presented at Conference of Atlantic Educators, St Johns, New Foundland, Canada.

Giorgi, A. (1994). A phenomenological perspective on certain qualitative research methods. Journal of Phenomenological Psychology, 25(2), 190-220.

Giorgi, A. (1997). The theory, practice, and evaluation of the phenomenological method as a qualitative research procedure. Journal of Phenominological Psychology, 28(2), 235-260. 
Giorgi, A. (2008). Difficulties encountered in the application of the phenomenological method in the social sciences. Indo-Pacific Journal of Phenomenology, 8(1), 1-9.

Goldin, P. R. (2011). Confucianism. Berkeley: University of California Press.

Goldman, P., Dunlap, D., \& Conley, D. (1993). Facilitative power and nonstandardized solutions to school site restructuring. Educational Administration Quarterly, 29(1), 69-92.

Goldring, L., \& Knox, C. (2002). The power of school culture. Leadership, 32(2), 32-35.

Gray, D. (2009). Doing research in the real world. London: Sage Publications.

Greenfield, T. (1984). Leaders and schools: willfulness and nonnatural order in organizations. In T. Sergiovanni \& J. Corbally (Eds.), Leadership and organizational culture. Urbana: University of Illinois Press.

Gudykunst, W. B., Gao, G., Schmidt, K. L., Nishida, T., Bond, M. H., Wang, G., \& Barraclough, R. A. (1992). The influence of individualism-collectivism, self-monitoring, and predicted-outcome value on communication in ingroup and outgroup relationships. Journal of Cross-Cultural Psychology, 23, 196213.

Gulick, L., \& Urwick, L. (1937). Papers on the science of administration. New York: Columbia University Press.

Hales, C. (1997). Power, authority and influence. In A. Harris, N. Bennett \& M. Preedy (Eds.), Organizational effectiveness and improvement in education (pp. 22-30). Buckingham - Philadelphia: Open University Press.

Hall, E. T. (1976). Beyond culture. New York: Doubleday.

Hallinger, P., \& Kantamara, P. (2002). Educational change in Thailand. In A. Walker \& C. Dimmock (Ed.), School leadership and administration: Adopting a cultural perspective (pp. 123-140). New York: RoutledgeFalmer.

Hallinger, P., \& Leithwood, K. (1996). Culture and educational administration: A case of finding out what you don't know you don't know. Journal of Educational Administration, 34(5), 98-116.

Hallinger, P., \& Leithwood, K. (1998). The impact of social culture on school leadership. Peabody Journal of Education, 73(2), 126-151.

Hallinger, P., Taraseina, P., \& Miller, J. (1994). Assessing the instructional leadership of secondary school principals in Thailand. School Effectiveness and School Improvement, 5(4), 321-348.

Handy, C. (1993). Understanding organizations. Harmondsworth: Penguin.

Hang, T. T. T. (2008). Women's leadership in Vietnam: Opportunities and challenges. Chicago Journals, 34(1), 16-21. 
Heck, R. (2002). Issues in the investigation of school leadership across cultures. In A. Walker \& C. Dimmock (Ed.), School leadership and administration: Adopting a cultural perspective (pp. 77-100). New York: RoutledgeFalmer.

Hiltrop, J. M. (1996). A framework for diagnosing human resource management practices. European Management Journal, 13(3), 243-254.

Hinkin, T. R., \& Schriescheim, C. A. (1989). Development and application of new scales to measure the French and Raven bases of social power. Journal Applied Psychology, 75(5), 61-76.

Ho, M. P. T., \& Berg, D. (2010). Educational leadership challenges: Vietnam's system of higher education. Paper presented at the Asian Leadership Roundtable 2010, Hong Kong Institution of Education, Hong Kong.

Hodgson, P. (1987). Managers can be taught, but leaders have to learn. ICT, November/December.

Hoepfl, M. C. (1997). Choosing qualitative research: A primer for technology education researchers. Journal of Technology Education, 9(1), 1-16.

Hofstede, G. H. (1980). Culture consequences: International differences in workrelated values. Beverly Hills, CA: Sage.

Hofstede, G. H. (1980). Culture's consequences: International differences in workrelated values. Beverly Hills, CA: Sage.

Hofstede, G. H. (1983). Cultural dimensions in management and planning. Asia Pacific Journal of Management, 1(2), 81-91.

Hofstede, G. H. (1995). Managerial values: the business of international business is culture. In T. Jackson (Ed.), Cross- cultural management (pp. 150-165). Oxford: Butterworth-Heinemann.

Hofstede, G. H. (1997). Cultures and organisations: Software of the mind. New York: McGraw Hill.

Hofstede, G. H. (2001). Culture's consequences: Comparing values, behaviours, institutions, and organisations across nations. Thousand Oaks, CA: Sage.

Hofstede, G., \& Bond, M. H. (1988). The Confucius connection: from cultural roots to economic growth. Organisational Dynamics, 16(4), 5-21.

Homan, R. (1991). The ethics of social research. London and New York: Longman.

House, R. J. (1988). Leadership research: Some forgotten, ignored, or overlooked findings. In J. G. Hunt, B. R. Baliga, H. P. Dachler \& C. A. Schriesheim (Eds.), Emerging leadership vistas (pp. 245-260). Lexington, MA: Lexington Books.

House, R. J., Hanges, P. J., Javidan, M., Dorfman, P. W., \& Gupta. V. (2004). Culture, leadership, and organizations: The GLOBE study of 62 societies. Thousand Oaks, CA: Sage. 
Hurty, K. (1995). Women principals - leading with power. In D. Dunlap \& P. Schmuck (Eds), Women leading in education (pp. 380-406). Albany, NY: State University of New York Press.

Husserl, E. (1950). Gesammelte Werke. The Hague: M. Nijhoff.

Husserl, E. (1962). Ideas: General introduction to pure phenomenology. New York: Collier Books.

Huy, N. N. (1998). The Confucian incursion into Vietnam. In W. H. Stole \& G. A. Devos (Eds.), Confucian and the family (pp. 91-103). New York: State University of New York Press.

Hycner, R. H. (1999). Some guidelines for the phenomenological analysis of interview data. In A. Bryman \& R. G. Burgess (Eds.), Qualitative research (pp. 143-146). London: Sage.

Jamieson. N. L. (1993). Understanding Vietnam. Berkeley: University of California Press.

Jankowicz, A. D. (1991). Business research project for students. London: Chapman and Hall.

Jehn, K., \& Weldon, E. (1997). Managerial attitudes toward conflict: Cross-cultural differences in resolution styles. Journal of International Management, 3, 291-321.

Johnson, B., \& Christensen, L. (2008). Educational research: Quantitative, qualitative, and mixed approaches (3th ed.). Thousand Oaks, CA: Sage Publications

Johnson, P., \& Short, P.(1998). Principal's leader power, teacher empowerment, teacher compliance and conflict. Educational Management and Administration, 26(2), 147-159.

Johnson, S. M. (1989). Schoolwork and its reform. In J. Hannaway \& R. Crowson (Eds.), The politics of reforming school administration (pp. 95-112). New York: Falmer.

Kaushal, R., \& Kwantes, C. T. (2006). The role of culture and personality in choice of conflict management strategy. International Journal of Intercutural Relations, 30, 579-603.

Keeble, H., \& Kirk, R. (2007). Exploring the existing body of research. In A. R. J. Briggs \& M. Coleman (Eds.), Research methods in educational leadership and management (pp. 69-90). London: Sage.

Keedy, J., \& Finch, A. (1994). Examining teacher-principal empowerment: an analysis of power. Journal of Research and Development in Education, 27(3), 162-75. 
Khanh, D. V., \& Hayden. M. (2010). Reforming the governance of higher education in Vietnam. In G. Harman., M. Hayden \& P. T. Nghi (Eds.), Reforming higher education in Vietnam (pp. 129-142). Springer: Dordrecht.

Kirkman, B. L., \& Shapiro, D. (1997). The impacts of cultural values on employees resistance to teams: toward a model of globalised self-managing work team effectiveness. Academy of Management Review, 22(3), 730-757.

Kotter, J. P. (1990). A force for change: How leadership differs from management. New York: Free Press.

Kruger, D. (1988). An introduction to phenomenological psychology $\left(2^{\text {nd }}\right.$ ed.). Cape Town, South Africa: Juta.

Lai, B. D. (2011). The role of Party Committee secretary in personnel affairs. Retrieved January 1, 2012, from http://www.xaydungdang.org.vn/Home/dien-dan/2011/4561/Vai-tro-cua-bithu-cap-uy-trong-cong-tac-can-bo.aspx

Lan, P. T. P. (2002). Mapping values in educational management and leadership in Vietnam: The impact of culture. Unpublished master's thesis, Dunedin College of Education, Dunedin, New Zealand.

Lareau, A. (2000). Home Advantage: Social Class and Parental Intervention in Elementary Education. Oxford: Rowman \& Littlefiled.

Lashway, L. (2006). Leadership styles and strategies. In A. C. Smith \& P. K. Piele (Eds.), School leadership: Handbook for excellence in student learning (pp. 77-103). Thousan Oaks, California: Corwin Press.

Lashway, L., Mazzarella, J., \& Grundy, T. (2006). Portrait of a leader. In S. C. Smith \& P. K. Piele (Eds.), School leadership: Handbook for excellence in student learning (pp. 52-76). Thousand Oaks: Corwin Press.

Law, S., \& Glover, D. (2000). Educational leadership and learning: Practice, policy and research. Buckingham: Open University Press.

Lawler, E. E. (1986). High involvement management. San Francisco: Jossey-Bass.

Lee, H. O., \& Rogan, R. G. (1991). A cross-cultural comparison of organisational conflict management behaviours. The International Journal of Conflict Management, 2(3), 181-199.

Lee, J. K. (2001). Confucian thought affecting leadership and organisational culture of Korean higher education. Retrieved February 10, 2012 , from http://radicalpedagogy.icaap.org/content/issue3_3/5-lee.html

Leugh, K. (1997). Negotiation and reward allocations across cultures. In P. C. Earley \& M. Erez (Eds.), New perspectives on I/O psychology (pp. 640-675). San Francisco: Jossey-Bass. 
Leung, K., \& Fan, R. M. (1997). Dispute processing: An Asian perspective. In H. S. R. Kao \& D. Sinha (Eds.), Asian perspectives on psychology, cross-cultural research and methodology series (pp. 201-217). Thousand Oaks: Sage.

Leung, K., \& Lind, E. A. (1986). Procedural justice and culture: Effects of culture, gender, and investigator status on procedural preferences. Journal of Personality and Social Psychology, 50, 1134-1140.

Li, C. (2000). Confucianism and feminist concerns: Overcoming the Confucian "Gender complex". Journal of Chinese Philosophy, 27(2), 187-199.

Lightfoot, S. L. (1986). On goodness of schools: themes of empowerment. Peabody Journal of Education, 63(3), 9-28.

Little, J. W. (1987). Teachers as colleagues. In V. Richardson-Koehler (Ed.), Educator's handbook: A research perspective. White Plains, N.Y.: Longman.

Little, J. W. (1988). Assessing the prospects for teacher leadership. In A. Lieberman (Ed.), Building a professional culture in schools (pp. 78-106). New York: Teachers College Press.

Locke, E. A., \& Latham, P. G. (1990). A theory of goal setting and task performance. Englewood Cliffs, NJ: Prentice Hall.

Lord, R. G., Brown, D. J., Harvey, J. L., \& Hall, R. J. (2001). Contextual constraints on prototype generation and their multilevel consequences for leadership perception. The Leadership Quarterly, 12, 311-338.

Lowe, K. B., \& Gardener, W. L. (2001). Ten years of the Leadership Quarterly: Contributions and challenges for the future. Leadership Quarterly, 11(4), 459-514.

Lukes, S. (1974). Power: A radical view. London: Macmillan Press.

Malarney, S. (2002). Culture, ritual and revolution in Vietnam. London: RoutledgeCurzon.

Martin, O. L. (1990). Instructional leadership behaviours that empower teacher effectiveness. Paper presented at the Mid-South Educational Research Association, New Orleans, LA, November.

Martinsons, M. G., \& Davision, R. M. (2007). Strategic decision-making and support systems: Comparing American, Japanese and Chinese management. Decision Support Systems, 4, 284-300.

Maurer, R. (1996). Beyond the wall of resistance. Austin, TX: Brad Books.

Maykut, P., \& Morehouse, R. (1994). Beginning qualitative research: A philosophical and practical guide. London: The Falmer Press.

McGrath, J. E. (1984). Groups: interaction and performance. Englewood Cliffs, NJ: Prentice-Hall. 
McGregor, D. (1960). The human side of enterprise. McGraw-Hill: New York.

McHale, S. (2002). Mapping a Vietnamese Confucian past and its transition to modernity. In B. A. Elman, J. B. Duncan \& H. Ooms (Eds.), Rethinking Confucianism: Past and present in China, Japan, Korea, and Vietnam (pp. 397-430). Los Angeles: University of California.

McLeod, J. (2001). Qualitative research in counselling and psychotherapy. New York: Sage.

McLeod, M., \& Dieu, N. T. (2001). Culture and customs of Vietnam. Westport, Connecticut - London: Greenwood Press.

McMurry, R. N. (1958). The case for benevolent autocracy. Harvard Business Review, 36(1), 82-90.

Mead, M. (1967). Cooperation and competition among primitive people. Boston: Beacon.

Miles, M. B., \& Huberman, A. M. (1994). Qualitative data analysis. Thousand Oaks: Sage.

Ministry of Education and Training. (2004). Luật giáo dục (Education Law). Ha Noi: National Politics Publisher.

MOET, (2000). Quy chế thưc hiện dân chủ trong hoạt động của nhà truờng (The regulation on the implementation of democracy in schools). Retrieved May 24, 2010, from http://www.vietlaw.gov.vn/LAWNET/docView.do?docid=11938

MOET. (2001). Vietnamese education and training development strategy to year 2010 for the cause of industrialisation and modernisation of Vietnam. Retrieved May 24, 2010, from http://planipolis.iiep.unesco.org/upload/Viet\%20Nam/Viet_Nam_Edu_Train ing-Strategy.pdf

Morris, M. W., Williams, K. Y., Leung, K., Bhatnagar, D., Li, J. F., Kondo, M., Luo, J. L., \& Hu, J. C. (1999). Culture, conflict management style, and underlying values: Accounting for cross-national differences in styles of handling conflicts among US, Chinese, Indian and Filipino managers. Journal of International Business Studies, 29, 729-748.

Morrison, M. (2007). What do we mean by educational research? In A. R. J. Briggs \& M. Coleman (Eds.), Research methods in educational leadership and management (pp. 13-36). London: Sage.

Moustakas, C. (1994). Phenomenological research methods. Thousand Oaks: Sage.

Moyles, J. (2007). Observation as a research tools. In L. Cohen, L. Manion \& K. Morrison (Eds.), Research methods in education (pp. 237-242). Oxon: Routledge. 
Mueller-Vollmer, K. (1985). Introduction - Language, mind, and artifact: An outline of hermeneutic theory since the Enlightenment. In K. Mueller-Vollmer (Ed.), The Hermeneutic reader (pp. 105-118). New York: Continuum.

Murphy, J. (2006). Introduction: Leadership for excellence in learning. In S. C. Smith \& P. K. Piele (Eds.), School leadership: Handbook for excellence in student learning (pp. 1-15). Thousand Oaks: Corwin Press.

Murrihy, L. (2002). Defining school culture for school effectiveness. New Zealand Journal of Educational Leadership, 17(1), 21-32.

Nam, P. X. (2001). Quản lý sự phát triển xã hội trên nguyên tắc tiến bộ và công bằng (Managing society's development on principles of progress and justice). Ha Noi.

Neuman, W. L. (2003). Social research methods: Qualitative and quantitative approaches $\left(5^{\text {th }}\right.$ ed.). Boston: Pearson Education, Inc.

New Zealand Ministry of Foreign Affairs and Trade. (2001). Study awards and postgraduate scholarships. Wellington: NZODA.

Nghe. N.V. (2005). Does Confucianism suit this modern age? Retrieved 25th December, 2008, from http://www.chungta.net/Desktop.aspx/ChungTaSuyNgam/Suy-ngam/Dao_Khong_con_hop_voi_thoi_nay_khong/

Ngoc, N. (2008). Giáo dục nước ta hiện đi bằng con đường nào? (What way is our present education on?). Retrieved 25th December, 2008, from http://niemtin.free.fr/gdbangconduongnao.htm

Nias, J., Southworth, G., \& Yeomans, R. (1989). Staff relationships in the primary school: A study of organizational cultures. Chicago: Mansell.

Northouse, P. G. (2006). Leadership: Theory and practice. Thousand Oaks: Sage.

Noss, J. B. (1974). Man's religion. New York: Macmillan Publishing Co.

Ogawa, R., \& Bosserts, S. (1995). Leadership as an organizational quality. Educational dministration. Quarterly, 31(2), 224-243.

Ohbuchi, K., \& Takahashi, Y. (1994). Cultural styles of conflict. Journal of Applied Social Psychology, 24, 1345-1366.

Ohbuchi, K., Fukushima, O., \& Tedeschi, J. T. (1999). Cultural values in conflict management: goal orientation, goal attainment, and tactical decision. Journal of Cross-cultural Psychology, 30(51), 51-71.

Ohbuchi, K., Shizuka, S., \& Tedeschi, J. (1999). Nationality, individualismcollectivism, and power distance in conflict management. Tohoku Psychologica Folia, 58, 36-49.

Orlikowski, W. J., \& Baroudi, J. J. (1991). Studying information technology in organizations: research approaches and assumptions. Information Systems Research, 2, 1-28. 
Oudenhoven, J. P., Mechelse, L., \& Dreu, C. K. W. (1998). Managerial conflict management in five European countries: the importance of power distance, uncertainty avoidance, and masculinity. Applied Psychology: An International Review, 47(3), 439-455.

Palestini, R. H. (2005). Educational administration. Lanham: Rowman \& Littlefield Education.

Park, H., Rehg, M. T., \& Lee, D. (2005). The influence of Confucian ethics and collectivism on whistleblowing intensions: A study of South Korean Public employees. Journal of Business Ethics, 58, 387-403.

Patton, M. Q. (1990). Qualitative evaluation and research methods. Newbury Park, London, New Delhi: Sage.

Patton, M. Q. (2002). Qualitative research and evaluation methods (3rd ed.). Thousand Oaks: Sage.

Pawlas, G. (1997). Vision and school culture. National Association of Secondary Principals. NASSP Bulletin, 81(587), 118-120.

Pfeffer, J. (1981). Power in organisation. Boston: Pitman.

Phillips, E., \& Cheston, R. (1979). Conflict resolution: What works? California Management Review, 21, 76-83.

Pickle, J. (1991). Teacher empowerment and the disappearing act: Making connections between empowerment and motivation. Thresholds-inEducation, 17(4), 8-10.

Picucci, A., Brownson, A., Kahlert, R., \& Sobel, A. (2002). Shaping school culture. Principal leadership, 3(4), 38-41.

Plestini, R. H. (2005). Educational administration: leading with mind and heart. Lanham: Rowman \& Littlefield Education.

Plummer, K. (2001). Documents of life 2: an invitation to a critical humanism. London: Sage.

Pollack, J. P., \& Mills, R. A. (1997). True collaboration: building and maintaining successful teams. Schools in the Middle, 6(5), 28-32.

Porter, G. (1993). Vietnam: The politics of bureaucratic socialism. New York: Cornell University Press.

Pruitt, D. G., \& Carnevale, P. J. (1993). Negotiation in social conflict. Pacific Grove, CA: Brooks/Cole.

Putnam, L. L., \& Wilson, C. E. (1982). Communication strategies in organisational conflicts: reliability and validity of measurement. In M. Burgoon (Ed.), Communication Yearbook 6 (pp. 629-652). Beverly Hills, CA: Sage.

Quy, L. T (1992). Some views on family violence. Social Sciences, 4, 81-87. 
Rabie, M. (1994). Conflict resolution and ethnicity. Westport, CT: Praeger.

Radford, M., Mann, L., Ohta, Y., \& Nakane, Y. (1993). Differences between Australian and Japanese students in decision self-esteem, decision stress, and coping styles. Journal of Cross-Cultural Psychology, 24(3), 284-297.

Rahim, M. A. (1983). A measure of styles of handling interpersonal conflict. Academy of Management Journal, 26, 368-376.

Rahim, M. A. (1989). Relationships of leader power to compliance and satisfaction with supervisors: Evidence from a national sample of managers. Journal of Management, 15(5), 45-56.

Rahim, M. A. (1992). Managing conflict in organisations ( $2^{\text {nd }}$ ed.). Westport, CT: Praeger.

Ralston, D. A., Tong, J. T., Maignan, I., Napier, N. K., \& Nguyen, V. T. (2006). Vietnam: A cross-cultural comparison of upward influence ethics. Journal of International Management, 12(1), 85-105.

Ralston, D. A., Vollmer, G., Srinvasan, N., Nicholson, J. D., Tang, M., \& Wan, P. (2001). Strategies of upward influence: A study of six cultures from Europe, Asia and America. Journal of Cross-Cultural Psychology, 32, 748-755.

Resick, C. J., Hanges, P. J., Dickson, M. W., \& Mitchelson. J. K. (2006). A crosscultural examination of endorsement of ethical leadership. Journal of Business Ethics, 63, 345-359.

Resick, C. J., Martin, G. S., Keating, M. A., Dickson, M. W., Kwan, H. K., \& Peng, C. (2011). What ethical leadership means to me: Asian, American, and European perspectives. Journal of Business Ethics, 101, 435-457.

Robbins, S. P. (1999). Managing today ( $2^{\text {nd }}$ ed.). Englewood Cliffs, NJ: Prentice Hall.

Robbins, S. P. (1999a). Management (6 ${ }^{\text {th }}$ ed.). Englewood Cliffs, NJ: Prentice Hall.

Romar, E. J. (2009, June 5-6). Harmony as strategic intent: How the Confucian concept of harmony can contribute to firm success. Paper presented at the International Conference on Management, Enterprise and Benchmarking, Budapest, Hungary.

Rosemont Jr, H. (2006). Two loci of authority: Autonomous individuals and related persons. In P. D. Hershock \& R. T. Ames (Eds), Confucian cultures of authority (pp. 1-20). Albany: State University of New York Press.

Rosenholtz, S. J. (1989). Teachers' workplace: The social organization of schools. White Plains, N.Y: Longman.

Rowe, A. J., \& Boulgarides, J. D. (1993). Decision style - a perspective. Leadership \& Organisation Development Journal, 4(4), 3-9. 
Rubin, H. (2002). Collaborative leadership: Developing effective partnerships in communities and schools. Thousand Oaks: Corwin Press.

Russel, B. (1938). Power. London: Allen \& Unwin.

Russell, R. F., \& Stone, G. A. A review of servant leadership attributes: developing a practical model. Leadership and Organisation Development Journal, 23, 145-154.

Sanders, P. (1982). Phenomenology: A new way of viewing organizational research. Academy of Management. The Academy of Management Review, 7(3), 353360.

Sanga, K. F., \& Walker, K. D. (2005). Apem moa Solomon Islands leadership. Wellington: Victoria University of Wellington.

Sarantakos, S. (1998). Social research ( $2^{\text {nd }}$ ed.). London: Macmillan Press LTD.

Schein, E. H. (1996). Culture: The missing concept in organization studies. Administrative Science Quarterly, 41(2), 229-240.

Schein, E. H. (2004). Organizational culture and leadership. San Francisco: Jossey Bass.

Schermerhorn, J. R., \& Bond, M. H. (1991). Upward and downward influence tactics in managerial networks: A comparative study of Hong Kong Chinese and Americans. Asia-Pacific Journal of Management, 8(2), 147-158.

Schneider, S. (1998). National versus corporate culture: implications for HRM. Human Resource Management, 27(2), 231-246.

Scully, J. A., Kirkpatric, S. A., \& Locke, E. A. (1995). Locus of knowledge as a determinant of the effect of participation on performance, affect, and perceptions. Organisational Behaviours and Human Decision Processes, 61, 276-288.

Sergiovanni, T. (1992). Moral leadership: getting to the heart of school improvement. San Francisco: Jossey-Bass.

Sergiovanni, T. (2001). The principalship: A reflective practice perspective. Boston: Allyn and Bacon.

Shaw, M. (2005). The Cultural context of educational leadership. In M. Coleman \& P. Earley (Eds.), Leadership and management in education (pp. 26-46). Oxford: Oxford University Press.

Silverman, D. (2005). Doing qualitative research ( $2^{\text {nd }}$ ed.). London: Sage.

Slote, W. H. (1998a). Psychocultural dynamics within the Confucian family. In W. H. Stole \& G. A. Devos (Eds.), Confucianism and the family (pp. 37-51). New York: State University of New York Press. 
Slote, W. H. (1998b). Destiny and Determination: Psychocultural reinforcement in Vietnam. In W. H. Stole \& G. A. Devos (Eds.), Confucianism and the family (pp. 311-328). New York: State University of New York Press.

Slote, W. H., \& DeVos. G. A. (1998). Confucianism and the family. New York: State University of New York Press.

Smith, J. A., \& Osborn, M. (2003). Interpretative phenomenological analysis. In J. A. Smith (Ed.), Qualitative psychology (pp. 53-80). London: Sage.

Smylie, M. A. (1992). Teacher participation in school decision-making: Assessing willingness to participate. Educational Evaluation and Policy Analysis, 14(53), 53-67.

Smylie, M. A., Lazarus, V., \& Brownlee-Conyers, J. (1996). Instrument outcomes of school-based participative decision-making. Educational Evaluation and Policy Analysis, 18, 181-191.

Somech, A. (2002). Explicating the complexity of participative management: An investigation of multiple dimensions. Educational Administration Quarterly, 38, 341-371.

Southworth, G. (2002). School leadership in English schools. In A. Walker \& C. Dimmock (Eds.), School leadership and administration: Adopting a cultural perspective (pp. 187-204). New York, NY: RoutledgeFalmer.

Spiegelberg, H. (1994). The phenomenological movement. Dordrecht: Kluwer Academic Publishers.

Stake, R. (2000). Case studies. In N. K. Denzin \& Y. K. Lincoln (Eds.). Handbook of qualitative research (2nd ed.). Thousand Oaks, CA: Sage.

Stewart, E. C. (1986). Culture and decision-making. In W. B. Gudykunst, L. P. Stewart \& S. Ting-Toomey (Eds.), Communication, culture and organisational processes (pp. 177-211). Beverly Hills: Sage.

Tamney, J. B., \& Chiang, H. L. (2002). Modernization, globalization, and Confucianism in Chinese societies. Westport: Praeger Publishers.

Tannenbaum, R., \& Warren, H. S. (1958). How to choose a leadership Pattern. Harvard Business Review, 36(2), 95-101.

Taylor, C. (1985). Human agency and language: Philosophical papers 2. Cambridge: Cambridge University Press.

Taylor, K. W. (1998). Surface orientation in Vietnam: beyond histories of nation and region. Journal of Asian Studies, 57(4), 373-404.

Taylor, K. W. (2002). Vietnamese Confucianism narratives. In B. A. Elman, J. B. Duncan \& H. Ooms (Eds.), Rethinking Confucianism: Past and present in China, Japan, Korea, and Vietnam (pp. 337-369). Los Angeles: University of California. 
Te, H. D. (n.d.). Vietnamese value system. Retrieved June 4, 2010, from http://www.vietspring.org/values/valsystem.html

Thang, D. T (2004). School culture, relationships and power: Vietnamese case studies. Unpublished master's thesis, the Dunedin College of Education, New Zealand.

Thang, L. C., Rowley, C., Quang, T., \& Warner, M. (2007). To what extent can management practices be transferred between countries? The case of human resource managent in Vietnam. Journal of World Business, 42, 113-127.

Thomas, K. W. (1976). Conflict and conflict management. In M. D. Dunnette (Ed.), Handbook of industrial and organisational psychology (pp. 889-935). Chicago: Rand McNally.

Thomas, K. W., \& Kilman, R. H. (1974). Thomas-Kilmann conflict mode instrument. New York: Xicom.

Thomas, K. W., \& Schmidt, W. H. (1976). A survey of managerial interests with respect to conflict. Academy of Management Journal, 19, 315-318.

Ting-Toomey, S. (1985). Toward a theory of conflict and culture. In W. B. Gudykunst, L. P. Stewart \& S. Ting-Toomey (Eds.), Communication, culture, and organisational processes (pp. 71-86). Beverly Hills, CA: Sage.

Ting-Toomey, S., Gao, G., Trubisky, P., Yang, Z. Z., Kim, H. S., Lin, S. L., \& Nishida, T. (1991). Culture, face maintenance, and styles of handling interpersonal conflict: A study in five cultures. International Journal of Conflict Management, 2, 275-296.

Tinsley, C. H. (1997). Understanding conflict in a Chinese cultural context. In R. Bies, R. J. Lewicki \& B. Sheppard (Eds.), Research on negotiations in organisations (pp. 209-225). Beverly Hills: Sage.

Tinsley, C. H. (1998). Models of conflict resolution in Japanese, German, and American cultures. Journal of Applied Psychology, 83(2), 316-323.

Tinsley, C. H., \& Brett, J. M. (2001). Managing workplace conflict in the United States and Hong Kong. Organisational Behaviour and Human Decision Processes, 85(2), 360-381.

Trevelyan, R. (2001). The paradox of autonomy: A case of academic research scientists. Human Relations, 54(4), 495-525.

Triandis, H. C. (1986). Collectivism vs. Individualism: A reconceptualisation of a basic concept in cross-cultural psychology. In C. Bagley \& G. Verma (Eds.), Personality, cognition, and values: Cross-cultural perspectives of childhood and adolescence (pp. 60-95). London: MacMillan.

Triandis, H. C. (1994). Culture and social behaviour. New York: McGraw-Hill.

Triandis, H. C. (1995). Individualism and collectivism. Boulder, CO: Westview. 
Triandis, H. C. (1996). The psychological measurement of cultural syndromes. American Psychologist, 51, 407-415.

Triandis, H. C., Bontempo, R., \& Villareal, M. J. (1988). Individualism and collectivism: cross-cultural perspectives on self-ingroup relationships. Journal of Personality and Social Psychology, 54(2), 323-338.

Trites, D., \& Weegar, T. (2003). Shared leadership: Bringing community colleges to the people. The Community College Enterprise, 9(2), 39-44.

Trompenaars, F. (1994). Riding the waves of culture: Understanding cultural diversity in business. New York: Irwin.

Trompenaars, F., \& Hampden-Turner, C. (1997). Riding the waves of culture $\left(^{\text {nd }}\right.$ ed.). London: Nicholas Brealy.

Trubisky, P., Ting-Toomey, S., \& Lin, S. L. (1991). The influence of individualismcollectivism and self-monitoring on conflict styles. International Journal of Intercultural Relation, 15, 65-84.

Tschannen-Moran, M. (2007). Becoming a trustworthy leader. In Jossey-Basss (Ed.), The Jossey-Bass reader on educational leadership (pp. 99-114). San Francisco: Jossey-Bass.

Tu, W. M. (1998a). Confucius and Confucianism. In W. H. Stole \& G. A. Devos (Eds.), Confucianism and the family (pp. 3-36). New York: State University of New York Press.

Tu, W. M. (1998b). Probing the "Three Bonds" and "Five Relationships" in Confucian humanism. In W. H. Stole \& G. A. Devos (Eds.), Confucianism and the family (pp. 137-161). New York: State University of New York Press.

Tuan, N. V. (2008). Chất luọng giáo dục đại họ: bắt đầu tù thầy và kết thúc ở trò (The quality of higher education: beginning from teachers and ending in students). Retrieved 25th December, 2008, from http://niemtin.free.fr/thaytro.htm

Tuan, V. V., \& Napier, N. K. (2000). Paradoxes in Vietnam and America: lessons earned. Human Resource Planning, 23(1), 7-10.

Vallely, T. J., \& Wilkinson, B. (2008). Vietnamese higher education: crisis and response. Retrieved January 5, 2012, from http://www.hks.harvard.edu/innovations/asia/Documents/HigherEducationO verview112008.pdf

Van Manen, M. (1990). Researching lived experience: Human science for an action sensitive pedagogy. New York: State University of New York.

Vavrus, M. (1989). Alienation as the conceptual foundation for incorporating teacher empowerment into the teacher education knowledge base. Proceedings of the National Forum of the Association of Independent Liberal Arts Colleges for Teacher Education. Indianapolis, IN. 
Vietnam Government. (2001). National strategy for advancement of women in Vietnam for the period 2001-2010. Retrieved January 5, 2012, from http://siteresources.worldbank.org/INTVIETNAM/Resources/DraftNational-Strategy.pdf

Vietnam National Assembly. (1992). Constitution of the Socialist Republic of Vietnam. Retrieved September 26, 2011, from http://www.vietnamlaws.com/freelaws/Constitution92\%28aa01\%29.pdf.

Vietnam National Assembly. (2005). Education Law. Retrieved 17th May, 2008, from http://en.moet.gov.vn/?page=8.8\&view=5101

Vietnamawesometravel. (n.d.). Waiting wife. Retrieved September 3, 2010, from http://www.vietnamawesometravel.com/detail_product.aspx?product_id=53 $\underline{0}$

Vietnam's National Assembly. (1964). The Constitution of the Democratic Republic of Vietnam. Retrieved 25 April, 2009, from http://laws.dongnai.gov.vn/1945_to_1950/1946/194611/194611090001

Vietnam's National Assembly. (2000). The marriage and family law. Hanoi.

Vitell, S. J., Nwachukwu, S. L., \& Barnes, J. H. ( 1993). The effects of culture on ethical decision-making: An application of Hofstede's typology. Journal of Business Ethics, 12(10), 753-760.

Walker, A., \& Dimmock, C. (2002). Cross-cultural and comparative insights into educational administration and leadership. In A. Walker \& C. Dimmock (Eds.), School leadership and administration: Adopting a cultural perspective (pp. 13-32). New York: RoutledgeFalmer.

Walsham, G. (1993). Interpreting information systems in organizations. Wiley: Chichester.

Weber, M. (1968). The interpretive understanding of social action. In M. Brodbeck (Ed.), Readings in the philosophy of the social sciences. New York: Macmillan.

Weimer, M. (2002). Learner-centered teaching: Five key changes to practice. San Francisco: Jossey-Bass.

Wengraf, T. (2001). Qualitative research interviewing. London: Sage.

Whitaker, P. (1997). Changes in professional development: The personal dimension. In L. Kydd, M. Crawford \& C. Riches (Eds.), Professional development for educational management (pp. 11-25). Buckingham-Philadelphia: Open University Press.

Whitmore, J. K. (1977). Chiao-chih and Neo-Confucianism: the Ming attempt to transform Vietnam. Ming studies, Spring.

Williams, E. (March, 1998). Research and paradigms. Retrieved July 25, 2009, from http://www.umdnj.edu/idsweb/idst6000/williams research+paradigms.htm 
Wong, K. (1998). Culture and moral leadership in education. Peabody Journal of Education, 73(2), 106-125.

Wright, G. N. (1985). Organisational, group and individual decision-making in crosscultural perspective. In G. N. Wright (Ed.), Behavioural decision-making (pp. 1949-166). New York: Plenum.

Wunder, K. M. (1997). Empowerment and professional community: keys to teacher efficacy, motivation and morale. Unpublished doctoral dissertation, The Pennsylvania State University, Malvern, PA.

Yao, X. (2000). An introduction to Confucianism. Cambridge: Cambridge University Press.

Yeager, J. A. (1987). The Vietnamese novel in French: a literary response to colonialism. Hanover: University Press of New England.

Yi, J., \& Park, S. (2003). Cross-cultural differences in decision-making styles: A study of college students in five countries. Social Behaviour and Personality, 31(1), 35-48.

Yin, R. (2009). Case study research: Design and method. Thousand Oaks: Sage.

Young, S. B. (1998). The orthodox Chinese Confucian social paradigm versus Vietnamese individualism. In W. H. Stole \& G. A. Devos (Eds.), Confucianism and the Family (pp. 137-161). New York: State University of New York Press.

$\mathrm{Yu}, \mathrm{X}$. (2002). Conflict resolution strategies in State-owned enterprises in China. In G. M. Chen \& R. Ma (Eds.), Chinese conflict management and resolution (pp. 183-201). Westport: Ablex Publishing.

Yukl, G., \& Falbe, C. M. (1991). The importance of different power sources in downward and lateral relations. Journal of Applied Psychology, 76, 416423. 


\section{APPENDICES}

Appendix 1: The National Education System of Vietnam

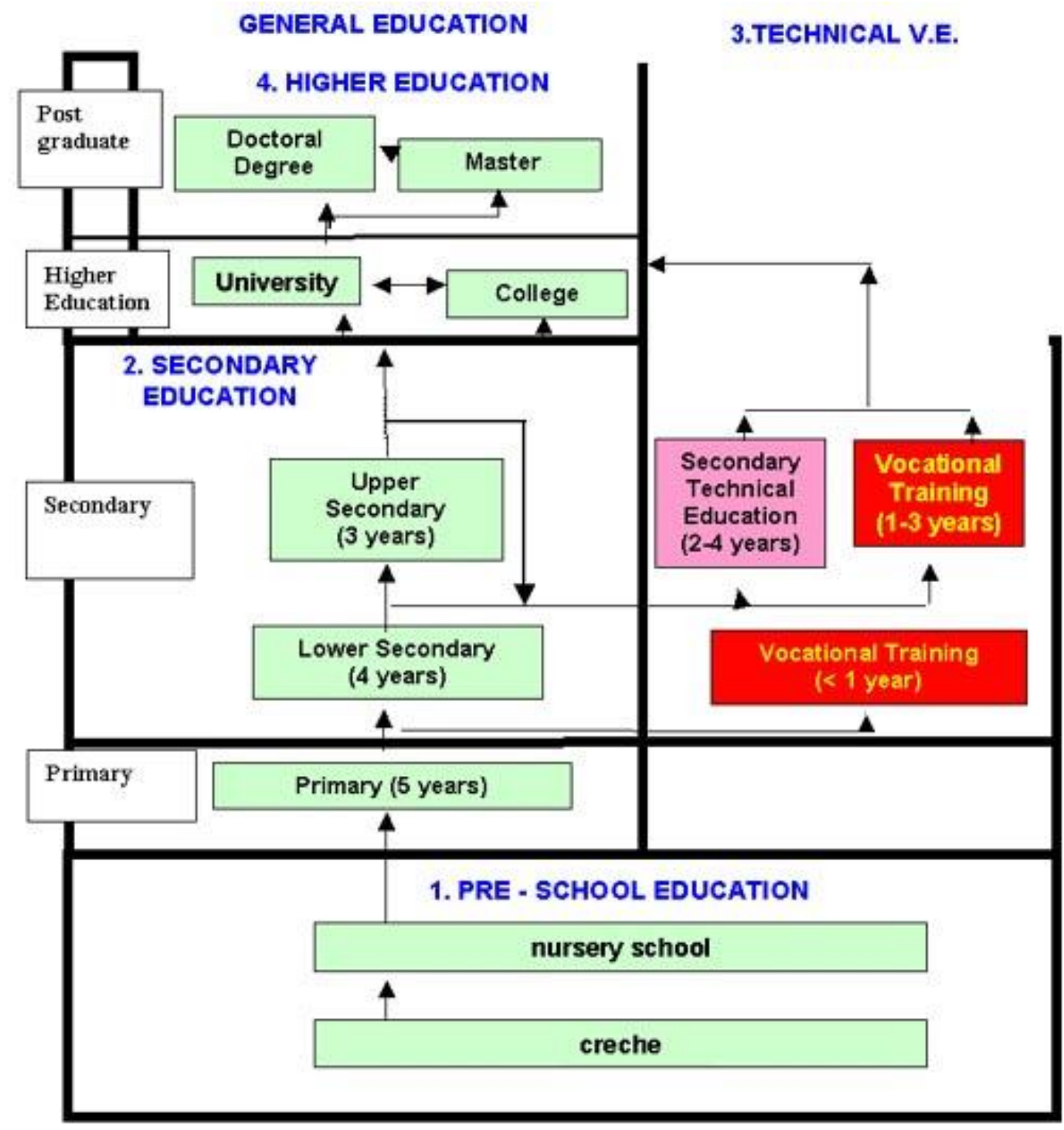

(Source: http://www.seameo.org) 


\section{Appendix 2: Letter to Director of Quang Tri Education and Training Service}

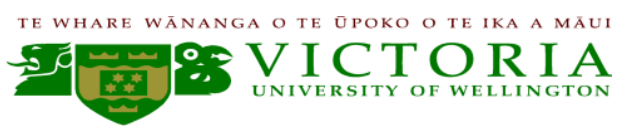

Subject: Asking for permission to conduct research

\section{Dear Director,}

I am a doctoral student at Faculty of Education, Victoria University of Wellington in New Zealand. As part of this degree I am required to undertake a research project leading to a thesis. I am writing to ask for your permission in order to implement my research in a high school in Quang Tri province from December 2009 to June 2010.

The research aims to explore the influence of traditional values on school leadership and management in Vietnamese school contexts. The research process will be undertaken in the following manner:

- Visiting the school: I will pay an initial visit to a selected high school and complete the relevant research procedures, including having a meeting with administrative school staff to provide the background information of the research and seeking the permission for conducting the research;

- Selecting participants: I will invite a principal, vice-principal(s), and six teachers to participate in the research. Prior to selection, participants will be fully provided with necessary information about the research for their consideration to participation. Their participation is voluntary and they may withdraw from the research at any time without any disadvantage of any kind;

- Collecting data: I will conduct interviews with participants, including an individual interview with the principal, individual interviews with vice-principals and a focusgroup interview with six teacher participants. Each interview session will take up to one hour and a half. Teacher participants will also be required spend around 30 minutes to complete the questionnaires for further data. Two other methods of data collection will also be carried out to gather supportive data, including observations (school meetings, activities) and documents (annual school reports, school disciplines and regulations, plans, reports, decisions and school statutes).

For more information about the procedures of my data collection, please find the Research Information Sheet attached.

This research project has been approved by the Human Ethics Committee, Faculty of Education, Victoria University of Wellington, New Zealand.

I would be very graceful if you could provide me a recommendation letter to conduct the research.

Thank you for your consideration of this request.

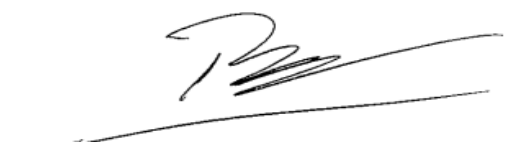

Yours sincerely,

\section{Truong Dinh Thang}




\section{Appendix 3: Letter to the Head of District Education-Training Service}

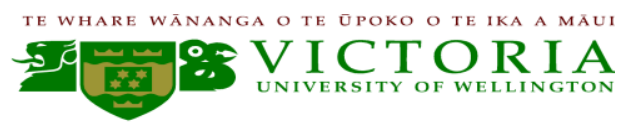

Subject: Asking for permission to conduct research

\section{Dear Head of District Education - Training Service,}

I am a doctoral student at Faculty of Education, Victoria University of Wellington in New Zealand. As part of this degree I am required to undertake a research project leading to a thesis. I am writing to ask for your permission in order to implement my research in a secondary school in Dong Ha city from December 2009 to June 2010.

The research aims to explore the influence of traditional values on school leadership and management in Vietnamese school contexts. The research process will be undertaken in the following manner:

- Visiting the school: I will pay an initial visit to a selected secondary school and complete the relevant research procedures, including having a meeting with administrative school staff to provide the background information of the research and seeking the permission for conducting the research;

- Selecting participants: I will invite a principal, vice-principal(s), and six teachers to participate in the research. Prior to selection, participants will be fully provided with necessary information about the research for their consideration to participation. Their participation is voluntary and they may withdraw from the research at any time without any disadvantage of any kind;

- Collecting data: I will conduct interviews with participants, including an individual interview with the principal, individual interviews with vice-principals and a focusgroup interview with six teacher participants. Each interview session will take up to one hour and a half. Teacher participants will also be required spend around 30 minutes to complete the questionnaires for further data. Two other methods of data collection will also be carried out to gather supportive data, including observations (school meetings, activities) and documents (annual school reports, school disciplines and regulations, plans, reports, decisions and school statutes).

For more information about the procedures of my data collection, please find the Research Information Sheet attached.

This research project has been approved by the Human Ethics Committee, Faculty of Education, Victoria University of Wellington, New Zealand.

I would be very graceful if you could provide me a recommendation letter to conduct the research.

Thank you for your consideration of this request.

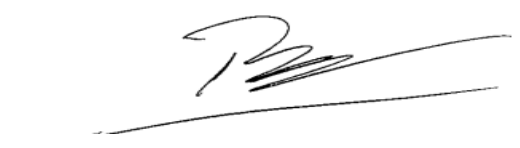

Yours sincerely,

\section{Truong Dinh Thang}




\section{Appendix 4: Letter to the Principal}

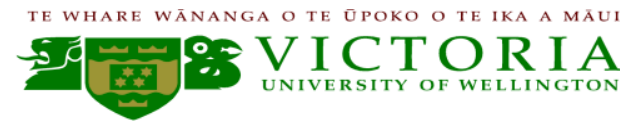

Subject: Asking for permission to conduct research

\section{Dear Sir or Madam,}

I am a doctoral student at Faculty of Education, Victoria University of Wellington in New Zealand. As part of this degree I am required to undertake a research project leading to a thesis. I am writing to ask for your permission in order to implement my research in your school from December 2009 to June 2010.

The research aims to explore the influence of traditional values on school leadership and management in Vietnamese school contexts. The research process will be undertaken in the following manner:

- Visiting the school: I will pay an initial visit to your school to have a meeting with you and your administrative staff to provide the background information of the research;

- Selecting participants: I will invite you (principal), vice-principal(s), and six teachers to participate in the research. Prior to selection, all participants will be fully provided with necessary information about the research for their consideration to participation. Their participation is voluntary and they may withdraw from the research at any time without any disadvantage of any kind.

- Collecting data: I will conduct interviews with participants, including an individual interview with the principal, individual interviews with vice-principals and a focusgroup interview with six teacher participants. Each interview session will take up to one hour and a half. Teacher participants will also be required spend around 30 minutes to complete the questionnaires for further data. Two other methods of data collection will also be carried out to gather supportive data, including observations (school meetings, activities) and documents (annual school reports, school disciplines and regulations, plans, reports, decisions and school statutes).

For more information about the procedures of my data collection, please find the Research Information Sheet attached.

This research has been approved by the Human Ethics Committee, Faculty of Education, Victoria University of Wellington, New Zealand. I should assure that all the identities related to the participants and your school will be protected. All the research information will be kept confidential. No information obtained in the study will be discussed with anyone outside me, my supervisors and the participants without their written permission.

For more information about the procedures of my data collection, please find the copy of the Research Information Sheet attached. The Recommendation Letter from Quang Tri Education and Training Service is also enclosed for your consideration.

If you have any questions, please do not hesitate to contact me at the Department of Research Management and External Relations, Quang Tri Teacher Training College. My office telephone number: (084) 53856048 and my email: thangnewzealand@ yahoo.com

I would be very graceful if you could grant me permission to conduct the research. I hope that you will be willing to offer me favourable conditions in order that the research will be successfully conducted.

Thank you for your consideration of this request. 


\section{Appendix 5: Research Information Sheet}

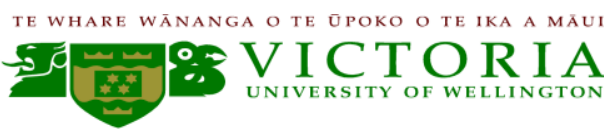

(Given to the participants)

Dear

I am a doctoral student at Faculty of Education, Victoria University of Wellington in New Zealand. As part of this degree I am required to undertake a research leading to a thesis. My research is aimed at exploring the influence of traditional values on school leadership and management in Vietnamese school contexts

I would like to invite you to participate in this study. I highly appreciate your participation and believe that your cooperation will be valuable for my research.

If you agree to participate in this project, you will be required to be available for one audiorecorded individual interview (for principal and vice-principal participants), or one audiorecorded focus group interview of up to an hour and a half, plus filling out a questionnaire (for teacher participants). It is envisaged that each interview session will take up to one hour and half. Each questionnaire will take you about thirty minutes up to an hour to complete in your own time and should be returned to me via the post with stamped addressed envelopes provided. The detailed schedule of the research will be discussed in an initial meeting.

Please be aware that your identity will be protected at all stages of the research unless prior written consent has been obtained from you for it to be disclosed. All the research information will be kept confidential. No information obtained from the participants will be discussed with anyone outside my supervisors. The responses to the questionnaire should be returned anonymously. The data collected [audio files] will be destroyed at the conclusion of the study but any raw data on which the results of the study depend will be retained in secure storage for five years, after which it will be destroyed. During your participation, if you feel hesitant or uncomfortable you may decline to answer any particular question(s) and/or may withdraw from the research at any time without any disadvantage of any kind.

I should like to assure that the study will strictly adhere to the Human Ethics Policy promulgated by the Victoria University of Wellington. This research has been approved by the Human Ethics Committee, Faculty of Education, Victoria University of Wellington.

If you are willing to take part in this research project, please read this information sheet carefully before signing the consent form enclosed. Please be aware that you may decide not to take part in the study without any disadvantage to yourself of any kind.

If you have any questions, either now or in the future, please do not hesitate to contact me at the Department of Research Management and External Relations, Quang Tri Teacher Training College. My office telephone number: (084) 53.3581199; my email: thangnewzealand@yahoo.com, or you can contact my supervisors: Dr. Kabini Sanga at Kabini.Sanga@vuw.ac.nz and Dr. Cherie Chu at Cherie.Chu@vuw.ac.nz

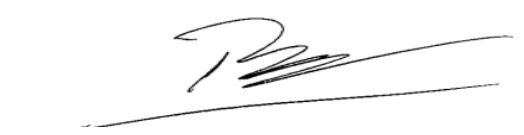

Yours sincerely,

\section{Truong Dinh Thang}




\section{Appendix 6: Participant Consent Form}

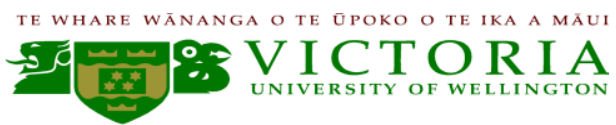

This consent form indicates that the subject involved in the study has carefully read the information given on the research information sheet.

Surname and given name(s):

Working

$\operatorname{position}(\mathbf{s})$..

School:

Home address (optional):

Telephone number (optional):

I have read the information sheet and understood its terms. All my questions have been answered to my satisfaction. I understand that I am free to request further information at any stage. I voluntarily consent to participate in the study.

Signature of participant

Date

Signature of researcher

Date

(The subject will be given a copy of this to keep after signing this form) 


\section{Appendix 7: Interview questions with principal (English and Vietnamese versions)}

\section{$\underline{\text { English version }}$}

\section{Part I: Unstructured Interview}

1. Could you please tell me something about yourself?

2. Please tell me which factors influenced your achievement of this position and explain why? (e.g., your expertise, your experience, your morality, your age, your gender, your interpersonal skills)

3. Could you please tell me something about your school?

4. Tell me your main roles as a school leader as defined by yourself?

\section{Part II: Semi-structured Interview}

\section{A. Exercising power/authority}

1. What do you understand about the terms "power/authority"?

2. In what way does the role of a school leader bring with it power and authority?

3. How do you as a school leader exercise power/authority?

4. How and in what ways do the following factors affect your exercise of power/authority:

- Your expertise?

- Your experience?

- Your morality?

- Your age?

- Your relationships?

- Your gender?

5. How and in what ways is school improvement influenced by a leader's exercise of power?

6. What traditional values might challenge you to exercise power/authority? Please explain.

\section{B. Building relationships}

1. How do you define 'a good relationship' within your school community?

2. How and in what ways do you try to build a good relationship with your staff and students?

3. Are there any social factors or traditional values that you think affect your ability to build relationships? Please explain.

4. What traditional values do you bring to the role of principal that enhance your ability to build relationships?

5. What traditional values might challenge the process of building relationships within your school community? Please explain.

\section{Decision-making}

1. Who makes decisions in your school? 
2. How is the school decision-making process undertaken within your school?

3. What is your role as a leader in the school decision-making process?

4. What barriers are there to effective decision-making?

5. How do you deal with or overcome barriers/dilemmas in decision-making?

6. What traditional values do you think affect or challenge your decisions? Please explain

\section{Conflict management and solving}

1. What types of conflict often happen within your school community?

2. Who is responsible for managing or solving conflicts in your school?

3. What kinds of measures do you often apply to solve these conflicts?

4. What traditional values do you think influence the process of conflict management and solving? Please explain. 


\section{Vietnamese version}

\section{CÂU HỎI PHỎNG VẤN VỚI HIỆU TRƯởNG}

\section{PHẦ I: Các câu hỏi chung}

1. Thầy/cô có thể cung cấp một vài thông tin về bản thân?

2. Thầy/cô cho biết các yếu tố nào có thể ảnh hưởng đến quá trình bổ nhiệm chức danh hiệu trưởng của thầy/cô? (ví dụ các yếu tố sau: chuyên môn, kinh nghiệm, phẩm chất đạo đức, độ tuổi, giới tính, kỷ năng thiết lập quan hệ xã hội). Xin thầy/cô giải thích lý do tại sao?

3. Thầy/cô có thể mô tả vai trò/nhiệm vụ của người hiệu trưởng như thế nào theo quan điểm riêng của mình?

\section{PHẦ II: Các câu hỏi nghiên cứu}

\section{A. Thực thi quyền lực/quyền hạn}

1. Theo quan điểm cá nhân, thầy/cô có thể giải thích như thế nào về hai khái niệm "quyền lực" và "quyền hạn"?

2. Theo thầy/cô, vị trí và vai trò của người hiệu trưởng liên quan thế như thế nào đối với quyền lực và quyền hạn?

3. Thầy/cô thực thi "quyền lực" hoặc "quyền hạn" của một hiệu trưởng như thế nào? Thầy/cô có thể cho một vài ví dụ để minh họa quá trình thực thi "quyền lực" và "quyền hạn" của mình?

4. Các yếu tố nào sau đây ảnh hưởng đến việc thực thi "quyền lực" và "quyền hạn" của thầy/cô trong vị trí của một người hiệu trưởng và các yếu tố đó ảnh hưởng như thế nào:

- Chuyên môn của thầy/cô?

- Kinh nghiệm của thầy/cô?

- Phẩm chất đạo đức của thầy/cô?

- $\quad$ Độ tuổi của thầy/cô?

- Các mối quan hệ của thầy/cô?

- Giới tính của thầy/cô?

- Các yếu tố khác?

4. Việc thực thi quyền lực của một người hiệu trưởng ảnh hưởng thế nào đến các công việc trong nhà trường?

5. Những giá trị truyền thống nào có thể thách thức/cản trở trong việc thực thi quyền lực và quyền hạn của người hiệu trưởng? Thầy/cô hãy giải thích các hiện tượng đó

\section{B. Xây dựng các mối quan hệ}

1. Theo quan điểm cá nhân, thầy/cô định nghĩa "một mối quan hệ tốt" trong cộng đồng nhà trường như thế nào? (lãnh đạo - lãnh đạo; lãnh đạo - nhân viên/giáo viên; lãnh đạo - học sinh; giáo viên - học sinh)

2. Thầy/cô xây dựng và phát triển các mối quan hệ với cán bộ quản lý, giáo viên, nhân viên và học sinh của mình như thế nào?

3. Các yếu tố xã hội hoặc giá trị truyền thống nào mà thầy/cô cho rằng có thể ảnh hưởng đến quá trình thiết lập và xây dựng các mối quan hệ của mình trong cộng đồng nhà trường? Xin hãy giải thích. 
4. Những giá trị truyền thống nào góp phần giúp người hiệu trưởng nâng cao khả năng xây dựng và thiết lập các mối quan hệ trong nhà trường?

5. Những giá trị truyền thống nào có thể cản trở quá trình thiết lập và xây dựng các mối quan hệ trong nhà trường? Xin hãy giải thích.

\section{Quyết định}

1. Ai là người chịu trách nhiệm đưa ra quyết định trong nhà trường?

2. Tiến trình đưa ra quyết định trong nhà trường được thực hiện như thế nào? Thầy/cô có thể cho một vài ví dụ minh họa tiến trình thực thi quyết định?

3. Thầy/cô với vị trí của người hiệu trưởng đóng vai trò như thế nào trong tiến trình đưa ra quyết định trong nhà trường?

4. Những cản trở nào có thể ảnh hưởng đến hiệu quả của việc đưa ra quyết định?

5. Những giá trị truyền thống nào mà thầy/cô cho rằng có thể ảnh hưởng hoặc gây khó khăn cho mình khi đưa ra quyết định và thực thi quyết định trong trường học?

6. Thầy/cô trong vị trí của người hiệu trưởng phải làm thế nào để vượt qua các rào cản văn hóa truyền thống trong việc đưa ra quyết định và thực thi quyết định?

\section{Quản lý và giải quyết các xung đột/mâu thuẫn}

1. Thầy/cô có thể cho biết các loại xung đột/mâu thuẫn nào thường xảy ra trong cộng đồng nhà trường? Thầy/cô có thể cho một vài ví dụ minh họa?

2. Ai là người có trách nhiệm để quản lý và giải quyết các xung đột/mâu thuẩn trong nhà trường?

3. Thầy/cô thường áp dụng những biện pháp nào để giải quyết các mâu thuẫn này?

4. Theo thầy/cô, những giá trị truyền thống nào ảnh hưởng đến quá trình quản lý và giải quyết xung đột/mâu thuẫn trong nhà trường? Xin hãy giải thích? 


\section{Appendix 8: Interview questions with vice-principal (English and Vietnamese versions)}

\section{English version}

\section{A. General information}

1. Could you please tell me something about your professional life?

2. When were you assigned to the position of a school leader?

3. How do you define your role as a vice-principal?

\section{B. Exercising power/authority}

1. What do you understand about the terms "power/authority"?

2. In what way does the role of a school leader bring with it power and authority?

3. How do you and your principal exercise power/authority?

4. How and in what ways do the following factors affect your exercise of power/authority

- Your expertise?

- Your experience?

- Your morality?

- Your age?

- Your relationships?

- Your gender?

5. How and in what ways do school leaders influence the teaching and learning improvement in their exercising of power/authority?

6. What traditional values might challenge you and other school leader to exercise power/authority? Please explain.

\section{Building relationships}

1. How do you define 'a good relationship' within your school community?

2. How do you build relationships with your principal, teachers and students?

3. Are there any social factors that you think affect your ability to build relationships? Please explain

4. What traditional values do you bring to the role of a vice-principal that enhance your ability to build relationships?

5. What traditional values might challenge the process of building relationships within your school community? In what ways?

\section{Decision-making}

1. Who makes decisions in your schools?

2. How is the school decision-making process undertaken within your school?

3. What is your role as a vice-principal in the school decision-making process?

4. What barriers are there to effective decision-making?

5. How do your school leaders overcome these barriers or dilemmas? 
6. What traditional values do you think affect or challenge the decision-making process within your school? Please explain.

\section{E. Conflict management and solving}

1. What types of conflict often happen within your school community?

2. Who is responsible for managing or solving conflicts in your school?

3. What strategies do you and your school leaders use to manage and solve the conflicts?

4. What traditional values do you think influence the process of conflict management and solving? Please explain. 


\section{Vietnamese version}

\section{CÂU HỎI PHỎNG VẤN VỚI PHÓ HIỆU TRƯởNG}

\section{A. Thông tin chung}

1. Thầy/cô có thể cung cấp một vài thông tin về bản thân?

2. Thầy/cô được bổ nhiệm vào vị trí phó hiệu trưởng khi nào?

3. Theo quan điểm của cá nhân, thầy/cô có thể mô tả vai trò/nhiệm vụ của người phó hiệu trưởng như thế nào?

\section{B. Thực thi quyền lực/quyền hạn}

1. Thầy/cô hãy giải thích khái niệm "quyền lực" và "quyền hạn" theo quan điểm riêng của cá nhân?

2. Theo thầy/cô, vị trí và vai trò của lãnh đạo nhà trường (hiệu trưởng - phó hiệu trưởng) liên quan thế như thế nào đối với quyền lực và quyền hạn?

3. Trong vị trí của một phó hiệu trưởng, thầy/cô thực thi "quyền lực" hoặc "quyền hạn" của mình như thế nào? Thầy/cô có thể cho một vài ví dụ để minh họa quá trình thực thi "quyền lực" và "quyền hạn" của mình?

4. Các yếu tố nào sau đây ảnh hưởng đến việc thực thi "quyền lực" và "quyền hạn" của thầy/cô trong vị trí của phó hiệu trưởng và các yếu tố đó ảnh hưởng như thế nào:

- Chuyên môn của thầy/cô?

- Kinh nghiệm của thầy/cô?

- Phẩm chất đạo đức của thầy/cô?

- Độ tuổi của thầy/cô?

- Các mối quan hệ của thầy/cô?

- Giới tính của thầy/cô?

- Các yếu tố khác?

5. Việc thực thi quyền lực/quyền hạn của lãnh đạo nhà trường ảnh hưởng thế nào đến các công việc trong nhà trường?

6. Những giá trị truyền thống nào có thể thách thức/cản trở trong việc thực thi quyền lực và quyền hạn của người hiệu trưởng? Thầy/cô hãy giải thích các hiện tượng đó?

\section{Xây dựng các mối quan hệ}

1. Theo quan điểm cá nhân, thầy/cô định nghĩa "một mối quan hệ tốt" trong cộng đồng nhà trường như thế nào? (lãnh đạo - lãnh đạo; lãnh đạo - nhân viên/giáo viên; lãnh đạo - học sinh; giáo viên - học sinh)

2. Thầy/cô xây dựng và phát triển các mối quan hệ với cán bộ quản lý, giáo viên, nhân viên và học sinh của mình như thế nào?

3. Các yếu tố xã hội hoặc giá trị truyền thống nào mà thầy/cô cho rằng có thể ảnh hưởng đến quá trình thiết lập và xây dựng các mối quan hệ của mình trong cộng đồng nhà trường? Xin hãy giải thích.

4. Những giá trị truyền thống nào góp phần giúp thầy/cô nâng cao khả năng xây dựng và thiết lập các mối quan hệ trong nhà trường?

5. Những giá trị truyền thống nào có thể cản trở quá trình thiết lập và xây dựng các mối quan hệ trong nhà trường? Xin hãy giải thích. 


\section{Quyết định}

1. Ai là người chịu trách nhiệm đưa ra quyết định trong nhà trường?

2. Tiến trình đưa ra quyết định trong nhà trường được thực hiện như thế nào? Thầy/cô có thể cho một vài ví dụ minh họa tiển trình thực thi quyết định?

3. Thầy/cô với vị trí phó hiệu trưởng đóng vai trò như thế nào trong tiến trình đưa ra quyết định trong nhà trường?

4. Những cản trở nào có thể ảnh hưởng đến hiệu quả của việc đưa ra quyết định?

5. Những giá trị truyền thống nào mà thầy/cô cho rằng có thể ảnh hưởng hoặc gây khó khăn cho mình khi đưa ra quyết định và thực thi quyết định trong trường học?

6. Thầy/cô trong vị trí phó hiệu trưởng phải làm thế nào để vượt qua các rào cản văn hóa truyền thống trong việc đưa ra quyết định và thực thi quyết định?

\section{E. Quản lý và giải quyết các xung đột/mâu thuẫn}

1. Thầy/cô có thể cho biết các loại xung đột/mâu thuẫn nào thường xảy ra trong cộng đồng nhà trường? Thầy/cô có thể cho một vài ví dụ minh họa?

2. Ai là người có trách nhiệm để quản lý và giải quyết các xung đột/mâu thuẩn trong nhà trường?

3. Thầy/cô thường áp dụng những biện pháp nào để giải quyết các mâu thuẫn này?

4. Theo thầy/cô, những giá trị truyền thống nào ảnh hưởng đến quá trình quản lý và giải quyết xung đột/mâu thuẫn trong nhà trường? Xin hãy giải thích? 


\section{Appendix 9: Focus group interview questions with teacher participants (English and Vietnamese versions)}

\section{$\underline{\text { English version }}$}

\section{A. Confucian values and school leadership}

1. What core traditional values do you think exist in our society?

2. Where do these values come from?

3. What new social values exist in our society?

4. Where do these new values come from

5. What conflicts, if any, exist between the core traditional values and new ones?

B. Exercising power/authority

1. What do you understand about the terms "power/authority"?

2. How do your school leaders exercise power/authority?

3. What traditional values do you think might affect the way that your school leaders exercise power/authority? Please tell me how and in what ways?

\section{Building relationships}

1. How do you define "good relationships" within your school community?

2. How are relationships built within your school community?

3. How are they sustained?

\section{Decision-making}

1. How is the school decision-making process undertaken within your school?

2. In making decisions, what traditional values affect the school decision-making process?

E. Conflict management and solving

1. What types of conflicts often happen within your school community?

How is the process of managing and solving conflict undertaken in your school? 


\section{$\underline{\text { Vietnamese version }}$}

\section{A. Các giá trị Nho giáo}

1. Trong xã hội ta hiện nay có các giá trị truyền thống cốt lõi nào mà thầy/cô có thể liệt kê và mô tả?

2. Theo thầy/cô, các giá trị truyền thống cốt lõi này bắt nguồn từ đâu?

3. Các giá trị xã hội mới ở xã hội ta ngày nay là gì?

4. Những giá trị xã hội mới này xuất phát từ đâu?

5. Theo thầy/cô, có sự xung đột giữa các giá trị truyền thống và các giá trị xã hội mới không?

\section{B. Thực thi quyền lực/quyền hạn}

1. Thầy/cô hiểu thế nào về khái niệm "quyền lực/quyền hạn"?

2. Lãnh đạo của các thầy/cô thực thi quyền lực/quyền hạn như thế nào?

3. Theo thầy/cô thì nhưng giá trị truyền thống nào có thể ảnh hưởng đến quá trình thực thi quyền lực/quyền hạn của người lãnh đạo? Thầy/cô có thể giải thích sự ảnh hưởng đó như thế nào được không?

\section{Xây dựng các mối quan hệ}

1. Thầy/cô định nghĩa thế nào là "mối quan hệ tốt" trong nhà trường?

2. Các mối quan hệ được xây dựng thế nào trong nhà trường?

3. Các mối quan hệ đó được duy trì thế nào?

D. Quyết định

1. Tiến trình đưa ra quyết định trong nhà trường được thực hiện như thế nào?

2. Các giá trị truyền thống nào ảnh hưởng đến tiến trình đưa ra quyết định trong nhà trường?

\section{E. Quản lý và giải quyết các xung đột/mâu thuẫn}

1. Những loại xung đột/mâu thuẫn nào thường xảy ra trong trường học?

2. Quá trình quản lý và giải quyết xung đột trong nhà trường được thực hiện như thế nào? 


\section{Appendix 10: Questionnaire for teacher participants (English and Vietnamese versions)}

\section{English version}

Please complete as many of the questions as you want to and feel free to write as much or as little as you can.

For more detailed information about the questionnaire, please contact me at the given address

\section{A. About You}

1. Your gender: Female $\quad \square \quad$ Male

2. Your age: From 20 to $29 \square$ From 30 to $39 \square \quad$ From 40 to 59

4. Type of school: Secondary school $\square \quad$ High school $\square \quad$ College $\square$

5. Teaching experience

2 to 5 years

6 to 10 years

11 to 15 years

16 or more years

6. Years of working with the current principal

2 to 5 years

6 to 10 years

11 or more years

\section{B. Questions}

\section{Exercising power/authority}

1. How does a leader's gender affect the process of exercising power/authority in your school?

2. In what ways do you think your school leaders exercise power/authority effectively? Please explain why you think so.

3. In what ways do you think your school leaders exercise power/authority ineffectively? Please explain why you think so. 


\section{Building relationships}

1. Which following factors do you think directly or indirectly affect the way that your school leaders build relationships with you and other people? Please explain as detailed as possible.

a) Gender

b) position/status quo

2. What traditional values as barriers do you think might challenge your school leaders to build relationships? Please explain as detailed as possible.

\section{Decision-making}

1. How do the genders of your school leaders affect the process of school decisionmaking? Please explain in detailed.

2. Are there any barriers of traditional values to the effective decision-making process? If yes, please explain.

\section{Conflict management and solving}

1. How do your school leaders use their power/authority to manage or solve conflicts?

2. Are there any traditional values that might affect the process of managing and solving conflicts? If yes, give examples and explain.

Date of completion: ...................../ 2010

Thank you very much for your cooperation

PLEASE SEAL YOUR QUESTIONNAIRE IN THE STAMPED ADDRESSED

ENVELOPE PROVIDED AND MAIL OR HAND IT DIRECTLY TO ME

\section{ADDRESS OF THE RESEARCHER:}

Truong Dinh Thang

Department of Research Management and External Relations

Quang Tri Teacher Training College

Highway No 9, Dong Ha, Quang Tri

Phone number: 053.3581199; E-mail: thangnewzealand@yahoo.com 


\section{Vietnamese version}

\section{BẢN CÂU HỎI NGHIÊN CÚU}

(Dành cho giáo viên tham gia nghiên cưu)

Chân thành cám ơn sự hợp tác của quý thầy/cô cho công trình nghiên cứu này. Nếu có bất cứ thắc mắc gì về bản câu hỏi nghiên cứu, xin liên lạc với tôi theo địa chỉ được cung cấp ở trang cuối.

A. Thông tin cá nhân (Thầy/cô hãy đánh dấu vào các mục thông tin phù hợp)

1. Giới tính: Nữ $\quad \square \quad$ Nam

2. Tuổi: Từ 20 đến $29 \square \quad$ Tù̀ 30 đến $39 \square \quad$ Từ 40 đến 59

4. Trường: Phổ thông cơ sở

Phổ thông trung học $\square \quad$ Cao đẳng

5. Kinh nghiệm giảng dạy

2 đến 5 năm

6 đến 10 năm

11 đến 15 năm

Trên 16 năm

6. Năm công tác với hiệu trưởng đương nhiệm
2 đến 5 năm
6 đến 10 năm
Trên 11 năm

\section{B. Câu hỏi}

\section{Thực thi quyền lực/quyền hạn}

1. Giới tính của người lãnh đạo (hiệu trưởng) ảnh hưởng thế nào đến quá trình thực thi quyền lực và quyền hạn trong nhà trường?

2. Trong trường hợp nào thì việc thực thi quyền lực/quyền hạn của lãnh đạo nhà trường được xem là có hiệu quả? Thầy/cô hãy giải thích.

3. Trong trường hợp nào thì việc thực thi quyền lực/quyền hạn của lãnh đạo nhà trường được xem là kém hiệu quả? Thầy/cô hãy giải thích.

\section{Xây dựng các mối quan hệ}

1. Theo thầy/cô, yếu tố nào sau đây có thể ảnh hưởng trực tiếp hoặc gián tiếp đến việc lãnh đạo nhà trường xây dựng/thiết lập mối quan hệ với thầy/cô và các thành viên khác trong nhà trường? Hãy giải thích chi tiết.

a) Giới tính 
b) Chức vụ/địa vị

2. Theo thầy/cô, những giá trị truyền thống nào được xem là rào cản mà có thể làm ảnh hưởng đến việc xây dựng các mối quan hệ trong nhà trường của người lãnh đạo? Xin hãy giải thích chi tiết.

\section{Quyết định}

1. Theo thầy/cô, giới tính của người lãnh đạo có thể ảnh hưởng thế nào đối với quá trình đưa ra quyết định trong công việc? Hãy giải thích chi tiết.

2. Theo thầy/cô, giá trị truyền thống nào là rào cản đối với việc đưa ra quyết định có hiệu quả hay không? Nếu có, xin hãy giải thích.

\section{Conflict management and solving}

1. Theo thầy/cô, lãnh đạo nhà trường thực thi quyền lực/quyền hạn của mình như thế nào để quản lý và giải quyết các xung đột hoặc các vấn đề nảy sinh trong nhà trường?

2. Theo thầy/cô, giá trị truyền thống nào có thể ảnh hưởng đến quá trình quản lý và giải quyết các xung đột/các vấn đề nảy sinh trong nhà trường? Nếu có, xin hãy đưa ra ví dụ và giải thích.

Ngày hoàn thành: ...................../ 2010

Cám ơn sự hợp tác của thầy/cô trong quá trình thực hiện nghiên cứu này.

Xin gửi bản câu hỏi nghiên cứu về địa chỉ đã được ghi sã̃n trên phong bì đã dán tem hoặc gửi trực tiếp cho người người nghiên cứu ở địa chỉ sau: Trương Đình Thăng, Phòng Quản lý Nghiên cứu Khoa học và Đối ngoại, Trường CĐSP Quảng Trị, Km3, Đường 9, Đông Hà, Quảng Trị. Số điện thoại: 053.3581199; địa chỉ email: thangnewzealand@yahoo.com 
Appendix 11: Observation Guidelines

\begin{tabular}{|c|l|l|l|}
\hline Focus inquiries & \multicolumn{1}{|c|}{ What to be observed } & \multicolumn{1}{c|}{$\begin{array}{c}\text { How to be } \\
\text { observed/recorded }\end{array}$} & Where to be observed \\
\hline $\begin{array}{l}\text { Contextual issues (school } \\
\text { settings, school cultures) }\end{array}$ & $\begin{array}{l}\text { - Monthly meetings of the Educational } \\
\text { School Committee } \\
\text { Daily communications }\end{array}$ & - Direct/unobtrusive & - School A \\
\hline Power exercise & - Administrative staff meetings & - Keep a research journal & - School B C \\
\hline Relationship building & - Daily communications & & \\
\hline
\end{tabular}

